\author{
UNIVERSIDADE DE SÃO PAULO \\ FACULDADE DE ECONOMIA, ADMINISTRAÇÃO E CONTABILIDADE DE \\ RIBEIRÃO PRETO \\ DEPARTAMENTO DE CONTABILIDADE \\ PROGRAMA DE PÓS-GRADUAÇÃO EM CONTROLADORIA E CONTABILIDADE
}

\title{
DIEGO QUEIRANTES
}

\begin{abstract}
A interferência de aspectos econômicos, organizacionais e cognitivos na relação entre o sistema de remuneração gerencial e a Orientação Temporal do Gestor em instituições de saúde.
\end{abstract}

ORIENTADOR: PROF. DR. CARLOS ALBERTO GRESPAN BONACIM

RIBEIRÃO PRETO

2014 
Prof. Dr. Marco Antonio Zago

Reitor da Universidade de São Paulo

Prof. Dr. Sigismundo Bialoskorski Neto

Diretor da Faculdade de Economia, Administração e Contabilidade de Ribeirão Preto

Prof. Dr. Vinícius Aversari Martins

Chefe do Departamento de Contabilidade 


\title{
DIEGO QUEIRANTES
}

\begin{abstract}
A interferência de aspectos econômicos, organizacionais e cognitivos na relação entre o sistema de remuneração gerencial e a Orientação Temporal do Gestor em instituições de saúde.
\end{abstract}

Dissertação apresentada ao Programa de PósGraduação em Controladoria e Contabilidade da Faculdade de Economia, Administração e Contabilidade de Ribeirão Preto da Universidade de São Paulo, para obtenção do título de Mestre em Ciências. Versão Corrigida. A original encontra-se disponível na FEA-RP/USP.

ORIENTADOR: PROF. DR. CARLOS ALBERTO GRESPAN BONACIM

\section{RIBEIRÃO PRETO}


Autorizo a reprodução e divulgação total ou parcial deste trabalho, por qualquer meio convencional ou eletrônico, para fins de estudo e pesquisa, desde que citada a fonte.

FICHA CATALOGRÁFICA

Queirantes, Diego.

A interferência de aspectos econômicos, organizacionais e cognitivos na relação entre o sistema de remuneração gerencial e a Orientação Temporal do Gestor em instituições de saúde / Diego Queirantes. - Ribeirão Preto, 2014.

178 p. : il.; $30 \mathrm{~cm}$

Dissertação de Mestrado apresentada à Faculdade de Economia, Administração e Contabilidade de Ribeirão Preto/USP. Área de concentração: Controladoria e Contabilidade.

Orientador: Carlos Alberto Grespan Bonacim

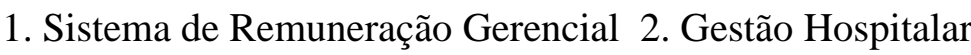
3. Orientação Temporal do Gestor 
Nome: QUEIRANTES, Diego

Título: A interferência de aspectos econômicos, organizacionais e cognitivos na relação entre o sistema de remuneração gerencial e a Orientação Temporal do Gestor em instituições de saúde.

Dissertação apresentada ao Programa de PósGraduação em Controladoria e Contabilidade da Faculdade de Economia, Administração e Contabilidade de Ribeirão Preto da Universidade de São Paulo, para obtenção do título de Mestre em Ciências. Versão Corrigida. A original encontra-se disponível na FEA-RP/USP

Aprovado em:

Banca Examinadora

Prof. Dr. Instituição:

Julgamento: Assinatura:

Prof. Dr. Instituição:

Julgamento: Assinatura:

Prof. Dr. Instituição:

Julgamento: Assinatura: 
À minha família,

cujo o apoio e incentivo foram essenciais. 


\section{AGRADECIMENTOS}

Primeiramente, quero agradecer a minha família que sempre esteve por perto para me apoiar no que precisei, e em especial minha companheira Raphaela.

Sou muito grato ao meu orientador, Prof. Dr. Carlos Alberto Grespan Bonacim por sua inestimável contribuição e apoio à realização deste trabalho, e aos professores Dr. José Carlos Tiomatsu Oyadomari e Dr. Andson Braga Aguiar, que muito agregaram com sua experiência e conhecimento durante o processo de qualificação. Agradeço também as professoras Dra. Carmen Silvia Gabriel e Dra. Maria Eulália Lessa do Valle Dallora.

Agradeço aos meus amigos de infância e da faculdade que me ajudaram a descontrair nos momentos necessários. Um obrigado especial aos colegas de trabalho da Valore Brasil, que me apoiaram nessa empreitada, e aos professores e colegas do programa de Mestrado em Controladoria e Contabilidade da FEARP pelo conhecimento compartilhado.

Expresso minha profunda gratidão aos colegas gestores dos hospitais entrevistados que voluntariamente se prontificaram a participar deste estudo e compartilhar suas experiências e percepções, bem como a todos aqueles que mesmo não citados nominalmente aqui, fizeram parte desta caminhada e ajudaram-me com seus comentários, conselhos e palavras amigas. 
"Dinheiro é um pedaço de papel,

Dinheiro não leva para o céu,

E nem cai do céu".

Arnaldo Antunes 


\section{RESUMO}

Queirantes, Diego. A interferência de aspectos econômicos, organizacionais e cognitivos na relação entre o sistema de remuneração gerencial e a Orientação Temporal do Gestor em instituições de saúde. 2014. Dissertação (Mestrado) - Faculdade de Economia, Administração e Contabilidade de Ribeirão Preto, Universidade de São Paulo, Ribeirão Preto, 2014.

Este estudo investiga a interferência de aspectos cognitivos, organizacionais e econômicos na Orientação Temporal do Gestor (OTG) de hospitais de grande porte no interior de São Paulo. A literatura prediz que OTG é influenciada por sistemas de incentivo, como o sistema de remuneração gerencial, e nessa pesquisa foi analisado outras perspectivas que impactariam nessa relação, com base em literatura contábil, econômica, de psicologia e gestão hospitalar, entretanto outros fatores poderiam impactar na OTG, tal como o desenho do contrato do gestor $e x$-ante, os processos empresariais, a incerteza do ambiente e tarefa, o sistema estratégico de avaliação de desempenho e a proximidade do gestor com a atividade fim. O estudo foi realizado com 18 gestores de 5 hospitais e 1 operadora, analisando os fatores que impactam na realização de tarefas e tomadas de decisões gerenciais, com foco em diferenciar as atividades de curto e longo prazo e quais os direcionadores que os fazem focar no resultado de curto ou longo prazo. Os dados foram obtidos por meio de entrevistas com os gestores e analisados com auxílio do software Nvivo, por meio da análise de discurso. O resultado da pesquisa foi um levantamento das tarefas com resultado no curto e longo prazo em ambientes hospitalares, identificação dos dilemas do sistema de saúde que impactam na gestão e a proposição de hipóteses de variáveis que possam impactar na OTG. As hipóteses levantadas são que no setor hospitalar fatores como dilemas com operadoras de saúde, incerteza do ambiente e de tarefa e gestão de urgência podem impactar na OTG de curto prazo, enquanto sistemas estratégicos de avaliação de desempenho, motivação prósocial, desenho do contrato de LP, gestão por processo e tempo de proximidade com a atividade final podem impactar na OTG de longo prazo.

Palavras-chave: Sistema de remuneração gerencial. Gestão hospitalar. Orientação Temporal do Gestor. 


\begin{abstract}
Queirantes Diego. The interference of economic, organizational and cognitive aspects in the relationship between aspects of the incentive system and the managerial time orientation in health institutions. 2014. Dissertação (Mestrado) - Faculdade de Economia, Administração e Contabilidade de Ribeirão Preto, Universidade de São Paulo, Ribeirão Preto, 2014.
\end{abstract}

This study investigates the interference of cognitive, organizational and economic aspects in Managerial Time Orientation (MTO) of large hospitals in the state of São Paulo. The literature predicts that MTO is influenced by incentive systems, like the system of managerial remuneration, and this research was analyzed other perspectives that would impact this relationship, based on accounting, economic, psychology and hospital management literature, although others factors could impact the MTO as the manager's contract design ex -ante, business processes, uncertainty of the environment and task, strategic system of performance evaluation of the manager and the proximity to the core activity. The study was conducted with 18 managers in 5 hospitals and 1 health insurance, analyzing the factors that impact the execution of tasks and managerial decision-making, focusing on differentiating activities of short and long term and what are the drivers that focus on results short or long term. Data were obtained through interviews with managers and analyzed using the software NVivo, through discourse analysis. The result of the research was a survey of tasks result in short and long term in a hospital, the dilemmas of the health system that impact the management and a propose hypotheses of variables that may impact the MTO. The hypotheses are that the hospital sector factors such dilemmas with health insurance companies, environmental uncertainty, task uncertainty and emergency management would impact in the short term MTO, while strategic systems performance evaluation, social motivation, design of the contract, process management and time of proximity to the core activity would impact the long term MTO.

Keywords: Incentive system. Hospital management. Managerial time orientation. 


\section{LISTA DE FIGURAS E GRÁFICOS}

Figura 1: Aspectos Econômicos, Organizacionais e Cognitivos que afetam a Orientação

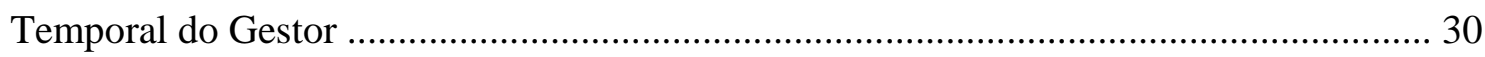

Figura 2: Dimensões e elementos do Sistema de Remuneração Gerencial...................... 42

Figura 3: Síntese dos eixos temáticos associados com OTG..........................................149

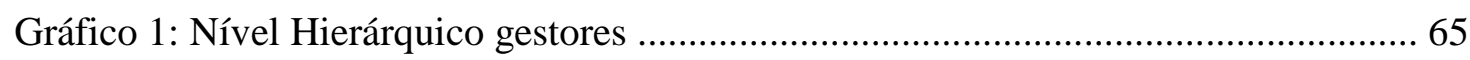

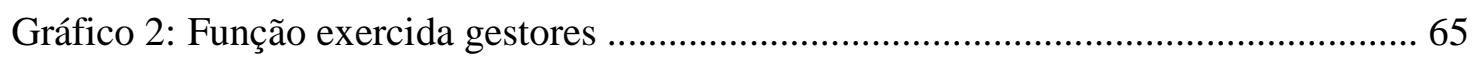

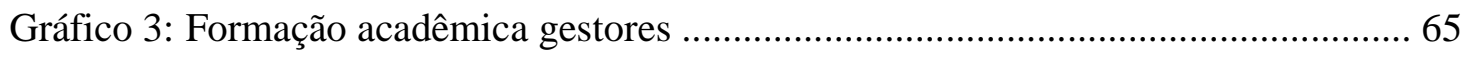

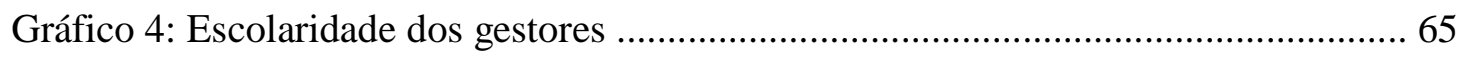




\section{LISTA DE TABELAS}

Tabela 1: Caracterização dos Hospitais selecionados para os Estudos Multicasos. 60

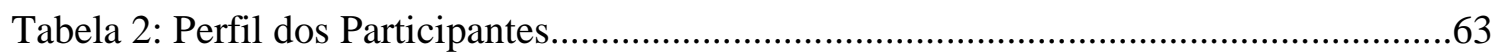

Tabela 3: Caracterização da experiência profissional dos gestores...................................... 66

Tabela 4: Relação dos nós identificados classificados por Grupo ..................................... 74

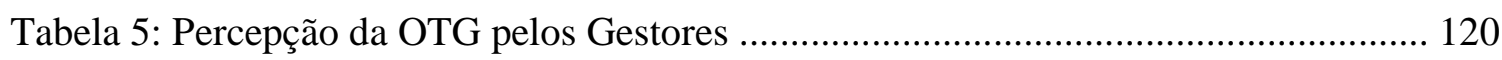

Tabela 6: Percepção de OTG dos gestores entrevistados por Formação Acadêmica......... 122

Tabela 7: Percepção de OTG dos gestores entrevistados por Departamento de Atuação 122

Tabela 8: Percepção de OTG dos gestores entrevistados por tempo de trabalho............... 122

Tabela 9: Percepção de OTG dos gestores entrevistados por experiência no setor de saúde 122

Tabela 10: Dilemas entre Operadora de Saúde e Hospital................................................. 135

Tabela 11: Variáveis independentes identificadas nos pressupostos preliminares para

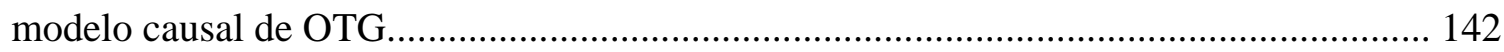

Tabela 12: Tarefas com efeitos no curto e longo prazo.................................................... 143 


\section{LISTA DE SIGLAS}

5W2H What, Why, Where, When, Who, How and How Much (O que, Porque, Onde, Quando, Quem, Como e Quanto)

ANS Agência Nacional de Saúde Suplementar

BPM Business Process Management (Gestão de Processos de Negócio)

BSC Balanced Scorecard

CME Central de Materiais Esterilizados

$\mathrm{CQH} \quad$ Compromisso com a Qualidade Hospitalar

CTI Centro de Tratamento Intensivo

DU Discounted Utility Theory (Teoria da Utilidade Descontada)

EBITDA Earnings before tax, interest, depreciation and amortization

HC Hospital das Clínicas

IBGE Instituto Brasileiro de Geografia e Estatística

IQG Instituto Qualisa de Gestão

ISO International Organization for Standardization (Organização Internacional de Padronização)

KPI Key Performance Indicator (Indicadores de desempenho chave)

LAJIDA Lucro antes de juros, impostos sobre a renda, depreciação e amortização

MBA Master of Business Administration (Especialização em Administração de Negócios)

MTO Managerial Time Orientation (Orientação Temporal do Gestor)

OGSM Objectives, Goals, Strategies and Measures (Objetivos, Metas, Estratégias e Indicadores)

ONA Organização Nacional de Acreditação

OPME Órtese, Prótese e Materiais Especiais

OTG Orientação Temporal do Gestor

PIB Produto Interno Bruto

SUS Sistema Único de Saúde

SWOT Strenghts, Weakness, Opportunities and Treaths (Forças, Fraquezas, Oportunidades e Ameaças) 


\section{SUMÁRIO}

1 INTRODUÇÃO

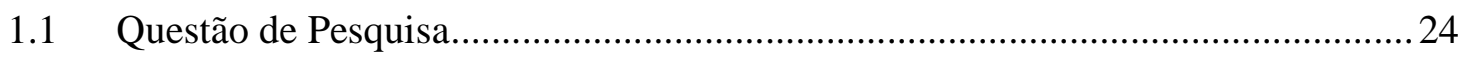

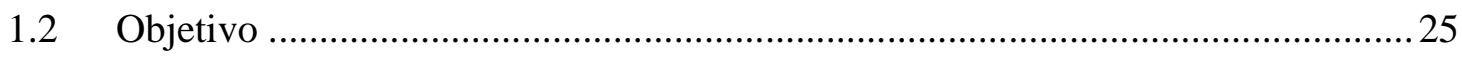

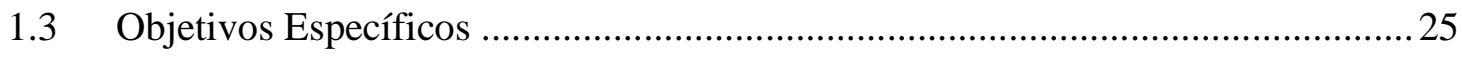

1.4 Justificativa da pesquisa e possibilidades de contribuição .....................................2 25

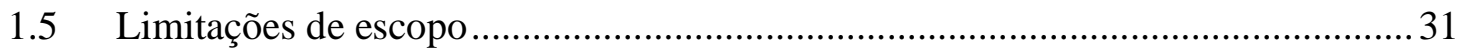

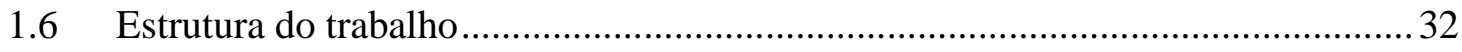

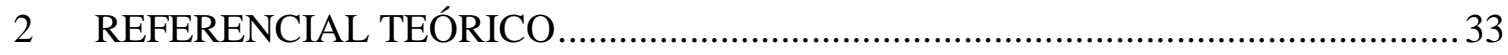

2.1 A Organização hospitalar, suas características e dilemas ........................................33

2.2 Sistemas de incentivo na gestão hospitalar............................................................... 41

2.3 Gestão por Processos e os processos hospitalares ..................................................... 47

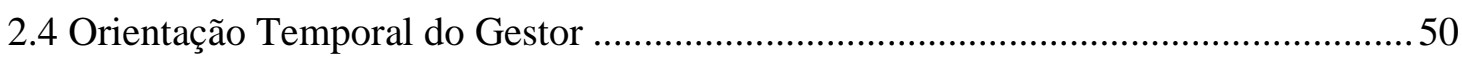

3 PROCEDIMENTOS METODOLÓGICOS DA PESQUISA .........................................57

3.1 Ações para minimizar ameaças à validade interna, externa e de construto.................57

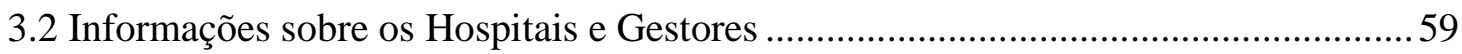

3.3 Instrumentos de coleta e organização de dados ........................................................... 67

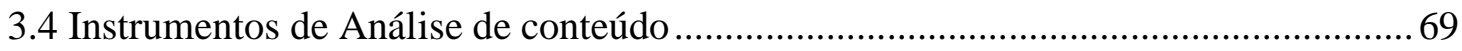

4 APRESENTAÇÃO, ANÁLISE E DISCUSSÃO DOS RESULTADOS ......................73

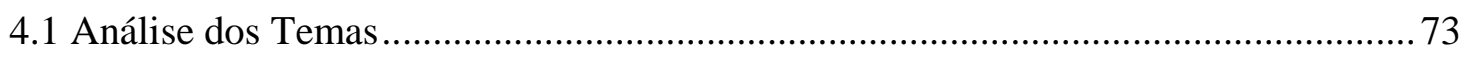

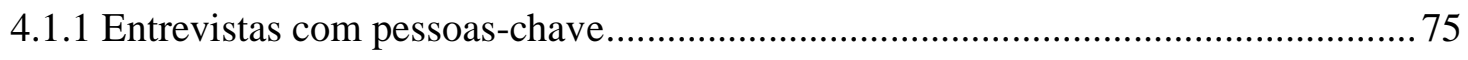

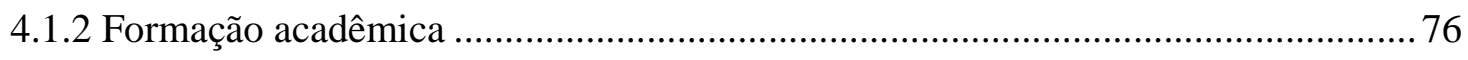

4.1.3 Formação profissional e experiência no setor de saúde ........................................ 76

4.1.4 Tempos de trabalho na empresa e expectativas .................................................. 77

4.1.5 Gestões de pessoas e relacionamento com superiores ......................................... 78

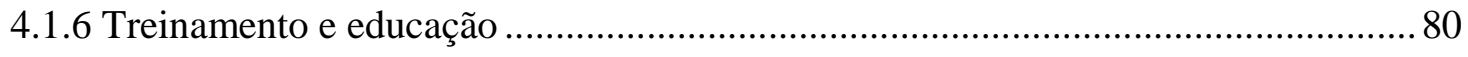

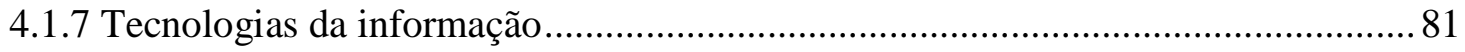

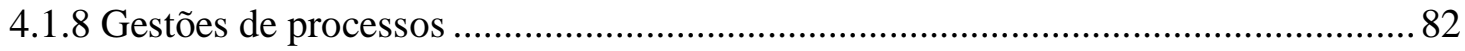

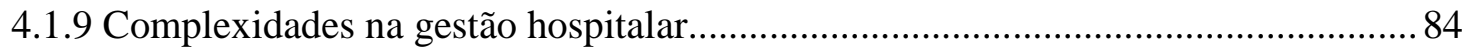

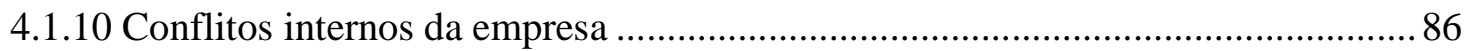

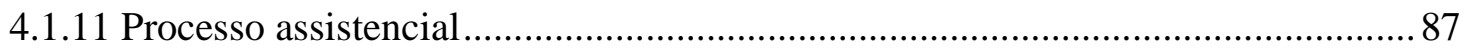




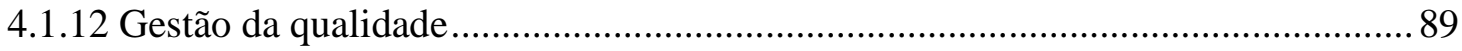

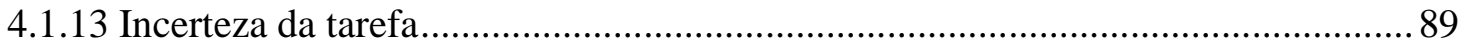

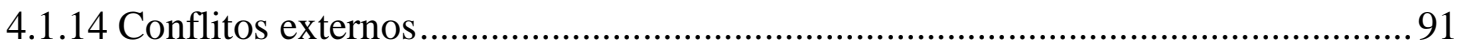

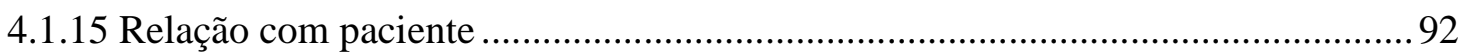

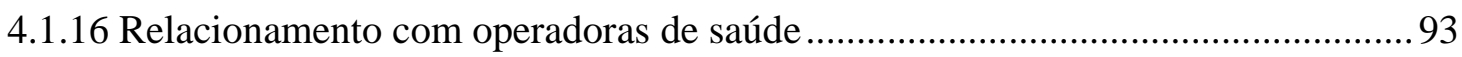

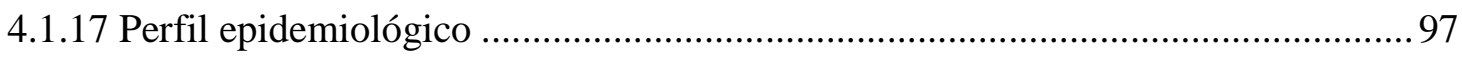

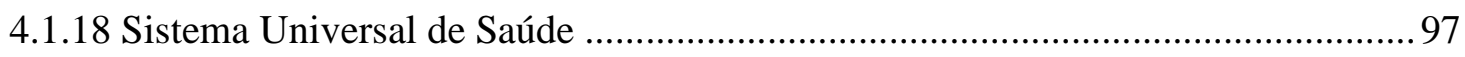

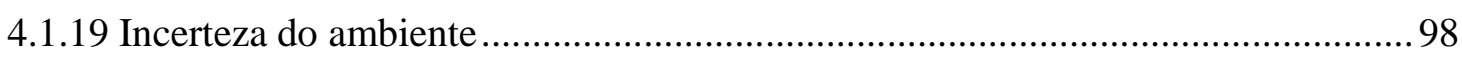

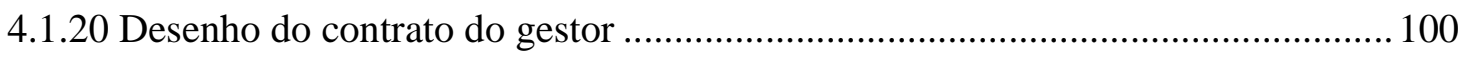

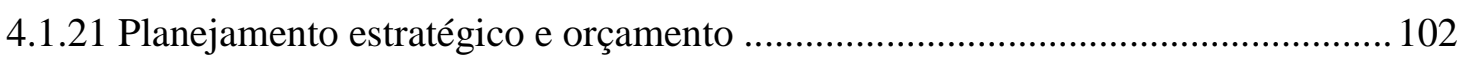

4.1.22 Sistemas de comunicação .................................................................................. 104

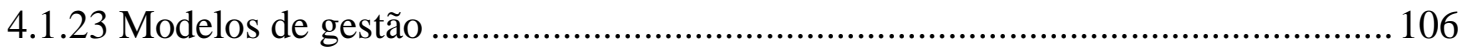

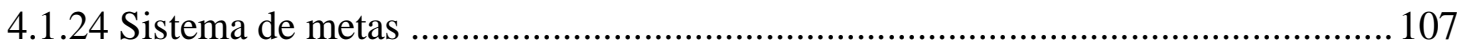

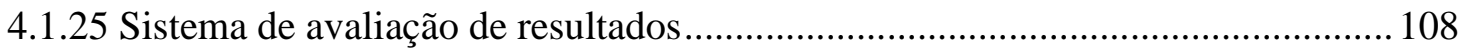

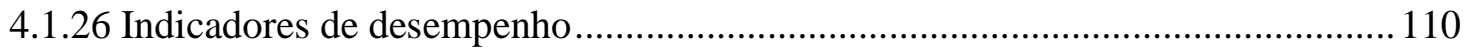

4.1.27 Sistemas estratégicos de mensuração de desempenho ........................................ 112

4.1.28 Sistemas de remuneração gerencial .................................................................. 113

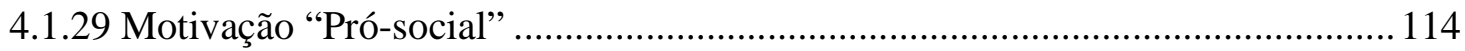

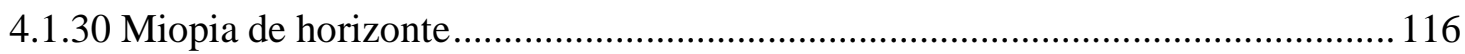

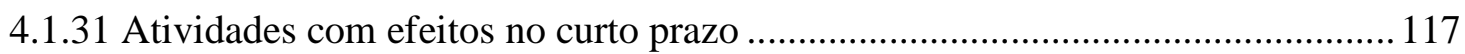

4.1.32 Atividades com efeitos no longo prazo .......................................................... 118

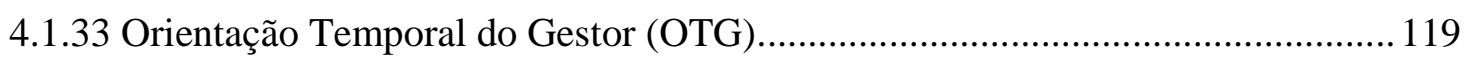

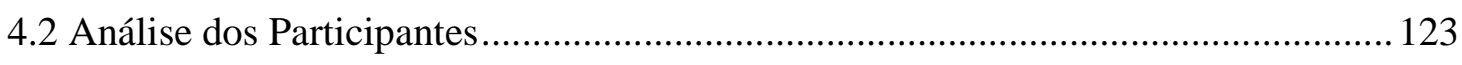

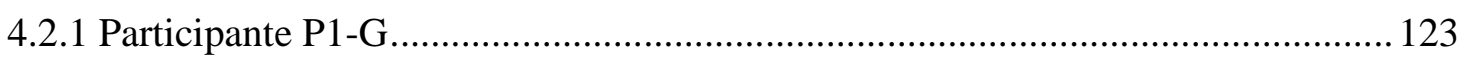

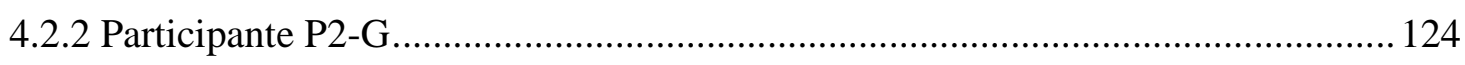

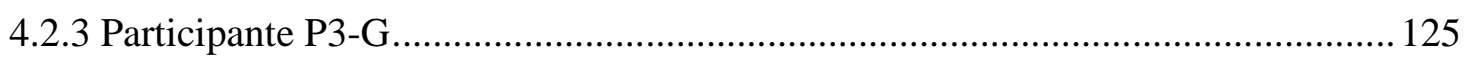

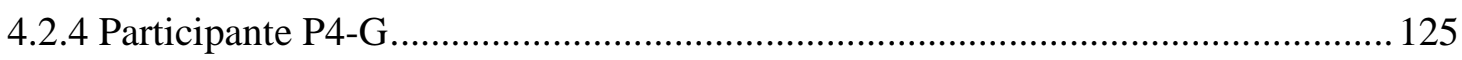

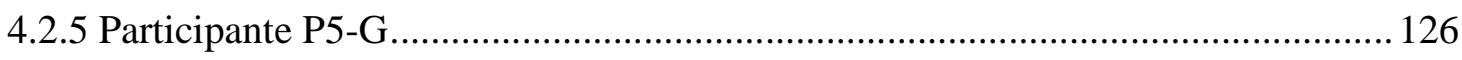

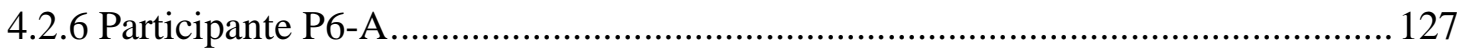

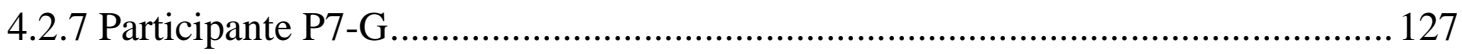

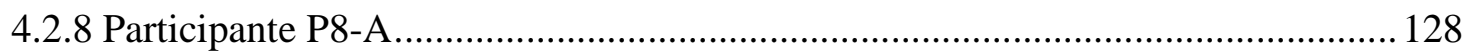




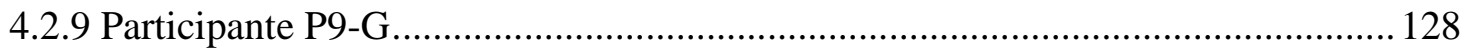

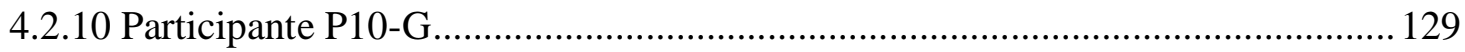

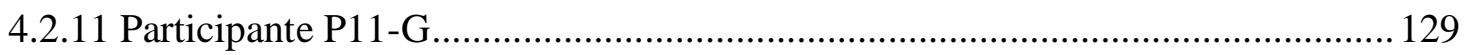

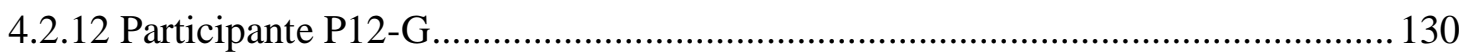

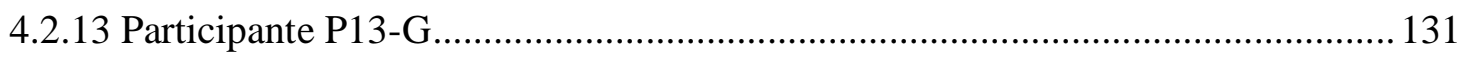

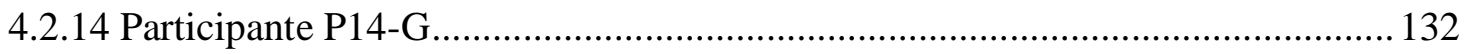

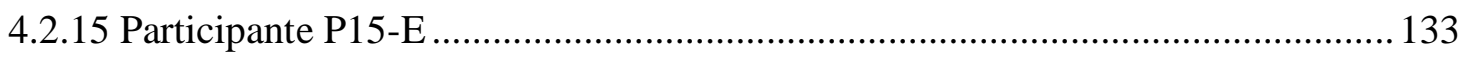

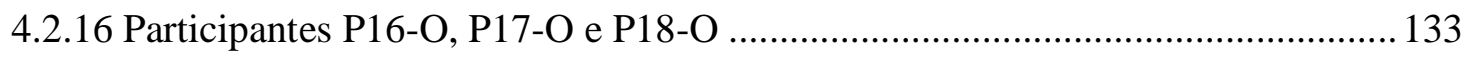

4.3 Dilemas no Setor de Saúde ............................................................................... 134

4.4 Categorização Tarefas com Efeitos no Curto e Longo Prazo ............................... 140

4.5 Pressupostos Preliminares para modelo causal da OTG ...................................... 141

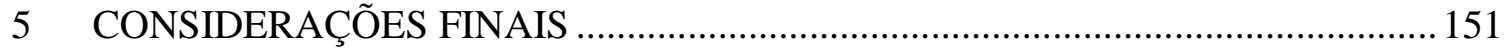

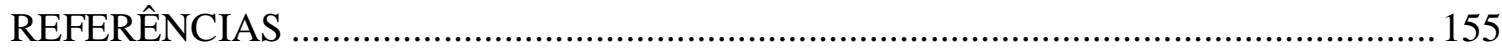

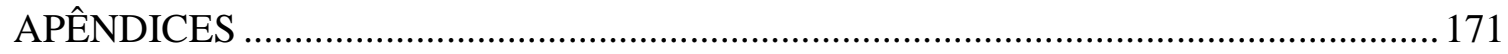





\section{INTRODUÇÃO}

A gestão hospitalar apresenta desafios únicos que contemplam a gestão da eficiência na utilização dos recursos com a administração do atendimento assistencial de qualidade. $\mathrm{Na}$ sociedade atual, com envelhecimento da população, tecnologias avançadas e necessidade de mais recursos para a saúde, uma gestão eficiente é um diferencial nesse setor, o qual tem, em sua base produtiva, profissionais altamente qualificados e com orientação assistencial.

Existe uma noção geral, tanto dos profissionais quanto dos acadêmicos, que o setor de saúde não apresenta uma gestão tão eficiente quanto em outros setores, e necessita de uma avaliação de ferramentas econômicas e modelos de gestão para melhoria no uso de seus recursos. Por outro lado existem defensores de que uma gestão focada no controle de custos pode causar uma transformação na qualidade e nos resultados de longo prazo da saúde do paciente (LA FORGIA e COUTTOLENC, 2009; CUNHA, 2011; GABRIEL et al., 2013).

Como toda organização econômica o hospital possui uma quantidade finita de recursos, como recursos financeiros, humanos e materiais, para oferecer seus serviços à população. E o modelo de financiamento da atividade assistencial é diferenciado, com o sistema SUS $^{1}$ e planos de saúde privados, assim o hospital precisa alocar seus recursos em tarefas que resultem em benefícios para organização, estabelecendo um balanceamento em foco, com resultados tanto no curto prazo como no longo prazo, equilibrando as atividades e necessidades atuais de atendimento, com demandas futuras para a continuidade e expansão da organização.

Gestores da área de saúde apontam para fatores que tornam a gestão hospitalar complexa, dado particularidades com recursos humanos, materiais e tensões e dilemas próprios da atividade assistencial, dessa maneira modelos de gestão alternativos e ferramentas econômicas são estudados para que possam aumentar a eficiência na utilização dos recursos hospitalares (LA FORGIA e COUTTOLENC, 2009; WEBER e GRISCI, 2010; CALDANA et al., 2011; GROHMANN et al., 2012; GABRIEL et al., 2013; OHIRA, JUNIOR e NUNES, 2014; OYADOMARI et al., 2014).

\footnotetext{
${ }^{1}$ Sistema Único de Saúde é o sistema nacional de saúde que garante o direito à saúde a todos os cidadãos como dever do Estado.
} 
Estudos demonstram considerável variação na qualidade, na produtividade e no custo hospitalar, tal variação é efeito do ambiente de atendimento à saúde com sua incerteza ambiental, modelo de financiamento, diferentes práticas de gestão e análise de desempenho, e relacionamento com o SUS e operadoras de saúde. (ALVES, 1997; ROTTA, 2004; LA FORGIA e COUTTOLENC, 2009; BONACIM e ARAUJO, 2009; CALDANA et al., 2011; CUNHA, 2011; GABRIEL et al., 2011; GROHMANN et al., 2012; TANAKA e TAMAKI, 2012; GABRIEL et al., 2013).

A literatura na área de gestão em saúde aponta para a necessidade de ferramentas que aumentem a eficiência na gestão hospitalar, com enfoque em práticas gerenciais para análise de desempenho e práticas para remuneração e gestão da equipe, com dificuldade para introduzir as práticas da gestão industrial para o setor de saúde (BITTAR, 1997; LIMA-GONÇALVES, 2002; ROTTA, 2004; LA FORGIA e COUTTOLENC, 2009; BONACIM e ARAUJO, 2009; WEBER e GRISCI, 2010; CUNHA, 2011; GABRIEL et al., 2011; OHIRA, JUNIOR e NUNES, 2014).

Nesse sentido, estudos buscam analisar os elementos dos modelos de gestão que possam ser incorporados ao setor de saúde para contemplar suas particularidades de estruturas e processos, como modelos de financiamento, relação médico-paciente, força de trabalho e processos de prestação de serviços (BITTAR, 1997; LIMA-GONÇALVES, 2002; ROTTA, 2004; BERNARDES et al., 2007; BONACIM e ARAUJO, 2010a; LA FORGIA e COUTTOLENC, 2009; CUNHA, 2011; GABRIEL et al., 2013).

O trabalho em saúde, por suas particularidades como trabalho imaterial com dependência da qualificação do trabalhador, o domínio e troca de conhecimentos, a capacidade de lidar com imprevistos e relacionar-se com as pessoas ainda não foi capturado eficientemente pelos esquemas de incentivo econômicos (WEBER e GRISCI, 2010; OHIRA, JUNIOR e NUNES, 2014).

Além disto, tem o sentimento de impotência e a alta recorrência de imprevistos por parte dos gestores e profissionais hospitalares (PITTA, 1994; MARTINS, ALVES e GODOY, 1999; ARAUJO e VIEIRA, 2004; BARIGOZZI e LEVAGGI, 2008; TOFAN et al., 2013; SANTOS e HORMANEZ, 2013), que atuam em "serviços sensíveis a vida humana" (OYADOMARI et al., 2014). 
Dada essas considerações fica a dúvida quanto ao motivo da ineficiência aparente do sistema de saúde e atendimento hospitalar, com constantes reclamações por parte dos usuários: será que o motivo é a falta de recursos ou ineficiência na gestão (LA FORGIA e COUTTOLENC, 2009)? Evidências demonstram que existem lacunas tanto no repasse de recursos, principalmente no que tange tabela SUS e relacionamento com operadoras, quanto de modelos de gestão que capturem a realidade do atendimento à saúde (BITTAR, 1997; LIMA-GONÇALVES, 2002; LA FORGIA e COUTTOLENC, 2009; BONACIM e ARAUJO, 2009; CUNHA, 2011; GABRIEL et al., 2013; VIEGAS e PENNA, 2013; OYADOMARI et al., 2014).

Assim a alta direção de hospitais apresenta dilemas quanto à utilização de seus recursos, nos hospitais públicos o dilema é a manutenção da entidade e orçamento versus o perfil epistemológico considerado na "Pactuação com SUS", e em hospitais-escola soma-se a isso os investimentos em ensino e pesquisa. Já nos hospitais privados o dilema é entre lucro e retorno versus o financiamento das operadoras de saúde e o perfil dos pacientes atendidos (WEBER e GRISCI, 2010; CAMACHO, ROCHA e MORAES, 2011; UGA, 2012; BONACIM e ARAUJO, 2010a; VIEGAS e PENNA, 2013; OYADOMARI et al., 2014).

Logo o fenômeno a ser estudado é a gestão dos dilemas e escolhas nas entidades hospitalares. O presente estudo investiga aspectos econômicos, organizacionais e cognitivos que interferem na Orientação Temporal do Gestor, assim como a relação entre sistema de remuneração gerencial com a Orientação Temporal do Gestor ${ }^{2}$ nas condições do ambiente organizacional do hospital.

A Orientação Temporal do Gestor representa a preferência temporal dos gestores em suas escolhas, e pode ser entendido com base em dois critérios, que são: a consistência das escolhas intertemporais dos gestores e o momento de ocorrência dos benefícios decorrente dessas escolhas (AGUIAR, 2011), são as escolhas intertemporais que representam decisões envolvendo escolhas compensatórias (trade-off) entre custos e benefícios ocorrendo em diferente momentos (FREDERICK; LOEWENSTEIN; O'DONOGHUE, 2002), e podem ser investigadas com base em aspectos individuais,

\footnotetext{
${ }^{2}$ Doravante tratado por OTG
} 
organizacionais e econômicos que afetam as preferências temporais dos gestores (LAVERTY, 1996).

A teoria da agência (JENSEN; MECKLING, 1976) preconiza que em toda relação contratual, que exista em um ambiente de assimetria informacional, conflito de interesses entre agente e principal e contratos imperfeitos, existe a possibilidade do agente não agir no melhor interesse do principal $^{3}$. Nos hospitais públicos o principal seria toda a sociedade, e os agentes seriam os gestores hospitalares, e nos hospitais privados o principal seria o acionista (ou acionistas) e os gestores hospitalares seriam os agentes.

O hospital contrata gestores para tomarem decisões sobre alocar seus recursos buscando a eficiência operacional do mesmo, esses gestores variam de gestores financeiros, de hotelaria, comercial, suprimentos, gestor médico e de enfermagem, entre outras designações. São os gestores responsáveis pelas unidades de atendimento e tratamento ao paciente, como centro cirúrgico, ambulatorial, CTI (Centro de Tratamento Intensivo), gestores responsáveis por áreas de suporte, como farmácia, hotelaria e suprimentos, e gestores administrativos financeiros, responsáveis por setores de contas a pagar, orçamento, recursos humanos, comercial, entre outros setores.

Esses gestores são intermediários na hierarquia hospitalar, estão entre os acionistas, que no hospital privado são os proprietários do hospital e no hospital público é a população em geral, e os funcionários de saúde. Eis que o principal espera que esses gestores tenham os interesses alinhados aos seus, e alinhem esses objetivos com os processos de trabalho e ações desenvolvidas pelos funcionários no hospital. Esse processo de alinhamento de interesses pode reduzir os custos com monitoramento e agência presente na relação contratual entre gestores e proprietários (JENSEN; MECKLING, 1976; MILGROM; ROBERTS, 1992; MOONEY e RYAN, 1993; SCOTT e VICK, 1999; LAMBERT, 2001; WEBER, GRISCI, 2010). E ainda os gestores hospitalares sofrem influência de uma estrutura de autoridade ambígua, com duas linhas de comando com lógicas, valores e

\footnotetext{
${ }^{3}$ Conforme a teoria da agência, agentes são maximizadores de utilidade e podem possuir interesses conflitantes com o principal. Nesse contexto de contrato no qual o principal é o contratante e o agente o contratado, e nesse contrato existe assimetria de informação entre as partes e o contrato é imperfeito, ocorrem custos de agência para minimizar o efeito de decisões dos agentes que não estão de acordo com o interesse do principal, a contabilidade é um sistema de informação para minimizar essa assimetria informacional, consequentemente um custo de agência.
} 
objetivos diferentes, uma administrativa e de suporte, voltada a interesses econômicos e outra profissional, voltada a valores médicos (CARAPINHEIRO, 2005).

A literatura em gestão e controladoria enfatiza os efeitos de sistemas de incentivo e controle gerencial no comportamento do gestor, tal como sistema de remuneração gerencial, sistemas de metas, sistemas estratégicos de avaliação de desempenho. Ao encontro desses conceitos a literatura em gestão hospitalar investiga a utilização de modelos de gestão, indicadores de desempenho nos diferentes ambientes institucionais de saúde e nas particularidades do modelo brasileiro de atenção à saúde (TVERSKY e KAHNEMAN, 1979; BERNARTZI e THALER, 1995; LOEWENSTEIN, 1996; THALER, 1999; ROTTA, 2004; VAN RINSUM, 2006; NEUMAN e NEUMANN, 2007; BERNARDES et al., 2007; DEVLIN, SARMA, 2008; AGUIAR, 2009; LA FORGIA e COUTTOLENC, 2009; CUNHA, 2011; GABRIEL et al., 2013; TOFAN et al., 2013; AGUIAR e FREZATTI, 2013; OYADOMARI et al., 2014; AGUIAR, PINHEIRO e OYADOMARI, 2014).

Em tese um hospital tem a possibilidade de possuir mecanismos para a adoção de sistemas de remuneração gerencial, que incentiva os gestores a realizarem suas tarefas e remuneram os esforços que eles realizaram, assim como pode funcionar como ferramenta de controle das ações dos gestores, em casos de sistemas de remuneração complexos, que avaliam as ações dos gestores. Mas qual será a influência desses sistemas de remuneração no desempenho do gestor hospitalar, dado a forte influência da incerteza ambiental e do risco da imprevisibilidade da tarefa (DEVLIN e SARMA, 2008; BARIGOZZI e LEVAGGI, 2008; WEBER e GRISCI, 2010).

Diante dessa contextualização, percebe-se um dilema comum aos gestores de hospitais, sejam públicos ou privados, que é o valor da vida versus o custo do tratamento, que impacta no lucro ou orçamento (LA FORGIA e COUTTOLENC, 2009; DEVLIN e SARMA, 2008; BARIGOZZI e LEVAGGI, 2008; WEBER e GRISCI, 2010).

Seja no setor público ou privado, os gestores precisam alinhar as necessidades do hospital, vinculadas à continuidade e expansão de atendimento, com os conflitos que os profissionais de saúde possuem junto aos pacientes, e a insegurança que o profissional de saúde possui quanto ao risco da incerteza do resultado do trabalho (BARIGOZZI e 
LEVAGGI, 2008; WEBER e GRISCI, 2010; TANAKA e TAMAKI, 2012; TOFAN et al., 2013).

Para o profissional de saúde o risco de um resultado negativo no serviço pode representar uma perda significativa, dado que este resultado pode significar uma diminuição ou aumento na expectativa de vida do paciente. O profissional de saúde procura minimizar o risco de que seu diagnóstico (e tratamento) esteja inconsistente, devido o impacto do resultado negativo, que no extremo negativo é a morte (PITTA, 1994; MARTINS, ALVES e GODOY, 1999; ARAUJO e VIEIRA, 2004; BARIGOZZI e LEVAGGI, 2008; TOFAN et al., 2013; SANTOS e HORMANEZ, 2013).

Como efeito, os gestores hospitalares necessitam alocar recursos que impactem em resultados de curto prazo, para garantir o atendimento aos pacientes que estão no hospital no momento, assim como alocar recursos cujo resultado e benefício ocorram no longo prazo, tal qual como expansão de estrutura, compra de novos equipamentos, novas tecnologias, treinamentos aos funcionários e certificações, estruturação de processos e blindagem aos riscos, que garantam a continuidade do atendimento hospitalar, com melhoria na qualidade e oferta de serviços.

Dessa maneira o gestor hospitalar possui o dilema de alinhar os interesses dos pacientes com os do hospital e seus controladores, assim como lidar com fatores cognitivos, organizacionais e econômicos que impactam nas suas decisões e sua OTG, que direciona seu foco de investimentos em tarefas com resultados no curto ou longo prazo. Mas como conciliar a alocação de recursos para o longo prazo, para garantir a continuidade do hospital no contexto de atendimento à saúde, com alto grau de imprevisibilidade e risco associado à tarefa e ao ambiente, com a alocação de recursos para o atendimento assistencial de curto prazo?

\subsection{Questão de Pesquisa}

Diante dessa contextualização, é relevante investigar quais os fatores econômicos, organizacionais e cognitivos interferem nas decisões dos gestores em alocar recursos com foco em resultados no curto ou longo prazo em hospitais? 


\subsection{Objetivo}

O objetivo principal dessa pesquisa é investigar os fatores econômicos, organizacionais e cognitivos que podem interferir na Orientação Temporal do Gestor.

\subsection{Objetivos Específicos}

São objetivos específicos dessa pesquisa: a) aprofundar na literatura sobre gestão hospitalar e conceitos econômicos e Orientação Temporal do Gestor; b) levantar a percepção de gestores hospitalares quanto a própria Orientação temporal c) identificar as tarefas e decisões que representam OTG de curto prazo e OTG de longo prazo para ser utilizado com base para um instrumento de mensuração de OTG em hospitais; d) levantar os dilemas entre hospital e operadoras de saúde e seus impactos na OTG; e) avaliar os resultados das entrevistas sobre possíveis causas para OTG sob as perspectivas propostas Laverty (1996).

\subsection{Justificativa da pesquisa e possibilidades de contribuição}

O estudo da interferência de fatores cognitivos, organizacionais e econômicos na Orientação Temporal do Gestor abrange dois temas relevantes no âmbito acadêmico e prático: a eficiência da gestão hospitalar e as causas da Orientação Temporal do Gestor.

No ambiente hospitalar, seja público ou privado, os gestores desempenham diversas tarefas para alcançar seus objetivos, conforme contrato estabelecido com o hospital, que variam de tarefas técnicas e operacionais referente aos processos e procedimentos de tratamento e diagnóstico quanto administrativas como contratação de funcionários, motivação de equipe, logística de suprimentos, viabilidade de atendimento e hotelaria entre outros. (WEBER e GRISCI, 2010; GROHMANN et al., 2012).

Dessa maneira o gestor tem que decidir qual é o esforço a ser alocado nas diferentes tarefas ao longo do tempo. E para avaliar esta decisão de alocação de esforços em diferentes tarefas o gestor analisa os benefícios dessas tarefas.

A teoria econômica normativa prediz que os indivíduos alocarão esforços a tarefas que otimizam seu retorno (HOLMSTRON,1979; BANKER e DATAR, 1989; LAMBERT, 2001; AGUIAR, 2009). A alocação de esforços em tarefas pode ser estudada com foco no 
tipo de tarefa, no retorno, no efeito temporal, no efeito sociológico e psicológico do mesmo, inclusive o efeito para o contrato (FREDERICK, LOEWENSTEIN e O'DONOGHUE, 2002; DIKOLLI e VAYSMAN, 2006; AGUIAR, 2009).

Dessa maneira o gestor hospitalar não irá alocar esforços e recursos em tarefas que não gerem resultados positivos, este benefício é relativo ao agente que irá utilizá-lo, sendo que a alocação dos recursos com focos em benefícios feitos pelo gestor pode estar alinhada com os efeitos esperados por outras partes relacionadas, como sócios e clientes, ou não (JENSEN e MECKLING, 1976; HOLMSTROM, 1979).

A mesma lógica pode ser extrapolada, pois o gestor hospitalar, dentro de suas responsabilidades e possibilidades de alocação de recursos irá realizar as tarefas que promovem incrementos em seu próprio benefício e desempenho de seu trabalho, e o resultado pode ou não estar alinhado com as estratégias do hospital. No caso das entidades hospitalares, consideremos dois objetivos principais, o tratamento dos pacientes e o cumprimento do orçamento.

Extrapolando, decisões locativas são funções de demandas, de escolhas de horizonte e representam na prática, alocar uma quantidade finita de recursos dos processos e serviços. Que podem atender as demandas de curto prazo, assim como demandas de longo prazo, como melhoria na qualidade, expansão do atendimento e inovações.

Não é objetivo, desta pesquisa, sugerir um modelo ou solução (modelo de gestão) para hospitais e sim observar o fenômeno da decisão de alocação de recursos dado efeitos do sistema de remuneração gerencial e do ambiente institucional. Parece ser racional que os gestores condicionem suas escolhas alocativas aos benefícios que visualizem para si ao longo do tempo, sejam pecuniários ou não pecuniários.

Dessa forma parece razoável investigar a influência de cada tipo de benefício na decisão do gestor hospitalar e entender quais os fatores que impactam na busca por esse benefício. Com esse foco investigativo esta pesquisa identificou outros fatores além de incentivos financeiros que influenciam os gestores em suas decisões, avaliando a percepção dos gestores quanto aos benefícios que atingiram em sua atividade de gestão.

Os benefícios das escolhas podem ser entendidos por critérios como tempo, valor e controle, podem ser mensurados conforme o momento de ocorrência. (FREDERICK, LOEWENSTEIN e O'DONOGHUE, 2002; DIKOLLI e VAYSMAN, 2006; AGUIAR, 
2011); conforme ao retorno dado a alocação de esforços ou conforme ao controle do benefício, que representa quem terá o direito de consumo do resultado. (MILGROM e ROBERTS, 1992; KAPLAN e NORTON, 1996). Basicamente o resultado pode ser avaliado de acordo com três perguntas: Quem? Como? Quando?

A alocação de esforços em tarefas é uma decisão tomada pelo gestor em qualquer ambiente organizacional, seja relacionado a atividades econômicas relacionadas ao cuidado com a saúde ou outras atividades econômicas. Segundo a literatura, as decisões são tomadas para minimizar a aleatoriedade negativa e o risco decorrente da incerteza ambiental, isso significa dizer que toda decisão é tomada para minimizar a possibilidade de um efeito indesejado ocorrer (VON NEUMANN e MORGENSTERN; 1944; TVERSKY e KAHNEMAN, 1979).

Os gestores tomam decisões quanto aos recursos que irão alocar, aos benefícios que irão buscar e aos processos que vão utilizar para desenvolver suas atividades. No ambiente hospitalar a incerteza ambiental e a imprevisibilidade da tarefa são fatores relevantes dada dificuldade de controle das enfermidades que podem acometer as pessoas, isso se acentua com uma sociedade focada no tratamento da enfermidade, sendo que as ações preventivas são recentes no contexto histórico de atendimento à saúde (LIMA-GONÇALVES, 2002; ROTTA, 2004; VIEGAS e PENNA, 2013).

A gestão hospitalar, como a gestão de outras atividades econômicas, se insere perfeitamente neste ambiente de alocação de recursos com foco em benefícios e questões de incentivo e monitoramento dos agentes em um contrato, além disso apresenta o desafio da gestão dos serviços, dado a característica intangível do serviço oferecido, a interveniência do paciente no processo de prestação do serviço e dificuldade do controle e padronização da qualidade do atendimento (DAL POZ, 1997; ROTTA, 2004).

Estudos demonstram que a utilização de ferramentas econômicas, como indicadores de desempenho, sistema de remuneração e modelos de gestão, desenvolvidos com base nos processos e estruturas hospitalares impactam na eficiência na gestão hospitalar e qualidade do atendimento, (BITTAR, 1997; DAL POZ, 1997; ALVES, 1997; ROTTA, 2004; LA FORGIA e COUTTOLENC, 2009; GABRIEL et al., 2011; CALDANA et al., 2011; CUNHA, 2011; VIEGAS e PENNA, 2013; GABRIEL et al., 2013; OYADOMARI et al.,2014). 
No setor hospitalar a decisão de alocar recursos pode ser impactada pelo tipo de tarefa desenvolvido, que é o cuidado à saúde, além dos aspectos da força de trabalho, formada por profissionais de saúde, com propensão menor a incentivos financeiros para direcionar a alocação de recursos, dado a proximidade com a atividade operacional de tratar a saúde e a relação de agência com o paciente (DEVLIN e SARMA, 2008; WEBER e GRISCI, 2010),

Teorias alternativas de motivação, como a teoria de motivação no setor público (PERRY e MASON, 1990), predizem que em organizações em que o profissional se relaciona diretamente com a sociedade e seu bem-estar devem ser consideradas normativas específicas para o comportamento dos agentes, que possuem motivação racional, ligada a aspectos de utilidade; motivação normativa, que representam adequação a sociedade e suas normas; e motivação afetiva, que derivam de respostas emocionais e de contexto social, como fazer parte de algo com importância social e o patriotismo de benevolência (PERRY e MASON, 1990; PERRY, HONDEGHEM e WISE, 2010), na mesma linha Bruchey (1958) defende que a renda e a felicidade não necessariamente estão relacionadas.

Assim, a decisão no âmbito hospitalar se relaciona com teorias psicológicas e sociológicas referentes influenciadores emocionais, relacionamento com paciente e ambiente organizacional, (MOONEY e RYAN, 1993; PITTA, 1994; BERNARTZI e THALER, 1995; LOEWENSTEIN, 1996; THALER, 1999; ROTTA, 2004; NEUMANN e NEUMANN, 2007; BARIGOZZI e LEVAGGI, 2008; DEVLIN e SARMA, 2008; TOFAN et al., 2013).

A teoria econômica normativa prediz que a decisão do gestor é afetada por fatores de incentivo, como retorno, valor e instrumentalidade, já a abordagem econômica cognitiva, enfatiza estratégias de controle mental, percepção de "auto-eficácia" e ponto de referência, e as teorias de psicologia e sociologia salientam aspectos como influencias viscerais, direcionadores emocionais, ambiente organizacional (TVERSKY e KAHNEMAN, 1979; BERNARTZI e THALER, 1995; LOEWENSTEIN, 1996; THALER, 1999; FREDERICK, LOEWENSTEIN e O'DONOGHUE, 2002; VAN RINSUM, 2006; AGUIAR, 2009; AGUIAR e FREZATTI, 2013; SHI, YANG e PRESCOTT, 2014). 
$\mathrm{Na}$ literatura de gestão por processos o foco é voltado para o efeito de atributos das tarefas e processos relacionados à cadeia de valor e estratégia no processo decisório e na avaliação de desempenho do gestor (SMART, 2009; BULTON, 2010; HERNAUS, 2012).

Com isso, um dos critérios relevante para analisar a alocação de esforços em tarefas parece estar associado aos efeitos temporais (FREDERICK, LOEWENSTEIN e O'DONOGHUE, 2002; DIKOLLI e VAYSMAN, 2006; AGUIAR, 2009; AGUIAR, PINHEIRO e OYADOMARI, 2014), dado que o momento de ocorrência do benefício impacta diretamente no momento de consumo do mesmo.

Essa complexidade de causas multidisciplinares, que abrange aspectos cognitivos, sociais e econômicos, que podem afetar as escolhas intertemporais dos gestores ainda é um campo de estudos iniciante, com poucos estudos com alto grau de profundidade no assunto. Ainda assim alguns estudos já destacam fatores como influencias viscerais, direcionadores emocionais, teorias de motivação no trabalho, de autocontrole, atributos organizacionais, entre outros fatores que causam efeito na Orientação Temporal do Gestor (BERNARTZI e THALER, 1995; LOEWENSTEIN, 1996; THALER, 1999; FREDERICK, LOEWENSTEIN e O'DONOGHUE, 2002; TROPE e LIBERMAN, 2003; VAN RINSUM, 2006; AGUIAR, 2009; AGUIAR e FREZATTI; 2013).

A figura 1 sintetiza os macros fatores que a literatura aborda para explicar a Orientação Temporal do Gestor, que são os aspectos econômicos como utilização de medidas de desempenho, sistema de remuneração e sistema de controle e monitoramento, aspectos organizacionais e aspectos cognitivos. 


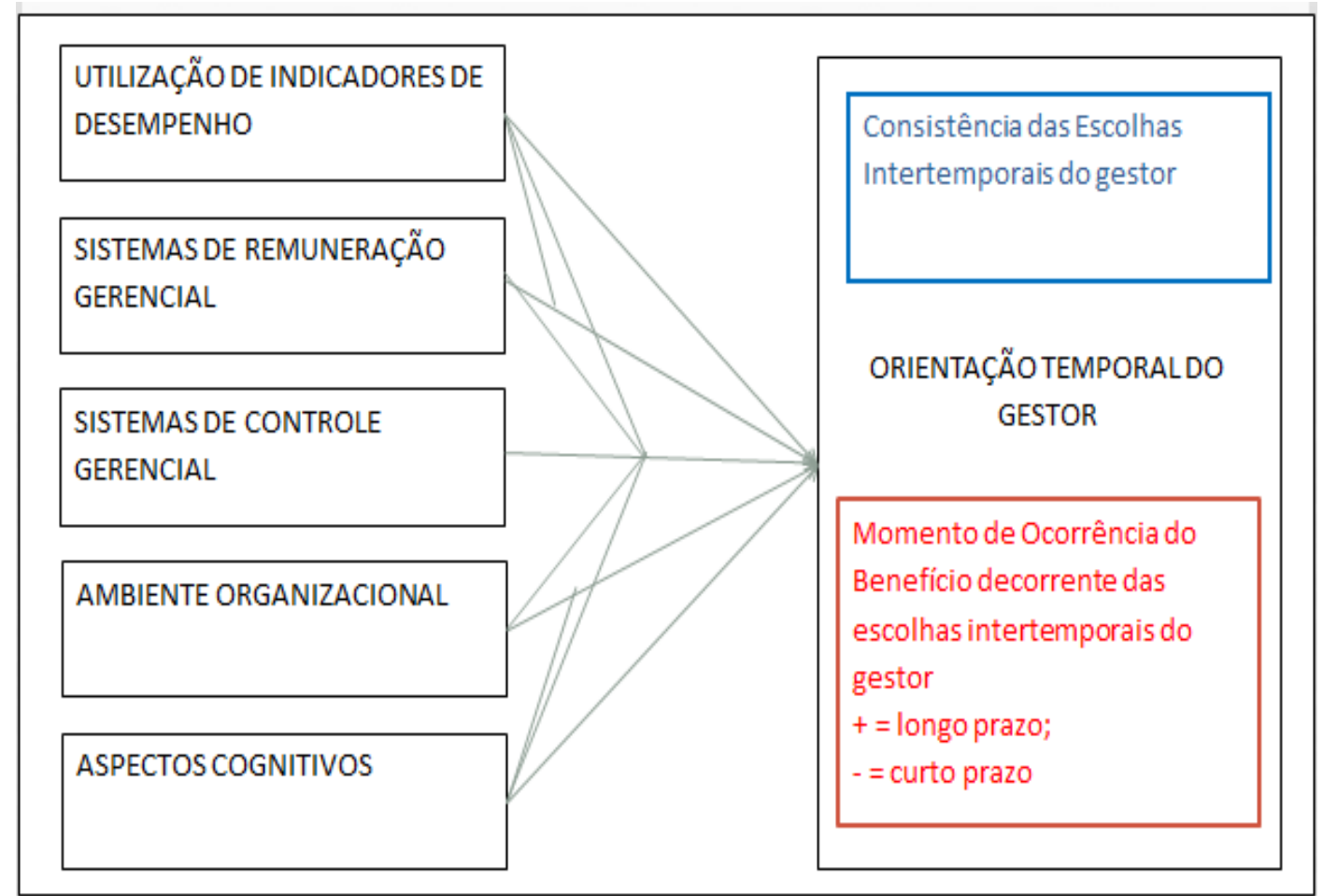

Figura 1: Aspectos Econômicos, Organizacionais e Cognitivos que afetam a Orientação Temporal do Gestor.

Fonte: Elaborado pelo autor com base em Laverty (1996) e Aguiar (2009).

A figura 1 demonstra a multidimensionalidade do construto Orientação Temporal do Gestor, que pode ser entendido pela consistência das escolhas intertemporais do gestor e pelo momento de ocorrência do benefício decorrente das escolhas intertemporais (AGUIAR, 2011), assim como os fatores, de acordo com as perspectivas de Laverty (1996), que podem causar efeitos na Orientação Temporal do Gestor, sejam efeitos diretos, interativos ou moderadores (LAVERTY, 1996; FREDERICK, LOEWENSTEIN e O'DONOGHUE, 2002; DIKOLLI e VAYSMAN, 2006; VAN RINSUM, 2006; AGUIAR, 2009; AGUIAR, 2011).

Esta pesquisa analisará quais os possíveis fatores que impactam na alocação das tarefas com diferentes efeitos temporais nas instituições hospitalares, visto as particularidades das entidades hospitalares já descritas, que podem fornecer observações relevantes para entendermos a OTG sob a luz das perspectivas sociológicas, psicológicas e organizacionais. 
No ambiente hospitalar, descrito na literatura nacional inclusive, o efeito de mecanismos econômicos, organizacionais e cognitivos ainda não foi investigado, sendo que a literatura aborda os efeitos de ambiente institucional, formas de financiamento, processos hospitalares, e modelo de gestão nas decisões hospitalares de maneira geral.

A contribuição dessa pesquisa consiste na análise das decisões hospitalares sob o critério da OTG, no incremento e expansão no conhecimento sobre os fatores que impactam na decisão hospitalar, no entendimento da OTG e suas causas e geração de conhecimento que auxilie outras pesquisas a continuar esse tema.

Portanto, esta investigação procurou entender fatores que impactam na OTG, que representa as decisões com foco em resultados em diferentes momentos no tempo, que no hospital pode representar uma escolha compensatória entre investir em inovações, qualidade e expansão, consumindo recursos para minimizar o risco da imprevisibilidade da tarefa dado a incerteza (longo prazo) e o atendimento pacientes atuais, com consumo dos recursos para sanar necessidades atuais (curto prazo).

Assim, buscou-se entender os fatores que impactam na OTG do gestor hospital amplia tanto o horizonte de práticas gerenciais no setor de saúde, quanto o horizonte dos fatores que afetam OTG. Espera-se, também, contribuir para a discussão sobre modelos de gestão e ferramentas econômicas utilizadas para decisão e monitoramento que podem ser utilizadas para a gestão do negócio, dadas características dos indivíduos e organizações.

Com o entendimento do impacto desses fatores na decisão do gestor de alocar recursos para benefícios de curto ou longo prazo espera-se uma alocação de recursos da saúde, tanto público quanto privado, de forma mais eficiente, garantindo melhor atendimento aos usuários e a continuidade do serviço.

\subsection{Limitações de escopo}

Os resultados deste trabalho se pautam na análise das percepções e experiências de gestores hospitalares, tanto em relação à própria atividade desempenhada por eles, quanto ao ambiente organizacional que estão inseridos. Desta forma, as conclusões não dizem respeito às organizações hospitalares ou perfis profissionais. O objetivo dessa pesquisa é entender as atividades desempenhadas pelos gestores hospitalares e os fatores que podem estar associados a orientação temporal desses gestores. 


\subsection{Estrutura do trabalho}

Este trabalho está estruturado em cinco seções: a primeira na introdução, onde são apresentados o contexto do tema de pesquisa e a situação problema, a questão de pesquisa, os objetivos gerais e específicos e as justificativas e contribuições, limitações do trabalho, e por fim a estrutura da dissertação.

A segunda seção explora o referencial teórico, compreendendo os temas Orientação Temporal do Gestor, sistema de incentivo e teorias motivacionais, gestão de processos e gestão hospitalar. Na terceira seção deste trabalho, apresentam-se os procedimentos metodológicos ordenados pelo método de pesquisa, o tipo de pesquisa, a amostra, o instrumento de coleta de dados e o procedimento para análise dos dados. Na quarta seção são exibidos e analisados os resultados da pesquisa, e na quinta e última seção foram expostas as considerações finais, limitações da pesquisa e perspectivas para estudos futuros. 


\section{REFERENCIAL TEÓRICO}

Essa dissertação procurou observar os fatores econômicos, organizacionais e cognitivos que podem estar associados à OTG e com o relacionamento entre o sistema de remuneração gerencial e OTG, e para atingir esse objetivo cumpre apresentar os pressupostos teóricos que condicionaram esta investigação.

A fundamentação teórica para essa pesquisa envolve teorias econômicas, sociológicas, psicológicas e de gestão. A seguir serão apresentados os fundamentos quanto a Organização hospitalar, suas características e dilemas, em seguida os Sistemas de Incentivo na gestão hospitalar, Gestão por Processos e os processos hospitalares, e por fim a Orientação Temporal do Gestor e Escolhas Intertemporais.

\subsection{A Organização hospitalar, suas características e dilemas}

No ambiente hospitalar, no qual a atividade a ser desenvolvida é tratar a saúde, o risco da falha tem alto valor ao hospital, visto que toda perda afeta a expectativa de vida de algum paciente, e os profissionais de saúde tem que lidar com morte e sofrimento constantemente no ambiente de trabalho (PITTA, 1994).

Para melhor entendimento da gestão hospitalar nos próximos parágrafos segue um panorama geral do ambiente social, econômico e histórico do sistema de saúde.

A atenção à saúde no Brasil possui particularidades significantes, como a reforma sanitária e o modelo SUS, o Sistema Único de Saúde, que garante o direito ao acesso gratuito à saúde a todo cidadão como dever do Estado. Em outros países existem modelos de saúde privatizados, como nos EUA, ou modelos de saúde que atendem todo trabalhador formal, como é na Alemanha e era no Brasil antes do SUS (TEXEIRA; MENDONÇA, 1989).

O SUS foi criado pela Constituição Federal de 1988, e constitui um sistema público de ações e serviços de saúde hierarquizados e regionalizados que são financiados com recursos do orçamento da seguridade social da União, dos Estados, do Distrito Federal, dos Municípios e de outras fontes, sendo que a participação da iniciativa privada é livre e 
complementa o SUS (LIMA-GONÇALVES, 2002; ROTTA, 2004; CAMPOS, AMARAL, 2007; LA FORGIA; COUTTOLENC, 2009; VIEGAS, PENNA, 2013).

O sistema único de saúde atua como a operadora de saúde, pois é a fonte financiadora dos hospitais, induzindo os gestores a tomarem suas decisões conforme os incentivos que recebem do SUS, assim como os planos de saúde são as fontes de financiamento para os hospitais privados.

Ainda não existe uma definição da influência do modelo de financiamento da saúde no Brasil na OTG do gestor, mas é razoável supor que a forma pela qual o hospital é financiado impacta nas decisões dos gestores de maior nível hierárquico, assim como nas escolhas intertemporais. O hospital é remunerado pelos procedimentos que realiza, assim, portanto, sua atenção será dada à manutenção ou ampliação para atendimento dos procedimentos com maior margem, seja na remuneração pela tabela SUS ou pela negociação com as operadoras.

Nesse sentido quatro hospitais estudados atuam fortemente com as operadoras de saúde privadas, enquanto um hospital atende predominantemente o sistema SUS, a escolha de hospitais com perfis diferentes de financiamento é justamente para contrapor essas perspectivas com as observações dos gestores e entender a influência do modelo de financiamento nas decisões gerenciais, assim como validar se os fatores identificados que podem impactam na OTG são consistentes em diferentes modelos de gestão hospitalar.

A iniciativa privada atua fortemente com a saúde suplementar, por meio de planos de saúde, que é regulamentado pela ANS (Agência Nacional de Saúde Suplementar), sendo que aproximadamente 26\% (47 milhões) da população brasileira é coberta pelas 1.323 operadoras de planos de saúde (IBGE, 2008).

Existe uma tendência de maior uso do sistema de saúde e maior relevância dele para a população brasileira devido o modelo universalista de atendimento à saúde, o envelhecimento da população brasileira, aumento da renda per capta da população brasileira e do PIB (Produto Interno Bruto) real dos brasileiros, e aumento dos gastos públicos com saúde em relação ao PIB (CUNHA, 2011).

Nesse contexto do SUS e atuação de operadoras de saúde o IBGE (2010) apurou que aproximadamente $\mathrm{R} \$ 283,6$ bilhões foram gastos com consumo final de bens e serviços de saúde no Brasil em 2009, representando 8,8\% do PIB nacional desse ano. A despesa de 
consumo das famílias com bens e serviços de saúde chegou a $\mathrm{R} \$ 157,1$ bilhões, representando 4,8\% do PIB, enquanto os gastos públicos foram de $\mathrm{R} \$ 123,6$ bilhões, representando $3,8 \%$ do PIB, e por fim as instituições sem fins lucrativos gastaram R 2,9 bilhões, representando $0,1 \%$ do PIB.

Para o entendimento do impacto do estudo é necessário entender a relação do setor de saúde com a sociedade, em relação ao total dos postos de trabalho do país 4,5\% são de atividades de saúde, em 2009 as atividades de saúde responderam por 4,3 milhões de ocupações, entretanto, isso não corresponde ao numero de pessoas ocupadas, visto que um indivíduo pode ocupar mais de um posto de trabalho (IBGE, 2010).

O consumo de serviços de saúde, como atendimento hospitalar e as consultas médicas mobilizou 5,6\% do PIB, enquanto o consumo final de medicamentos 1,9\% (IBGE, 2010), a despesa com hospitais consome quase metade das despesas totais no setor de saúde (ROTTA, 2004). Em 2013 no Brasil existem aproximadamente 6.706 hospitais (DATASUS, 2013), entre hospitais gerais, especializados e hospitais-dia, sendo 45\% privados, $33 \%$ públicos e $22 \%$ filantrópicos. Outras classificações em saúde pública dividem os hospitais entre hospitais públicos, privados e universitários (CAMPOS, 1999). Na base DATASUS os hospitais universitários figuram tanto em hospitais privados quanto públicos.

O hospital historicamente vem cumprindo uma função mais curativa que preventiva, funcionando como um estabelecimento para serviços médicos que incluem assistência e cuidados contínuos aos pacientes com finalidade de diagnóstico e tratamento. O hospital ainda tem uma função social em sua versão mais restrita, como prestadora de saúde, que inclui funções associadas de responsabilidade pela saúde de toda comunidade, e não apenas dos enfermos, incluindo ações preventivas (BITTAR, 1997; ROTTA, 2004; BONACIM, 2006; LA FORGIA, COUTTOLENC, 2009).

Apesar dos esforços para aumentar os recursos destinados à saúde e a implantação do sistema único de saúde ainda há escassez de recursos e necessidade de gerir os recursos existentes de maneira eficiente para melhoria na qualidade e quantidade do atendimento à saúde nos hospitais (CUNHA, 2011). E o modelo de financiamento da tabela SUS é fixo por procedimento, não considerando as situações imprevistas que podem aumentar a necessidade de recursos para cada procedimento, isso pode provocar o afastamento de 
hospitais particulares, dado margens baixas ou negativas em determinados procedimentos e a imprevisibilidade do atendimento, nesse sentido as operadoras de saúde privadas representam a condição de financiamento para esses hospitais (ESCRIVÃO JÚNIOR e KOYAMA, 2007; LA FORGIA, COUTTOLENC, 2009; BONACIM e ARAUJO, 2010a).

Esse cenário propicia supor que é necessário o estudo da gestão hospitalar, que permita acompanhar o aumento de demanda e recursos, visto que estudos demonstram que o desempenho da gestão hospitalar ainda precisa ser entendido e aperfeiçoado no Brasil, tanto pela ótica dos usuários do sistema de saúde quanto dos colaboradores do sistema de saúde (LIMA-GONÇALVES, 2002; ROTTA, 2004; BERNARDES et al., 2007; LA FORGIA e COUTTOLENC, 2009; GABRIEL et al., 2013).

Gestores da área de saúde apontam para fatores que dificultam a gestão, tanto com recursos humanos, materiais e modelos de gestão alternativos que possam aumentar a eficiência na utilização dos recursos hospitalares. Estudos demonstram grande variação na qualidade, na produtividade e nos custos hospitalares dada influência do ambiente de atendimento à saúde com sua incerteza ambiental, modelo de financiamento, diferentes práticas de gestão e análise de desempenho, e relacionamento com o SUS e operadoras de saúde (ALVES, 1997; ROTTA, 2004; LA FORGIA, COUTTOLENC, 2009; BONACIM; ARAUJO, 2009; CALDANA et al., 2011; CUNHA, 2011; GABRIEL et al., 2011; GROHMANN et al., 2012; GABRIEL et al., 2013).

Grohmann et al. (2012) investigaram as competências que os gestores de saúde acreditam ser importante para eles e as competências que eles acreditam que já possuem, o conceito de competência foi segregado em três dimensões: a de conhecimento, habilidade e atitude. Os resultados dessa pesquisa demonstram que os gestores consideram importantes os conhecimentos sobre os serviços oferecidos, objetivos e missão do hospital, normas e procedimentos e perfis epistemológico.

As habilidades mais citadas foram gerenciar equipes, promover e manter relacionamento com funcionários e usuários, desenvolver o trabalho em equipe e criatividade, e as atitudes mais importantes foram ser justo com equipe e usuários, ser aberto ao diálogo e ter envolvimento com o trabalho.

Os resultados ainda indicam que os gestores consideram pontos fracos de seu desempenho conhecimentos em políticas públicas, sistema de informação e administração 
estratégica, as habilidades de gerenciar as equipes, ser inovador e agente de mudanças, usar o planejamento com prática gerencial e gerenciar os programas desenvolvidos e motivar funcionários, e as atitudes são ser um líder educador e desenvolver a iniciativa a autonomia da equipe (GROHMAN et al., 2012).

Assim sendo, o relacionamento entre o paciente (que é o consumidor do serviço hospitalar) e o profissional de saúde tem grande importância e uma expectativa alta por parte do paciente, e o profissional de saúde percebe também a importância que possui para os pacientes e como a vida e a existência são dependentes do agente de saúde (MOONEY e RYAN, 1993; SCOTT e VICKY, 1999; NEUMANN e NEUMAN, 2007; JAEGHER, 2012; TOFAN et al., 2013; SANTOS e HORMANEZ, 2013; OYADOMARI et al., 2014).

Esses agentes de entidades de saúde estão intimamente relacionados com o risco da finitude humana, fato esse que os leva serem menos propensos aos riscos decorrentes de incerteza quanto ao futuro, além da própria atividade demandar esforços em tarefas de emergência e urgência (PITTA, 1994; MARTINS, ALVES e GODOY, 1999; ARAUJO e VIEIRA, 2004; BARIGOZZI e LEVAGGI, 2008; SANTOS e HORMANEZ, 2013).

A curva de utilidade dos indivíduos pode ser entendida, em sua essência, em duas dimensões: Sobrevivência e Felicidade. Sobreviver significa a continuidade do indivíduo, tal como agir para garantir que novas ações possam ser tomadas. Felicidade, por outro lado, é a ação que garante a possibilidade de busca daquilo que lhe trará maior benefício, não se relacionado diretamente com a maximização da sobrevivência, traduzindo-se da experiência interna de cada indivíduo que emite julgamento sobre como se sente e o seu grau de satisfação com a vida (FREY; STUTZER, 2002; SCORSOLINI-COMIN; SANTOS, 2010).

No escopo dessa pesquisa não foi tratado em profundidade o que é felicidade, dado que se trata de um construto complexo, será considerado que a curva de utilidade desejada representa os benefícios que o indivíduo entende que lhe sejam necessários, e a curva de utilidade é composta pelas escolhas que o indivíduo pode fazer de consumo imediato ou postergado (FREDERICK; LOEWENSTEIN; O'DONOGHUE, 2002).

A curva de utilidade do indivíduo pode ser positiva, e por isso quer consumir toda felicidade o quanto antes, dado os riscos do futuro, que não somo capazes de mensurar com exatidão, ainda que possamos minimizar a variância da incerteza (TVERSKY; 
KAHNEMAN, 1979; PRELEC; LOEWENSTEIN, 1991; WEBER; CHAPMAN, 2005; HARTMAN, 2005). Também não somos capazes de definir o prazo de vida do indivíduo quanto ao futuro, para que facilitasse a alocação de recursos em tarefas com efeito imediato ou postergado.

Dado essas considerações, que a curva de utilidade pode ser entendida como felicidade mais sobrevivência, é razoável investigar qual a ponderação desses fatores na curva de utilidade dos gestores, considerando o relacionamento com os pacientes.

Logo pode ser que os profissionais de saúde possuam uma maior propensão a proposições de medidas e soluções de curto prazo para garantir menores riscos do resultado negativo, através de correções tempestivas que aumentem a probabilidade de sucesso e diminuam o risco de morte, ou diminuição da expectativa de vida, do paciente.

Então, é razoável supor que quanto mais o profissional de saúde (gestor ou colaborado) presencia e visualiza para si a possibilidade de finitude da existência (morte), mais no curto prazo serão as ações do agente. Profissionais da saúde visualizam e presencia a possibilidade da finitude dos clientes que atendem, e alocam os esforços para garantir que o cliente receba sua parte no acordo de serviço contratado, que é estender a sobrevivência atual, o paciente chegar no hospital com uma possibilidade de finitude da vida ou de algo que afete a felicidade dado a dor em determinado nível e sair dele com maior expectativa de vida e felicidade que antes de usá-lo (MOONEY e RYAN, 1993; PITTA,1994; ARAUJO e VIEIRA, 2004; BARIGOZZI e LEVAGGI, 2008; SANTOS e HORMANEZ, 2013).

Consequentemente, dadas essas características, parece plausível esperar que as organizações de saúde tenham como desafio o estabelecimento de mecanismos de incentivo que balanceiem esforços em atividades com efeito no curto e longo prazo, com o desafio de induzir os profissionais que possuem proximidade com o risco da finitude da vida a esse balanceamento.

A complexidade do contexto está no fato da decisão de alocação de esforços para resultados de curto e longo prazo pode representar escolhas compensatórias dado que os recursos são escassos, logo pode ocorrer que para alocar esforços e recursos para tarefas com resultado no longo prazo seja necessário diminuir a alocação de recursos e esforços para tarefas com resultado no curto prazo (FREDERICK, LOEWENSTEIN e O’DONOGHUE, 2002). 
Enfim, é uma contribuição da contabilidade e controladoria observar e acompanhar a eficácia dos mecanismos de incentivo dos gestores hospitalares propostos, sobretudo quanto aos quesitos de balanceamento (curto e longo prazo). Adotando o pressuposto de que as decisões individuais afetam as decisões organizacionais, estudos demonstram que o foco excessivo no curto prazo pode levar instituições a uma breve existência, dessa maneira o horizonte temporal do gestor é fator decisivo de suas escolhas (NARAYANAN, 1985; MERCHANT e BRUNS, 1986; DEMIRAG; 1995; AGUIAR, 2009; MARGINSON et al., 2010; BRAUER, 2013; CALLEN e FANG, 2013; DAVIES et al., 2014).

A gestão hospitalar apresenta o desafio da gestão dos serviços, dado a característica intangível do serviço oferecido, a interveniência do paciente no processo de prestação do serviço, dificuldade do controle e padronização da qualidade do atendimento e natureza do serviço (DAL POZ et al., 1997; ROTTA, 2004, LA FORGIA e COUTTOLENC, 2009; WEBER e GRISCI, 2010; OYADOMARI et al., 2014).

Artefatos e instrumentos contábeis, financeiros e econômicos, como o sistema de remuneração e modelo de gestão impactariam na eficiência na gestão hospitalar, na qualidade do atendimento, assim como na utilização dos recursos. É pressuposto desta pesquisa que tal impacto seria maior quando tais ferramentas capturam as particularidades do setor, desenvolvidos com base nos processos de negócios e estruturas de autoridade hospitalares (BITTAR, 1997; DAL POZ et al., 1997; ROTTA, 2004; CARAPINHEIRO, 2005; LA FORGIA e COUTTOLENC, 2009; GABRIEL et al.; 2011; CUNHA, 2011).

O sistema de remuneração gerencial e de avaliação de desempenho ainda tem importância como ferramenta de gestão e tomada de decisão, impactando na decisão do gestor de alocar eficientemente os recursos para a obtenção do benefício, minimizando a aleatoriedade negativa da escolha, ou seja, a tomada de decisão é utilizada para minimizar que o resultado do "acaso negativo" se realize (VON NEUMANN e MORGENSTERN; 1944; TVERSKY e KAHNEMAN, 1979; KELLY, 2007).

Segundo a literatura o processo de tomada de decisões do gestor envolve o processo de escolha, de alocação e acompanhamento das tarefas, podendo ser tarefas operacionais ou administrativas e de suporte e avaliadas de acordo com o resultado dessa escolha, seja quanto ao valor do resultado, o tempo em que ocorrerá o resultado ou quem poderá usufruir 
do resultado (FREDERICK, LOEWENSTEIN e O'DONOGHUE, 2002; DIKOLLI e VAYSMAN, 2006; AGUIAR, 2009).

Assim as escolhas tomadas pelos gestores podem ser analisadas sob a perspectiva temporal, ou seja, a decisão de alocar recursos (financeiros ou não) na data de hoje reflete benefícios em determinado período, seja imediato ou futuro, logo o gestor necessita analisar como alocar seus recursos com foco no momento em que ocorrerá o benefício, para garantir a continuidade da organização e a eficiência do contrato (FREDERICK, LOEWENSTEIN e O’DONOGHUE, 2002; DIKOLLI e VAYSMAN, 2006; VAN RINSUM, 2006; AGUIAR, 2009; AGUIAR, PINHEIRO e OYADOMARI, 2014).

No ambiente hospitalar, especialmente, é relevante observar as escolhas tomadas pelos gestores sob a perspectiva temporal dado a tendência de aumento no uso dos serviços de saúde (LA FORGIA e COUTTOLENC, 2009; CUNHA, 2011) e dado a proximidade dos profissionais da saúde com o risco de morte e sofrimento (MOONEY e RYAN, 1993; PITTA, 1994; ARAUJO e VIEIRA, 2004; BARIGOZZI e LEVAGGI, 2008; SANTOS e HORMANEZ, 2013) que pode determinar alocação de tarefas excessivas no curto prazo, comprometendo a continuidade do hospital e atendimento aos futuros pacientes.

Então, estudar o impacto da mensuração de desempenho na decisão do gestor é importante para minimizar os custos decorrentes da falha de comunicação entre agentes e proprietário que podem afetar o resultado econômico geral do contrato, assim como maximizar o efeito da decisão como minimizador do resultado negativo possível (VON NEUMANN e MORGENSTERN, 1944; JENSEN e MECKLING, 1976; TVERSKY e KAHNEMAN, 1979; MILGRON e ROBERTS, 1992).

O ambiente hospitalar é peculiar e regulamentado pelo Governo devido sua natureza de direito básico do ser humano, no caso brasileiro particularidades do SUS, tabelas de preços e relacionamento com operadores de saúde, governo e população afetam o modelo dos processos e regras de negócio. Da mesma maneira as operadoras de saúde são reguladas pela ANS e possuem forte regulação quanto a cobertura dos procedimentos e prazos de atendimento, gerando assim um complexo modelo de negócio da assistência à saúde no Brasil (CARAPINHEIRO, 2005; ESCRIVÃO JUNIOR e KOYAMA, 2007; SATO, 2007; UGA et al., 2009; LA FORGIA e COUTTOLENC, 2009; PORTELLA et al., 2010; CAMACHO, ROCHA e MORAES, 2011; OYADOMARI et al., 2014). 
Este estudo analisou os hospitais dado suas especificidades, seu caráter público, privado ou hospital escola, o objetivo do hospital, a relação entre hospital e usuário do sistema de saúde, relação do hospital com operadoras de saúde e formas de financiamento do hospital para seu funcionamento e investimentos. Cumprido a caracterização da atividade hospitalar, o sistema de saúde e os dilemas enfrentados pelos gestores de saúde, esses aspectos serão relacionados aos sistemas de incentivo, gestão por processos e por fim com a Orientação Temporal do Gestor.

\subsection{Sistemas de incentivo na gestão hospitalar}

O hospital também pode ser entendido como uma organização econômica vinculada aos processos de atenção à saúde. Como organização econômica, suas transações são organizadas por um portfólio de contratos: oferece serviços aos seus pacientes, contrata funcionários, recursos, serviços e bens para a realização de suas atividades. (ALCHIAN e DEMSTEZ, 1976).

Nesse contexto, o hospital necessita de ferramentas de remuneração aos funcionários e serviços que contrata, assim como ferramentas de incentivo para que os prestadores de serviço atuem conforme as necessidades do hospital (ALCHIAN e DEMSTEZ, 1976; MILGRON e ROBERTS, 1992).

Por sua vez, os mecanismos de incentivo afetam as atividades que o gestor escolhe desempenhar, assim como a qualidade das decisões gerencias (KELLY, 2007). E, dessa maneira afeta a OTG, dado que as tarefas desempenhadas levariam a aumentos imediatos ou postergados do consumo da curva de utilidade do agente (BONNER e SPRINKLE, 2002).

A literatura econômica, contábil e psicológica sugere que o sistema de remuneração gerencial afetaria a decisão do gestor de alocação de recursos, inclusive em seus efeitos temporais (DIKOLLI; VAYSMAN, 2006; VAN RINSUN, 2006; AGUIAR, 2009; AGUIAR e FREZATTI, 2013; STROBL, 2014). O sistema de remuneração gerencial pode ser entendido em termos de suas dimensões de mensuração e incentivo (BANKER e DATAR, 1989).

A dimensão de mensuração estaria relacionada com áreas de desempenho, composto por elementos de metas de desempenho, medidas de desempenho e período de avaliação do 
desempenho. Por sua vez, a dimensão de incentivo seria composta por elementos do tipo de incentivo e de características do esquema de incentivo (BANKER e DATAR, 1989). A figura 2 apresenta as dimensões e elementos propostos por Banker e Datar (1989).

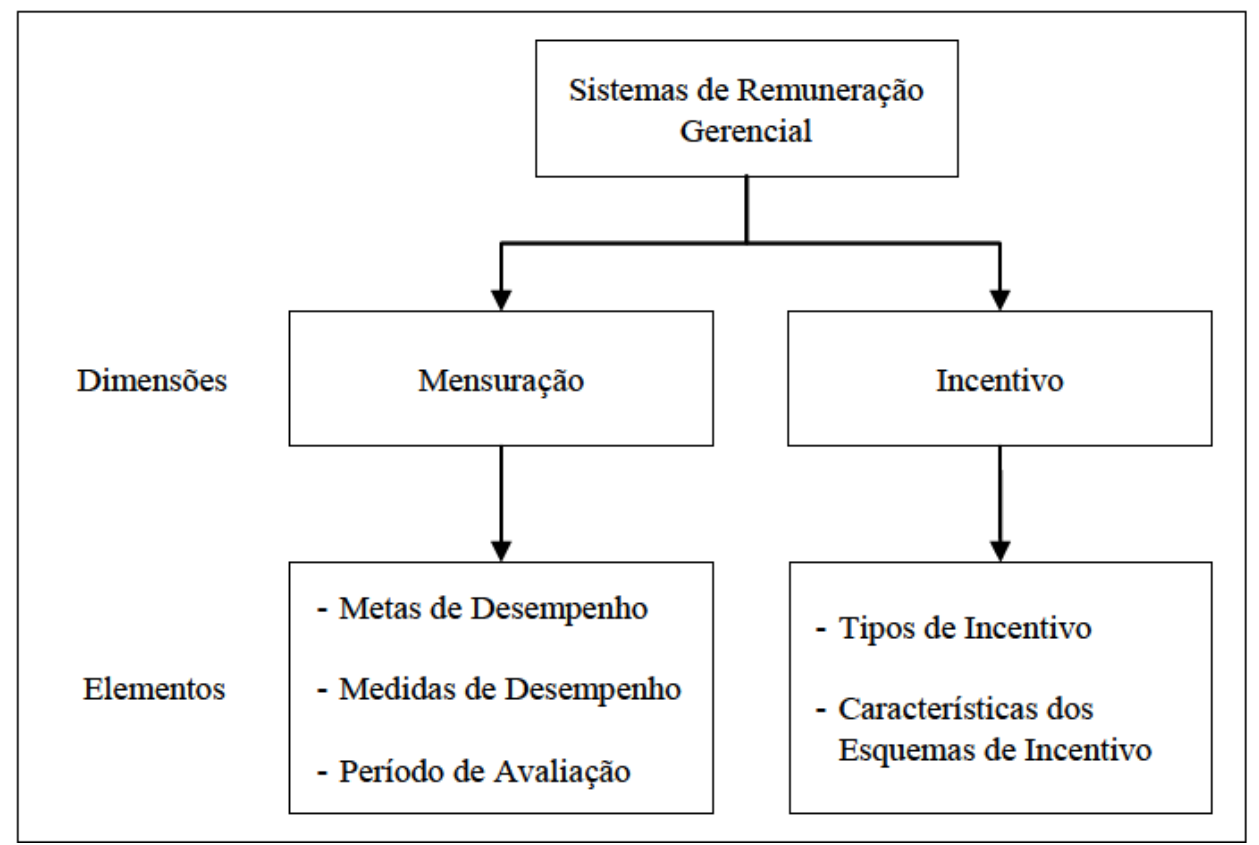

Figura 2: Dimensões e elementos do Sistema de Remuneração Gerencial.

Fonte: Aguiar (2009).

É fato que, historicamente, a pesquisa contábil tem dado atenção aos efeitos da dimensão de mensuração na decisão de alocação de esforços em tarefas. Principalmente estudos que buscavam verificar o impacto de medidas de desempenho que deveriam ser consideradas no sistema de remuneração gerencial para mitigar orientação temporal de curto prazo (NARAYANAN, 1985; MERCHANT e BRUNS, 1986; LEWELLEN et al., 1987; DECHOW e SLOAN, 1995; DUTTA e REICHELSTEIN, 2003; GIBBS et al., 2004; MOERS, 2006; VAN RINSUM, 2006; MARGISON e MCAULAY, 2008; AGUIAR, 2009; ABERNETHY et al., 2013; AGUIAR, PINHEIRO e OYADOMARI, 2014).

Estudos recentes também verificam o efeito do período de avaliação na Orientação Temporal do Gestor (VAN RINSUM; 2006; AGUIAR; FREZATTI, 2013). E as metas de desempenho são relacionadas com a motivação do gestor, assim como o potencial de realização das metas e sistemas de controle (MERCHANT, 1990; TROPE e LIBERMAN, 2003; WEBB, 2004; VAN DER STEDE, 2010). 
No contexto, a utilização de indicadores de desempenho representaria um mecanismo para que a escolha do gestor possua um parâmetro para decisão, com base na atividade da empresa e resultado econômico da mesma. As medidas e indicadores são maneiras de mensurar o desempenho da atividade dada regras e padrões pré-estabelecidas (STEVENS, 1946; KAMEL, 2007), e os indicadores devem permitir o acompanhamento do efetivo sucesso da estratégia da empresa e o real desempenho da mesma (IJIRI e JAEDICKE, 1966; CONNOLLY e DEUTSCH, 1980; ABERNETHY et al., 2013), assim como instrumento base para gestão e tomada de decisão e ponto de comunicação entre gestor e subordinado (ROTTA, 2004; TARABOULSI, 2005; HARTMAN e SLAPNICAR, 2009; CUNHA, 2011; AGUIAR, 2011; PINHEIRO, GALDI e OYADOMARI, 2012), e tal importância é relatada na literatura em gestão hospitalar (ROTTA, 2004; ESCRIVÃO JUNIOR, 2007; MALIK e VELOSO, 2010; GABRIEL et al., 2011; CUNHA, 2011; CALDANA et al., 2011; GABRIEL et al., 2013; OYADOMARI et al., 2014).

A teoria contábil prediz que a utilização de indicadores de desempenho depende da percepção de utilidade que o gestor possui quanto ao indicador de desempenho (HARTMAN, 2000), assim como a força da relação causal entre o indicador de desempenho com metas organizacionais aumenta o comprometimento do gestor, dado que aumenta a percepção de utilidade que o gestor possui quanto ao indicador (WEBB, 2004; HERNAUS, 2012; HO, WU e WU, 2014).

Portanto, a confiança na medida de desempenho pode ser impactada pela incerteza ambiental e de tarefa (HARTMAN, 2000; HARTMAN, 2005), sendo a primeira relacionada com o fato do gestor não conhecer o tipo de decisão e dilema que enfrentará e sobre o qual não possui poder de prever, já a incerteza da tarefa está relacionada em como os gestores agem de acordo com os dilemas e decisões que ocorrem, quanto maior a variabilidade de desfechos para o mesmo dilema e decisão, maior a variabilidade da tarefa.

Nesse sentido sistemas estratégicos de avaliação de desempenho, que são conjunto de objetivos, metas e medidas de desempenho não financeiros e financeiros com relações causais e alinhados com a estratégia da empresa, podem aumentar o comprometimento dos gestores com as metas, independente do sistema de remuneração, da mesma forma a utilização de indicadores de desempenho alinhados com os processos da empresa aumentam a eficiência das decisões gerenciais por apresentarem aos gestores relações 
causais entre os indicadores utilizados, metas designadas e os objetivos estratégicos da empresa (KAPLAN e NORTON, 1996; CHENNAL, 1997; MALINA e SELTO, 2001; WEBB, 2004; GERSCH et al., 2011; HERNAUS, 2012).

No âmbito hospitalar os indicadores de desempenho econômicos são referenciados como importantes para gestão, mas pesquisas na área demonstram uma subutilização dos mesmos, decorrentes principalmente da dificuldade em vincular indicadores assistenciais com indicadores financeiros e econômicos (ROTTA, 2004; ESCRIVÃO JUNIOR, 2007; CUNHA, 2011; CALDANA et al., 2011; GROHMANM et al., 2012)

Já na dimensão de incentivo são observadas discussões associadas aos tipos de incentivo, tais como bônus, planos de incentivo de longo prazo ou opção de ações, enquanto outros estudos analisam as características do esquema de incentivo, que podem ser monetários, sociais, baseados em desempenho, fixos ou variáveis, imediato ou postergado, entre outros. (NARAYANAN, 1985; LEWELLEN et al., 1987; DECHOW e SLOAN, 1995; BHOJRAJ e LIBBY, 2005; AGUIAR, 2009; STROLB, 2014; ANANTHARAMAN e LEE, 2014; MATTSON, TORBIÖRN e HELLGREN, 2014)

Milgron e Roberts (1992) discutem a fórmula bônus do agente, que pode representar o tipo de incentivo que o gestor recebe, explicado pela participação da remuneração variável e fixa na remuneração do gestor. A fórmula bônus é representada pelo ganho total percebido pelo agente. $\mathrm{O}$ ganho total é representado pela fórmula descrita abaixo:

$\mathrm{I}=\ddot{\mathrm{I}}-1 / 2 \mathrm{R}(\ddot{\mathrm{I}}) \times \operatorname{Var}(\ddot{\mathrm{I}})$, onde

$\ddot{I}$ = Ganho esperado médio (fixo e variável)

$\mathrm{R}(\ddot{\mathrm{I}})=$ Coeficiente de aversão ao risco.

VAR (Ï) = Variância da remuneração nos cenários.

R (Ï) x Var (Ï) = Prêmio de Risco.

Segundo os autores, a remuneração total do agente deve considerar o prêmio do risco por aceitar uma remuneração variável. Isso significa que a remuneração total (fixo mais variável) menos o prêmio por assumir o risco deve ser igual à remuneração fixa, que não possui risco ao contratado (MILGRON e ROBERTS, 1992).

Conceitualmente, o sistema de remuneração gerencial deveria ponderar a remuneração variável de acordo com o risco associado a ela. Esse risco está associado a 
aversão ao risco do agente contratado e a variação da remuneração nos cenários, ou seja, o prêmio do risco contém aspectos cognitivos de aversão ao risco do agente e da incerteza ambiental em relação ao futuro e ao atingimento da meta para receber a remuneração variável (MILGRON e ROBERTS, 1992).

A variância da remuneração nos cenários depende tanto da incerteza ambiental quanto dos elementos do sistema de remuneração, ao passo que quanto melhor os indicadores de desempenho para avaliação e remuneração capturar os esforços e resultados das tarefas desenvolvidas pelo gestor menor será a variância da remuneração nos cenários, diminuindo o prêmio pelo risco (MILGRON e ROBERTS, 1992; AGUIAR, 2009), ao encontro dessa linha de pensamento estudos demonstram que a incerteza ambiental é um aspecto relevante na atividade hospitalar (LA FORGIA e COUTTOLENC, 2009; WEBER e GRISCI, 2010; TANAKA e TAMAKI, 2012; ABERNETHY et al., 2013; OYADOMARI et al., 2014).

Além do sistema de incentivo, também seria necessário avaliar o ambiente empresarial para avaliar as incertezas quanto aos cenários, assim como fatores cognitivos quanto à aversão ao risco (MILGRON e ROBERTS, 1992). No ambiente hospitalar essa discussão se intensifica, dado o caráter emergencial e de urgência inerentes aos processos de negócios, aumentando a incerteza quanto aos cenários futuros, além disso, fatores cognitivos dos agentes de saúde os orientam a uma maior aversão ao risco, dado a natureza de seu trabalho e atendimento ao paciente (PITTA, 1994; MARTINS, ALVES e GODOY, 1999; ARAUJO e VIEIRA, 2004; BARIGOZZI e LEVAGGI, 2008; TOFAN et al., 2013; SANTOS e HORMANEZ, 2013).

Portanto, a presente pesquisa tem o potencial de contribuir nas discussões em contabilidade gerencial e controladoria para o referencial conceitual do relacionamento entre sistema de remuneração gerencial e OTG, se aproximando dos trabalhos desenvolvidos por Van Rinsum (2006) e Aguiar (2009), bem como do referencial em gestão hospitalar e utilização de ferramentas econômicas.

Dessa maneira, quanto aos elementos da dimensão de mensuração do sistema de remuneração gerencial foram analisados os tipos de medidas de desempenho, o período de avaliação e comprometimento com as metas, enquanto na dimensão de incentivo foram analisados o momento de recebimento e a característica do incentivo em termos do 
percentual de remuneração variável baseada em desempenho em relação ao total de remuneração recebida.

Como pressuposto desta pesquisa, considera-se que o sistema de remuneração gerencial, na relação contratual da firma, possui o papel de incentivo ao contratado para realizar suas tarefas e cumprir suas metas organizacionais, assim como um fator de monitoramento para o contratante, que pode utilizar esquemas de incentivo para alinhar e influenciar a alocação dos esforços dos contratados em tarefas que otimizam os resultados para os contratantes.

Para isso o sistema de remuneração gerencial possui elementos e características que possuem o potencial de alinhar os interesses dos contratados e contratantes, em concordância com as particularidades dos processos de negócio, ao passo que seja capaz de captar o desempenho dos agentes e remunerá-los conforme seus esforços e resultados, possibilitando o melhor resultado do contrato (MILGROM; ROBERTS, 1992; KAPLAN; NORTON, 1996; LAMBERT, 2001).

Teorias alternativas de motivação defendem que os colaboradores se relacionam com questões sociais do seu trabalho, e suas funções possuem um significado social importante, que por si só, já é um motivador a essas pessoas, ou seja, essa relação direta com a sociedade e o bem-estar impactam na motivação das pessoas (MCCLELLAND e LIBERMAN, 1949; PERRY e WISE, 1990; CREWSON, 1997; HOUSTON, 2000; HOUSTON, 2006; MOYNIHAN e SANJAY, 2007; RODRIGUES et al., 2014), assim como teorias motivacionais incluem autossatisfação, felicidade como motivadores e no mesmo sentido estudos em economia defendem que renda não afeta felicidade (MCCLELLAND e LIBERMAN, 1949; BRUCHEY, 1958; FREY e STUTZER, 2002; SCORSOLINI-COMIN e SANTOS, 2010).

Na atividade hospitalar é razoável supor que os conceitos motivacionais referentes a função social exerçam influência nos gestores, devido a proximidade do mesmo com serviços sensíveis a vida humana.

Motivações são também definidas como as forças que dão energia, direcionam e sustentam o comportamento (PERRY, HONDEGHEM e WISE, 2010). As motivações são divididas em três características: racionais, normativas e afetivas. As motivações racionais são aquelas que relacionam-se com a maximização de utilidade que cada ser; as motivações 
normativas referem-se a ações geradas pelos esforços para se adequar às normas; e, por último, as características das motivações afetivas, que são aquelas cujos fundamentos envolvem respostas emocionais a diversos contextos sociais.

Extrapolando esses conceitos no ambiente hospitalar as motivações racionais podem estar relacionadas com o reforço da imagem do indivíduo de autoimportância, além da própria remuneração, já as normativas, a característica mais aparente é o desejo de servir ao interesse público e associam-se o conceito de equidade social, de modo que a entrada no serviço hospitalar aumenta o bem estar de necessitados. Entre as motivações baseadas em características afetivas, está a convicção a respeito da importância social do programa e por isto o comprometimento com ele (BITTAR, 1997; LIMA-GONÇALVES, 1998; DIAS, 2001; FRANCO, BENNETT e KANFER, 2002; SEIXAS e MELO, 2004; LA FORGIA e COUTTOLENC, 2009; LIMA et al., 2009; WEBER e GRISCI, 2010; TSOUNIS, SARAFIS e BAMIDIS, 2014).

Como consequência parece razoável supor que existem diferenças sobre como o sistema de remuneração afeta as decisões quanto às escolhas intertemporais dos gestores hospitalares, entretanto, no ambiente hospitalar ainda não existem estudos que demonstrem esse efeito, dado que existe também a influência dos processos de negócio hospitalares, que possuem particularidades que serão apresentadas a seguir.

Após observar os aspectos associados aos sistemas de incentivos, entre eles o sistema de remuneração gerencial, e as particularidades do ambiente hospitalar, cumpre observarmos que os processos de negócio e suas características são fatores que precisam ser considerados nas análises, nesse sentido a seguir serão apresentados os conceitos referentes à gestão de processos associados a gestão hospitalar.

\subsection{Gestão por Processos e os processos hospitalares}

A atividade hospitalar possui processos específicos e diferenciados em sua estrutura, dado que um atendimento de emergência difere de um atendimento eletivo, assim como um atendimento ambulatorial de um atendimento cirúrgico, decorrente das diferentes atividades de negócio e ativos envolvidos, é coerente analisar os sistemas de incentivo dado essas perspectivas e as associações e relações com as decisões intertemporais. 
A importância de se entender as especificidades dos processos no ambiente hospitalar é para avaliação do risco do negócio e da incerteza da tarefa e relacionar com a utilidade da informação para a gestão (LIMA-GONÇALVES, 1998; ROTTA, 2004; PIZZINI, 2006; SILBERSTEIN, 2006; LA FORGIA e COUTTOLENC, 2009; SOUSA ET al., 2011; BURGESS, RADNOR e DAVIES, 2009; DAHLGAARD e PETTERSEN, 2011; SOUZA e PIDD, 2011; AL-BALUSHI et al., 2014).

De maneira que a fórmula bônus do gestor é impactada pela variância nos cenários e em cenários com ativos específicos, processos com ciclos de vida diferentes e incerteza de tarefa essa variância pode ser maior. Logo para minimizar essa variância o entendimento dos processos de negócio e das tarefas que o gestor hospitalar gere são aspectos que minimizam a incerteza e risco do processo.

A literatura em gestão por processos de negócio $\left(B P M^{4}-\right.$ Business Process Management) enfatiza a importância do alinhamento dos processos com a cadeia de valor ao cliente e com a estratégia empresarial, sistema de remuneração e indicadores de desempenho (KAPLAN e NORTON, 1996; SMART et al., 2009; BURLTON, 2010; GERSCH et al., 2011; KANG et al., 2012).

O BPM demonstra a importância de avaliar as atividades e tarefas conforme seu papel na cadeia de valor, de maneira a capturar as incertezas de tarefas que podem existir no decorrer do processo.

Hartman (2000 e 2005) avaliou a incerteza da tarefa e os efeitos que essa causa na adoção de sistemas de mensuração de desempenho contábil, a gestão por processos minimiza a incerteza da tarefa ao passo que a gestão não é focada nas pessoas e funções e sim nas tarefas que devem ser desenvolvidas (SMART et al., 2009; BURLTON, 2010).

Seguindo essa linha de investigação, pode se observar que a utilização de indicadores de desempenho alinhados com os processos da empresa e BPM, com foco no valor ao cliente, aumentam a eficiência das empresas (KAPLAN e NORTON, 1996; CHENNAL, 1997; MALINA e SELTO, 2001; WEBB, 2004; GERSCH et al., 2011;

\footnotetext{
${ }^{4}$ Business Process Management (BPM) cuja tradução é Gestão de Processos de Negócio, é a terminologia o com maior utilização na literatura acadêmica, ainda outros termos são utilizados para referenciar a gestão com foco nos processos de negócio, como Strategic Business Process Management, Lean Model, Business Process Blueprint, entre outros. Essas terminologias derivam do modelo de gestão no qual a gestão por processos foi derivada, e entre esses métodos podem possuir algumas diferenças de terminologia, ainda assim os conceitos chaves de gestão por processos são equivalentes, tal como foco no processo de negócio e não na função, foco na agregação de valor ao cliente e mapeamento dos processos.
} 
KANG et al., 2012 HERNAUS, 2012), inclusive na gestão hospitalar, visto que estudos demonstram os efeitos positivos de alinhar o processo assistencial com indicadores qualitativos e quantitativos, inclusive financeiros, de maneira a introduzir ferramentas que capturem as particularidades da atividade hospitalar (SCHRAIBER et al., 1999; BITTAR, 2000; CECCIM e FEUERWERKER, 2004; JOOSTEN, BONGERS e JANSSEN, 2009; LA FORGIA e COUTTOLENC, 2009; DAHLGAARD e PETTERSEN, 2011; SOUZA e PIDD, 2011; AL-BALUSHI et al., 2014).

Portanto, a gestão por processos representaria uma visão diferente da gestão tradicional, visto que o foco não é a gestão funcional (uma gestão segregada por monitores por função desempenhada), e sim uma gestão com foco nos processos. Os gestores gerem o processo, analisando os recursos necessários, as tarefas desenvolvidas, as interações com stakeholders e clientes e os resultados entregues.

Essa visão ponta a ponta permite o gestor visualizar o alinhamento dos processos de negócio e das tarefas desenvolvidas nele com os objetivos da empresa e a agregação de valor ao cliente (SMART et al., 2009; BURLTON, 2010; SILVA et al., 2012; KANG et al., 2012; VALLEJO et al., 2012; GERSCH et al., 2012; NIEHAVES et al., 2012).

Com isso, a gestão hospitalar se relaciona com a gestão por processos ao passo que seus processos são específicos e interagem diferentes funções, dessa maneira um processo emergencial, que foca no atendimento dos pacientes que chegam com enfermidades que necessitam de atendimento imediato, difere de um processo eletivo, que representa um atendimento agendado ao paciente, assim como que atendimentos clínicos e cirúrgicos representam diferenças significativas quanto aos recursos a serem alocados.

Nesse contexto os processos hospitalares, somado as pressões de financiamento, seja SUS, que preconiza uma hierarquia de complexidade nos atendimentos, seja operadoras de saúde, é razoável a hipótese que os processos e tipos de tarefas afetam no relacionamento entre o sistema de remuneração e as escolhas intertemporais.

Modelos de gestão, como gestão participativa, são propostos como solução para a gestão dos recursos hospitalares (BERNARDES et al., 2007; CALDANA et al., 2011), tal modelo foca em uma gestão com base nos processos e não na função.

$\mathrm{Na}$ literatura em contabilidade gerencial estudos de custeio $\mathrm{ABC}$ aplicados em gestão hospitalar vão ao encontro dessas linhas de pesquisa, ao passo que o custeio $\mathrm{ABC}$ 
foca no entendimento da atividade para custeio do serviço prestado, denotando a necessidade de entender os processos de negócio da empresa para fornecer informação relevante e útil ao administrador hospitalar (ABBAS, 2001; ROTTA, 2004; DALMÁSCIO, AGUIAR e REZENDE, 2007; MIRANDA et al., 2007; BONACIM e ARAUJO, 2010a)

Assim, o custeio ABC permite trabalhar a análise de custo sob duas visões, a visão econômica e a visão de aperfeiçoamento dos processos, sendo que o $\mathrm{ABC}$ reduz as distorções provocadas por rateios arbitrários, entretanto a implementação da gestão por custos $\mathrm{ABC}$ é um dos desafios na gestão hospitalar, dado a complexidade para o entendimento dos processos e detalhamento dos procedimentos. (MARTINS, 2003; MIRANDA et al., 2007 BONACIM e ARAUJO, 2010a; MARTINS et al., 2013).

Com base na literatura em gestão hospitalar e gestão por processos é plausível acreditar que as particularidades dos processos hospitalares e as especificidades das tarefas possam influir na OTG, ao passo que os gestores de saúde lidam com maior risco do efeito negativo do resultado de seu trabalho e podem ser menos propensos a incentivos pecuniários. Logo é importante verificar o efeito do processo em si nas escolhas intertemporais do gestor e na consistência das mesmas.

Portanto para a investigação da associação entre elementos da gestão por processos e do sistema de remuneração gerencial na OTG, considerando as particularidades da atividade hospitalar, cumpre apresentar a literatura que trata do conceito de Orientação Temporal do Gestor e dos fatores que influenciam no mesmo.

\subsection{Orientação Temporal do Gestor}

O processo decisório dos gestores envolve escolhas de alocação de recursos, com intuito de benefícios, dado um conjunto de informações, conhecimentos e características do próprio gestor. Dessa maneira os gestores decidem quanto a alocação dos recursos no momento atual, com foco em um benefício em determinado momento do tempo, seja presente ou futuro. As escolhas intertemporais representam decisões envolvendo escolhas compensatórias (trade-off) entre custos e benefícios ocorrendo em diferentes momentos (FREDERICK, LOEWENSTEIN e O'DONOGHUE, 2002). 
A Orientação Temporal do Gestor representa a preferência temporal dos gestores em suas escolhas, e pode ser entendido com base em dois critérios, que são: a consistência das escolhas intertemporais dos gestores e o momento de ocorrência dos benefícios decorrente dessas escolhas (AGUIAR, 2011).

Os gestores empresariais, inclusive nos hospitais, se deparam com diversas tarefas, e necessitam decidir como alocar seus recursos para atingir seus objetivos, dado os benefícios que busca. No contexto empresarial, existem ferramentas econômicas que buscam alinhar os interesses entre o gestor e a empresa, para que esse aja de acordo com o contrato (JENSEN e MECKLING, 1976; BANKER e DATAR, 1989; MILGRON e ROBERTS, 1992; LAMBERT, 2001; CHENNAL, 2003; GIBBS et al., 2004; ABERNETHY et al., 2013; HO, WU e WU, 2014).

O efeito do sistema de controle gerencial, por meio de um sistema de incentivo baseado em resultados e desempenho, pode ser entendido por teorias de motivação, que predizem que o esforço é maior conforme uma maior percepção do agente em relação à atratividade e remuneração dos resultados de seu esforço (LAWLER, 1994; AGUIAR, 2009). A qualidade da decisão também é afetada pelos incentivos do sistema de remuneração gerencial (KELLY, 2007).

Essa decisão do gestor pode ser analisada conforme o efeito temporal dos benefícios decorrentes dela, e estudos demonstram que elementos do sistema de remuneração, como tipo de medida de desempenho, período de avaliação, tipo de incentivo ou características desses incentivos, afetam as escolhas intertemporais (NARAYANAN, 1985; MERCHANT e BRUNS, 1986; LEWELLEN et al., 1987; DEMIRAG, 1995; DECHOW e SLOAN, 1995; DIKOLLI, 2000; BHOJRAJ e LIBBY, 2005; VAN RINSUM, 2006; MARGISON et al., 2008; AGUIAR, 2009; ABERNETHY et al., 2013; AGUIAR e FREZATTI, 2013; BRAUER, 2013; AGUIAR, PINHEIRO e OYADOMARI, 2014).

Por sua vez, a preferência sobre essas escolhas intertemporais representa a Orientação Temporal do Gestor, que capta as preferências de um gestor em uma organização quanto ao momento de consumo dos benefícios decorrentes da sua decisão de alocação de esforços em diferentes tarefas, em diferentes momentos de decisão (FREDERICK, LOEWENSTEIN e O'DONOGHUE, 2002; DIKOLLI e VAYSMAN, 2006; AGUIAR, 2009). 
Cumpre ser ressaltado que a literatura contábil aborda a temática OTG com foco em um comportamento disfuncional em alocar esforços em tarefas com efeitos no curto prazo, que vem causando problemas econômicos em empresas (LEWELLEN, LODERER e MARTIN, 1987; DECHOW e SLOAN, 1991; BUSHEE, 2001; BHOJRAJ e LIBBY, 2005; MARGISON e MACAULAY, 2008).

A abordagem adotada na presente pesquisa, contudo, não considera disfuncional nem uma OTG de curto prazo nem de longo prazo a priori. Dessa maneira busca identificar fatores que afetam a alocação de tarefas com diferentes consequências temporais, indo além da análise de fatores que minimizem a orientação temporal de curto prazo (DIKOLLI, 2000; GRANLUND e TAIPALEENMAKI, 2005; DIKOLLI e VAYSMAN, 2006; VAN RINSUM, 2006; AGUIAR, 2009).

E portanto, a principal implicação da referida abordagem para a pesquisa é adoção de um modelo que permite avaliar os efeitos de aspectos cognitivos, sociais e econômicos para diferentes momentos de ocorrência do benefício, ampliando os resultados que buscam apenas identificar as causas de OTG de curto prazo.

A teoria da utilidade descontada (DU - Discounted Utility Theory), que é base para muitos estudos econômicos, considera que os agentes são consistentes em suas escolhas intertemporais e que todos os motivos para essas escolhas podem ser condensados em um único parâmetro, a taxa de desconto (SAMUELSON, 1937; O’DONOGHUE e RABIN, 2000; FREDERICK, LOEWENSTEIN e O’DONOGHUE, 2002; AGUIAR, 2011).

Ainda que utilizada como base normativa para literatura econômica o próprio Samuelson (1937) que criou o modelo prevê suas limitações, admitindo que é completamente arbitrário assumir o comportamento do individuo de modo ao previsto no modelo. Com isso modelos alternativos foram desenvolvidos, tal como a taxa de desconto hiperbólico, que prevê que os indivíduos possuem uma taxa de desconto declinante para preferência temporal, ou seja, a taxa de desconto será maior quando o período de postergação do consumo do benefício for menor (THALER e SHEFRIN, 1981; LOEWENSTEIN, 1987; PRELEC e LOEWENSTEIN, 1991; FREDERICK, LOEWENSTEIN e O'DONOGHUE, 2002).

O modelo de desconto hiperbólico apresenta implicações que os indivíduos serão mais pacientes quando a decisão for tomada antecipadamente, isso significa que eles 
preferem poupar a consumir quando estão decidindo previamente ao momento do recebimento do recurso, mas conforme esse momento chega o indivíduo se torna impaciente e escolher consumir ao invés de poupar (AGUIAR, 2011, p.7).

No contexto de escolhas intertemporais, tem-se observado atenção a modelos para análise de taxas de descontos e sistemas de incentivo, com uma falta de abordagens psicológicas e sociológicas que afetam o indivíduo, sendo todos fatores sumarizados na taxa de desconto (FREDERICK, LOEWENSTEIN e O'DONOGHUE, 2002; VAN RINSUM, 2006; AGUIAR, 2011).

Nos estudos seminais sobre escolhas intertemporais foram considerados os fatores psicológicos, incluindo fatores como o "efetivo desejo de acumular" (RAE, 1834), o doloroso esforço que o ser humano sofre em abster-se do prazer imediato (SENIOR, 1836), mais recentemente a economia tem dado atenção aos aspectos cognitivos que afetam as escolhas intertemporais, tal como influências viscerais e direcionadores de emoções, assim como estratégias de controle mental (BERNARTZI e THALER, 1995; THALER, 1999; FREDERICK, LOEWENSTEIN e O'DONOGHUE, 2002).

Além dessas abordagens, estudos em economia justificam que a racionalidade limitada impacta nas inconsistências no julgamento individual que ocorrem (LAVERTY, 1996).

Dessa maneira, parece razoável admitir a existência de fatores econômicos, sociológicos e psicológicos que afetam escolhas intertemporais, que afetam a alocação de esforços entre tarefas com diferentes momentos de beneficio, sendo essas escolhas tomadas por gestores que são indivíduos com preferências por consumo ou postergação de seus benefícios, conforme sua curva de utilidade e questões de autocontrole (LAVERTY, 1996; FREDERICK, LOEWENSTEIN e O'DONOGHUE, 2002).

Teoricamente, a decisão do gestor afetaria valor econômico agregado da entidade para os diferentes stakeholders, sejam acionistas ou outros beneficiários, que esperam que o valor da empresa aumente tanto no curto prazo quanto mantenha continuidade, gerando valor para o longo prazo.

A gestão baseada em valor sugere que para que ocorra geração de valor aos stakeholders é necessário apurar os custos explícitos sobre a atividade e também os custos implícitos, como o custo de oportunidade do capital (ASSAF NETO, 2003, p. 165), que é o 
custo da renuncia da utilização do capital em seu melhor uso alternativo (CATELLI, 1999, p. 415).

Segunda esta lógica, a responsabilidade do gestor, para cumprir sua parte do contrato, com a empresa poderia ser entendida como maximizar o valor corrente sem prejudicar resultados futuros, trata-se da sustentabilidade é fazer o resultado presente melhorar sem prejudicar gerações futuras.

Assim, segundo os pressupostos da gestão baseada em valor, seria importante maximizar o valor futuro garantindo continuidade sem prejudicar os resultados presentes necessários para garantir que o futuro chegue. Portanto, parece ser fundamental balancear os esforços em tarefas que "otimizem resultado presente e futuro" (VAN RINSUM, 2006, p. 2; AGUIAR, 2009, p. 13).

Este balanceamento de esforço entre tarefas com diferentes efeitos temporais implica na superação de outra barreia: o indivíduo e suas preferências. O ser humano é maximizador de utilidade e prefere consumir sua curva de utilidade, quando positiva, no curto prazo, dado aspectos cognitivos de incerteza e risco e de incentivos econômicos e organizacionais (THALER, 1981; LOEWENSTEIN, 1987; PRELEC e LOEWENSTEIN, 1991; FREDERICK, LOEWENSTEIN e 'DONOGHUE, 2002).

Mas o que faria um indivíduo postergar o consumo? Será talvez que a preocupação com o futuro, dada incerteza dos riscos a que vai incorrer, mais a certeza de necessidades futuras que já conhece faz o ser humano alocar parte do esforço para resolver problemas de longo prazo, aproveitando o espaço temporal para alocar esforços com planejamento e calma para inovar (DE MASI, 2000).

Nesse sentido os indivíduos que possuem menor dificuldade em avaliar as consequências e expectativas de longo prazo possuem menor orientação de curto prazo (LEWELLEN et al., 1987; MERCHANT, 1990; LAVERTY, 1996; MARGISON e MCAULAY, 2008).

Correntes ideológicas em sociologia demonstram que a evolução tecnológica do ser humano, decorre de mudanças em alocar esforços em tarefas com efeitos temporais balanceados, com inovação para sempre gerar ações cujo efeito seja mais constante e minimize tanto o risco presente quanto futuro (DE MASI, 2000). 
Já a literatura em psicologia e economia prediz que os agentes são aversos a postergar o consumo, seja por motivos de autocontrole, incentivo ou risco decorrente da incerteza quanto ao futuro (THALER, 1981; LOEWENSTEIN, 1987; PRELEC e LOEWENSTEIN, 1991; FREDERICK, LOEWENSTEIN e 'DONOGHUE, 2002; VAN RINSUM, 2006).

Admitindo tais pressupostos, os gestores no ambiente hospitalar, hipoteticamente dariam ênfase maior em alocar tarefas no curto prazo dado uma maior aversão ao risco da incerteza quanto ao futuro, dado que pode significar a sobrevivência ou não do cliente. Além disso, outro fator que produziria influencia seria a essa proximidade com a morte (PITTA, 1994), a estrutura de trabalho, com profissionais de saúde, como médicos e enfermeiros, na base operacional, e uma estrutura de autoridade ambígua, com duas linhas de comando com lógicas, valores e objetivos diferentes, uma voltada a interesses econômicos e outros valores éticos (CARAPINHEIRO, 2005).

Então, compreender os mecanismos que influenciam a OTG nos hospitais significa aumentar a possibilidade de prever satisfatoriamente o comportamento dos gestores em termos de seu processo de direcionamento de atenção entre tarefas. Isso, pois, os efeitos temporais das tarefas que o gestor escolhe desempenhar refletem sua ORIENTAÇÃO TEMPORAL (LAVERTY, 1996; FREDERICK; LOEWENSTEIN; O'DONOGHUE, 2002; VAN RINSUM, 2006; AGUIAR, 2009; BRAUER, 2013; AGUIAR, PINHEIRO e OYADOMARI, 2014).

A literatura especializada em OTG discute conceitos desde excessivo foco no curto prazo, miopia gerencial, problema de horizonte e orientação temporal de curto prazo (LEWELLEN et al., 1987; MERCHANT, 1990; JACOBSON, 1993; COATES et al., 1995; BUSHEE, 2001; BOHJRAJ e LIBBY, 2005; MARGISON e MCAULAY, 2008). Com o intuito de aumentar a consistência do conhecimento se utiliza o termo Orientação Temporal do Gestor, focando nas trocas compensatórias entre escolhas intertemporais (GRANLUND e TAIPALEENMAKI, 2005; VAN RINSUM, 2006; AGUAIR, 2010; PINHEIRO, GALDI e OYADOMARI, 2011; AGUIAR e FREZATTI, 2013; AGUIAR, PINHEIRO e OYADOMARI, 2014).

Com base na literatura econômica e contábil quanto às escolhas intertemporais e OTG o presente estudo segue a abordagem de Aguiar (2011) e a Orientação Temporal do 
Gestor é considerada um construto multidimensional, e pode ser entendida com base em dois critérios, que são (1) a consistência das escolhas intertemporais dos gestores e (2) o momento de ocorrência dos benefícios decorrente dessas escolhas.

Entre os aspectos econômicos o sistema de remuneração gerencial tem chamado a atenção dos pesquisadores, com estudos que observam os efeitos de seus elementos na OTG, tal como tipo de indicador de desempenho, período de avaliação (VAN RINSUM, 2006; AGUIAR, 2009; AGUIAR; FREZATTI, 2013), momento de recebimento (AGUIAR, 2009), tipo de incentivo (NARAYANAN, 1985; LEWELLEN et al., 1987; DECHOW; SLOAN, 1995; BHOJRAJ; LIBBY, 2005), metas de desempenho (MERCHANT, 1990).

Outros fatores como ambiente institucional, horizonte temporal, idade, influencia social, cultura foram pesquisados como fatores que podem impactar na OTG (MERCHANT, 1990; FARREL et al., 2008; AGUIAR, 2009;). Por fim, o conhecimento e pesquisa quanto a OTG aponta para três perspectivas para estudo das causas da OTG, que são os aspectos individuais, organizacionais e econômicos ${ }^{5}$ (LAVERTY, 1996).

$\mathrm{O}$ estudo foi realizado em Hospitais, que dado suas particularidades organizacionais, com a base operacional composta por agentes (médicos, enfermeiros, profissionais da saúde em geral) com foco voltado para a qualidade do serviço e menos propensos a aceitação de limitações colocadas pelos gestores e proprietários na dimensão financeira, como acontece em empresas tradicionalmente industriais, necessita de mecanismos específicos de indicadores de desempenho, que sejam capazes de capturar os processos hospitalares e auxiliar na tomada de decisão eficiente do gestor para resultados tanto no longo quanto no curto prazo.

O foco dessa pesquisa é a gestão do atendimento assistencial, feito pela instituição hospital, que possui dilemas específicos, dado a relação com o paciente e com a fonte financiadora, assim como os processos específicos e a necessidade de ferramentas específicas de gestão. Espera-se que, as particularidades da instituição hospital possa contribuir com inferências sobre novos construtos que podem impactar na OTG.

\footnotetext{
${ }^{5}$ Vide figura 1, página 27.
} 


\section{PROCEDIMENTOS METODOLÓGICOS DA PESQUISA}

O enfoque utilizado nessa pesquisa é qualitativo, por meio de uma análise comparativa qualitativa estudo de caso, com observações e entrevistas com gestores de instituições de saúde de diferentes níveis hierárquicos e papéis funcionais em hospitais da região, com o intuito de identificar os fatores que influenciam em suas tarefas, decisões e a orientação temporal.

O estudo proposto se caracteriza como descritivo exploratório, pois busca “descrever as características de um fenômeno" (RICHARDSON, 2008, p. 66), assim como identificar novos fatores que precisam ser avaliados para o entendimento do fenômeno.

A pesquisa será realizada na área hospitalar, mas não acarretará risco conhecido à saúde e ao bem estar dos indivíduos entrevistados, visto que o trabalho será desenvolvido com entrevistas com os gestores e funcionários do hospital, não ocorrendo contato com os pacientes. O estudo está em conformidade com as normas da Comissão Nacional de Ética em Pesquisas e possui o parecer da Comissão de Ética (Apêndice A). Além disso, foram coletadas autorizações de todos os hospitais e de todos os entrevistados da pesquisa. Os dados das entrevistas foram tratados com sigilo, tanto dos indivíduos quanto das instituições.

\subsection{Ações para minimizar ameaças à validade interna, externa e de construto}

A utilização de análises de entrevistas, seja via estudo de caso, multicasos ou análise comparativa qualitativa, é incentivada na literatura management accounting como uma estratégia de pesquisa importante para validação de teorias e refinamento de teorias (KAPLAN e ATKINSON, 1998, AQUINO, 2005), e vem sendo utilizado na literatura específica de Sistema de remuneração gerencial (MALINA e SELTO, 2001), Gestão por Processos de Negócio (GERSCH et al., 2011; SILVA et al., 2012; SOUSA et al., 2012), e OTG (CARR e TOMKINS, 1998; GRANLUND e TAIPALEENMANKI, 2005).

Algumas das vantagens da utilização nesses tipos de abordagem são: contribuir para o aprofundamento da teoria, possuir diferentes métodos de coletas de dados, e pode atender diferentes estratégias de pesquisa, como descrição, criação e teste de teorias. Entretanto, a complexidade das teorias pode causar limitações de validação externa, dado condições 
restritas (EISENHERDT, 1998; AQUINO, 2005; YIN, 2005; MARTINS e THEÓPHILO, 2008).

A pesquisa em gestão hospitalar (que vai além da literatura contábil e de gestão, com literatura em enfermagem, medicina e outras áreas de conhecimento em saúde) também se utiliza dessas análises, com uma abordagem de controle do ambiente institucional fortemente instituída (ROTTA, 2004; BERNARDES et al., 2007; GABRIEL et al., 2011; GABRIEL et al., 2013).

Para tanto, é necessário minimizar ameaças à confiabilidade e validade como efeitos causados pela observação, o viés do observador, a limitação de acesso aos dados e a complexidade e limitação da mente humana (MCKINNON, 1988). Para minimizar essas ameaças, McKinnon (1988) sugere uma interação limitada e um controle ativo, que significam que o pesquisador deve se envolver de com interação limitada, permitindo que a pessoa observada se sinta a vontade para responder as questões e o pesquisador usa a conversa para clarificar o significado de eventos e conteúdos, sejam através de uma conversa casual, questionário (interação limitada) ou entrevista (controle ativo).

A análise comparativa qualitativa foi conduzida em hospitais da região (que estão caracterizados logo adiante) por meio de uma pesquisa de campo, conduzida por este pesquisador, que fez uso de um rigoroso protocolo de pesquisa e de registro, com destaque para gravação de áudio, das atividades dos gestores hospitalares, entrevistas semiestruturadas e entrevistas com facilitadores, que são funcionários chaves para o desenvolvimento do projeto nos hospitais.

Para minimizar a ameaça do efeito do observador, que seria o gestor mudar seu comportamento e respostas dado a presença do pesquisador foi primeiramente realizado o acompanhamento com o gestor de suas atividades, e a conversa será conduzida pelo próprio gestor, sem interferência do pesquisador, a ideia foi aproximar a primeira parte da intervenção a um tour com o gestor pelo hospital e suas atividades (MCKINNON, 1988; YIN, 2005; MARTINS e THEÓPHILO, 2008).

Após a observação foi realizada a entrevista semi-estruturada, na qual o pesquisador conduziu as perguntas conforme necessidade, com o intuito de explorar assuntos não abordados ainda pelo gestor e para validação de assuntos já abordados. Espera-se com essas duas ações minimizar o efeito do observador, assim como minimizar o viés de observação 
do pesquisador, visto que o pesquisador possuirá conteúdo que o gestor conduziu e que ele conduziu. $\mathrm{O}$ fato de o pesquisador utilizar conteúdo sem interferência minimiza o viés da bagagem de conhecimento e ideias do pesquisador (MCKINNON, 1988; YIN, 2005; MARTINS e THEÓPHILO, 2008).

Para minimizar a ameaça de acesso à informação foram feitos os contatos com as pessoas-chave em cada hospital, assim como o projeto de pesquisa foi submetido e aprovado pelo comitê de ética da Faculdade de Filosofia Ciências e Letras de Ribeirão Preto e pelo Hospital das Clínicas de Faculdade de Medicina de Ribeirão Preto.

Para consulta do status do projeto na Plataforma Brasil consultar o protocolo 13520813.3.3001.5440. Além disso, o projeto foi autorizado pelos superintendentes e diretores gerais de cada instituição.

As pessoas-chave contatadas e entrevistadas foram as pessoas responsáveis pelo setor de Projetos, Avaliação de Desempenho, Controladoria e funcionário do RH, com isso foi analisado a estrutura de autoridade da empresa, o modelo utilizado para avaliação e os contatos a serem entrevistados.

A seguir caracterizou-se os hospitais selecionados para o estudo multicasos, em seguida uma breve apresentação dos gestores que serão entrevistados, depois um resumo dos dados coletados nas entrevistas com as pessoas-chave. A partir de então serão apresentados os instrumentos de mensuração, os objetivos dos mesmos, a operacionalização e tabulação dos dados, e por fim o modelo de análise dos resultados.

\subsection{Informações sobre os Hospitais e Gestores}

Para observar as tensões típicas de horizonte vividas por gestores hospitalares foi feita a opção de avaliar a percepção desses gestores por meio de entrevistas.

Foram realizadas entrevistas com gestores e funcionários em cinco hospitais do interior de São Paulo, sendo um hospital publico universitário e quatro hospitais privados, e em uma operadora de saúde privada. A pesquisa de campo envolveu a observação da percepção de 18 gestores, sendo 15 gestores hospitalares e três gestores de operadoras de saúde, vale ressaltar que dois gestores foram entrevistados por duas funções diferentes, devido sua experiência em setores diferentes, e analisados separadamente. 
A seleção dos indivíduos para as entrevistas se deu pelo critério de acessibilidade ou conveniência, justificado pela dificuldade em identificar gestores hospitalares dispostos a falar sobre suas atividades. Ainda assim na seleção o pesquisador verificou a existência de variabilidade entre os gestores, no que concerne a formação acadêmica, experiência de trabalho, nível hierárquico e função exercida. Na figura 3 está a caracterização dos hospitais.

Tabela 1: Caracterização dos Hospitais selecionados para o Estudo de Caso

\begin{tabular}{|c|c|}
\hline Hospital A & $\begin{array}{l}\text { Público, universitário, capacidade instalada } \\
\text { de } 876 \text { leitos, } 57 \text { anos de funcionamento, } \\
\text { localizado no interior do estado de São } \\
\text { Paulo. Atende a todas as especialidades e } \\
\text { possui atividades de ensino e pesquisa. Está } \\
\text { fisicamente dividido em } 2 \text { unidades, mas } \\
\text { possui administração única. Conveniado ao } \\
\text { SUS. Não possui sistema de remuneração } \\
\text { variável por desempenho. }\end{array}$ \\
\hline Hospital B & $\begin{array}{l}\text { Privado, com fins lucrativos, capacidade } \\
\text { instalada de } 167 \text { leitos, } 68 \text { anos de } \\
\text { funcionamento, localizado no interior do } \\
\text { estado de São Paulo. Atende todas as } \\
\text { especialidades exceto obstetrícia. Integra um } \\
\text { grupo de } 3 \text { hospitais da região controlados } \\
\text { pela mesma empresa (que possui um plano } \\
\text { de saúde de medicina de grupo). Possui } \\
\text { sistema de remuneração variável por } \\
\text { desempenho. }\end{array}$ \\
\hline
\end{tabular}




\begin{tabular}{|c|c|}
\hline Hospital C & $\begin{array}{l}\text { Privado, com fins lucrativos, capacidade } \\
\text { instalada de } 68 \text { leitos, localizado no interior } \\
\text { do estado de São Paulo. Integra um grupo de } \\
3 \text { hospitais da região controlados pela } \\
\text { mesma empresa (que possui um plano de } \\
\text { saúde de medicina de grupo). Possui sistema } \\
\text { de remuneração variável por desempenho. }\end{array}$ \\
\hline Hospital D & $\begin{array}{l}\text { Privado, com fins lucrativos, capacidade } \\
\text { instalada de } 106 \text { leitos, } 29 \text { anos de } \\
\text { funcionamento, localizado no interior do } \\
\text { estado de São Paulo. Atende somente } \\
\text { mulheres e crianças nas especialidades de } \\
\text { pediatria, cirurgia geral, ginecologia, } \\
\text { obstetrícia e UTI (Unidade de Tratamento } \\
\text { Intensivo) neonatal. Integra um grupo de } 3 \\
\text { hospitais da região controlados pela mesma } \\
\text { empresa (que possui um plano de saúde de } \\
\text { medicina de grupo). Possui sistema de } \\
\text { remuneração variável por desempenho. }\end{array}$ \\
\hline Hospital E & $\begin{array}{l}\text { Privado, com fins lucrativos, capacidade } \\
\text { instalada de } 95 \text { leitos, } 42 \text { anos de } \\
\text { funcionamento, localizado em localizado no } \\
\text { interior do estado de São Paulo. Atende } \\
\text { todas as especialidades. Não possui sistema } \\
\text { de remuneração variável por desempenho. }\end{array}$ \\
\hline
\end{tabular}

Fonte: Elaborado pelo autor.

A operadora não está sendo descrita, visto que seus gestores foram entrevistados para levantar e validar os dilemas entre hospitais e operadoras, sendo que para as outras 
análises esses gestores não foram avaliados, pois o foco dessa pesquisa é o entendimento das particularidades da atividade hospitalar, o atendimento assistencial, e os dilemas dos gestores desse tipo de instituição.

Procurou-se observar em cada hospital os gestores que possuem responsabilidade por decisões operacionais e/ou financeiras para a seleção para as entrevistas, inclusive foram analisadas diferenças de estruturas hierárquicas e se tal diferença possui impacto na Orientação Temporal do Gestor. Foram entrevistados desde superintendentes até gerentes e em alguns casos coordenadores, conforme a estrutura hierárquica do hospital.

A definição dos participantes das entrevistas foi feita junto às pessoas-chave de cada hospital, que definiu quem são os gestores responsáveis por cada área, e também funcionários que se relacionam com esses gestores.

Previamente foram realizadas entrevistas com as pessoas-chave para identificar se as organizações e gestores entrevistados na pesquisa tomavam decisões e se inseriam no ambiente hospitalar e situações de gestão que esta pesquisa buscou identificar. Confirmado a existência de variabilidade de situações e pessoas que responderiam a questão de pesquisa foram definidos os gestores a serem entrevistados, os detalhes das informações coletadas sobre o sistema de remuneração, metas e modelos de gestão observados estão no tópico "4.1.1 Entrevistas com pessoas chaves".

Dos entrevistados 12 são do mesmo grupo empresarial de hospitais (B, C e D), sendo sete (39\% do total de entrevistados) exclusivos de um hospital, dois (11\%) de outro hospital, um (6\%) do terceiro hospital, e os outros dois gestores (11\%) atendem todos os três hospitais, totalizando $67 \%$ dos entrevistados selecionados dentro do mesmo grupo empresarial. Dos hospitais A e E foram selecionados três gestores, dois gestores (11\%) do hospital A e um gestor $(6 \%)$ do E, e dos gestores de operadora foram selecionados três gestores $(17 \%)$ também.

Os participantes do grupo empresarial de hospitais estão identificados com um "G" na frente, os entrevistados do hospital A com um "A" na frente, do hospital E com um "E" na frente, e da operadora de saúde com um "O” na frente da identificação.

Explorando o perfil dos entrevistados, foi observado algumas características relevantes para a análise dos resultados. Existe, de partida, certa heterogeneidade quanto à nomenclatura dos cargos nas unidades observadas, ainda assim, os gestores entrevistados 
apresentaram diferentes nomenclaturas para cargos com a mesma responsabilidade, para uniformização do nível hierárquico foi representado com o número de pessoas acima no comando.

Os gestores com nível hierárquico "1" são aqueles que respondem diretamente ao conselho, acionista ou Estado, cujos cargos variam de diretoria geral e superintendência, foram selecionados nesse nível três gestores (17\% do total de entrevistados); já os gestores nível "2" são aqueles que respondem aos gestores de nível "1", com cargos de diretoria operacional, diretoria assessoria técnica, diretoria clínico, gerência operacional, gerência comercial e gerência de melhoria contínua e foram sete gestores (39\%); no nível "3" estão os gestores que respondem aos gestores de nível "2", com cargos de gerência médica, gerência de enfermagem, gerência de farmácia, gerencia hotelaria, coordenação comercial, coordenação administrativa, coordenação de governança e coordenação de manutenção, totalizando oito gestores (44\%) entrevistados.

Os gestores de nível " 1 " podem ser classificados como superintendentes, enquanto os de nível "2" representam os diretores, e os gestores de nível "3” representam os gerentes e coordenadores, conforme a estrutura da empresa, mas representam o nível de liderança acima dos líderes de equipes. A tabela 2 apresenta o perfil dos participantes.

Tabela 2: Perfil dos Participantes

\begin{tabular}{lllllllll}
\hline Cod. & $\begin{array}{l}\text { Hierar- } \\
\text { Quia }\end{array}$ & Setor & Instituição & Idade & $\begin{array}{l}\text { Tempo em } \\
\text { gestão } \\
\text { anos) }\end{array}$ & Escolaridade & Formação & Gênero \\
\hline P1-G & 2 & Administrativo & Hospital & 51 ou mais & 14 & Graduação & Saúde & F \\
\hline P2-G & 2 & Administrativo & Hospital & $30-40$ & 4 & Graduação & Outros & M \\
\hline P3-G & 3 & Administrativo & Hospital & 51 ou mais & 15 & Especialização & Saúde & F \\
\hline P4-G & 2 & Apoio & Hospital & $30-40$ & 2 & Graduação & Negócios & M \\
\hline P5-G & 2 & Apoio & Hospital & $30-40$ & 5 & Graduação & Outros & F \\
\hline P6-A & 2 & Administrativo & Hospital & 51 ou mais & 25 & Pós-graduação & Outros & F \\
\hline P7-G & 3 & Apoio & Hospital & $30-40$ & 5 & Especialização & Saúde & F \\
\hline P8-A & 3 & Administrativo & Hospital & $40-50$ & 8 & Graduação & Negócios & F \\
\hline P9-G & 3 & Apoio & Hospital & $20-30$ & 2 & Graduação & Outros & F \\
\hline P10-G & 2 & Assistencial & Hospital & $40-50$ & 12 & Especialização & Saúde & M \\
\hline P11-G & 3 & Assistencial & Hospital & $20-30$ & 4 & Especialização & Saúde & F \\
\hline P12-G & 3 & Assistencial & Hospital & $30-40$ & 6 & Especialização & Negócios & M \\
\hline P13-G & 3 & Assistencial & Hospital & 51 ou mais & 20 & Pós-graduação & Saúde & F \\
\hline P14-G & 1 & Geral & Hospital & 51 ou mais & 25 & Pós-graduação & Negócios & M \\
\hline
\end{tabular}




\begin{tabular}{llllllllll}
\hline P15-E & 1 & Geral & Hospital & 51 ou mais & 15 & Pós-graduação & Saúde & F \\
\hline P16-O & 1 & Administrativo & Operadora & $40-50$ & 11 & Pós-graduação & Negócios & M \\
\hline P17-O & 3 & Administrativo & Operadora & 51 ou mais & 14 & Graduação & Saúde & F \\
\hline P18-O & 2 & Operação & Operadora & $40-50$ & 12 & Especialização & Saúde & M \\
Média $^{6}$ & 3 & Administrativo & Hospital & $40-50$ & 11 & Graduação & Saúde & F \\
\hline
\end{tabular}

Fonte: Elaborado pelo autor

Quanto à função exercida na estrutura da empresa, os gestores estão segregados em assistencial, apoio, administrativo e geral. Os gestores classificados como assistencial são cinco, referente aos cargos de diretoria clínico, diretoria técnica, gerência de enfermagem, gerência de laboratório e gerência médica. Os gestores das áreas de apoio são cinco, a diretoria operacional, gerência de farmácia, gerência de hotelaria, coordenação de manutenção e coordenação de governança, já os gestores administrativos foram seis, referente aos cargos de "diretoria administrativos", diretoria de assessoria técnica, gerencial comercial, gerencia de qualidade, coordenação comercial e coordenação administrativa. Os gestores gerais são aqueles que se envolvem em mais de uma das áreas tratadas, como o superintendente e o diretor geral, que são dois.

Quanto à escolaridade sete possuem graduação (39\% do total), seis possuem especialização (33\%) e cinco possuem pós-graduação, como mestrado, doutorado (28\%). Quanto à formação dos gestores cinco são formados em administração, três em medicina, três em enfermagem, dois em engenharia, dois em assistência social e em farmácia, hotelaria e estatística tem um gestor cada, com isso nove gestores são formados em áreas relacionadas à saúde, cinco em áreas relacionadas a negócios, e quatro em outras graduações, sendo que dois gestores não formados em saúde fizeram pós graduação em saúde, um total de onze gestores possuem alguma formação na área de saúde.

\footnotetext{
${ }^{6}$ Foi utilizada a média como medida de centro para os critérios Idade e Tempo de Gestão, e foi utilizada a Moda como medida de frequência para a Hierarquia, Administrativo, Hospital, Escolaridade, Formação e Gênero.
} 
Os gráficos a seguir ilustram o perfil dos entrevistados.

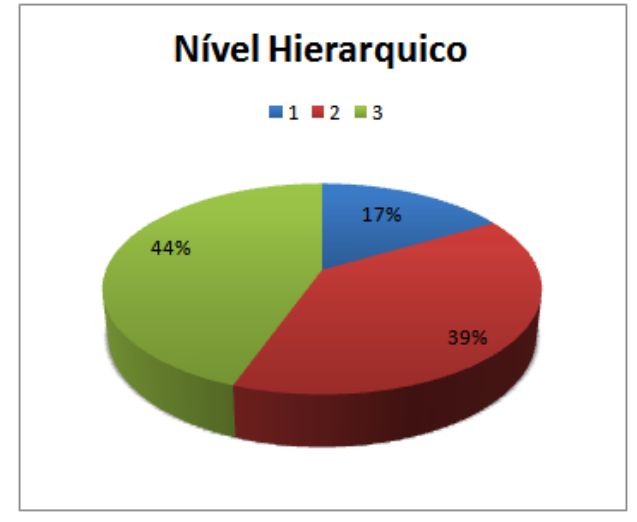

Gráfico 1: Nível Hierárquico gestores Fonte: Elaborado pelo autor

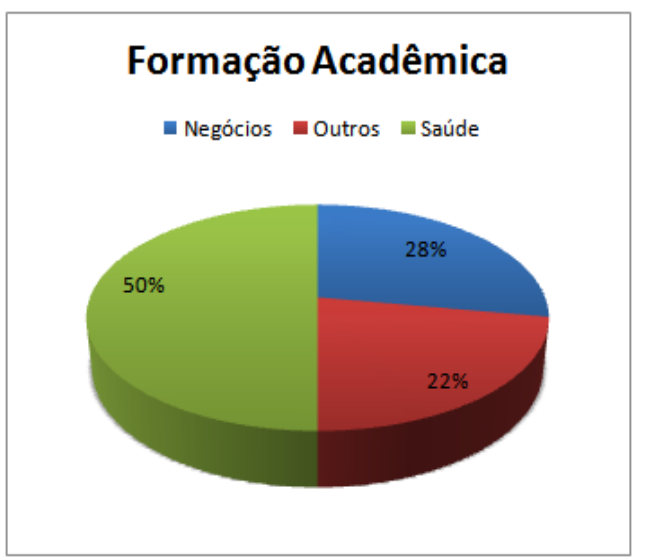

Gráfico 3: Formação acadêmica gestores Fonte: Elaborado pelo autor

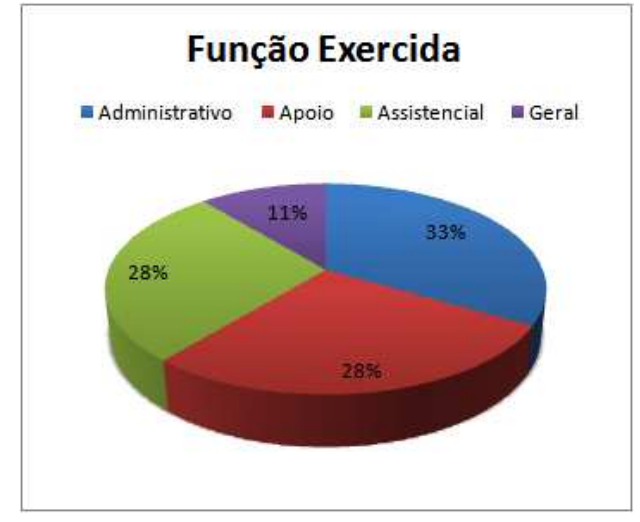

Gráfico 2: Função exercida gestores Fonte: Elaborado pelo autor

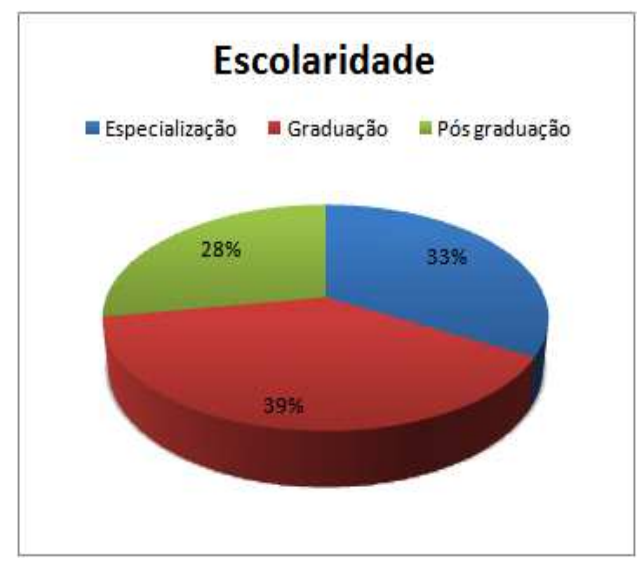

Gráfico 4: Escolaridade dos gestores Fonte: Elaborado pelo autor

Quanto à caracterização dos gestores em relação a experiência foi analisada cinco variáveis: o tempo de trabalho total; o tempo de trabalho na empresa atual; o tempo de trabalho no setor de saúde (experiência em saúde); o tempo de trabalho como gestor (experiência como gestor); e o tempo de trabalho no cargo atual (experiência no cargo atual). Essas informações são relevantes na análise dos resultados que concerne a experiência do gestor e horizonte temporal. 
Tabela 3: Caracterização da experiência profissional dos gestores

\begin{tabular}{lclccccc}
\hline Cod. & $\begin{array}{c}\text { Hierar- } \\
\text { quia }\end{array}$ & Idade & $\begin{array}{l}\text { Tempo de } \\
\text { Trabalho } \\
\text { (em anos) }\end{array}$ & $\begin{array}{l}\text { Tempo de } \\
\text { trabalho na } \\
\text { empresa } \\
\text { (em anos) }\end{array}$ & $\begin{array}{l}\text { Experiência } \\
\text { em saúde } \\
\text { (em anos) }\end{array}$ & $\begin{array}{l}\text { Experiência } \\
\text { como } \\
\text { gestor } \\
\text { (em anos) }\end{array}$ & $\begin{array}{l}\text { Experiência } \\
\text { no cargo } \\
\text { atual } \\
\text { (em anos) }\end{array}$ \\
\hline P1 & 2 & 51 ou mais & 29 & 27 & 29 & 14 & 8 \\
\hline P2-G & 2 & $30-40$ & 9 & 2 & 2 & 4 & 4 \\
\hline P3-G & 3 & 51 ou mais & 30 & $>6$ meses & 25 & 15 & $>6$ meses \\
\hline P4-G & 2 & $30-40$ & 15 & 2 & 2 & 2 & $>6$ meses \\
\hline P5-G & 3 & $30-40$ & 29 & $>6$ meses & $>6$ meses & 5 & 7 meses \\
\hline P6-A & 2 & 51 ou mais & 35 & 30 & 30 & 25 & 20 \\
\hline P7-G & 3 & $30-40$ & 17 & 2 & 15 & 5 & 2 \\
\hline P8-A & 3 & $40-50$ & 20 & 15 & 15 & 8 & 8 \\
\hline P9-G & 3 & $20-30$ & 4 & 2 & 4 & 2 & 2 \\
\hline P10-G & 2 & $40-50$ & 23 & 19 & 23 & 12 & 5 \\
\hline P11-G & 3 & $20-30$ & 6 & 6 & 6 & 4 & 2 \\
\hline P12-G & 2 & $30-40$ & 14 & $>6$ meses & 8 & 6 & 4 \\
\hline P13-G & 3 & 51 ou mais & 33 & 20 & 30 & 20 & 20 \\
\hline P14-G & 1 & 51 ou mais & 31 & 2 & 20 & 25 & 15 \\
\hline P15-E & 1 & 51 ou mais & 30 & 12 & 30 & 15 & 11 \\
\hline P16-O & 1 & $40-50$ & 22 & 6 & 6 & 11 & 6 \\
\hline P17-O & 3 & 51 ou mais & 29 & 27 & 29 & 14 & 8 \\
\hline P18-O & 2 & $40-50$ & 23 & 19 & 23 & 12 & 5 \\
\hline Média & 3 & $40-50$ & 22 & 13 & 17 & 11 & 8 \\
\hline
\end{tabular}

Fonte: Elaborado pelo Autor com base nas entrevistas e Aguiar (2009).

A faixa média de idades dos gestores é de 40 a 50 anos, com 22 anos de experiência de trabalho e no emprego atual a média é de 13 anos, com mínimo de menos de seis meses e máximo de 30 anos. Já a experiência no setor de saúde média é de 17 anos, sendo que quatro gestores trabalham na área de saúde há menos de cinco anos, e seis gestores trabalham a mais de 20 anos na área de saúde, a experiência como gestor tem uma média de 11 anos, sendo que o mais novo gestor possui dois anos em gestão e o mais experiente gestor possui 25 anos em posições estratégicas, por fim a média de permanência que esses gestores têm no atual emprego é de oito anos, sendo que três gestores responderem por posições anteriores e foi informado o tempo de trabalho naquela posição.

\footnotetext{
${ }^{7}$ Foi utilizada a média para todos os critérios analisados, com exceção da hierarquia que novamente foi utilizada a medida de tendência "moda".
} 
A caracterização dos participantes demonstrou que a seleção possui variabilidade quando analisado sob diferentes perspectivas. A maioria dos gestores ( $83 \%$ do total de entrevistados) está em posições hierárquicas de nível "2" (39\%) e nível "3” (44\%), a função exercida está dividida entre administrativo, apoio e assistencial. Quanto a formação está balançada a escolaridade dos gestores, com prevalência de gestores com graduação (39\%) e quanto à formação acadêmica $50 \%$ é relacionado às áreas de saúde e 50\% a outras formações.

Na seleção dos entrevistados também prevaleceu gestores com mais de 30 anos, apenas dois gestores tinham menos de 30 anos, sendo a maioria dos gestores, logo os entrevistados são pessoas mais experientes, com maior tempo de vida, assim como tempo de trabalho, a maioria dos gestores possuem mais de 20 anos de trabalho, apenas seis gestores possuem menos de 20 anos de trabalho, da mesma forma a seleção engloba gestores experientes no segmento de saúde, assim como gestores novatos, mas com prevalência de gestores experientes em saúde. Quanto ao tempo de trabalho na empresa está dividido entre gestores recém chegados e gestores com longo tempo de casa, por fim a seleção engloba gestores com longo tempo de experiência como gestor, e gestores novos, assim como no cargo atual.

Com isso pode-se concluir que os indivíduos selecionados para a amostra possuem variabilidade em diferentes aspectos, assim como possuem experiência tanto como gestor quanto no setor de saúde, minimizando o risco potencial de um viés de seleção nos achados da pesquisa.

\subsection{Instrumentos de coleta e organização de dados}

A coleta de dados foi feita por meio de uma entrevista semiestruturada, a utilização de entrevista como instrumento de coleta de dados se justifica porque possibilita a interação face a face entre as pessoas (DIAS, 2013, p. 31). As entrevistas foram conduzidas individualmente com cada participante em salas de reuniões ou na própria sala do entrevistado. Para garantir a condução das entrevistas elas foram antecipadamente agendadas com as secretárias das diretorias dos hospitais que organizaram as agendas em função da agenda dos entrevistados. 
A interação inicial nos hospitais se deu por meio dos contatos chaves, e posteriormente com os superintendentes e diretores gerais para a obtenção das autorizações, só após as autorizações formais pelos superintendentes realizou-se as entrevistas com as pessoas-chave e definiu-se os gestores a serem entrevistados. Nesse momento foram enviados e-mails para os gestores convidando-os a participar da pesquisa, que com o apoio dos superintendentes e diretores gerais teve aceitação total na participação na pesquisa. Com isso foi agendado junto às secretárias desses gestores os melhores horários para as entrevistas, que ocorreram individualmente com cada gestor, em sala de reunião ou sala do gestor. Para fins de protocolo, relatamos que a duração média das entrevistas foi de 47:02 minutos, sendo que a entrevista mais demorada durou 58:48 minutos e mais rápida foi de $27: 43$ minutos.

Relatando o padrão estruturado no protocolo de pesquisa para a condução das entrevistas na primeira parte da entrevista o gestor foi convidado a expor as tarefas que realiza, com liberdade de usar exemplos, casos, ferramentas, espaço físico, computador para demonstrar o que faz e o que utiliza.

$\mathrm{Na}$ segunda parte da entrevista foi utilizado o roteiro semi-estruturado, com questões abertas na seguinte ordem sobre os seguintes assuntos: as tarefas realizadas; os efeitos dessas tarefas ao longo do tempo; quanto tempo é dedicado a cada tarefa; quais tarefas o gestor considerava trazer resultado no curto ou longo prazo; exemplos de situações dilemas que enfrentavam; fatores externos e internos que impactavam na rotina; ferramentas utilizadas para tomada de decisão; sistemas de avaliação e remuneração; e as expectativas na empresa; e conforme o andamento da entrevista e a ênfase que o participante dava para determinados assuntos foram acrescentados outros tópicos na entrevista do participante.

Como regra geral, todos os comentaram sobre a carreira acadêmica e profissional, tarefas, os efeitos temporais das tarefas, quanto do tempo dedicam as tarefas de curto e longo prazo, quais tarefas consideravam de curto prazo e de longo prazo, comentaram a incerteza do ambiente e da tarefa, as particularidades dos processos hospitalares, sistemas de avaliação de desempenho, uso de indicadores e sistema de remuneração gerencial, na análise do conteúdo serão apresentados todos os conceitos abordados nas entrevistas. 
As entrevistas foram gravadas em áudio digital e posteriormente transcritas, durante a entrevista o pesquisador também fez anotações, tanto do conteúdo quanto de expressões e atitudes, tudo mediante prévia autorização dos entrevistados.

\subsection{Instrumentos de Análise de conteúdo}

Para as análises dos dados coletados nas entrevistas foram realizadas análises de conteúdo do discurso, que pressupõe avaliação dos padrões de respostas nos discursos dos entrevistados, por meio de hierarquizações e associações de eixos temáticos. O processo de análise se deu com o suporte do software NVivo ${ }^{8}$, software especializado, que permite análise de discurso por meio de funções de divisão de texto, navegação por hipertexto, indexação automática e trechos repetidos.

Conforme Bardin (2009), a análise de conteúdo torna-se um conjunto de técnicas de análises das comunicações que utiliza procedimentos sistemáticos e objetivos de descrição de conteúdo das mensagens. Essa análise se dá por meio de testes de associação de palavras, como estereótipos e conotações. O tratamento dos dados consistiu em três fases: pré-análise (organização), exploração do material e tratamento dos resultados e interpretação (BARDIN, 2009).

Na pré-análise, foram carregados no NVivo os arquivos com o registro de áudio das entrevistas, procedendo-se então a transcrição dos registros do áudio das entrevistas (DIAS, 2013, P.32). Para a transcrição utilizou o sistema proposto por Marcuschi (1986), com as alterações propostas por Dias (2013) tendo em mente que a transcrição tem que apresentar o essencial para que o pesquisador possa analisar seus dados, assim, para transcrever as entrevistas deste projeto adotou-se o seguinte (DIAS, 2013, p.32):

a) Uso do sistema ortográfico, seguindo a escrita padrão da língua portuguesa, porém sempre em letras minúsculas;

b) Falas simultâneas ou sobreposições são marcadas por colchetes;

c) Pausas são marcadas por vírgulas, ponto ou reticências, indicando, respectivamente, uma pausa breve, uma pausa com uma descida leva na

\footnotetext{
${ }^{8} \mathrm{O}$ uso de softwares para análise de conteúdo é visto como benéfico na condução das análises, conforme relatado por Creswell (2007) Bardin (2009) E Lage (2011) entre outros. Também é utilizado em trabalhos de controladoria, como Dias (2013) entre outros.
} 
entonação (marcando o término da fala) e uma pausa mais longa com suspensão do raciocínio; pausas superiores a meio segundo são indicadas pela duração da pausa entre colchetes;

d) Mudanças de entonação que marquem exclamação ou interrogação são marcadas por ponto de exclamação e de interrogação, respectivamente;

e) Ênfase em sílabas ou palavras (ou seja, quando elas são pronunciadas com um acento mais forte que o normal) são representadas por sua transcrição em letras maiúsculas;

f) Truncamentos bruscos são representados por uma barra;

g) Dúvidas e suposições - ou seja, ocorrências em que uma palavra ou trecho não é compreensível - são indicadas por parêntesis;

h) Comentários na transcrição (informações sobre gestos ou algum elemento extralinguístico importante) são indicados entre colchete;

i) Alongamentos de vogal são representados por dois pontos; e

j) Repetições são transcritas segundo sua ocorrência, repetindo-se a letra, sílaba ou palavra; e

k) Os falantes serão identificados assim: "E" para o entrevistador e "P" seguido de um número para os participantes (P1-G, P2-G, P3-G e assim por diante).

Para cada entrevista também foi associado um documento "memorando" com as observações coletadas pelo pesquisador (BAZELAY, 2007; DIAS, 2013). Os passos seguintes foram estruturados conforme proposto por Dias (2013), com a codificação das transcrições e memorandos, ou seja, a segmentação e atribuição de códigos, rótulos, a cada seguimento, com vista a obter uma representação do conteúdo (BARDIN, 2009; CRESWELL, 2012, DIAS, 2013).

"A unidade de registro para a codificação foi estabelecida segundo critérios semânticos, ou seja, de significação. Neste sentido, a codificação foi feita em torno de temas" (DIAS, 2013, p.33), e conforme Bardin (2009) a codificação envolve três escolhas, o recorte, a contagem e a classificação e agregação.

O recorte é a escolha das unidades de registro e de contexto, as unidades de registro são as unidades base para a contagem, podem ser palavras chaves ou temas (núcleos de sentido), a unidade de contexto corresponde ao trecho do texto e serve para codificar as 
unidades de registro. A contagem é a escolha das regras de enumeração e associação, como serão contadas as unidades de registro e contexto nos textos analisados, que podem ser por presença ou ausência de unidade de registro, pela frequiência de aparição, pela intensidade na aparição, pela ordem de aparição e pala ocorrência de unidades de registro juntas. E por fim, foram classificadas as categorias que agrupam as unidades de registro e contexto conforme o eixo temático que correspondem.

Os eixos temáticos são representados no NVivo por "nós”, e um fragmento do texto pode ser associado a mais de um nó, de maneira a organizar a informação, logo neste processo envolveu a criação de "árvores" para estruturar e organizar os nós (BAZELEY, 2007; LAGE, 2011).

Por fim, foi realizada a análise e interpretação dos resultados, considerando as categorias estabelecidas e como elas se relacionam aos casos (participantes) e com as outras categorias (DIAS, 2013, p.33).

Com base nas definições acima a técnica de analise de conteúdo se aplica adequadamente aos objetivos desse estudo, de identificar fatores econômicos, organizacionais e cognitivos que impactam nas decisões gerencias em relação ao momento de ocorrência dos benefícios das mesmas.

A análise de conteúdo das entrevistas permitiu o detalhamento dos dilemas enfrentados pelos gestores hospitalares, contribuindo para a caracterização das tarefas realizadas pelos gestores, do ambiente institucional e das tensões nas decisões gerencias. Isso, associado ao referencial teórico apresentando, permitiu a realização de inferências sobre o conteúdo informado pelos gestores sobre a teoria existente quanto ao assunto. 


\section{APRESENTAÇÃO, ANÁLISE E DISCUSSÃO DOS RESULTADOS}

A seguir são apresentados os resultados da pesquisa, que se organiza da seguinte forma: primeiramente foram analisados os nós identificados ${ }^{9}$, em seguida o perfil de cada participante e por último as tarefas de curto e longo prazo no ambiente hospitalar, os dilemas do sistema de saúde e as hipóteses propostas para explicar OTG.

Com base na revisão de literatura e nas entrevistas foram estabelecidos eixos temáticos, que são tratados por "nós”. A definição dos nós está pautada nos conceitos relacionados à Orientação Temporal do Gestor, elementos do sistema de remuneração gerencial, elementos da gestão de processos, incerteza ambiental e de tarefa e dos processos hospitalares. Da mesma forma que os "nós" que representam eixos temáticos, foram identificados grupos, chamados de "árvores", para facilitar a organização das informações e associação entre os "nós" através do agrupamento dos mesmos.

Conforme demonstrado no protocolo as entrevistas foram conduzidas de maneira a capturar as informações relacionadas a esses temas, assim como foi permitido ao entrevistado apresentar suas opiniões de maneira livre, para que fossem identificados fatores além dos previamente levantados na literatura e estruturados no roteiro de entrevista.

\subsection{Análise dos Temas}

Os dados utilizados na análise de conteúdo foram obtidos por meio das entrevistas gravadas e transcritas. A análise utilizou, junto com a transcrição do áudio, o memorando escrito pelo pesquisador.

Com a identificação das unidades de registro e unidades de contexto e a contagem dos mesmos, que foi feita por presença da unidade de registro e contexto, freqüência do mesmo, ordem de aparição e intensidade apresentada no discurso, foi feita a codificação, que é a associação dos dados coletados em eixos temáticos, chamados "nós" no software NVivo.

\footnotetext{
${ }^{9}$ Os nós são os eixos temáticos nos quais, as unidades de registro e unidade de contexto, estão categorizadas, representando o agrupamento dentro de um sentido semântico mais amplo.
} 
Dessa maneira, foram identificados 33 nós, sintetizados na tabela 4, e também quatro grupos para a organização dos dados.

Tabela 4: Relação dos nós identificados classificados por Grupo

\begin{tabular}{|c|c|}
\hline NÓS & GRUPOS \\
\hline Entrevista com pessoas-chave & Pessoas e recursos \\
\hline Formação acadêmica & Pessoas e recursos \\
\hline Formação profissional e experiência no setor de saúde & Pessoas e recursos \\
\hline Tempo de trabalho na empresa e expectativas & Pessoas e recursos \\
\hline Gestão de pessoas e relacionamento com superiores & Pessoas e recursos \\
\hline Treinamentos e educação & Pessoas e recursos \\
\hline Tecnologia da informação & Pessoas e recursos \\
\hline Gestão de processos & Processo Hospitalar \\
\hline Complexidade na gestão hospitalar & Processo Hospitalar \\
\hline Conflitos internos da empresa & Processo Hospitalar \\
\hline Processo assistencial & Processo Hospitalar \\
\hline Gestão da qualidade & Processo Hospitalar \\
\hline Incerteza da tarefa & Processo Hospitalar \\
\hline Conflitos externos da empresa & Processo Hospitalar \\
\hline Relação com paciente & Processo Hospitalar \\
\hline Relacionamento com operadoras de saúde & Processo Hospitalar \\
\hline Perfil epidemiológico & Processo Hospitalar \\
\hline Sistema universal de saúde & Processo Hospitalar \\
\hline Incerteza do ambiente & Processo Hospitalar \\
\hline Desenho do contrato do gestor & Sistema de Gestão \\
\hline Planejamento estratégico e orçamento & Sistema de Gestão \\
\hline Sistema de comunicação & Sistema de Gestão \\
\hline Modelos de gestão & Sistema de Gestão \\
\hline Sistema de metas & Sistema de Gestão \\
\hline Sistema de avaliação dos resultados & Sistema de Gestão \\
\hline Indicadores de desempenho & Sistema de Gestão \\
\hline Sistema estratégico de mensuração de desempenho & Sistema de Gestão \\
\hline Sistema de remuneração gerencial & Sistema de Gestão \\
\hline Motivação pró-social & Sistema de Gestão \\
\hline Miopia horizonte & OTG \\
\hline Atividades com efeito no curto prazo & OTG \\
\hline Atividades com efeito no longo prazo & OTG \\
\hline Orientação Temporal do Gestor (OTG) & OTG \\
\hline
\end{tabular}

Fonte: Elaborado pelo autor com base nas entrevistas e revisão de literatura. 
Os nós foram agrupados em quatro grupos, representados por Pessoas e Recursos, Processo Hospitalar, Sistema de Gestão e OTG. No grupo Pessoas e Recursos estão os nós associados à caracterização dos entrevistados, a relação com gestores superiores e com colaboradores de nível hierárquico inferior, a relação com treinamentos e educação dos funcionários e os comentários sobre o uso de tecnologia de informação e outros recursos materiais.

Já o grupo Processo Hospitalar apresenta os nós que estão associados às particularidades da atividade hospitalar, como conflitos internos e externos, incerteza ambiental e de tarefa, o processo assistencial, os dilemas com operadoras de saúde e com os pacientes, a própria gestão de processos e o sistema de saúde. No grupo Sistema de Gestão estão referenciados os eixos temáticos referentes aos elementos do sistema de remuneração gerencial e elementos de incentivo, assim como modelos de gestão. Dessa forma os nós são relacionados ao planejamento estratégico, orçamento, desenho do contrato, comunicação entre setores, sistemas de metas, avaliação e mensuração de desempenho e sistemas de incentivo e motivação.

Por fim, são apresentados os nós referentes à OTG, tanto quanto a miopia de horizonte apresentada pelos gestores, quando a definição das atividades com efeitos no curto e longo prazo e por fim a percepção do gestor quanto sua Orientação Temporal. Cada eixo temático será detalhado a seguir.

\subsubsection{Entrevistas com pessoas-chave}

Esse nó foi criado para expor os dados obtidos a partir das entrevistas com as pessoas-chave, com destaque para os modelos de remuneração, modelos de avaliação, modelo de comunicação e informação e verificar as responsabilidades dos gestores a serem entrevistados.

A partir dessas entrevistas foram verificados os gestores operacionais, administrativos e de suporte que possuem poder de decisão, seja em nível estratégico, tático ou operacional. Foi verificado que em três hospitais dos cinco hospitais observados existe a política de remuneração de desempenho por KPI (Key Performance Indicator). Os cinco hospitais possuem avaliação de desempenho, frequência de reunião de conselho e metas de 
desempenho, quatro hospitais possuem forte relação e influencia de operadoras de saúde, enquanto um hospital sofre influência do Estado.

Cumpre ser ressaltado que todos os hospitais possuíam na data da entrevista e até o último contato com os mesmos um setor para gerar informação, seja denominada Controladoria, Central de Custos ou Grupo de Avaliação de Desempenho.

Com isso foi verificada a existência de variabilidade entre formação profissional, cargo e nível hierárquico entre os gestores, sistemas de remuneração de desempenho, avaliação de desempenho, pressões internas e externas que afetam a organização e estratégias de negócio. Fato que viabilizou a condução da investigação nos hospitais préselecionados.

\subsubsection{Formação acadêmica}

Esse nó representa as particularidades nas entrevistas referentes a formação acadêmica dos gestores. Todos os 18 gestores discorreram sobre sua formação acadêmica, e cinco gestores comentaram sobre a formação acadêmica como ponto importante para a gestão em saúde, denotando que a formação acadêmica em áreas relacionadas com saúde é um ponto fundamental para que o gestor conheça as necessidades hospitalares, maiores detalhes sobre a formação acadêmica dos gestores na seção de metodologia e descrição dos entrevistados.

\subsubsection{Formação profissional e experiência no setor de saúde}

Esse nó foi criado para sumarizar o efeito do tempo de experiência dos gestores com as atividades de saúde, assim como na formação acadêmica. Todos os 18 gestores comentaram sobre sua própria experiência, bem como ressaltaram como o tempo de experiência interfere nas suas atividades hoje, seja por ser novo no segmento, seja por possuir mais tempo de trabalho. Três gestores acreditam que apesar das diferenças entre a atividade hospitalar e outras atividades é possível utilizar ferramentas de gestão e buscar eficiência na atividade hospitalar.

Também foi verificado que gestores com mais tempo de experiência apresentaram maior propensão a orientação temporal de longo prazo, visão mais ampla do cenário de 
saúde, menor propensão a benefícios financeiros e maior expectativa positiva quanto ao futuro na empresa, elementos que corroboram com os achados de Dikolli (2000) em relação do horizonte temporal do gestor na empresa impactar na OTG longo prazo dependendo de maior utilização relativa de indicadores não financeiros e também com os achados de Bruchey (1958), Frey e Stutzer (2002) e Perry, Hondeghem e Wise (2010) quanto a motivação em realizar tarefas que impactam no bem-estar social e da motivação relacionado a fatores não financeiros.

“ [...] isso tudo me deu condições de conhecer os processos do hospital, quer dizer, desde o atendimento do cliente numa recepção e o que você tem que fazer até a a a estadia, a permanência dele no hospital, inclusive visitas de qualidade, de atendimento, de soluções de problemas, de satisfação, de acompanhar o paciente internado [...], vê o resultado final disso no fechamento da conta e tal." (P1-G)

“ [...] e segmento hospitalar para mim é novidade, eu vim para cá recentemente, dois meses atrás, é ... é diferente porque tem muitos equipamentos delicados, [...] são equipamentos diferentes hospitalar né, a eletrônica do equipamento hospitalar é uma eletrônica mais fina, o sistema talvez seja o mesmo, mas o equipamento hospitalar é muito mais delicados, isso ai ... requer aqui no hospital especialista para estar atuando na realização de manutenções, tem muitos contratos de manutenção nesse sentido." (P5-G)

\subsubsection{Tempos de trabalho na empresa e expectativas}

Foi avaliado nesse nó o tempo de trabalho dos gestores e as expectativas do mesmo sobre o futuro na empresa. Os 18 gestores comentaram sobre o assunto, sendo que todos aqueles que possuíam 10 anos ou mais de empresa, ou haviam recebido promoção recentemente relataram, expectativas positivas quanto sua permanência na empresa.

Outro fator relatado com frequência pelos gestores foi que a tarefa desempenhada representa condição importante para continuar na empresa, é um fator motivacional para os gestores, fatos que corroboram com Bruchey (1958), Frey e Stutzer (2002) e Perry, Hondeghem e Wise (2010), Lima et al. (2009), Grohman et al (2012), e Tsounis, Sarafis e Bamidis (2014) quanto aos fatores motivacionais dos gestores hospitalares, relacionadas a tarefa realizada e ao ambiente organizacional em que trabalha. 
O comprometimento com as metas parece ser maior em situações com maior motivação pela tarefa desenvolvida e pelo tempo de trabalho e expectativa na empresa. Ainda foi identificado que os gestores que possuem mais anos de trabalho na instituição percebiam que desenvolviam mais tarefas com possibilidade de resultados no longo prazo, corroborando com Dikolli (2000) e Farrel et al. (2008) quanto a OTG de gestores com expectativa positiva na empresa, ainda que Aguiar (2009) não identificou relação entre o horizonte temporal e OTG.

\footnotetext{
"eu pessoalmente gosto muito de trabalhar na empresa e faço planos de ficar nela enquanto ela me quiser, enquanto meu trabalho estiver agradando espero continuar aqui." (P4-G)

"minha expectativa é positiva [...] é uma empresa boa de trabalhar, uma empresa honesta, presta serviços de maneira coerente, por isso estou há tanto tempo, tanto pelas pessoas como pelo meu contexto de trabalho, [...] e sempre tem aquele olhar como gestor de verificar se você está agregando para que a empresa cresça, além de ter uma técnica apurada você tem capacidade para trabalhar com o capital humano [...]." (P10-G)

"eu espero ficar aqui! por muito tempo, e uma empresa que me deu muita oportunidade como eu disse, estou aqui a algum tempo e venho crescendo, mostra que a empresa reconhece o nosso trabalho e: gosto muito de trabalhar aqui, por ser uma empresa que eu entendo que conhece o nosso trabalho mas é...eu me vejo aqui por muito tempo.” (P11-G)
}

\subsubsection{Gestões de pessoas e relacionamento com superiores}

Referido pelos 15 gestores hospitalares esse nó representa os desafios na gestão de pessoas, tanto pelo volume de trabalho decorrente dessa gestão, quanto pelo perfil das pessoas a gerir ou/e pela importância de uma gestão adequada de pessoas. A dificuldade com a gestão do pessoal médico foi citada por cinco gestores, oito participantes comentaram sobre o tempo dedicado a tarefas de pessoas, como resolução de conflitos internos, admissão, demissão e promoções.

Ainda, quatro gestores deram ênfase para a importância da gestão de pessoas, defendendo do sucesso ou fracasso seria determinado pelas pessoas, e que, portanto, a gestão e capacitação das pessoas gerariam resultados positivos para a empresa. Outros dois entrevistados fizeram críticas à qualificação das pessoas que trabalham no hospital, em 
todos os níveis, comentando que a baixa qualificação dos colaboradores impactaria diretamente na qualidade dos serviços e na implantação de projetos de longo prazo.

Por fim, mais três gestores criticaram o alto turn-over no hospital, fator que segundo eles impactaria no desenvolvimento dos processos de negócios, corroborando com os achados de Ceccim e Feuerwerker (2004); Bernandes (2007), La Forgia e Coutolenc (2009), Dahlgaard e Pettersen (2011) e Grohman et al. (2012) quanto a relação de pessoas e processos na gestão hospitalar.

O relacionamento com o gestor superior também foi um ponto destacado pelos gestores, conforme suas falas o respeito e admiração ao gestor superior motivam a buscar os melhores resultados, pois enxergam no emprego ganhos não pecuniários, como aprendizado e experiência profissional, corroborando com os achados de Dias (2001), Weber e Grisci (2010) e Grohman et al. (2012) sobre a importância das lideranças nas instituições hospitalares.

“[...] é muito bom trabalhar com ele [gestor maior nível hierárquico], eu falo para ele que to fazendo um MBA trabalhando aqui com ele, ele é um MBA, não é uma opinião minha, é uma opinião geral." (P3-G)

“[...] a base é o capital humano, capital humano é tudo numa empresa, primeiro você tem que identificar qual é o seu capital humano, [...] esse é o capital humano que a gente tem que treinar, essa coisa do recurso humano é algo que a gente tem que trabalhar exaustivamente para que tenhamos uma EQUIPE que esteja a altura de nossos PROPÓSITOS, só ter propósitos e não ter capital humano para trabalhar muitas vezes se traduz na não execução de nossos projetos. a premissa da base é o capita humano, a primeira coisa, a segunda coisa é a melhoria contínua que você tem que implementar em QUALQUER ambiente de trabalho." (P10-G)

“ [...] trabalhar para o $\mathrm{Sr} \_$[gestor maior nível hierárquico] é uma coisa que me motiva, que eu conheço, acho extremamente competente, um ótimo estrategista e etc, um executivo bastante completo, isso agrega na sua evolução profissional [...].” (P12-G)

"[...] a dificuldade que a instituição tem que o corpo clínico tenha aderência a essas políticas, porque ele que leva o cliente para o hospital privado, quem leva o cliente para o hospital privado é o médico, é muito diferente do $\mathrm{HC}$ que o paciente quer ir, então na verdade você estava caminhando nisso, trazer o corpo clínico para fazer o controle de OPME, seguir nossos protocolos, pra lavar a mão, pra dar informações adequadas, preencher o prontuário adequadamente, então isso melhorou mas é uma coisa muito difícil, sempre muito difícil.” (P15-E) 


\subsubsection{Treinamento e educação}

Essa atividade foi referida por 10 participantes como uma atividade potencialmente geradora de resultados no longo prazo, e com relevância para o desenvolvimento da entidade, por meio do desenvolvimento das pessoas. Na pesquisa de campo foram identificados pelo menos oito gestores entrevistados se envolvem diretamente com os treinamentos, alguns inclusive dando treinamentos e cursos, como o caso dos participantes P2-G, P13-G e P15-E, e outros indiretamente incentivam seus funcionários a participarem de treinamento.

Além do treinamento para seus funcionários, os gestores também destacaram a própria participação em treinamentos e comitês de inovação. A percepção do treinamento e educação como atividades que impactariam na eficiência da gestão e também impactariam nos resultados de longo prazo vão ao encontro dos achados de Dechow e Sloan (1991), Dutta e Reichelstein (2003), Ceccim e Feuerwerker (2004), Borba e Kliemann (2008), Brown e Krull (2008) e Oyadomari et al. (2014) que argumentam que o aprendizado organizacional e individual impactariam na eficiência das decisões gerenciais e também é entendido como atividade que impactaria no longo prazo.

"[...] outra coisa é o treinamento dos funcionários, pois cada um fazia uma coisa, e quando essa saía não tinha quem fazia aquela função, saía de férias tinha que esperar regressar, agora a gente começou a treiná-los para que quando um sai outro possa fazer essa tarefa do outro, até para entender a estrutura de trabalho." (P3-G)

"qual é o trabalho que a gente faz hoje dentro do hospital com os resíduos, de conscientização do funcionário quanto ao resíduo, de fazer treinamento, ir até o setor abrir a lixeira na frente deles e mostrar o que tem lá dentro, o que tem errado dentro do lixo dele, hoje dentro dos resíduos eu não trabalho sozinha, eu tenho um comitê para isso." (P9-G)

"então treinamento e protocolos é de longo prazo, então, por exemplo, esse protocolo antibiótico profilático eu defini que o anestesista deve aplicá-lo, nem o médico, nem o enfermeiro, então todo ano eu dou essa aula para os anestesistas e já fazem 20 anos, eu nunca parei de medir nem de treinar, e tem outro protocolo que eu gosto muito que é a cirurgia segura, que é a checagem de pontos críticos antes do paciente chegar em sala, e a gente treina exaustivamente para que isso seja feito, desde então nunca parei de treinar, então e fundamental para os residentes aqui [...]." (P13-G) 


\subsubsection{Tecnologias da informação}

Esse nó foi criado para representar as alusões a sistemas de informática, identificamos que participantes destacaram atividades que envolvem o sistema de informática, três deles ainda identificaram que mudanças nos sistemas de informática geram resultados de longo prazo, sempre alinhados com os processos da empresa.

Todos os participantes trataram o sistema de informática como um recurso para alcançar os objetivos estratégicos e suportar os processos de negócio, três gestores também pontuaram a importância do alinhamento do sistema de informática com os processos da empresa e da necessidade de uma análise dos processos, corroborando com a literatura de gestão de processos e gestão da informação, como Webb (2004) Souza et al. (2011), Kang et al. (2012) e Vallejo et al. (2012), que enfatizam o alinhamento entre os processos, as informações e os recursos tecnológicos.

“eu tenho vários projetos na minha mão, principalmente de desenvolvimento. Eu trabalho muito com [2s] pegar e utilizar o sistema a favor de ser a primeira barreira de segurança. [...] Primeiro eu desenho os processos com o TIi e depois eu avalio, faço os testes e depois eu venho parametrizando, então a gente assim, eu [...] faz um ano e meio que eu venho mudando o sistema diariamente pra redução de erro, são erros que você sabe que, não adianta, não adianta, vai acontecer, então eu coloco um filtro para não deixar acontecer." (P7-G)

“[...] hoje a gente usa dois sistemas, varias telas, e não sei o que, as vezes você perde porque deu erro no lote, não da tempo de corrigir porque fechou o lote e por ai vai, então com o mapeamento do posto de coleta a gente vai começar por lá, porque se der certo lá, a gente vai usar esse projeto piloto em outros lugares, então com isso a gente ganha tempo pra faturar, passa a faturar em um sistema único, controle melhora, os indicadores melhoram, que daí você deixa de fazer planilha Excel e começa a fazer via sistema e a gente deixa de perder faturamento uma série de coisas". (P12-G) 


\subsubsection{Gestões de processos}

A gestão de processos é percebida como uma ferramenta para análise do negócio que impacta em resultados para o longo prazo, mas também pode ser utilizada para resultados de curto prazo. Os gestores comentaram a necessidade de apoio e patrocínio do gestor com maior nível hierárquico com o projeto de gestão de processos. Destes 14 gestores relataram dessa necessidade latente, ressaltando os modelos de mapeamento e gestão de processos, como o "Lean Health Management" e "Business Process Management”.

O recorte da investigação pode explicar a prevalência de citações dos modelos acima, dado que foram entrevistados predominantemente os gestores hospitalares, e $67 \%$ dos entrevistados são parte do mesmo grupo empresarial, tal amostra denota a recorrência de determinadas técnicas e conceitos entre os entrevistados.

Assim os gestores de departamentos de qualidade e projetos comentaram sobre os desafios de implementação de gestão por processos, em concordância com a visão deles que a gestão de processos traz benefícios a empresa, por causa do seu foco no valor para o cliente e no "processo core" ${ }^{10}$, com eliminação ou redução de tarefas que não agregam valor, gestores operacionais também elogiaram essas ferramentas por facilitar a análise das tarefas realizadas por eles e como elas agregam valor a empresa.

Ressalta-se que a gestão por processos também foi relacionada com sistemas de avaliação de desempenho e planejamento estratégico, como Balanced Scorecard (BSC) e OGSM Model (Objetivos, Metas, Estratégias e Indicadores, do inglês Objectives, Goals, Strategies and Measures). Isso foi capturado com os gestores comentando que o uso dessas ferramentas alinhadas com os processos da empresa facilita a tomada de decisão quanto ao que agrega valor para o paciente e para a empresa, corroborando com as pesquisas em controladoria de Chennal (1997), Malina e Selto (2001) e Webb (2004), com as pesquisas em gestão por processos de Gersch et al. (2011), Silva et al. (2012), Kang et al. (2012), Vallejo et al. (2012), Niehaves et al. (2012), assim como na literatura em gestão hospitalar, como Abbas (2001), Ceccim e Feuerwerker (2004), Rotta (2004), Pizzini (2006),

\footnotetext{
10 "Processo core", na terminologia de processos refere-se ao processo principal da empresa, relacionado a atividade fim. Em um hospital o processo core é o atendimento assistencial ao paciente, enquanto o atendimento de hotelaria é um processo de apoio, assim como o serviço de farmácia, por exemplo.
} 
Dalmáscio, Aguiar e Rezende (2007), Miranda et al. (2007), Joosten, Bongers e Janssen (2009), La forgia e Coutoolent (2009) e Bonacim e Araujo (2010 e 2010b), que enfatizam o relacionamento das medidas de desempenho alinhadas com os processos da empresa, inclusive através de sistemas estratégicos de mensuração de desempenho e utilizando metodologias de gestão de processos.

"[...] o superintendente já tinha trabalhado com o Lean, e é muito do gestor líder apoiar, tem que vir da alta administração, é o patrocinador, porque tem que quebrar paradigmas né, ainda mais aqui que ninguém conhece nada de gestão de processos, se não tiver um patrocinador esse negócio vai para trás, até porque demora para isso gerar os resultados, isso facilitou ele [gestor maior nível hierárquico] já conhecer, ele me ajuda a segurar forte porque a tendência é as pessoas sempre pensaram e se segurarem a rotina, e a foco é pensar fora da caixa, todos os dias o que eu posso fazer melhor, em todos os processos." (P2-G)

"[...] então os projetos que eu atuo são de acordo com a estratégia da empresa, então projetos de longo prazo, a gente faz o makigami, mapeia o processo e daí tem varias oportunidades de melhoria, essas oportunidades de melhoria, a gente vai fazer plano de ação, e tem o kaisen, que é a melhoria contínua, outra palavra em japonês, então se usa muito, então você pega uma semana, para desenvolver isso, então todo mundo para com a rotina, mão na massa e vamos mudando, mudança de layout, de sistema, e uma semana na outra segunda feira está funcionando o novo modelo, faz a virada, então a gente faz eventos kaisen, esse é longo prazo [...]." (P2-G)

"estamos fazendo um trabalho focado no Lean Heath Care, que é o departamento da qualidade, que por exemplo, esse mapeamento [...] eu participo mas na verdade tem um time direcionado para isso, quem participa, tem um cara do $\mathrm{Ti}$, um cara do faturamento, vem uma pessoa da qualidade, que conhece a metodologia, e ela precisa de informação, então eu trago o líder [...] que diretamente conhece todo o processo, e até tem uma pessoa que está diretamente ligado a ele, uma coordenadorazinha, que vem também, e a gente faz uma espécie de brainstorm." (P12-G)

"[...] levam bastante tempo [projetos relacionados a mudança de processos], tem muita análise, muito levantamento, tem que olhar processos, muitas vezes corrigir processos, que é o adequado, não é simplesmente aquela coisa do porque está falho é aquela pessoa, não é a pessoa é o processo, vamos, o que que ta ocasionado aquilo, vamos entender o processo e pronto, então a gente tem atuado muito nesse sentido, porque a coisa tem que rodar independente das pessoas né, e, e assim a ideia é que a coisa flua a tal ponto que a gente possa ter um desprendimento para fazer um trabalho de campo tranqüilo, porque se eu tiver que ficar aqui apagando fogo o tempo inteiro né.” (P12-G) 
“[...] ai já tive a ajuda dele [gestor melhoria contínua e processos], que com suas técnicas me ajudou a escrever um fluxo com mais harmonia entre os setores". (P13-G)

\subsubsection{Complexidades na gestão hospitalar}

Conforme as informações capturadas na pesquisa de campo, a complexidade da gestão hospitalar é vista sob duas perspectivas. Parte dos gestores, aqueles menos experientes no setor de saúde entendem que essa gestão é diferente, devido o valor da vida, e a importância de cada tarefa para o atendimento assistencial. Essa visão também é compartilhada pelos gestores de nível mais assistencial.

Em contrapartida, gestores com mais experiência no setor e nível hierárquico mais alto acreditam que a complexidade de um hospital é próxima da complexidade de outras atividades econômicas. Esses gestores também defendem o valor da vida e a importância do atendimento assistencial, mas acreditam que é possível gerir com certa previsibilidade e focando na agregação de valor ao paciente, visto que a tarefa de atendimento ao paciente tem suas particularidades.

Pareceu ser comum a percepção de que na cadeia do processo de negócio os processos de apoio e administrativos podem ser administrados como em outras atividades econômicas, e também que o processo assistencial também pode ser gerido com planejamento, apesar das incertezas inerentes a atividade, que afetariam determinadas tarefas no processo, relacionadas ao planejamento terapêutico. Cumpre ressaltar que os gestores também demonstraram que existe uma preocupação com a atividade fim do hospital, que é o tratamento à saúde e que essa responsabilidade afeta as decisões dos gestores e que necessita que a gestão seja eficiente, livre de erros e desperdícios.

Por fim, por justamente ter a questão do valor da vida que a gestão precisa ser mais eficiente e com menos incertezas, reforçando a visão de Pitta (1994), Ceccim e Feuerwerker (2004), Araujo e Vieira (2004), Rotta (2004), Miranda et al. (2007), Joosten, Bongers e Janssen (2009), La forgia e Couttolenc (2009), Bonacim e Araujo (2010a), Weber e Grisci (2010), Tanaki e Tamaka (2012), Martins et al. (2013), Santos e Hormanez (2013) e Gabriel et al. (2013) que defendem que a complexidade na gestão hospitalar impactaria na utilização de ferramentas econômicas, mas que tais ferramentas e modelos de gestão trazem benefícios para a gestão hospitalar e eficiência da instituição. 
Um ponto levantado por 13 gestores se refere a complexidade e urgência no atendimento assistencial, que acaba exigindo maior preparação dos departamentos de apoio e assistenciais, e cinco gestores comentaram que a falta de gestores que entendam dos processos hospitalares e acompanham indicadores assistenciais impacta negativamente nos resultados de longo prazo da empresa, inclusive na geração de valor para o paciente, ao passo que estes não visualizam os efeitos de longo prazo no processo assistencial, corroborando com a linha de pensamento que o entendimento do processo impacta na visão de longo prazo dos gestores, e a necessidade do hospital visualizar seu papel no sistema de saúde nacional (ROTTA, 2004; LA FORGIA e COUTTOLENC, 2009; BULRTON, 2010; GERSCH et al., 2011; HERNAUS, 2012; SKRINJAR e TRKMAN, 2013).

“ [...] no segmento hospitalar é diferente então, está fazendo uma cirurgia o equipamento quebra, então compromete a vida de uma pessoa, então o suporte a vida é ... o suporte a vida é o equipamento que dá o suporte a vida, a gente atua, então isso deve ter, realmente, uma confiabilidade muito maior." (P5-G)

“[...] mas a nossa atribuição é de longo prazo, outro exemplo de longo prazo que eu acho muito importante é que a gente fez um mapa assistencial do hospital, que é saber que por exemplo um ambulatório, ele ... ambulatório de ortopedia vamos dizer, coluna, que é tudo coluna, pé, mão, cada um é uma área separada, nós podemos atender 10 pacientes novos por semana porque esses 10 pacientes novos eles tem um percurso aqui dentro do hospital a cada 10 que entra 7 vão para a cirurgia, então a gente tem que ter um planejamento de acordo com a infraestrutura hospitalar, se a gente tem a capacidade de atender aos exames daqueles pacientes, dar o encaminhamento, então a nossa porta de entrada é do tamanho da nossa capacidade interna de resolução dos problemas, não adianta a gente colocar muito paciente de câncer no hospital se a gente não da conta de fazer cintiolografia, que é um exame que todo paciente com câncer tem que fazer, então eu atendo se eu tiver como atender tudo, é o que a gente chama de mapa assistencial, isso é planejamento hospitalar, então é feito de acordo com nossos recursos e capacidade também com nosso planejamento [...]." (P6-A)

"hoje a gente usa uma classificação de risco que chama fugolin pra dimensionar trabalho de enfermagem, ele classifica em pontos conforme de acordo a necessidade do paciente, quanto maior a necessidade de enfermagem do paciente na maioria das vezes é porque é um paciente mais crítico, então / e isso é feito a cada troca de turno pra saber quantos funcionários eu vou deixar em cada posto, então eu pego todos os dias o Fugolin [...]" (P7-G) 
“ [...] o sofrimento [conciliar produtividade e qualidade] é dois tipos, tem o sofrimento intelectual, pensar nas suas estratégias e que essas estratégias sejam viáveis a longo prazo, para o hospital depois não sofrer o revés de um, de uma premissa incorreta, [...] depois vem a fase do suor, que é a fase da operacionalização daquilo que você propôs como premissa, [...] e o desenvolvimento é muita canseira, suor [...] e que traga resultado para a empresa, resultados positivos, veja dentro do contexto geral é um ganho para todos, paciente, que é nosso foco principal, pra quem lida com a assistencial, que é a enfermagem, a farmácia, fisioterapia, nutrição, psicologia, assistência social, são todos que lidam com o paciente, os médicos, todos que lidam com o paciente, que esses sejam beneficiados por um modelo coerente de trabalho, e ai uniformização isso ai e fazer um planejamento da assistência, uma coisa que a gente chama de planejamento terapêutico, uma coisa mais globalizada em termos hospitalar. para que isso aconteça de maneira satisfatória você precisa também ver o outro lado da coisa que é a administração do modelo assistencial, e esse modelo assistencial tem que ser compatível com tudo aquilo que você desempenha com todos recursos que você / porque os recursos são finitos" (P10-G)

"[...] o que eu olho diretamente, são os indicadores de custo e um que a gente trabalha bastante também chama Fugolin que é uma ferramenta de dimensionamento de pessoal. é: principalmente na enfermaria que a gente tá trabalhando em busca de produtividade, então a gente usa essa ferramenta para basear quantidade de funcionários que a gente vai ter pela produtividade que eles estão alcançando em conjunto [...]." (P11-G)

"o hospital é ... na verdade uma conjugação de várias atividades fim dentro de um mesmo, dentro de uma mesma organização, vou te dar um exemplo, é possível você ter um pronto atendimento fora do hospital, como uma unidade independente, é possível, nos EUA existem redes grandes de pronto atendimento que são completamente independentes de hospitais, então ele por si só é um negócio, e ele por si só a partir do momento que é visto como negócio e medido como negócio, ele consegue talvez enxergar atividades de potencial que não estão disputando a atenção do hospital porque ele faz parte de um todo.” (P14-G)

\subsubsection{Conflitos internos da empresa}

Trata-se de um nó central observado na pesquisa de campo, que sintetiza os principais conflitos internos apresentados pelos gestores, composto por conflitos entre setores quanto ao conhecimento dos processos de negócio da empresa. Entre os conflitos internos estão os conflitos entre departamentos dentro hospital, e também os conflitos com a equipe médica. 
Essas tensões estariam diretamente relacionadas com a gestão por processos e o acompanhamento do mesmo pelos diferentes setores, bem como no relacionamento da equipe assistencial com os pacientes, fatores que reforçam os dilemas internos descritos na literatura (LIMA-GONÇALVES, 1998; MACHADO, 2000; ROTTA, 2004; LA FORGIA e COUTTOLENC, 2009; WEBER e GRISCI, 2010; TANAKI e TAMAKI, 2012).

"[...] o que mais interfere diretamente no nosso trabalho é, não sei se se aplica na situação que estamos conversando, serviço de enfermagem incompleto interfere diretamente no nosso trabalho, falta de checagem enfermagem, é falta de lançamento de enfermagem [...], serviço de farmácia, falta de de lançamento, lançamento em excesso sem ser feito a devida devolução interfere diretamente no nosso trabalho, a parte médica, a falta de anotação médica, devolução médica, prescrição cirúrgica, falta de medicação, tudo interfere diretamente no nosso trabalho." (P3-G)

“[...] tinha uma grande parte que era lidar da relação da enfermagem com outras unidades, exemplo, farmácia, faturamento... e participar dos espaços onde precisava desses setores para fazer negociações, né, é o planejamento e acompanhamento de todo o desempenho assistencial né, e da parte de hotelaria." (P15-E)

\subsubsection{Processo assistencial}

O processo assistencial foi citado por 14 gestores, com foco no valor da vida. Esse nó foi criado para estabelecer os pontos levantados pelos gestores diretamente relacionados ao processo assistencial, tanto no fornecimento de recursos quanto do próprio atendimento e cadeia produtiva dentro do hospital. Foi dado destaque para os diferentes processos assistenciais dentro de um hospital, visto que o atendimento na emergência difere totalmente de um atendimento clínico ou cirúrgico, que por sua vez diferem de um atendimento no CTI. Cumpre ser observado que um só paciente poderia transitar por diferentes pontos assistenciais conforme a "evolução" de seu quadro médico.

Conforme observação na pesquisa de campo pode-se constatar que o planejamento terapêutico e o dimensionamento de enfermagem, com ferramentas como o método Fugolin, foram fatores recorrentemente citados pelos gestores entrevistados, de áreas assistenciais e de apoio, como ferramentas que potencialmente melhorariam a eficiência do processo assistencial, dado que forneceriam um método de planejamento do processo assistencial. Os gestores hospitalares entrevistados também pontuaram situações no 
processo assistencial que ocorrem com relativa freqüência e que exigiriam deles interações de curtíssimo prazo, relacionadas a resolução de problemas operacionais referentes a assistência, como escolha de materiais e medicamentos, realocação de funcionários, decisões acerca do tratamento ao paciente, entre outros.

Com base nas entrevistas pode-se constatar que os processos assistências são complexos e diversos conforme a situação do paciente, sendo que determinados processos assistências possuem maior potencial relativo de planejamento que em outros, e essa diferenciação de processos e incertezas inerentes poderia afetar a OTG, corroborando com os achados de Hartman (2000 e 2005) acerca da incerteza da tarefa e o ambiente, e reforçando a necessidade de incrementar os estudos sobre a incerteza da tarefa e do ambiente na relação com OTG (AGUIAR, 2009), assim como dos ciclos de vida dos processos (BURLTON, 2009; JOOSTEN, BONGERS e JANSSEN, 2009; GERSCH et al, 2012), considerando as particularidades de cada processo assistencial (CECCIM e FEUERWERKER, 2004; LA FORGIA e COUTTOLENC, 2009; GABRIEL et al., 2013).

“[...], por exemplo, necessidade de materiais, montagem de kits para cirurgia, né, é ... agendamento que é um parte que está em transição do assistencial para o operacional." (P4-G)

“[...] a: tem um paciente na emergência que não tem direito a cirurgia, está em carência. e aí eu sou responsável por decidir ah opera, não opera ou tento regular! a... teve um problema de encontrar o sobre aviso, tempo de espera da emergência está muito alto, é: a cme ... estão atrasadas as cirurgias, deu problema com o material de suporte médico, são problemas que vão acontecendo no dia a dia.” (P11-G)

"eu faço o controle de infecção e só não tem risco de infecção que não opera e a gente não compreende todo o risco de infecção, basicamente eu trabalho com dois indicadores, a taxa de infecção e número de processos realizados dentro do protocolo, então hoje eu faço a gestão do controle de infecção no hospital, que é garantir que não se tenham infecções no hospital." (P13-G)

"dentro do conceito de unidade de negócio estamos criando o conceito de paciente puxado, igual produção puxada, o que significa isso, uma vez que o paciente está saindo da emergência e ele está indo para o centro cirúrgico, a emergência avisa: eu estabilizei o paciente e estou te enviando, o centro cirúrgico fala opa para mim ele é um cliente e eu vou lá recebê-lo, e daí ele vai seguir os protocolos, vai fazer uma checagem do que foi feito, ou seja, trazer o melhor qualitativamente para o paciente, se segue os protocolos, a medição de sinais vitais do paciente.” (P14-G) 


\subsubsection{Gestão da qualidade}

Conforme identificado na pesquisa a gestão de qualidade é percebida como um investimento no longo prazo, devido processo de melhoria que o hospital passa para alcançar qualidade. Algumas certificações e normas foram citadas, tais como a Organização Nacional de Acreditação - ONA I, ONA II e ONA III, ISO, IQG e a CQH. Cumpre ser destacado que, nesta pesquisa de campo dois hospitais possuem a certificação ONA, um a ONA III e outro ONA I.

Todos os seis entrevistados que citaram as certificações apontaram que o resultado da obtenção seria no longo prazo, visto que o fato do hospital ter uma certificação não influenciaria diretamente no aumento de procura do serviço hospitalar no curto prazo. Isso, pois a demanda no curto prazo depende tanto da demanda do perfil epidemiológico, quanto da escolha dos pacientes em serem atendidos no hospital certificado, que poderia ser influenciado pela escolha da própria operadora em se credenciar no hospital certificado e indicá-lo a seus pacientes.

Ainda assim, a certificação estabeleceria alguns ganhos intangíveis, como aumentar o reconhecimento do hospital, que no longo prazo pode impactar no resultado financeiro do hospital com o aumento no volume de atendimento.

\footnotetext{
“[...] e também implantar um serviço clínico que coincidiu [1s] com uma das visitas do IQG, que é hoje o hospital, é um hospital acreditado, que é uma certificação que fala que o hospital trabalha com segurança, por trabalhar com segurança a cadeia medicamentosa ela tem um peso muito grande no processo, aonde você pensa que todo mundo que entrou no hospital teoricamente utiliza um medicamento, então você tem que garantir que toda cadeia, todo esse processo [...]" (P7-G)

"[...] o hospital começou a escolher uma ferramenta de melhoria de qualidade, então nós passamos pela ISO, pelo curso do ISO, trabalhamos um pouco com a $\mathrm{CQH}$, e optamos pela ferramenta da ONA, Organização Nacional de Acreditação, então toda parte de implantação, implementação de melhoria de qualidade [...]" (P15-E)
}

\subsubsection{Incerteza da tarefa}

A incerteza da tarefa representa as situações em que o gestor comentou que para o mesmo problema ocorriam diferentes soluções ou desfechos. No ambiente hospitalar o 
atendimento é realizado com base em protocolos e, em tese, eventuais incertezas não tratadas pelo protocolo seriam pouco prováveis. Tais incertezas seriam determinadas pela evolução no quadro clínico do paciente, e esse sim possuiria grau de imprevisibilidade.

Logo na parte assistencial o protocolo de atendimento teria, teoricamente, condições de prever determinados desfechos, reduzindo a incerteza de tarefa. Além dos protocolos, os entrevistados também mencionaram o planejamento terapêutico como ferramenta para tratar os recursos e tarefas necessários para o processo assistencial com mais segurança.

Os gestores assistenciais também enfatizaram que os atendimentos eletivos e cirúrgicos possuem maior previsibilidade no processo assistencial, pois são atendimentos planejados com antecedência e com maior controle dos fatores que afetam o paciente, do que em atendimentos de urgência ou emergência e clínicos, esses com maior incerteza da tarefa, decorrente da dificuldade de prever a evolução do quadro clínico do paciente, em concordância com a literatura em gestão hospitalar (BITTAR, 2000; LIMA-GONÇALVES, 2002; LA FORGIA e COUTTOLENC, 2009; WEBER e GRISCI, 2010; TANAKI e TAMAKA, 2012; GABRIEL et al., 2013; OYADOMARI et al., 2014).

Os gestores entrevistados descreveram situações rotineiras que são previstas, mas o desfecho não, decorrente da complexidade do tratamento clínico, enfatizando essa incerteza no processo assistencial, com menor importância relativa nos processos de apoio. Essa dificuldade de planejamento das atividades decorrente da incerteza da tarefa corrobora com os achados de Hartman (2005) acerca da utilização de indicadores em ambientes com incerteza da tarefa e também com a necessidade de estudos focados em entender a relação da incerteza da tarefa com a OTG (AGUIAR, 2009).

"[...] é uma questão que você tem que resolver internamente mas que vem de uma demanda externa, É MUITO DIFÍCIL SABE, porque assim é de fases, você consegue focar muito em determinados assuntos e resolver e ai vem outros e a gente vai resolvendo." (P4-G)

“[...] por ser hospital não tem diferença na imprevisibilidade [...].” (P5-G)

“[...] são atendimentos diferentes um paciente que chega na emergência, o paciente que chega na enfermaria de um paciente que chega no centro cirúrgico. têm pacientes que entram na emergência, e ai são consultas simples, de pacientes não urgentes, segue consulta e vai embora, tem pacientes que são, um pouco mais complexos que são considerados emergência ou urgência são atendidos no andar de cima e uma parte desses interna e vão para a enfermaria e ai depende tanto da internação, 
pode ficar dois dias, três dias, tem pacientes que da emergência vão pro CTI, daí tem um tempo de internação um pouco maior, tem cirurgias eletivas que vão no hospital dia e vão embora no mesmo dia, tem outras que entram para o centro cirúrgico e internam, tem vários fluxos e tempo diferente." (P11-G)

“[...] eu acho que dá pra falar que o que é planejado é mais fácil, por exemplo, cirurgias eletivas são mais fáceis que pacientes que chegam na emergência e você não sabe qual vai ser o caminho dele [...] do mesmo jeito os pacientes cirúrgicos são muito mais previsíveis que os clínicos. cirúrgico eu tenho um tempo mais definido de internação, clinico não, pode ser de um dia a meses. [...] cirúrgica é uma cirurgia de coração, uma fratura de perna. e já sabe [tempo de internação], cirurgia cardíaca eu já tenho definido que o paciente fica 7 dias, agora um paciente com pneumonia você não sabe quanto tempo vai tratar, depende da melhora clinica do paciente." (P11-G)

"[...] na verdade eu acho que sempre que estamos tendo muita atividade urgente é porque deixamos de planejar alguma coisa, e no setor de saúde ao contrário dos demais setores é onde você não pode ter urgência porque você tem que ter uma operação bem planejada, porque na hora que tem urgência nós estamos falando em vidas, então a gente tem que tomar o dobro de cuidado para que não tenha atividades de urgência, obviamente como em outras atividades terão atividades que você precisa tomar o pronto, a nossa pronta ação, que precisam ser encaminhadas rapidamente, mas isso não pode ser a regra nunca, para mim isso não é a regra." (P14G)

\subsubsection{Conflitos externos}

É um nó pai, que agrupa os conflitos externos apresentados pelos gestores, que variam do relacionamento com as operadoras ao perfil epidemiológico da região assim como da sazonalidade das epidemias e ocorrências.

A regulação e relacionamento com fornecedores também foram citados, assim como as incertezas ambientais, corroborando com a visão da importância da incerteza ambiental e conflitos internos na gestão hospitalar (HARTMAN, 2000; LIMA-GONÇALVES, 2002; HARTMAN, 2005; LA FORGIA e COUTTOLENC, 2009; WEBER e GRISCI, 2010; TANAKI e TAMAKA, 2012; GABRIEL et al., 2013)

"E você vê outro fator externo que está diretamente ligado, é uma coisa que me prejudicou muito, eu tenho um fornecedor de determinado equipamento que está em falta com os kits [...].” (P12-G) 


\subsubsection{Relação com paciente}

A relação com o paciente foi abordada tanto no que se refere o processo assistencial, quanto ao que se refere o atendimento ao cliente, com conceitos mais próximos de hotelaria e atendimento.

Na pesquisa de campo pode-se observar por meio da percepção dos entrevistados que a relação com o paciente é de atender assistencialmente com a melhor qualidade e também fazer o paciente se sentir confortável em sua estadia no hospital, visto que a priori, o paciente já não estaria no hospital por escolha.

Nesse ponto foram apontados tanto projetos diferenciados de atendimento ao paciente, que impactariam no resultado do hospital no longo prazo, quanto a percepção de que o atendimento assistencial focado na saúde do paciente no longo prazo poderia impactar em ações de prevenção ao invés de ações corretivas, focando na agregação de valor ao paciente, corroborando com a percepção na revisão de literatura que o sistema de saúde necessita balancear ações curativas e preventivas, assim como a dificuldade do gestor hospitalar em lidar com escolhas que afetam sensivelmente à vida humana (PITTA, 1994; MARTINS, ALVES e GODOY, 1999; ARAUJO e VIEIRA, 2004; ROTTA, 2004; BARIGOZZI e LEVAGGI, 2008; LA FORGIA e COUTTOLENC, 2009; CUNHA, 2011; SCHIOZER, SAITO e SAITO, 2011; WEBER e GRISCI, 2010; TOFAN, BODOLICA e SPRAGGON, 2013; SANTOS e HORMANEZ, 2013; OYADOMARI et al., 2014).

\footnotetext{
“então eu foco no valor para o cliente, essa é a filosofia do Lean, você focar no paciente, o paciente vem fazer cirurgia cardíaca aqui, qual é o valor para ele Diego? ter um coração saudável certo?” (P2-G)

"é um novo departamento que vamos criar que [...] é acompanhar o paciente desde a hora que ele põe o pé no hospital até a hora que ele sai do hospital, e toma conta de toda essa estada dentro dele, [...] é fazer o paciente chegar e se sentir mais confortável, que hoje por mais que ele venha, ele está vindo ao hospital ele não tem esse conforto, de chegar e saber que vai ser bem atendido, será que eu vou ficar uma hora, um dia, será que vou pro quarto assim que terminar a cirurgia, vou esperar quarto, essas dúvidas que eles tem, que a gente pretende ajudar, para ficar mais próximo do cliente paciente." (P9-G)

“o acolhimento é importante, não só o paciente a família também, então é como se uma empresa o cliente ficasse dentro dela o tempo todo, e a família nesse contexto como esse também fica doente, porque é um ente
} 
querido, que não está bem, porque não fez uma opção de vir, então todos ficam afetados, então a parte emocional da família tem que ser bem cuidado tanto quanto a parte de enfermagem para o paciente, isso é importante, tanto que a gente define prêmios para aqueles colaboradores que mais recebem elogios e assim por diante, o tempo todo tem esse olhar qualitativo." (P14-G)

\subsubsection{Relacionamento com operadoras de saúde}

Citado por 10 gestores hospitalares e três gestores de operadoras de saúde esse nó representa os principais pontos de relacionamento entre operadora e hospital, nesse nó estão apresentadas as visões tanto dos gestores hospitalares, quanto de gestores de operadoras de saúde. Os pontos de contato entre operadoras e hospital mais citados foram os mecanismos de monitoramento e controle, em termos de cadastros, guias e autorizações para procedimentos, em um segundo momento a auditoria médica e a glosa, além do relacionamento comercial de negociação propriamente dito.

Os gestores hospitalares os da operadora também destacaram os interesses conflitantes entre operadora e hospital no que tange objetivo empresarial, assim como na forma de lidar com as decisões de alocação de recursos no processo assistencial. Nesse sentido o tempo alocado no relacionamento com as operadoras de saúde é visto por sete gestores hospitalares como uma tarefa cujo efeito é no curto prazo e três gestores entendem que esse esforço para um relacionamento saudável e transparente com a operadora poderia trazer benefícios no longo prazo. Os gestores entrevistados que defenderam essa condição de longo prazo ocupam posições hierárquicas mais altas e mais próximas da administração, enquanto os gestores assistenciais e de áreas de apoio foram os que consideraram que as relações com as operadoras como típicas ações de curto prazo.

Nesse sentido, o relacionamento com as operadoras de saúde, descrito pelos gestores entrevistados, reforça e amplia os dilemas previstos na literatura, conforme demonstrado por Lima-Gonçalves (2002) Sato (2004), Escrivão-Junior e Koyama (2007), Uga et al. (2009), La Forgia e Couttolenc (2009) e Camacho, Rocha e Moraes (2011).

“[...] você tem uma tabela, uma negociação anual de reajuste, uma negociação anual de inclusão de itens na tabela, negociação de pacotes, valores e tal, mas o que o convênio vai te pagar no final do mês é por aquilo que ele usou, então você fechar mas não tem garantia de utilização, então você tem que trabalhar para ser utilizado [...]." (P1-G) 
“[...] com relação a operadora os principais detalhes são OPME, o é: órtese, prótese e materiais especiais e medicamentos de alto custo.esses esses materiais nem sempre o valor que vem o material utilizado está conforme, conforme previamente autorizado pela operadora [...] a cotação quando vem, vem faltando um item, e essa falta de item gera alguns stress entre hospital e operadora, porque a operadora ela informa que não autorizou aquilo que o médico utilizou, nós precisamos fazer justificativa médica daquela cobrança, daquela cobrança, então o médico faz uma justificativa para a gente poder cobrar, mas mesmo assim gera glosa, gera muito STRESS. esse é um ponto bem nefrágico.” (P3-G)

“[...] ás vezes eles glosam alguma conta e eu faço uma justificativa técnica da necessidade de uso, solicitou um medicamento pra uso ambulatorial e eles falam que só paga: hospitalizado, ai eu explico para eles que é muito mais barato garantir o ambulatorial que se esse paciente recai fica numa cti e ele paga uma diária de CTI, é um... uma ... das operadoras esses dias me chamaram no faturamento pra conversar com eles porque ela não sabia porque estava usando um tipo de bomba, ai eu fechei, fiquei de mandar um manual pra ela explicando quais as drogas são críticas e porque aquilo tem que ser usado no modo de infusão." (P7-G)

"[...] a diferença é que o hospital está voltado, a direção técnica do hospital ela se volta para as questões administrativas, porém dentro do operacional da assistência médica, praticamente em cima só de assistência, você criar meios e regular as ações dos colegas médicos para que o resultado do hospital, assistencialmente seja o melhor possível e prover o hospital com todos os recursos necessários para que o hospital mantenha e desenvolva competências em vista de sua missão [...] a operadora é uma função administrativa, não existe assistência na operadora, porque a missão da operadora é a comercialização dos planos de saúde e a regulação dos seus resultados, ou seja, controle de credenciamento, médicos, pagamentos, faturamento junto com outros prestadores hospitalares ou médicos.” (P10-G)

"[...] a gente melhorou muito do que era, mas da para trabalhar mais próximo, hoje nossa maior relação e com a auditoria médica, que é: o que demanda mais contato, que é por conta das autorizações de internação e principalmente procedimentos. então com eles a gente conseguiu um relacionamento bem próximo. ah teve um problema a gente liga, tenta resolver, pede para adiantar autorização [...]." (P11-G)

"[...] só que ninguém vai perguntar quanto que cada infecção que fica um dia a mais fica mais caro, os hospitais ficam cada vez mais com um foco financeiro, então tem que usar sabiamente nossos recursos, mas o que é difícil é a operadora percebe é o custo de cada coisa, então o paciente vem para colocar uma prótese, tem uma que é 50 mil mais caro, só que ele sai no dia, é um paciente obeso, ela coloca a prótese mais barata ele fica na CTI uns 5 a 10 dias, corre risco de infecção e pronto a conta ficou mais caro, [...] o pessoal lá acha que é fácil, que acham que economizou um monte com isso e no fim vai ficar mais caro, e essa conta eles não olham, 
isso eu aprendi com os americanos, que os americanos o que já está comprovado, é mais rápido o paciente vai embora mais cedo eles já fazem, aqui [...] olham preço, sempre foca no curar com o mais barato, não olha o paciente com um tempo de vida que vai ter que voltar mais vezes e se gastar um pouco mais agora voltará menos, então paga uma fisioterapia de $\mathrm{R} \$ 20,00$ a mais por dia de fisioterapia, mas não, não pagam e depois paga uma dose de antibiótico que o paciente ficou na CTI, que custa muito mais que isso, e não é uma só que usa, essa conta é fácil, já está feita pelos americanos, mas não, pegam o quanto economizaram naquele dia e só, e são médicos que fazem isso [...] e é tudo corretivo, caro, nada preventivo, e agora vai ficar um tempão aqui e vai pagar a conta [...] então vou te dar outro exemplo, tinha que dar um remédio Omeprazol e era em veia e custava $\mathrm{x}$, daí viu que se desse via oral, com sonda o medicamento ficava mais barato, mas não via que sonda ficava mais caro, que tinha chance de problema, que é mais invasivo, então são umas coisas, teve um paciente que fez um ponte de safena, e querem sempre economizar no stent, que é uma mola, só que usando ela o número de internações futuras do paciente diminui, ela é cara no curto prazo, mas no futuro ele vem menos ao hospital, mas preferem não usar e depois esse paciente com a ponte de safena vem todo ano umas 3 a 4 vezes aqui, sai mais caro, fica muito no curativo, então não tem [...] essa gestão de médio e longo prazo na operadora, a operadora fica olhando só ticket médio e ticket médio entende." (P13-G)

"[...] então a fonte pagadora no serviço assistencial [operadora de plano de saúde] ainda é um mero detalhe mediante a política comercial que a gente tenha, em que sentido, é um mero detalhe a medida que é o paciente que traz a necessidade para nós, o que nós temos que fazer com a fonte pagadora é manter relações bastante transparente, cordiais, no sentido que a gente tem que seguir as regras deles para que a gente possa viabilizar essa assistência, mas ainda hoje a origem da assistência é o paciente, as vezes a operadora pode dirigir o paciente de um hospital ao outro, mas se não existir a necessidade do paciente não há assistência.” (P14-G)

“então, a operadora tem a preocupação de que, nós tenhamos o máximo de previsibilidade possível no tratamento, então se a pessoa vem aqui para fazer uma cirurgia no apêndice ela gostaria que essa pessoa se comportasse, que a assistência se comportasse como se fosse padronizada ao longo do tempo, vai ficar por determinado tempo e usar determinados materiais e medicamentos, sempre que algo sai desse padrão a operadora se preocupa porque de certa maneira o interesse da operadora é antagônico ao do hospital em alguns sentidos, ou seja, o hospital se o paciente ficar aqui 10 dias de UTI pela cirurgia de apêndice o hospital vai estar recebendo por isso, e a operadora pode não compreender isso, porque ele está aqui 10 dias por essa cirurgia, então as relações com a operadora tem que estar muito transparente, mostrar que a gente está praticando uma assistência de alto nível, que é uma assistência que vai ao encontro dos interesses da operadora, eu não quero que o paciente fique aqui mais tempo do que ele precisaria ficar, mesmo porque o movimento de giro é mais interessante que a manutenção de um paciente no leito com baixo consumo de medicação, de enfermagem e assim por diante, a ideia é 
casar esses interesses, a medida que você dá previsibilidade para operadora ela tem tudo o que ela precisa, isso para ela tem muito valor, isso a gente tenta fazer através do planejamento terapêutico, negociação de pacote, do procedimento gerenciado e assim por diante. a relação tem que ser muito transparente, tanto que nosso hospital é aberto para auditores de qualquer operadora, e que possam acompanhar seus pacientes nesse período todo que eles estiverem, e nós temos uma estrutura para atender a operadora, tanto pessoas do faturamento quanto assistencial, então vamos pegar um caso que a previsibilidade era de 2 dias e quando detectaram uma outra anomalia e tivemos que manter ele por um tempo maior, e daí essa é uma conversa eminentemente entre médicos, uma conversa muito técnica." (P14-G)

"ocupava muito tempo meu [a relação com as operadoras], era com glosa, negociação, guia, autorização de procedimento, eu acabava me metendo em tudo isso, uns $20 \%$ do tempo era com a questão de resolução de problemas com a operadora, ir até a operadora discutir questões, discutir glosa, discutir novas regras, eu fazia parte do grupo que fazia isso." (P15E)

"[...] a operadora foca no controle do sinistro, minimizar o risco dela, o hospital para a operadora é um centro de custo, mas a operadora foca muito em Ebtida ${ }^{11}$, tem que focar mais em resultados de longo prazo, ações como prevenção, campanhas, desenvolver saúde da população para que no futuro utilizem menos o sistema assistencial.” (P16-O)

"eu vendo com um valor vida, é uma série de procedimentos [...] é um preço fechado por vida para determinados procedimentos [...] eu faço a gestão de risco de sinistralidade [...].” (P17-O)

"você me fez uma pergunta (as missões do hospital e operadora concorrem?), que embora ela seja pertinente, se você olhar de uma maneira indistinta não guarda relação, porque veja só, o hospital trabalha em um modelo de assistência, e a operadora de um plano de saúde comercializa planos de saúde e faz a gestão daquilo que ele vende, ou seja, o seu sinistro. é isso que acontece, mas agora, vai depender muito do modelo de negócio que você tem, qual o modelo de negócio que você tem, você tem uma cooperativa, você tem uma associação médica, você tem uma autogestão, você tem uma medicina de grupo, você tem uma cooperativa, QUAL É O MODELO DE NEGÓCIO QUE ESTAMOS FALANDO? se estivermos falando de modelo de cooperativa é diferente, você reúne um grupo de médicos, que na realidade é um negócio, eles vendem planos de saúde e aferem seus serviços, conforme ele faz isso ele paga suas despesas, obtém uma margem de lucro, teoricamente deveria ser dividida entre seus associados, na verdade uma associação médica, uma cooperativa visa dividir os lucros, é isso ok? Teoricamente agora se

\footnotetext{
${ }^{11}$ Do inglês Earnings before tax, interest, depreciation and amortization, é um indicador contábil, que representa o lucro operacional antes de impostos sobre a renda, juros, depreciação e amortização (LAJIDA). É um indicador bastante utilizado nas empresas como potencial de geração de caixa pela operação no curto prazo.
} 
estivermos falando de medicina de grupo, o que que é o conceito de medicina de grupo? o conceito de medicina de grupo é quando você tem uma operadora de plano de saúde e você tem sua rede própria, ou seja, aquilo que você vende, é aquilo que você tem uma rede pra ... de prestação de serviço, que pode incluir hospitais, clínicas, laboratórios, etc, da qual você faz a gestão, onde o centro de custo é unificado é um só, então cabe você fazer a gestão daquilo que você vende, assim como cabe fazer a gestão daquilo que você entrega como resultado, ou seja, o resultado da assistência e as duas coisas sejam balanceadas no final para que você tenha o resultado que está almejando, suas metas financeiras e assistenciais."(P18-O)

\subsubsection{Perfil epidemiológico}

O perfil epidemiológico foi outro ponto bastante discutido pelos gestores entrevistados, de forma geral como sendo o causador da demanda do hospital. Também foi classificado como um ponto que possui certo grau de imprevisibilidade, fundamentalmente por causa de epidemias e sazonalidade.

Ainda assim, na opinião de alguns entrevistados existem estudos que possibilitam prever a demanda do hospital, muito embora os entrevistados reconheçam as dificuldades associadas ao dimensionamento e ao perfil de demandas epidemiológicas pontuais. Cumpre ser ressaltado que esses pontos estão destacados, também, no nó de Incerteza ambiental.

\footnotetext{
"então um exemplo dengue, sempre tem epidemia, então a gente tem um pronto atendimento aqui [...], é a porta de entrada do hospital, onde o pessoal vê o hospital [...], então o que aconteceu em 2011 eu escrevi um protocolo para dengue e passei para todos utilizarem e seguirem aquilo, que tem que olhar os recursos, fazer triagem [...]." (P13-G)
}

\subsubsection{Sistema Universal de Saúde}

Esse nó foi criado para as citações acerca do modelo assistencial brasileiro e os desafios na gestão hospitalar com a fonte financiadora SUS. Os gestores comentaram sobre a demanda vir do paciente, e ele ser o foco do atendimento, dessa forma o SUS é apenas a fonte financiadora, assim como o Governo (Municipal, Estadual ou Federal). Nesse quesito o hospital foca em gerar valor ao cliente paciente, que é quem gera a demanda e busca o hospital. Alguns pontos como a Tabela SUS foram citados, sobretudo quando os gestores entrevistados procuravam reforçar os como modelos cujo financiamento é abaixo do custo 
de determinados procedimentos, o que na percepção dos entrevistados explica a baixa propensão dos hospitais privados estabelecerem convênios relevantes com o SUS, em aderência aos dilemas já levantados na revisão de literatura (LIMA-GONÇALVES, 2002; ROTTA, 2004; CAMPOS, AMARAL, 2007; LA FORGIA; COUTTOLENC, 2009; VIEGAS, PENNA, 2013).

\begin{abstract}
“o convenio SUS a gente não negocia né, tem a tabela é imposta, não da para eu ir lá falar meu custo é esse e você ta pagando isso, isso é um ponto ruim, não existe negociação, o que a gente tem de estratégia aqui é fazer a gestão de custo, [...] só com o SUS não é suficiente, Estado vai dar a verba independente do quanto eu produzir, claro que tem um acompanhamento, mas não é igual ao SUS que é para cada procedimento, então o SUS ele subfinancia, o Estado complementa, mas tudo tem um limite, porque senão tivesse Estado não teria como atender, aqui a gente faz gestação de alto risco, um hospital de uma cidade do interior faz gestação, faz parto normal, gestação de baixo risco, a nossa é de alto risco, o custo já é elevado." (P6-A)

"o SUS fala que a gente tem que ter um plano de metas, a gente faz os indicadores e metas e pactua com eles, então eles não impõem nada, é pactuado, e depois acompanhado, temos um setor de avaliação de desempenho que gera esses indicadores que são apresentados em reuniões com o gestor do Governo." (P8-A)
\end{abstract}

\title{
4.1.19 Incerteza do ambiente
}

A incerteza do ambiente foi apontada pelos gestores mais em relação ao volume de atendimento do que em relação às patologias, ou seja, na percepção dos entrevistados existe dificuldade fundamentalmente na previsão do momento e do porte da demanda, dado que a natureza da demanda poderia ser prevista, isso, pois, segundo o relato dos entrevistados, existem bancos de dados sobre o histórico de epidemias e o perfil epidemiológico da população.

Ainda assim, o hospital está sujeito a ocorrências inesperadas e que impactam em sua atividade. Portanto a incerteza do ambiente é decorrente do volume de atendimento e do momento de atendimento, impactando na necessidade de volume de recursos e trabalhos nos diferentes setores do hospital. Para os gestores a incerteza do ambiente impacta diretamente no trabalho de dimensionamento das atividades assistenciais e de apoio, dado 
que em casos de imprevisibilidade e de urgência eles estariam sujeitos a decidir pela realocação de funcionários e recursos materiais.

Além das patologias e volume de atendimento, demandas pontuais dos pacientes são vistas como incerteza do ambiente pelos gestores. A percepção de cinco gestores é que a incerteza do ambiente impacta negativamente na OTG de longo prazo, ao passo que não é possível elaborar eficientemente e seguramente o planejamento, entretanto seis outros gestores acreditam que a incerteza do ambiente poderia impactar negativamente na OTG de longo prazo, mas sugerem que essa incerteza ambiental não seria tão diferente do que a incerteza de ambiente em outras atividades. Para esses últimos como o foco do hospital é o atendimento assistencial a incerteza ambiental teria que ser, e poderia ser, minimizada.

A importância dada a incerteza do ambiente corrobora com a visão de Hartman (2000 e 2005), e com a necessidade mais estudos relacionando a incerteza do ambiente com OTG (AGUIAR, 2009). Da mesma forma a literatura em gestão hospitalar relaciona a incerteza do ambiente com a dificuldade de gestão nos hospitais (BITTAR, 1997; LIMAGONÇALVES, 2002; ROTTA, 2004; CAMPOS, AMARAL, 2007; LA FORGIA; COUTTOLENC, 2009).

“[...] aqui [apontando caixa da atividade no mapeamento de processo] é onde tem essa imprevisibilidade, incerteza, na caixinha do atendimento no cliente, o resto continua tudo igual, pode mudar o tempo, atrasar, ter novas demandas, mas tudo nessa caixinha, as outras áreas continuam igual, mas área da saúde é assim mesmo, falam sempre isso, que não dá para fazer por causa disso, mas gente é aqui só, o resto a gente consegue trabalhar normal, e toda imprevisibilidade a gente consegue contornar, você consegue mapear a imprevisibilidade." (P2-G)

"então Diego tem de tudo, sai uma resolução da ANS, daí tem q envolver as pessoas que precisa para tratar aquelas questão, (...) a gente tem algum problema em algum equipamento, ai é uma questão interna, mas que remete a manutenção (...) questões vinculadas ao relacionamento do hospital com alguma operadora, faturou, glosou porque teve esse processo e a gente não está apontando isso, ai é uma questão de corrigir o processo de fechamento da conta, então tem de todo o que é lado[...]." (P4-G)

"[...] eu acho que no ambiente de saúde a gente apaga muito incêndio, todo dia acontece um negócio, às vezes eu chego aqui e não tenho uma reunião marcada, mas meu dia enche num minutinho [...]." (P6-A)

"[...] comigo nunca aconteceu, eu sei que teve uma vez que explodiu uma caldeira que afetou muitos funcionários, então teve problema no hospital 
todo, com medicamento, e teve com enxoval também, que tem hoje um estoque reduzido, que eu não posso ter muito mais do que eu uso." (P9-G)

"os problemas são mais ou menos os mesmos, mas nem todos dependem de um planejamento antecipado para que não aconteçam, por exemplo, tempo de espera na emergência, eu não tenho como prever que vai chegar muito paciente ou não, eu tenho uma séria histórica, mas tem dias que extrapolam essa serie histórica ... a: um paciente reclamando de alguma coisa no quarto, vai acontecer, eu não tenho como prever isso [...] é o que eu enxergo assim a diferença entre um hospital e uma indústria e uma produção é essa, como é que / a gente lida com pessoas com doenças, as coisas vão acontecendo [...].” (P11-G)

"no setor hospitalar o que acontece é sazonalidade, o que não implica em uma imprevisibilidade, em um hospital como o nosso não foi desenhado para enfrentar uma epidemia, e eu tenho a impressão que nenhum hospital o é, por exemplo, e entanto nós sabemos que nessa época do ano nós corremos o risco de ter uma epidemia de dengue por causa das chuvas e tudo mais, então fala quando vem a epidemia hoje eu não chamo de falta de previsibilidade, bem a falta de previsibilidade está em saber se vai haver ou não a epidemia, mas como já ela é recorrente anos a fio, o que nós fazemos é nos preparamos para nessa época do ano ter uma epidemia, a outra coisa há uma sazonalidade de doenças respiratórias no período da seca, como junho, julho que há pouca chuva, faz com que a gente tenha uma incidência de mais pessoas aqui procurando ajuda por problemas respiratórios, então. a gente se procura se planejar a elas, obviamente pode acontecer alguma coisa muito diferente, muito distinta, estamos falando do setor de saúde você pode ter um acidente alguma coisa ae, que faz com que toda sua estrutura tenha que ser focada em algum evento em prejuízo das demais que não são tão urgentes, mas eu diria que isso ocorre com a mesma frequiência que toda industria." (P14-G)

“ [...] eu acho que uma coisa que a gente não conseguia controlar que era complicado era a demanda, basicamente a DEMANDA, então a gente tinha um constante problema de falta de leito, pronto socorro sempre alto." (P15-E)

\subsubsection{Desenho do contrato do gestor}

A partir da pesquisa de campo, foram detalhadas as atividades relevantes dos gestores e, também, a função gerencial na organização. Na maioria dos casos observou-se que as tarefas realizadas são diretamente relacionadas às tarefas para as quais o gestor foi contratado, muitos inclusive aludiram suas tarefas ao que foi acordado com o gestor superior, seja na contratação no caso de gestores mais recentes, seja na promoção ou troca de gestor superior para os gestores que estão há mais tempo na organização. 
Quanto a esse tema foi verificado que as tarefas realizadas pelo gestor estão alinhadas ao que foi proposto no desenho do contrato ex-ante do gestor, de maneira que a orientação temporal do mesmo poderia estar relacionada ao desenho do contrato. Os gestores apontaram de forma clara que algumas funções são inerentemente voltadas para ações de longo prazo, e outras para ações de curto prazo. Por exemplo, gestores de assessoria técnica, projetos, melhoria contínua são focados em ações de longo prazo, pois isso decorre do desenho do contrato de trabalho de forma intrínseca.

Inclusive nas entrevistas com os gestores em relação a seus subordinados pode-se capturar os diferentes cargos e funções existentes no organograma, bem como seus objetivos, e também que existe um direcionamento do gestor para o preenchimento dessas funções e objetivos. Pode-se observar, também, que o comprometimento com o desenho do contrato é diretamente relacionado com a confiança que os gestores possuem no gestor superior. A importância do desenho do contrato ex-ante, corrobora com a literatura em controladoria sobre a teoria da firma sob a perspectiva da teoria dos contratos, e custos de transação (ALCHIAN e DEMSTEZ, 1976; MILGRON e ROBERTS, 1992; LAMBERT; 2001).

\footnotetext{
"o setor (melhoria contínua) ocupa uma posição muito estratégica aqui no hospital, a gente lida com o hospital todinho, está sob nossa responsabilidade o programa de qualidade hospitalar, [...] a gente tem também uma área de gerenciamento de risco, ta, a parte de planejamento de materiais, tanto de material de consumo, que é o medicamento médico hospitalar, inclusive órtese e prótese, quanto de material permanente, então como já é sabido, a saúde sempre tem limitação de recursos, então cabe a nós priorizar o que será feito [...] a gente trata investimentos em equipamentos, [...] e novos projetos [...] outra coisa também a parte de informática, está sob a assessoria técnica, não só informática, é a gestão da informação, tanto informática quanto indicadores de desempenho, avaliação de desempenho, estabelecimentos de metas, avaliação de metas, a avaliação de desempenho né [...] então tudo o que tem que ser discutido no hospital a gente atua em todos os departamentos, e como se fosse uma área de projetos, então a gente trabalha bastante com o gerenciamento de projetos. [...] olha eu acho que é mais para longo prazo [o foco do gestor], por causa da área, é para planejar." (P6-A)

"quando eu vim pra cá a proposta era um pouco diferente, era cuidar da logística interna, e aí tinha um, tem um gerente de suprimentos que responderia por essa parte de gestão de compras, essas outras coisas que antes era minha competência." (P7-G)
} 
"e ai surgiu a oportunidade de entrar no grupo, ai fiz a entrevista, foram com a cara e resolveram apostar e o projeto [...] foi muito interessante porque é: ele tem bastante oportunidade para a gente atuar, e isso me motiva porque você está sempre em desenvolvimento, buscando expansão, atuação em áreas novas, porque assim o meu perfil sempre foi muito de: desenvolver o projeto, colocar em prática, enfim e sigo adianta, [...] e ai você acaba como que missão cumprida, e fica só na gestão da coisa, mas eu gosto muito de viajar, de projetos né, [...] o que eu achei muito interessante e que me atraiu bastante é que nós estamos em uma fase de transição, onde hoje nós expandimos muito." (P12-G)

\subsubsection{Planejamento estratégico e orçamento}

O planejamento estratégico é visto como um norte para os gestores entrevistados, por compreender a visão de longo prazo da empresa e dos gestores superiores e conselheiros.

Para a realização do planejamento estratégico algumas ferramentas econômicas, já mencionadas, como BSC e OGSM são utilizadas, assim como análise SWOT (Forças, Fraquezas, Oportunidades e Ameaças, do inglês Strenghts, Weakness, Opportunities and Treaths) e 5W2H (O que, Porque, Onde, Quando, Quem, Como e Quanto, do inglês What, Why, Where, When, Who, How and How Much).

Segundo a percepção dos gestores essas ferramentas facilitam a visualização dos objetivos estratégicos em objetivos pontuais e específicos para cada gestor, corroborando com a literatura em controladoria e planejamento estratégico (KAPLAN; NORTON, 1996; MALINA e SELTO, 2001; WEBB; 2004; SILVA et al., 2012; VALLEJO et al., 2012).

$\mathrm{O}$ orçamento empresarial foi visto como um desmembramento do planejamento estratégico, quantificando em valores monetários as ações necessárias para alcançar os objetivos estratégicos. Todos os gestores comentaram sobre o orçamento e seu uso como ferramenta para acompanhamento das atividades mensais e se as metas estão sendo alcançadas, visto que várias metas são relacionadas ao orçamento, que em tese relacionaria tanto caixa quanto lucro nos hospitais entrevistados.

Nos hospitais em que os gestores atuam também foram pontuados KPI (Key Performance Indicator) que são orçados, são os indicadores chaves de cada gestor, nesse quesito existem indicadores tanto financeiros quanto qualitativos, como taxa de ocupação, taxa de infecção, taxa de resíduo hospitalar, entre outros, corroborando com os estudos em 
OTG que focam na relação do orçamento com OTG (MERCHANT, 1990; VAN DER

STEDE, 2010).

"[...] o planejamento é visão de longo prazo, são projetos de melhoria pro hospital." (P6-A)

"[...] a gente faz [planejamento estratégico], trabalha com OGSM, [...] ele [gestor maior nível hierárquico] faz o da empresa, e ai ele manda pra gente dentro daqueles objetivos da empresa cada um faz da sua área. tem os objetivos macros que ele coloca e daí como eu faço para minha área eu alcançar aquilo. por exemplo ele coloca, aumentar 5\% a produtividade do hospital, então eu tenho que tentar fazer aquilo nas áreas que eu consigo para atingir o objetivo dele." (P11-G)

“[...] então cada uma dessas atividades tem uma data para começar e se eu atraso isso atrapalha a receita que eu orcei para aquele período que deveria iniciar essa atividade, então tudo isso está atrelado, é um planejamento, então se falhar a gente tem que identificar o que aconteceu, para ver quando vai gerar a produção e quando vai faturar e de repente pode ser que a gente faz uma estimativa e também é surpreendido positivamente [...].” (P12-G)

"vou te falar como funciona mais ou menos, os objetivos, na verdade eu tenho uma orientação de como o conselho vê o hospital no longo prazo, isso está até definido na nossa missão, e aí a missão é sempre uma coisa muito genérica, do ponto de vista de deflagrar objetivos específicos, então a gente defini essa missão com a minha interpretação da missão deles, a partir do momento que nós conseguimos fazer esse alinhamento, aí então eu começo a traçar os objetivos em comum acordo com os supervisores do hospital, eu defino no máximo dois ou três objetivos por ano, e a partir daí definimos qual vai ser a forma de alcançar esse objetivos, primeiro a gente quantifica, quais são as metas e depois como chegar a essas metas, e daí cada um dos gerentes e diretores concordados com esses objetivos sentam com sua equipe e discutem as metas e objetivos para o ano. então é uma maneira da gente permeia toda a organização com os objetivos definidos, normalmente meus objetivos não são objetivos que tem uma permutuação grande ano a ano, são objetivos para a visão se longo prazo, o que nós vamos mudando ano a ano são as metas e estratégias ano a ano." (P14-G)

“[...] o ebitda é definido conforme a estratégia de longo prazo, então na hora que eu defini isso e eu quantifico isso no orçamento, isso já está sendo considerado lá, então o conselho diria você não está cortando sua verba de pesquisa pra melhorar seu ebitda, não, nesse sentido, está tudo negociado, pra isso a gente tem várias reuniões para análise quantitativa e qualitativa para que a gente alinhe quanto aos objetivos quali e quantitativos, assim como as metas para não comprometer o valor." (P14G) 


\subsubsection{Sistemas de comunicação}

A comunicação dos objetivos e metas estratégicas foi um assunto discutido em abundancia pelos gestores, que acreditam que os objetivos gerais das instituições não chegam ao nível operacional, chegam normalmente até o $4^{\circ}$ nível hierárquico, como coordenador ou supervisor.

A dificuldade de comunicação das estratégias e objetivos com o setor clínico do hospital, principalmente com os médicos, foi apontada por três gestores entrevistados. Gestores do $3^{\circ}$ e $4^{\circ}$ nível também foram citados como gestores com dificuldade para comunicar os objetivos e estratégias da empresa. Todos os 12 gestores que falaram sobre a comunicação do planejamento estratégico comentaram sobre a dificuldade de comunicar o que foi acordado no planejamento estratégico e orçamento empresarial, e que essa comunicação é essencial para a eficiência organizacional.

Ainda que os objetivos macros não cheguem até o operacional os gestores defendem que no nível mais operacional chegam os objetivos específicos, e ainda que esses colaboradores possam não conseguir visualizar o alinhamento entre os objetivos da sua área com o objetivo do hospital, eles entendem os objetivos específicos e os acompanham.

Nesse ponto os sistemas de avaliação de desempenho estratégicos, como BSC e OGSM, foram citados como facilitadores nessa comunicação e entendimento, corroborando com as teorias em controladoria e gestão (KAPLAN e NORTON, 1996; MALINA e SELTO, 2001; WEBB; 2004; SILVA et al., 2012; VALLEJ et al., 2012).

Esses gestores também foram questionados sobre de que forma seu trabalho afetaria os objetivos organizacionais e todos foram capazes de relacionar seus objetivos com o planejamento estratégico, confirmando o cenário de comunicação descrito pelos mesmos.

“[...] o indicador não chegava, o estratégico, então o que eu fiz eu transformei o estratégico do superintendente em operacional, então fizemos o gambá em relação esses indicadores que eles entendem, se eu falar estratégico fica muito distante para eles entenderem, então, por exemplo, atraso de cirurgia, estratégico faturamento, qualidade e imagem, então um problema que acontece lá é atrasou a cirurgia porque a $\mathrm{CME}^{12}$ molhou a caixa e a caixa veio não desinfectada, então atrasou a cirurgia, então a gente coloca esses indicadores [...].” (P2-G)

\footnotetext{
${ }^{12}$ Central de Materiais Esterilizados.
} 
"a gente usa uma ferramenta que chama OGSM, daí a gente coloca o objetivo e como a gente vai chegar nele [...] chega a todos os níveis, qual a idéia que a gente passa no OGSM do hospital é que cada área discuta como vai contribuir e depois eles façam isso permear pela empresa, para chegar lá na ponta, mas tem gente que tem menos conhecimento que outro, tem, pode acontecer, porque pode ser que tenha muita rotatividade, entra gente nova o OGSM não chega, então tem como melhorar isso, essa comunicação dos líderes para baixo, mas até os líderes está chegando, até gerente, coordenador está bem integrado [...]." (P4-G)

"[...] então a gente vai quebrando objetivo e estratégia macro em vários objetivos, pelas áreas, que tem a estratégia, o indicador e a meta e a ação, então no planejamento estratégico eu tenho o portfólio de ações. a gente / a comunicação é problema sério, a gente tem bastante dificuldade, mas até diretor tem que chegar, o planejamento estratégico quando a gente fez e o acompanhamento a gente coloca na intranet, mas não é uma coisa que gera curiosidade das pessoas, então a gente vai fazer agora um jornal do planejamento estratégico para divulgar [...] e fizemos uma oficina de planejamento estratégico, e a cada seis meses a gente faz uma oficina do planejamento estratégico com os diretores para discutir isso e até como uma forma de prestação de contas, para ver o que aconteceu, [...] mas o macro eles não conhecem mas eles conhecem os deles, mas eu não sei se eles enxergam a importância do trabalho dele para os objetivos macros do hospital [...] essa é a importância do indicador, é estabelecer uma meta para cada área e fazer eles cumprir, então a gente vai analisar e conversa se cumpriu meta, se não cumpriu o porquê, então a gente estimula o chefe da área a conversar com o funcionário, o que a gente propõe é que cada área faça a gestão de seus indicadores, com os seus funcionários." (P6-A)

"sim chega, mas a gente ainda tem dificuldade para passar isso para todos os níveis, por exemplo eu consigo passar isso para as coordenadoras, mas eu acho que os funcionários enfermeiras não conhecem a estratégia da empresa, que é algo só dos níveis mais acima, de coordenadores para cima." (P11-G)

"[...] se você chegar no nível mais básico da estrutura e falar do macro objetivo ele provavelmente desconhece o macro objetivo, mas se você falar do objetivo que foi definido pelo supervisor dele para ele, ele sabe, e esse objetivo que o supervisor direto definiu para ele para aquele ano para aquelas atividades ele está em linha com os objetivos macro definidos aqui, então é como se a gente fosse fazendo o desmembramento do objetivo macro em metas e estratégias menores, que se bem executadas são de grande resultado, então eles entendem que tem um objetivo e que eles tem que trabalhar por ele. a maioria das pessoas tende a achar que os objetivos deveriam ser compartilhados em todos os níveis, a minha experiência é que os objetivos compartilhados em todos os níveis eles não são nem memorizados, o que você pode ter uma ideia geral do que está acontecendo mas se perde naquilo que é específico, então hoje a gente tenta trabalhar com o específico e não o geral, para ele não ficar confuso quanto ao que fazer." (P14-G) 


\subsubsection{Modelos de gestão}

Os gestores citaram modelos de gestão para o acompanhamento das atividades, que variam de modelos com focos mais funcionais para modelos com foco nos processos. Esse nó apresenta os diferentes modelos comentados, como gestão participativa e unidades de negócio.

As unidades de negócio foram citadas por sete participantes como uma mudança estratégica do hospital, que vê cada uma de suas unidades assistências como unidades de negócio independente e que deve ser gerida como tal, a mudança do modelo de gestão em si é uma mudança cujo resultado é visto no longo prazo.

“[...] a gente tem um programa que chama gestão a vista (mostrando impressão colada num quadro de recados na parede), então esse painel tem em todos os setores, onde o indicador que é acompanhado lá fica nesse painel para ele ver, se eu vou na oficina é ordem de serviço, se eu vou no berçário é a taxa de infecção do berçário, e isso nós é que montamos essa estratégia, e esses indicadores são atualizados trimestralmente, e alguns mensalmente. "(P6-A)

"então a gente vai unir ali os talentos para ter rodando direitinho tecnicamente e incrementar com a área de negócios, que até hoje não era visto como uma unidade de negócio né, assim agregar no Ebitda do grupo positivamente economicamente, era um centro de custo, e ai então deram conta que por ali também pode entrar um bom lucro no resultado final, então a gente vai atuar para aumentar essa lucratividade, é óbvio, do nosso centro de negócio, atuando nessas frentes, vamos partir para o mercado, identificar quais são os possíveis clientes [...]." (P12-G)

"então o que estamos fazendo hoje, estamos identificando unidades de negócio que consideramos importantes para o hospital e definido como unidades de negócio, com gestores, uma unidade de negócio independente, esse é um projeto de muito longo prazo, [...] esse é uma coisa de longo prazo, um modelo de gestão novo, então vamos pegar nosso negócio cirurgia, ele estava em um modelo de negócio totalmente dependente, com um organograma funcional, então a farmácia tem seu organograma, o centro cirúrgico está padecendo por causa da farmácia, então centro cirúrgico você está perdoado, não é assim que funciona uma organização, então agora no centro cirúrgico estamos montando um modelo completo de gestão, informatizado, que funciona de maneira muito mais integrado, desde o agendamento, casado com o gerenciamento de leitos, casado com o consumo de materiais no centro cirúrgico, casado com programas assistências como cirurgia segura e adiante, pra que a gente consiga um modelo de funcionamento mais eficiente e trazer para o centro cirúrgico uma característica de negócio.” (P14-G) 


\subsubsection{Sistema de metas}

Um dos elementos da dimensão de mensuração do sistema de remuneração gerencial (BANKER; DATAR, 1989; GIBBS et al., 2004; VAN RINSUM, 2006; AGUIAR, 2009), os sistemas de metas estão diretamente relacionados com o planejamento estratégico, orçamento empresarial e comunicação empresarial. Na percepção dos gestores, a meta por si só é vista como a comunicação do que a diretoria espera do gestor. Os gestores comentaram sobre a motivação que possuem em alcançar metas desafiadoras, e reforçaram que os sistemas estratégicos de avaliação de desempenho facilitam o entendimento e alinhamento da meta com o objetivo do hospital.

O alcance das metas é um fator motivacional na opinião de oito gestores, que relataram a satisfação pela realização das metas estabelecidas e outros gestores entrevistados deixaram transparecer a frustração quando da não realização das metas.

Outro ponto interessante abordado pelos gestores foi o fato de todos os gestores entrevistados conhecerem suas metas organizacionais e se preocuparem com o atingimento delas, corroborando com as teorias motivacionais e de controladoria quanto aos sistemas de incentivos por metas (ABERNETHY e STOELWINDER, 1991; WEBB, 2004; GIBBS et al., 2004; DIKOLLI e VAYSMAN, 2006; AGUIAR, 2009), mas nem todos os gestores sabiam explicar o modelo de remuneração vinculado a meta, e quatro gestores não souberam comentar quanto ou se haviam recebido remuneração variável e quanto da remuneração variável está vinculado a cada meta.

Alguns ainda relataram o recebimento de remunerável variável, pois tinham atingido determinadas metas. Outro ponto levantado pelos gestores foi a diferenciação entre as metas organizacionais, que são comuns a todos e as metas específicas de cada gestor. Tais constatações corroboram com teorias alternativas de motivação que não são relacionadas aos aspectos financeiros (MCCLELLAND e LIBERMAN, 1949; BRUCHEY, 1958; FREY e STUTZER, 2002; SCORSOLINI-COMIN e SANTOS, 2010; PERRY, HONDEGHEM e WISE, 2010).

“[...] ficou abaixo [e meta] a hora que a gente vai olhar o que perdeu foram mudanças que eu não podia controlar, então se eu tivesse o mesmo cenário eu conseguiria bater a meta, mas é muito ruim ficar abaixo, ainda 
bem que não ficou menor que 2012, que não bater e ficar menor que o ano anterior é ruim, assim como não bater e ficar muito abaixo." (P1)

"então nós temos uma meta que é o sucesso do planejamento estratégico, nós temos uma ação e nós queremos saber se ela foi cumprida, executada no prazo esperado, então é um indicador nosso, acompanhamento do planejamento estratégico e o índice de sucesso do planejamento estratégico." (P6-A)

"[...] então importa sim [ter metas], todos os setores da nossa vida falam muito da capacidade de produção, os gestores precisam, que, na realidade, a produção na verdade nada mais é fazer de forma maximizada tudo aquilo que está dentro do foco com o mínimo de recursos, sem perder o foco na qualidade. Cabe a você saber caminhar nessa linha tênue entre o que é viável e o que é realizável na qualidade." (P10-G)

\subsubsection{Sistema de avaliação de resultados}

A avaliação de resultados dos gestores foi comentada pelos entrevistados em quatro diferentes situações: na avaliação formal do resultado do gestor, na avaliação informal do gestor, nas reuniões de acompanhamento com os gestores e nas reuniões de conselho das organizações. Na maioria dos casos relatados a avaliação formal era realizada uma vez por ano, tanto em formulário do departamento de Recursos Humanos, quanto em reuniões diretamente com o gestor superior.

A avaliação informal foi citada por todos os gestores ouvidos, porém com frequência variada, desde mensal quanto quadrienal, conforme cada gestor recebia o feedback de seu superior. Nos casos em que a avaliação informal possuía um prazo maior para acontecer o gestor avaliava a satisfação do gestor superior de acordo com reuniões de acompanhamento dos resultados do hospital e reuniões de trabalho.

As reuniões de acompanhamento relatadas acontecem tanto entre os gestores entrevistados e seus superiores quanto entre os gestores entrevistados e seus respectivos subordinados. Os gestores de nível 2, 3 e 4 acompanham no mínimo semanalmente as atividades de seus subordinados, com reuniões com os líderes das áreas, por sua vez, os gestores de nível 1 acompanham normalmente semanalmente com os gestores de nível 2 e mensalmente com todos os gestores. Outra prática levantada na pesquisa de campo foram as reuniões de acompanhamento semanal para gestores do mesmo nível hierárquico apresentarem seus resultados entre si e com os gestores superiores. 
Essas reuniões de acompanhamento em que todos os gestores participam foram citadas como algo positivo, na medida em que facilita a comunicação entre os setores, contudo, alguns gestores foram críticos quanto ao tempo gasto para a preparação para essas reuniões, atribuindo o consumo de tempo a dificuldade de se obter dados confiáveis, corroborando com achados em controladoria sobre a importância da avaliação de desempenho para aumentar a confiança entre gestor e subordinado (HARTMAN e SLAPNICAR, 2009).

As reuniões de conselho, representando as reuniões com os acionistas, segundo os entrevistados estas ocorrem uma vez ao mês para o acompanhamento das metas. No caso do hospital público ocorre uma vez ao trimestre a reunião do gestor com o secretário de Saúde do Estado. Segundo os relatos, em nenhum dos casos o sistema de avaliação dos resultados mensais dos setores está diretamente relacionado com a remuneração variável, apenas a avaliação anual estaria relacionada com o alcance de metas para remuneração gerencial.

Ainda assim, os gestores demonstraram uma preocupação com o atingimento das metas do período pelo qual são avaliados, o que pode corroborar com as conclusões de Aguiar (2009), que um período de avaliação com menor prazo impacta na Orientação Temporal do Gestor de curto prazo, em contrapartida foi levantado que o desenho dos indicadores e metas podem reduzir esse impacto, se considerarem efeitos de longo prazo nessa avaliação.

“[...] por isso a gente tem reuniões semanais, que participam todos os gerentes, além deles apresentarem mensalmente como estão as metas mês a mês, sempre nessas reuniões você fica sabendo o que está acontecendo $[\ldots] . "(P 1-G)$

“[...] nós temos uma reunião de sexta, temos uma reunião de gerentes e coordenadores, é uma reunião administrativa, cada um apresenta seus indicadores e temos algumas discussões sobre o que fazer ou não fazer para atingir as metas e assim por diante [...].” (P4-G)

"[...] e tem todos esses indicadores que a gente vai apresentar ao SUS, a cada três meses tem uma reunião que vai representante do $\mathrm{HC}$, representante do Estadual, Municipal, representante dos docentes, representante dos funcionários, representante dos alunos e representante da comunidade, e essa reunião é para discutir se o hospital cumpriu ou não as metas." (P8-A) 
"[...] existe uma reunião semanal com todos os gerentes, onde cada semana um apresenta seus resultados e também uma reunião semanal com a superintendência onde a gente atualiza ele sobre o que foi assumido, tudo de acordo com o planejamento estratégico, e cada coisa que eu te falei tem data." (P12-G)

\subsubsection{Indicadores de desempenho}

Esse nó representa inferências feitas pelos participantes sobre atributos dos indicadores utilizados na empresa, seja em questão de ruído, confiabilidade ou tipo de indicador, a importância ao indicador corrobora com o terceiro elemento para mensuração utilizado em sistemas de incentivo (BANKER; DATAR, 1989, AGUIAR, 2009, AGUIAR, PINHEIRO e OYADOMARI, 2014).

Os gestores comentaram da importância e dificuldade na produção de indicadores confiáveis e tempestivos, bem como a necessidade de existir tanto indicadores financeiros quanto indicadores assistenciais e operacionais. Para gestores envolvidos em projetos de longo prazo, os indicadores qualitativos também seriam interessantes, visto que os resultados quantitativos ainda não podem ser mensurados. Nesse ponto também foi levantado a necessidade mais indicadores assistenciais, no próximo tópico será tratado de sistemas estratégicos de mensuração de desempenho que visa preencher essa lacuna.

A percepção dos gestores entrevistados é que a falta de confiança e tempestividade dos indicadores faz com que eles tenham que alocar mais tempo em tarefas com resultados no curto prazo, tanto pelo desconhecimento do cenário atual, quanto pelo próprio trabalho de levantar essas informações confiavelmente. Segundo os entrevistados, trata-se de um tempo que poderia ser alocado em atividades com maior valor agregado ao paciente e ao hospital, ou seja, com resultado no longo prazo.

Tais percepções dos gestores corroboram com as pesquisas em OTG que avaliam o efeito do tipo de indicadores de desempenho na OTG e que possuem resultados conflitantes, necessitando de mais estudos na área (DIKOLLI, 2000; SLIWKA, 2002; VAN RINSUM, 2006; DIKOLLI e VAYSMAN, 2006; AGUIAR, 2009; AGUIAR e FREZATTI, 2013; ABERNETHY et al., 2013; AGUIAR, PINHEIRO E OYADOMARI, 2014) , bem como com as pesquisas em controladoria e gestão hospitalar acerca da importância e utilidade dos indicadores de desempenho para o gestor, conforme a confiança 
que o gestor possui no indicador e na força da relação causal do indicador financeiro com indicadores não financeiros (HARTMAN, 2000; MALINA e SELTO, 2001; WEBB, 2004; GIBBS et al., 2004; ROTTA, 2004; HARTMAN, 2005; HARTMAN e SLAPNICAR, 2009; CUNHA, 2011; CALDANA et al., 2011; GABRIEL et al., 2013).

“[...] esses indicadores para as áreas, como todo indicador o mais saudável para gestão é que eles estejam em cima do tempo, ou seja, para que você tenha a capacidade de ação e previsibilidade e quando você tem indicadores muito defasados no critério cronológico você tem uma dificuldade maior de ação, mesmo por que já se passaram algum tempo, e o tempo é importante para os indicadores para a ação. Precisa ter indicadores mais rápido, e que eles sejam preciso, e sejam justos no tempo, que seja coerente com o modelo de gestão de negócio." (P10-G)

"[...] por que a gente olha muito ticket, e ai quando o ticket [médio de custo por paciente] saiu muito [fora do padrão] tem que tentar entender o que caiu ali, se caiu alguma coisa errada, se gastou muito esse mês, qual medicamento gastou que subiu muito ticket [...] acontece todo dia [linha errada]. e da um trabalho ENORME, por que primeiro você olha aquilo e tem que tentar entender o que é verdade dali e o que está errado, pra depois começar analisar. [...] A semana que eu tenho que apresentar eu fico a semana toda por conta disso. então que $25 \%$ do seu tempo no mês é para relatório. é um tempinho grande, da bastante trabalho, junto com os problemas do dia a dia dessa semana." (P11-G)

"[...] ai tem os indicadores de cada uma das áreas, principalmente indicadores assistenciais. é: por exemplo na enfermaria, a gente tem indicador de queda, de flebite, de úlcera, que são indicadores assistências, e que nos ajudam também na tomada de decisão [...]” (P11-G)

"[...] então tudo sempre tem que ter o acompanhamento de indicadores, para que a gente saiba como estão indo as coisas, que a gente possa mensurar e conhecer, eu sempre falo administrar sem indicador é igual piscar no escuro, ninguém sabe que fez só você (risos), eu tenho mais dessas frases de impacto (risos), e o indicador tem que ser confiável então eu mesmo vou lá ver para ver se está acontecendo [...]" (P13-G)

“[...] tenho um indicador que olha óbito, que pode ser evitável ou inevitável, os evitáveis a gente tem que entender o porquê e trabalhar em cima, então eu faço de acordo com o OGSM, eu GOSTO do OGSM, essa ferramenta é fantástica, a minha grande briga é incluir mais a assistência, então hoje $80 \%$ dos gestores são administradores, a gente fica olhando o indicador financeiro e falta olhar indicadores de assistência, porque esse é difícil de fazer, então hoje falta indicadores assistenciais." (P13-G)

“[...] então todas as unidades tinham indicadores, tanto indicadores de estrutura, produção, produtividade, como indicadores de processo e indicadores de resultado, e indicadores financeiros, esses indicadores 
foram sendo, como eu diria, melhorado ao passar do tempo, nós começamos com relatórios gerenciais com indicadores que eram de produção e produtividade, taxa de ocupação, média de permanência, rotatividade, número de funcionários leito, a gente trabalhava indicadores econômicos eram mais receitas, despesas, e depois isso foi sendo melhorado e cada área começou a melhorar seus indicadores e trabalhar nos resultados dos indicadores para fazer ciclos de melhorias." (P15-E)

\subsubsection{Sistemas estratégicos de mensuração de desempenho}

Esse nó representa as alusões feitas pelos participantes aos sistemas estratégicos de mensuração de desempenho, tal qual o Balanced Scorecard e o OGSM. Em tese esses sistemas têm o potencial de alinhar os indicadores em diferentes níveis com os objetivos estratégicos da empresa.

Esses sistemas foram citados como benéficos para alinhar as ações dos gestores com o planejamento estratégico, fazendo com que os indicadores fiquem alinhados com a visão e missão da organização, corroborando com os pressupostos e achados de Kaplan e Norton (1996), Malina e Selto (2001), Webb (2004), Souza et al. (2012), Kang et al. (2012) e Hernaus (2012) entre outros na literatura de controladoria e gestão de processos.

Para os entrevistados, tais sistemas também poderiam estimular ações de longo prazo que favorecem a estratégia da organização, elemento de longo prazo. Os gestores ligados as áreas assistenciais, normalmente mais afastados de técnicas administrativas, foram os que mais elogiaram esses modelos, pela facilidade de acompanhar as metas financeiras com as metas não financeiras corroborando com achados de Chennal (1997), Malina e Selto (2001) e Webb (2004), DahlGaard e Pettersen (2011) e Hernaus (2012) que identificaram que os sistemas estratégicos de mensuração de desempenho eram referenciados positivamente pelas áreas operacionais e na eficiência organizacional.

"[...] a gente usa o $B S C$, a gente usa a matriz $S W O T$, e a partir disso que a gente vai construindo nossos objetivos estratégicos, de acordo com ponto forte, ponto fraco, oportunidades e ameaças e as ações a gente usa aquele $5 \mathrm{w} 2 \mathrm{~h}$, o que, quando, onde, quanto, quem." (P6-A)

"os indicadores eles são alinhados com o $O G S M$, aos objetivos institucionais e isso é cadenciado até chegar o nível operacional, então nós temos uma meta global que é crescer, que é ser um hospital de determinado jeito [...] eu quero aumentar minha demanda eu tenho que quanto menor o tempo de internação desse paciente que eu quero atender 
melhor, ai então onde entra na minha área, eu não posso errar com essa paciente." (P7-G)

"[...] é o $O G S M$, e cada setor tem o seu $K P I$, e a gente vai desenvolver os objetivos e metas financeiras e de qualidade. as metas existem de qualidade, como verificar se os pacientes estão satisfeitos com o serviço, tem outros indicadores não internos, que são externos, como a demanda, tem demandas por má prestação de serviço, ou por má resolutividade, são aspectos assistenciais, e os outros são aspectos financeiros, administrativos, são resultados da DRE, se vocês estão dentro ou fora daquilo que foi orçado e realizado." (P10-G)

“[...] tem que ter o propósito da medição, muito claro, por isso eu GOSTEI desse negócio do $O G S M$, primeiro que eu vi confesso, lá vem outra invenção administrativa, não agüento mais, [...] mas depois que eu entendi, eu trabalho com o $O G S M$ na minha frente, olho para ele todos os dias, então eu escolhi o meu $O G S M$ e como é que eu posso ajudar ele [superintendente] a fazer aquelas coisas que ele se propôs, um hospital de referência e etc, eu não vou fazer o EBITDA para ele eu vou ajudar na parte de infecção e melhorar o custo, então tudo relacionado com a segurança do paciente a gente [...].” (P13-G)

\subsubsection{Sistemas de remuneração gerencial}

Dos cinco hospitais observados na pesquisa de campo quatro possuem sistema de remuneração gerencial por desempenho. Os modelos observados e relatados pelos gestores foram remuneração por desempenho global, remuneração por desempenho individual, por $K P I s$, e remuneração mista, com o desempenho global como condicionante para a avaliação dos indicadores individuais.

Dos 15 gestores hospitalares, dois possuem remuneração variável pelo desempenho global, dois possuem remuneração variável pelo desempenho individual, seis possuem remuneração variável pelo desempenho individual condicionado pelo desempenho global e cinco não possuem remuneração variável, e destes quatro relataram não ter certeza dos critérios e metas para receber remuneração variável pelo desempenho. Apesar de conhecerem as metas individuais e da empresa, o que não souberem explicar foi como a realização das metas impactou, ou impactaria, em sua remuneração variável.

A utilização de sistema de remuneração gerencial corrobora com os achados na literatura de OTG quanto aos diferentes modelos de remuneração gerencial (NARAYANAN, 1985; MERCHANT e BRUNS, 1986; LEWELLEN et al., 1987; DEMIRAG, 1995; DECHOW e SLOAN, 1995; DIKOLLI, 2000; BHOJRAJ e LIBBY, 
2005; VAN RINSUM, 2006; MARGISON et al., 2008; AGUIAR, 2009; AGUIAR e FREZATTI, 2013; BRAUER, 2013).

A maioria dos gestores relatou considerar benéfico a remuneração por desempenho e meritocracia, ainda assim outros fatores de incentivo foram identificados. Esse nó representa a dimensão de incentivo do sistema de remuneração gerencial (BANKER; DATAR, 1989; AGUIAR, 2009), visto que os elementos da dimensão de mensuração foram tratados em nós específicos.

"[...] tem o lucro e indicadores individuais, como o gestor [...] eu tinha indicadores individuais, batia o resultado do grupo, daí entrava nos meus indicadores individuais." (P4-G)

"[...] é relacionado as metas que existem sob ponto de vista administrativo e sob o ponto de vista assistencial, nós aqui do hospital seguimos as premissas do $O G S M$ e existem os KPIs, no final das contas tem os resultados assistenciais e administrativos [...]."(P10-G)

“[...] ele [hospital] trabalha com bônus anual de até x salários, são mais 6 salários mensais, um bônus agressivo, existem objetivos macros e meus objetivos, os meus objetivos e o da instituição, então todo mundo tem que atingir para depois eu vejo se eu recebo também, então primeiro a empresa depois o meu." (P12-G)

\subsubsection{Motivação "Pró-social"}

Esse nó foi criado para agrupar os comentários dos gestores acerca de fatores motivacionais não relacionados ao sistema de remuneração variável, que foram traduzidos com motivação em bater a meta e em ajudar a instituição, corroborando com a teoria de Perry e Wise (1990).

Para esses gestores a motivação em executar as tarefas propostas nos objetivos e metas estratégicas estaria relacionada com a satisfação pessoal em atingir a meta, em ajudar a instituição a realizar o papel social de sua função. Dos entrevistados dez gestores comentaram outros fatores de incentivos não financeiros. Destes seis gestores trabalham com saúde há mais de 15 anos e apenas dois gestores trabalham em hospitais há menos de cinco anos.

A motivação "Pró-social" pode ser entendida como um fator de incentivo cognitivo, que poderia impactar na OTG conforme sua interação com outros elementos, como o 
desenho das metas, contrato do gestor e tipo de indicadores utilizados. As observações e relatos dos entrevistados corroboram com as teorias motivacionais alternativas, que incluem fatores não pecuniários (MCCLELLAND e LIBERMAN, 1949; BRUCHEY, 1958; FREY e STUTZER, 2002; SCORSOLINI-COMIN e SANTOS, 2010; PERRY, HONDEGHEM e WISE, 2010).

“[...] então em 2013 a gente começou a trabalhar a gente se preocupa mais em bater a meta pela meta do que pela remuneração, tanto que eu nem sabia qual era a regra, eu acho que a gente olha mais para a realização do que, do que para a remuneração financeira, porque senão, estou fazendo o raciocínio agora, com certeza eu saberia quanto eu iria ganhar financeiramente, mas eu não sei nem quantos salários, eu só olhei o lado da entrega, o lado da empresa e também da realização pessoal." (P1-G)

"conheço sim [sistema de remuneração], mas eu não preciso disso para me motivar, claro que para a maioria das pessoas é fantástico, com certeza é bom ter uma remuneração variável, eu falo que eu não preciso disso porque eu estou numa área nova e quero aprender muito por isso que eu to motivado, eu estou aprendendo também, eu considero do ponto de vista de as pessoas estarem felizes onde estão, eu vi isso do ... do cara do ... presidente da GE, ele fala que é o tripé, salário, conhecimento e ambiente de trabalho, o salário é o variável, o que eu ganho é o que eu sei, eu mereço, eu fico feliz, o que eu to conhecendo aqui, adquirindo conhecimento e ambiente de trabalho, então tem que estar equilibrado, então se dois estiverem ruim, está ruim, se dois estão bons um está ruim, o cara está mais ou menos, mas o ideal é estar os três equilibrado, apesar de eu obviamente gostaria de ter um ... todo mundo gostaria de ter uma remuneração variável por desempenho, meritocracia, é legal né, é o ser humano, quando você ganha não é só dinheiro, quando você ganha você fica feliz que bateu suas metas, tem reconhecimento também, qualquer um, não é só a grana, tem o fator motivacional, emocional [...].” (P2-G)

"[...] então hoje se não bater as metas é uma perda para a instituição, individualmente a pessoa vai ficar chateado por não bater a meta, e batendo a meta agente consegue ajudar, desenvolver o hospital porque tudo o que está no planejamento estratégico é para desenvolver o hospital, são melhorias, então o que motiva o pessoal é saber que está ajudando a instituição, com modernização, tecnologia, e tem também a cobrança do superintendente né, $[. .$.$] a gente tem que dar uma satisfação, acho que é a$ responsabilidade de cada um." (P6-A)

“[...] é a visão macro, o que é melhor para a empresa e assistência, é preciso laborar, trabalhar, promover, é um modelo no qual as pessoas fiquem satisfeitas, como você trabalha, como você é remunerado, que as metas sejam claras, por qual motivo você é cobrado, é TRANSPARENTE, eles sabem as metas setoriais, é um modelo que envolve avaliação de performance, para alcançar o resultado, resultado o pessoal pensa em cifrão, não é só financeiro, é assistencial também, 
qualitativo, as duas coisas, a assistência também é quantitativa, não é só qualidade, então o gestor tem que conciliar, o que a empresa espera dele e como ela avalia seu trabalho, então um modelo de trabalho por competência, mérito, meritocracia[...]." (P10-G)

“[...] eu tenho [remuneração variável] Diego, mas para ser sincera nem sei como que é, nem ligo muito, eu sei que eu tenho, eu ganho se o grupo ganhar e quando bato minhas metas. [...] não sei [se recebeu a remuneração variável], e não sei mesmo, para você ver chega um ponto que o que importa mais é o trabalho, é a motivação em fazer, em fazer os projetos andarem que a gente nem se preocupa muito com a remuneração, tanto que eu nem sei se ganhei esse ano e nem como eles me avaliaram, eu já passei por avaliações aqui, mas para ser sincera, esse ano nem sei como foi e nem como eu fui ou vou ser avaliada para receber a remuneração variável, acho que fazer parte de uma instituição assim, o trabalho que a gente desenvolve já é tão estimulante que a questão financeira em si não é tão importante, não estou falando que eu não ligo para dinheiro, dinheiro comprou muitas coisas para minha vida pessoal, ajudou a criar meus filhos e colocá-los na faculdade, mas agora já o salário bom a remuneração variável não me preocupo tanto, tanto que nem procurei saber como fui, o que me motiva mais é o trabalho em si, é conseguir fazer minha parte para o hospital atingir suas metas." (P13-G)

\subsubsection{Miopia de horizonte}

A miopia de horizonte é definida na literatura como a dificuldade de visualizar os impactos no longo prazo das ações atuais (LAVERTY, 2004; AGUIAR, 2011). Esse nó apresenta os casos em que o gestor não conseguiu definir claramente as ações de longo e curto prazo que realiza. A partir da pesquisa de campo, pode-se observar que três gestores não conseguiram definir claramente o horizonte de suas as ações. Outros três gestores que conseguiram definir quais eram as ações com resultado de longo prazo e curto prazo não conseguiram definir se confundiram ao tentar exemplificar tais o resultado de algumas ações.

Outros quatro gestores comentaram de ações que impactam tanto no resultado de longo quanto de curto prazo, dado que na percepção deles em alguns casos os resultados de longo prazo seriam decorrentes da solução de uma demanda de resultados de curto prazo.

“[...] não dá para te falar Diego porque é muito variável sabe, você está com uma série de situações ocorrendo, e daí você vai ver você só está lidando com tarefas de curto prazo, ai você resolve aquilo, fica acalmado, e você se concentra, se dedica em tarefas de médio e longo prazo. então eu procuro gastar pelo menos metade do meu tempo pra ... pra... vamos 
falar de uma forma informal pra não ficar só apagando incêndio, então é uma disciplina que eu tento ter, o que que eu faço, eu reservo tempo para reflexões, eu reservo, eu organizo meu tempo para que eu consiga fazer coisas além de ficar apagando incêndio, apesar que quando apaga incêndio a gente vai na causa raiz a gente tem diversas oportunidades de corrigir nossos processos e as vezes isso gera uma demanda de médio e longo prazo." (P4-G)

"agora quantificar quanto do tempo eu gasto com relacionamento com operadora e cliente não é algo que dá para fazer para você, é decorrente do dia a dia, mas eu mantenho interface com a operadora, interface com o médico, interface com o corpo de enfermagem, com serviços de apoio do hospital, logística, é isso tudo o que o diretor faz, são todos os dias, é todo o tempo. Existem as coisas programadas, que estão dentro da agenda, onde eu colaboro com a minha... minha capacidade técnica, e o resto são coisas que aparecem, são inter ocorrências do dia a dia.” (P10-G)

\subsubsection{Atividades com efeitos no curto prazo}

Esse nó foi criado para agrupar as atividades, que refletem os resultados de curto prazo, levantadas pelos gestores. Assim as atividades de curto prazo descritas com maior frequência foram: os problemas operacionais e rotineiros relacionados ao atendimento e assistência, gestão com funcionários, conflitos internos entre setores e burocracia com operadora, além das reuniões para esses fins.

“[...] de curto prazo a gente tem o $E A G I^{13}$, então o que eu fiz para manter a sustentabilidade do projeto com melhorias de curto prazo a gente tem o GAMBÁ MICHI, que são reuniões curtas com todas as áreas do hospital, a gente coloca indicadores." (P2-G)

“[...] então logo que eu cheguei tinham muitas pendências então eu identifique o que fazer para dar vazão nessas pendências, muitas delas era por falta de / ah ta parado, era só por isso, então ia lá e atuava para poder resolver e continuar, daí começou a surgir pendências maiores [...] então isso ai acaba demandando tempo de mim mais para a operação, um cronograma pra resolução de atividade. (P5-G)

“[...] infelizmente a maior parte do tempo é já resolvendo problemas operacionais, uns $50 \%$ do tempo, mais em reunião,que ATRAPALHA bastante!" (P11-G)

\footnotetext{
${ }^{13}$ EAGI e GAMBÁ MICHI são conceitos do Lean Model, o primeiro relacionado a projetos menores de curto prazo e específicos de processos de cada área e o segundo relacionada a reuniões específicas com os setores vinculados a determinado processo.
} 
"[...] agora aquelas questões do dia a dia que é recrutamento, seleção, lidar com o pessoal, lidar com aquelas ocorrências que são mais do dia a dia você vê o resultado imediato [...] seguramente $90 \%$ tarefas de curto prazo, que precisavam ser resolvidas imediatamente, [...] basicamente conflitos, conflitos da equipe, conflitos da equipe com outra equipe médica, com outras unidades do hospital, problemas com paciente, com família, com estrutura, falta de estrutura, falta de leito, falta de equipamento, eu acho que uma coisa que a gente não conseguia controlar que era complicado [...]." (P15-E)

\subsubsection{Atividades com efeitos no longo prazo}

Esse nó foi criado para agrupar as atividades que refletem os resultados de longo prazo levantadas pelos gestores. Segundo os entrevistados, tais atividades normalmente estariam relacionadas aos objetivos estratégicos da empresa, às mudanças nos processos e estruturas de negócio, assim como treinamentos, análise e mapeamentos, tanto assistenciais quanto de áreas de apoio e administrativas.

"[...] é de longo prazo [foco do gestor], os macro processos, os treinamentos, 1 ano, 2 anos, demora um certo tempo, uns $70 \%$ é médio e longo prazo, e ter o resultado no processo e ter o resultado financeiro, que demora, é o aumento de produtividade natural, o turnover ao longo do tempo você não precisa repor, então $20 \%$ é o tempo que a pessoa fazia que agregava valor, daí o turnover natural você o não vai substituindo em alguns processo, vai ganhando produtividade naturalmente, o lean é um projeto de médio a longo prazo, de 3 a 4 anos para enraizar, tem uma equipe, patrocínio, fazendo acontecer, não é uma pessoa só [...].” (P2-G)

“[...] o que demanda mais são os novos projetos, eu acabo discutindo muito com novos projetos, a gente fala novos projetos, mas eu tenho um projeto que é a ampliação de um setor [...] nós estamos implantando um hospital novo, tem horas que tem problemas de obra, tem que interdita a rua atrapalha a rotina do resíduo, da engenharia, então a gente faz essa interface quando a obra tem algum impacto no andamento normal do hospital, assim como nós fizemos toda a previsão de quadro de funcionários, toda previsão de compra de novos equipamentos para equipar esse hospital, a previsão de material de consumo para atender as operações nesse prédio novo e botar para funcionar, toda estratégia de funcionamento, fluxo de paciente, por onde entra o paciente, por onde não entra, se o paciente vai ser regulado da rede, se não vai ser regulado da rede [...] então é o planejamento e o acompanhamento, então a gente planeja e coloca para funcionar, entendeu? a gente não só faz o plano a gente implanta, a implantação é nossa, depois é a área." (P6-A) 
"[...] hoje eu não consigo mudar no curto prazo, esse projeto de conscientização, [...] é um trabalho de conscientização, eu conto uma vez por mês, e demora essa mudança, é ao longo prazo [...].” (P9-G)

“[...] então você tem um ambiente muito vasto para explorar, então depois que você entra nesse terreno, então foi muito motivador porque eu participei de todo o processo de identificação do nosso cenário atual né, e ... a partir daí a gente teria que estudar qual é o futuro do segmento e como nós estamos posicionados em relação ao que o segmento é hoje e para onde ele está indo, e aí onde está a oportunidade que eu te falei que me motivou muito, porque a partir daí você passa a ter que estudar os concorrentes, etc e tal, e a gente acaba que deixa de ser uma unidade de negócio mais interna e passa a virar uma unidade de negócio independente a médio e longo prazo." (P12-G)

"[...] tem a melhoria contínua, essa é uma área que tem valorizado dentro do hospital, então eu tenho reuniões periódicas com ele, essa é uma área que a gente vai executando transformações no hospital, para que a gente tenha um hospital melhor, mais eficiente no futuro [...]." (P14-G)

“[...] processos e estrutura [são de longo prazo], essas mudanças estruturais que estamos fazendo de unidades de negócio, reestruturação, não é só processos, é estrutura também, de mudança de objetivos, de pessoas, mudança de cultura em relação a cada uma dessas unidades, esse é um projeto que eu particularmente me envolvo bastante, mas tem outros, hoje na área comercial tem um projeto para mudar o perfil dos pacientes que a gente atende [...] então são mudanças de longo prazo e importantes, não acontecem do dia para a noite, são resultado de ações bem organizadas, estruturadas casadas para que a gente vá dando aos hospitais a característica que é eficiente nisso ou eficiente naquilo, até que a população se informe e tenha isso bem consolidado são anos a fio." (P14G)

"[...] na verdade o que a gente vê o resultado lá na frente, é quando você trabalha na reestruturação de um processo, então implementação de pacote, é um novo protocolo ou vários novos protocolos, um novo processo, como programa de qualidade, fazer avaliação de complexidade assistencial nos pacientes, isso é uma nova tecnologia, isso é mais a médio e longo prazo." (P15-E)

\subsubsection{Orientação Temporal do Gestor (OTG)}

No presente estudo foi realizado um levantamento da percepção dos gestores acerca da própria OTG, com base no critério do momento de ocorrência dos benefícios decorrente 
dessas escolhas (AGUIAR, 2011). Assim a avaliação do critério da consistência das escolhas intertemporais dos gestores não fez parte do escopo dessa pesquisa.

Os gestores foram solicitados a, primeiramente, apontar as atividades que realizam. Depois quanto tempo (em termos percentuais) dedicam a cada atividade, em seguida a apontar quais atividades impactariam no resultado de curto ou longo prazo. E em momento posterior da entrevista foi solicitado aos gestores que apontassem qual a percepção deles acerca do tempo que se dedicam em tarefas que impactariam o resultado de curto prazo e tarefas que impactariam no resultado de longo prazo (em termos percentuais). A tabela 5 sintetiza os resultados desses apontamentos.

Tabela 5: Percepção da OTG pelos Gestores.

\begin{tabular}{lllrrl}
\hline COD & SETOR & FORMAÇÃO & \multicolumn{1}{c}{ OTG CP } & OTG LP & Definiu OTG? \\
\hline P1 & Administrativo & Saúde & $60 \%$ & $40 \%$ & Tarefas \\
\hline P2-G & Administrativo & Outros & $20 \%$ & $80 \%$ & Sim \\
\hline P3-G & Administrativo & Saúde & $70 \%$ & $30 \%$ & Não \\
P4-G & Apoio & Negócios & $60 \%$ & $40 \%$ & Não \\
P5-G & Apoio & Outros & $70 \%$ & $30 \%$ & Tarefas \\
P6-A & Administrativo & Outros & $30 \%$ & $70 \%$ & Sim \\
P7-G & Apoio & Saúde & $50 \%$ & $50 \%$ & Sim \\
P8-A & Administrativo & Negócios & $30 \%$ & $70 \%$ & Sim \\
P9-G & Apoio & Outros & $60 \%$ & $40 \%$ & Tarefas \\
P10-G & Assistencial & Saúde & $50 \%$ & $50 \%$ & Não \\
\hline P11-G & Assistencial & Saúde & $70 \%$ & $30 \%$ & Sim \\
P12-G & Assistencial & Negócios & $20 \%$ & $80 \%$ & Tarefas \\
P13-G & Assistencial & Saúde & $20 \%$ & $80 \%$ & Tarefas \\
P14-G & Geral & Negócios & $50 \%$ & $50 \%$ & Tarefas \\
P15-E & Geral & Saúde & $90 \%$ & $10 \%$ & Sim \\
\hline
\end{tabular}

Fonte: Elaborado pelo autor.

Acompanhando a tabela 5, pode-se observa que dos 15 gestores hospitalares entrevistados, sete gestores pontuaram diretamente qual sua percepção de tempo gasto com atividades com resultado de longo prazo e de curto prazo. E essa percepção foi corroborada com o tempo alocado para as tarefas que o gestor pontuou que realiza e o resultado dessas tarefas ao longo do tempo (também definido pelo próprio gestor).

Outros cinco gestores pontuaram o tempo alocado para as atividades que realizam e o efeito dessas tarefas no resultado ao longo do tempo, mas quando solicitados a pontuar o 
tempo gasto em tarefas no curto e longo prazo diretamente argumentaram que não era possível quantificar quanto impactaria no resultado do longo prazo e quanto impactaria no resultado do curto prazo.

Ainda assim classificaram quais eram as atividades de curto e longo prazo e quanto tempo dedicam a cada tarefa. Segundo eles a dificuldade estaria associada ao fato de que determinadas tarefas potencialmente impactariam tanto no curto quanto no longo prazo. Reforçaram o argumento de que em determinados momentos o gestor era mais exigido pelos resultados de curto ou longo prazo, conforme as necessidades atuais e os projetos em andamento, tais resultados corroboram com a multidimensionalidade proposta por Aguiar (2011) e pela necessidade de avaliar as causas de OTG sob diferentes perspectivas (LAVERTY, 1996).

Por fim três gestores não definiram quanto tempo alocam em tarefas que impactariam no curto ou longo prazo e nem conseguiram definir claramente quais tarefas eram de curto ou longo prazo. Na tabela 5 a percepção da OTG desses três gestores foi avaliada por todo o discurso e os exemplos dados, se eram relacionadas com resultados de curto ou longo prazo.

Assim, em uma avaliação geral dos entrevistados, na média $49 \%$ do tempo estaria alocado em tarefas com efeito no curto prazo, enquanto $51 \%$ do tempo alocado em tarefas com efeitos no longo prazo.

Ainda assim, existe variabilidade, dado que entre os gestores com formação de saúde, por exemplo, em um extremo um participante definiu que alocava $90 \%$ para atividades de curto prazo, enquanto outro participante, de função e hierarquia próxima, alocava $80 \%$ do tempo para atividades de longo prazo, o mesmo ocorreu quando os resultados foram entre gestores com outras formações acadêmicas ou por departamento.

A seguir apresentamos as percepções de OTG dos gestores segmentadas por formação acadêmica, departamento de atuação, tempo de atuação como gestor e tempo de atuação no setor de saúde. Em seguida das tabelas estão às percepções colhidas na pesquisa de campo. 
Tabela 6: Percepção de OTG dos gestores entrevistados por Formação Acadêmica

\begin{tabular}{clcc}
\hline Qtde $^{14}$ & Formação & CP & LP \\
\hline 4 & Outros & $45,0 \%$ & $55,0 \%$ \\
4 & Negócios & $35,0 \%$ & $65,0 \%$ \\
7 & Saúde & $58,6 \%$ & $41,4 \%$ \\
\hline
\end{tabular}

Fonte: Elaborado pelo autor

Tabela 7: Percepção de OTG dos gestores entrevistados por Departamento de Atuação

\begin{tabular}{clcc}
\hline Qtde & Departamento & CP & LP \\
\hline 4 & Assistencial & $40,0 \%$ & $60,0 \%$ \\
4 & Apoio & $60,0 \%$ & $40,0 \%$ \\
5 & Administrativo & $42,0 \%$ & $58,0 \%$ \\
2 & Geral & $60,0 \%$ & $40,0 \%$ \\
\hline
\end{tabular}

Fonte: Elaborado pelo autor

Tabela 8: Percepção de OTG dos gestores entrevistados por tempo de trabalho como gestor

\begin{tabular}{clrc}
\hline Qtde & Tempo de trabalho como gestor & CP & LP \\
\hline 4 & 0 a 5 anos & $52,5 \%$ & $47,5 \%$ \\
4 & 5 a 10 anos & $42,5 \%$ & $57,5 \%$ \\
2 & 10 a 15 anos & $55,0 \%$ & $45,0 \%$ \\
2 & 15 a 20 anos & $80,0 \%$ & $20,0 \%$ \\
3 & acima de 20 anos & $26,7 \%$ & $73,3 \%$ \\
\hline
\end{tabular}

Fonte: Elaborado pelo autor

Tabela 9: Percepção de OTG dos gestores entrevistados por experiência no setor de saúde

\begin{tabular}{clcc}
\hline Qtde & Experiência em saúde & CP & LP \\
\hline 4 & 0 a 5 anos & $52,5 \%$ & $47,5 \%$ \\
2 & 5 a 10 anos & $45,0 \%$ & $55,0 \%$ \\
0 & 10 a 15 anos & - & - \\
2 & 15 a 20 anos & $40,0 \%$ & $60,0 \%$ \\
6 & acima de 20 anos & $50,0 \%$ & $50,0 \%$ \\
\hline
\end{tabular}

Fonte: Elaborado pelo autor

"eu gasto metade, não, meu tempo é dividido em três, uma parte é de preparo [...] outro pedaço eu vou negociar [...] no outro pedaço eu vou planejar o que está acontecendo, então meu tempo é dividido em três, então é como se fosse o campo, o que está fazendo, o outro o operacional, preparo do que vai fazer e outro é o planejamento, o que está acontecendo,

\footnotetext{
14“Qtde" nas tabelas 6, 7, 8 e 9,se referente a quantidade de gestores em cada classificação.
} 
como é que vai ser o mês que vem, eu acho que é dividido em três, operação, realização e planejamento.”(P1-G)

"eu posso te dizer que uma noção assim $30 \%$ é para o curto prazo e $70 \%$ eu trabalho com ações de longo prazo, até uns $80 \%$ eu não sei te precisar, até porque é pelo o que eu respondo, a minha cobrança do superintendente é isso, ele me cobra ações de longo prazo." (P6-A)

"Os meus [resultados] são de longo prazo, a cada 6 meses eu tenho um grande projeto, mas eu diria que é 50\% do tempo para longo prazo e 50\% para demandas do dia a dia." (P7-G)

"nós temos outros projetos, que são os projetos de grande transformação, aonde nós fazemos uma revisão do processo e a partir da revisão do processo nós vamos fazer algumas alterações estruturais, então são projetos de longo prazo, o ponto todo é que eu não dedico um tempo maior ou menor para um projeto de longo prazo, é que eu dedico o tempo conforme a aderência do projeto dentro dos objetivos que foram traçados para o ano, então se nós temos o objetivo de um ganho de produtividade no corpo de enfermagem, abrimos um projeto dessa natureza, do tipo vamos estudar as atividades que agregam valor dentro do tempo que a enfermagem vem despendendo, ou vamos criar um mecanismo de gerenciamento de tempo para a enfermagem, um projeto como esse que se está dentro do objetivo eu estou mais dentro de desempenhá-lo, mesmo que seja um projeto de longa duração, que necessite informática, coisas desse tipo, mas eu dedico conforme os objetivos, eu tento dar uma ordenação nos projetos a partir daí." (P14-G)

\subsection{Análise dos Participantes}

Após a categorização e codificação dos dados coletados na pesquisa de campo a análise dos resultados passou a associar cada caso (participante) com os nós (eixos temáticos) abordados e construir um perfil sobre as atividades que impactariam no processo decisório do gestor e, por consequência, sua orientação temporal. Para tanto, segue uma descrição detalhada da percepção de cada participante acerca dos eixos temáticos.

\subsubsection{Participante P1-G}

$\mathrm{O}$ gestor $\mathrm{P} 1-\mathrm{G}$ percebe que seu comprometimento com as metas estratégicas é influenciado por fatores extras financeiros, tal qual a satisfação pessoal e o fato de participar da melhoria da instituição. Esse gestor possui mais de 25 anos de experiência no setor de saúde, assim como no hospital em que trabalha atualmente. E essa experiência em 
diferentes processos dentro do hospital resultou ao gestor uma percepção de entendimento de todo o processo.

Em tese, sua função exige demandas constantes com as operadoras de saúde o que impacta diretamente em resultados de curto prazo em sua maioria, como negociação e constante relacionamento político e comercial, ainda que em determinadas ações com as operadoras determinem resultados de longo prazo, como preparação de novas formas de negociação.

O sistema de metas, indicadores de desempenho e reuniões de avaliação semanais com todos os gestores foram pontos citados como benéficos para a gestão e próprio trabalho do gestor. A percepção do gestor é que sua OTG é definida pela função organizacional que desempenha, ou seja, o desenho do contrato, assim como por fatores cognitivos relacionados à satisfação pessoal e responsabilidade social em atingir a meta, e com o sistema estratégico de mensuração de desempenho estar alinhado com o planejamento estratégico da empresa.

\subsubsection{Participante P2-G}

O participante P2-G demonstrou forte influência da gestão de processos na Orientação Temporal do Gestor de longo prazo, assim como o alinhamento entre Planejamento Estratégico e os indicadores de área e o tempo dedicado a treinamentos e cursos. O desenho do contrato do gestor também é um fator relevante na OTG do mesmo, que é focado nos resultados de longo prazo.

O comprometimento desse gestor com a meta também parece estar relacionada aos ganhos não pecuniários. Este gestor possui menor experiência em instituições de saúde e aparentemente sua motivação estaria relacionada aos ganhos potenciais de experiência e conhecimento, tanto que nem souber explicar como eram os critérios para a sua remuneração variável. Por outro lado, conhece as metas que deveria atingir e sabe que possui remuneração variável.

Esse participante também comentou que não concorda com a importância dada nas incertezas de ambiente e de tarefa sobre a OTG de curto prazo dos gestores hospitalares. Existe também a percepção que a gestão por processos e a utilização de sistemas 
estratégicos de mensuração de desempenho impactam na comunicação do planejamento estratégico e o comprometimento com metas.

\subsubsection{Participante P3-G}

O participante P3-G possui experiência relevante na gestão em saúde, passando por diferentes setores, destacou a importância dos treinamentos e gestão de pessoas na mudança cultural e no ganho de eficiência no curto e longo prazo. Também argumentou que o tempo despendido nas relações com as operadoras de saúde tomam bastante tempo para resolução de questões operacionais do "dia-a-dia", relacionadas a autorizações, guias, auditoria médica entre outros.

Esse gestor foi um dos poucos gestores que não possuía expectativas positivas quanto sua permanência no hospital, dado principalmente falta de oportunidades e divergências em relação ao seu superior direto. O gestor também demonstrou insatisfação com o sistema de informática, argumentando que é complexo e pouco funcional em termo de interface.

Esse gestor também elogiou o uso de sistemas estratégicos de mensuração de desempenho como ferramenta para aproximar os objetivos estratégicos aos objetivos específicos e alinhá-los com os processos hospitalares. Esse gestor fez uso durante sua explicação de apresentações e dados para demonstrar as tarefas realizadas e os resultados alcançados.

\subsubsection{Participante P4-G}

O participante $\mathrm{P} 4-\mathrm{G}$ apresentou dificuldade em definir as tarefas realizadas diariamente, assim como em definir quais eram as ações de longo e curto prazo. A análise de seu discurso evidenciou que a incerteza de tarefa poderia impactar na orientação temporal de curto prazo, conforme as atividades descritas pelo gestor, sobretudo aquelas com foco na resolução de problemas e reuniões.

A incerteza do ambiente também foi um fator levantado como impactante na rotina de trabalho do gestor, dado que segundo seus relatos atrapalha na definição ações de longo prazo. Para minimizar isso o gestor relatou que procura realizar semanalmente reuniões 
para definir ações de médio e longo prazo. A relação com operadoras de saúde também foi comentada como um ponto que impactaria em suas atividades diárias.

O gestor soube definir satisfatoriamente como eram suas metas e sua remuneração variável, denotando que o incentivo financeiro seria um fator relevante. $\mathrm{O}$ cumprimento de metas e a gestão de pessoas e conflitos internos também foram pontos levantados pelo gestor. O modelo de gestão e as mudanças culturais e estruturais foram apontados pelo gestor como tarefas que potencialmente impactariam no longo prazo.

\subsubsection{Participante P5-G}

O gestor P5-G possui pouco tempo de experiência no setor hospitalar e sua percepção é que a responsabilidade é maior nas tarefas, devido o valor da vida e o papel que cada gestor em um hospital representa para cada paciente, denotando o impacto da atividade sobre a responsabilidade e comprometimento do gestor.

O pouco de tempo de trabalho na área e no hospital foi um fator relevante que impactou na realização de tarefas com resultados de curto prazo, pois o gestor foca na resolução de problemas de curto prazo, dado que ainda está na fase de levantamento das rotinas e situações para as quais precisa fazer ações de longo prazo.

Assim, apesar de atualmente o gestor dedicar mais tempo em tarefas que geram resultados de curto prazo aparentemente o mesmo está estruturando o setor de sua responsabilidade para que possa focar também em tarefas que resultam no longo prazo, denotando que apesar do gestor atualmente focar em atividades de curto prazo, o mesmo já estuda como aumentar o tempo disponível para alocar a tarefas de longo prazo.

O gestor comentou recorrentemente sobre os indicadores que utiliza, explicando o significado de cada um deles e como eles ajudam a mensurar como seu trabalho impacta nas atividades de outros setores e no próprio atendimento assistencial. Como não possui remuneração variável sua motivação em atingir a meta foi relacionada com a função que exerce e a importância no processo assistencial. 


\subsubsection{Participante P6-A}

O participante P6-A percebe a instituição de saúde com particularidades que, em tese, impactariam diretamente na OTG de curto prazo, como a incerteza do ambiente e da tarefa. Entretanto percebe sua OTG como de longo prazo, derivada do desenho de seu contrato como gestor e das responsabilidades que lhe foram atribuídas.

Esse gestor foi um dos que relacionou o comprometimento com as metas com fatores cognitivos, como fazer parte de uma instituição com a responsabilidade social que tem, ele possui mais de 25 anos de experiência no setor de saúde, todos no mesmo hospital.

Os indicadores de desempenho, sistemas estratégicos de mensuração de desempenho e a comunicação da estratégia também foram fatores levantados por esse gestor, tratados como relevantes para resultados de longo prazo.

Dentre as dificuldades apontadas para o alcance dos objetivos foi relatada a dificuldade de comunicação da estratégia e a dificuldade de comunicação com o corpo clínico. Esse gestor também comentou sobre o Sistema Único de Saúde (SUS) e a dificuldade de financiamento para determinados procedimentos.

\subsubsection{Participante P7-G}

O participante P7-G é um gestor de área de apoio cuja percepção é que suas tarefas são equilibradas para resultados no curto e longo prazo. As tarefas de curto prazo são para resolução de problemas assistências e de processos pontuais, ao passo que essas necessidades geram projetos de melhoria par ao longo prazo.

O gestor tratou do treinamento, do sistema estratégico de mensuração de desempenho e do sistema de informação como fatores que impactariam no resultado de longo prazo, assim como o processo de implantação de gestão de qualidade e programas de qualidade. No mapeamento das necessidades de recursos e do perfil assistencial do hospital também foram citadas como tarefas que impactam no resultado de longo prazo.

Quanto ao relacionamento com operadoras o gestor também percebe que esse relacionamento orienta suas ações para o curto prazo, ao passo que se preocupa com a situação de atendimentos assistenciais, suas guias, autorizações e auditoria médica do momento atual. 


\subsubsection{Participante P8-A}

O participante P8-A demonstrou entender que os indicadores de desempenho e o alinhamento com o planejamento estratégico são fatores importantes para a gestão, sua OTG também é percebida como de longo prazo pelo desenho do contrato, ao passo que suas tarefas estão alinhadas com os objetivos do setor e cargo que ocupa.

Sua motivação, a priori, não estaria relacionada com incentivos financeiros e sim com o fato de estar em uma instituição da importância que o hospital em que trabalha. Os fatores do sistema de remuneração gerencial, como as metas, as medidas e o período de avaliação aparentemente afetariam a OTG desse gestor, conforme o alinhamento dos mesmos com o planejamento estratégico.

\subsubsection{Participante P9-G}

Esse gestor é pouco experiente em cargos de liderança, dado sua pouca experiência de trabalho e idade. Esses fatores parecem influenciar diretamente na expectativa do gestor quanto sua permanência no hospital. Pode-se observar que este gestor não possui expectativa de permanência no hospital no longo prazo.

Em contrapartida a falta de expectativa de longo prazo nesse hospital o gestor realiza tarefas de longo prazo, como foco de aumentar o resultado da empresa conforme os objetivos estratégicos passados para ele. O gestor atualmente se motiva no cargo e no atingimento das metas como decorrência das novas responsabilidades que está assumindo, sobretudo por ser responsável pela condução de um projeto de grande impacto na estratégia de longo prazo.

Essa constatação pode indicar que o desenho do contrato para ações que possuem impacto duradouro e de longo prazo motivaria os gestores em suas funções de forma mais consistente que em funções cujo resultado é breve, de curto prazo ou que eventualmente não tenha pressuposto de continuidade.

Esse gestor também ressaltou a importância do acompanhamento ao paciente (e familiares), da conciliação do atendimento assistencial e do atendimento ao cliente nas atividades de suporte, tais como hotelaria e nutrição. Houve relato pelo gestor de um projeto para melhorias nos processos de atendimento ao paciente. 


\subsubsection{Participante P10-G}

A gestão de pessoas foi o elemento mais comentado pelo gestor P10-G. Deu ênfase para a questão epidemiológica, sugerindo a ausência de controle do hospital nesse tópico. Também deu ênfase para o sistema estratégico de mensuração de desempenho. Quanto aos dilemas que o gestor convive, pontuou o "sofrimento intelectual" entre a estratégia viável no longo prazo e suas premissas e a operacionalização desta estratégia, com o desenvolvimento, mudança cultural e gestão com pessoas.

As principais tarefas no hospital relatadas estariam relacionadas com a interlocução com o corpo clínico e com as operadoras. Comentou sobre o planejamento terapêutico, com foco no atendimento, e da necessidade de um modelo assistencial consistente em seus objetivos. Segundo o gestor se a base de tudo é o capital humano, então seria relevante qualificar o pessoal, sempre com foco na melhoria contínua.

Explicou a diferença entre objetivos da instituição hospital e da instituição operadora. Segundo P10-G a operadora busca controlar o sinistro e o hospital a assistência, contudo enfatizou que depende do modelo de negócio adotado entre hospital e operadora, que se bem desenhado poderia impactar em resultados de longo prazo.

Outro elemento tratado foi a importância de indicadores precisos e justos no tempo, assim como indicadores financeiros e não financeiros, que aliados a expertise do gestor levariam as melhores decisões. Quanto aos incentivos foi um dos gestores que deu maior importância para fatores assistenciais e pessoais que a remuneração pecuniária.

\subsubsection{Participante P11-G}

Trata-se de um gestor assistencial, cuja maior parte do tempo é dedicada a tarefas de curto prazo, por causa das demandas assistenciais e incerteza do ambiente. Ainda assim argumenta que a incerteza não se refere ao que vai acontecer e sim quando vai acontecer e em qual volume. Para o participante $\mathrm{P} 11-\mathrm{G}$ os problemas recorrentes estariam relacionados a materiais e insumos, postos de internação e hotelaria, central de materiais esterilizados e pronto atendimento e emergência. As soluções poderiam ser diversas, denotando uma incerteza de tarefa, decorrente da evolução do quadro clínico do paciente. 
Quando tratou dos indicadores o participante se mostrou incomodado pela demora das informações financeiras e também pelos erros de informações, denotando a necessidade de confiabilidade e tempestividade das informações contábeis. Utiliza mais indicadores assistenciais, assim como ferramentas de dimensionamento e planejamento terapêutico. E destacou o uso do sistema estratégico de mensuração de desempenho como ferramenta que facilitaria o alinhamento entre de objetivos e metas estratégicas.

Em relação às operadoras de saúde, para o gestor os processos de autorização e auditoria médica, que são questões operacionais, demandam tempo considerável de sua atuação. Sugere a necessidade de criação de procedimentos padrões para tratar interações entre o hospital e a operadora, sobretudo para os problemas rotineiros, como forma de reduzir o tempo despendido pelo gestor com essas situações e propiciar maior autonomia aos subordinados.

Conhece o sistema de remuneração gerencial por desempenho e sabe quais são suas metas. Ainda deu ênfase que a remuneração variável que estaria relacionada ao resultado do grupo e não aos indicadores individuais. Para o P11-G, o atingimento de metas dos indicadores individuais estariam relacionados a função organizacional de sua posição, assim como a satisfação pessoal e em realizar um serviço assistencial adequado.

\subsubsection{Participante P12-G}

O gestor P12-G tem a percepção de possuir uma OTG de longo prazo, sugestionado por ele como sendo uma característica pessoal o envolvimento em projetos de longo prazo, reforçado ao descrever que em carreira que vem sendo construída em diferentes instituições, de forma vinculada aos projetos de longo prazo. Segundo os relatos do gestor foi a proposta de implantar um novo modelo de gestão em uma área assistencial que o motivou a aceitar o emprego atual, de maneira que, em tese, a OTG desse gestor estaria relacionada tanto a fatores cognitivos quanto ao desenho do contrato.

O gestor possui em torno de 10 anos de experiência no setor de saúde e menos de seis meses no cargo atual, demonstrou a utilização de indicadores de desempenho e projetos ao longo de seu discurso, denotando um uso recorrente dessas ferramentas, também elogiou o uso do sistema estratégico de mensuração de desempenho. A gestão de processos foi um 
tema constante no discurso desse gestor, sempre relacionando os processos com os resultados de longo prazo. A necessidade de gerir (e compreender) os processos foi relatada como benéfico para a melhoria contínua e a sustentação dos resultados ao longo do tempo.

\subsubsection{Participante P13-G}

O participante $\mathrm{P} 13-\mathrm{G}$ tem três posicionamentos de destaque relacionados à gestão hospitalar, o primeiro foi quanto à importância dos indicadores para gestão, a importância de se medir confiavelmente os dados para tomar decisões. A segunda quanto à necessidade de se acompanhar mais de perto os indicadores assistências, algo que segundo ele deveria ser aprimorado pelos "gestores administradores". E a terceira relacionada à preocupação, segundo ele, excessiva da operadora com o ticket médio, condição de curto prazo que desconsideraria as futuras intervenções do paciente junto com o hospital.

Ainda, foi enfático quanto à importância de treinamentos e acompanhamento. Relatou sua experiência com protocolos clínicos, e demonstrou satisfação ao evidenciar os resultados de suas intervenções, muitos fundamentados por meio de indicadores. Foi um dos gestores que sugeriu maior importância relativa para os fatores não pecuniários na motivação em atingir a meta do que para incentivos financeiros. Esses fatores não pecuniários identificados foram a satisfação pessoal, a realização profissional e, segundo o próprio gestor, o fato de se alcançar resultados positivo e consistentes na assistência.

Pela pesquisa pode-se atribuir ao gestor P13-G um potencial OTG de longo prazo, sobretudo por focar sua atenção no atendimento assistencial para obtenção resultados de longo prazo, tanto para o paciente quanto para o hospital. Sugeriu também o termo "planejamento assistencial", com foco em agregar valor ao paciente e tratá-lo com inteligência para que o mesmo permaneça saudável por mais tempo, com menor necessidade de recursos hospitalares. Portanto, demonstrou possuir um olhar preventivo em saúde, além do curativo. 


\subsubsection{Participante P14-G}

O participante P14-G é um gestor que responde diretamente aos proprietários, com experiência de mais de 25 anos como gestor de alto escalão, define sua orientação temporal pela estratégia e objetivos da empresa, foca bastante em tarefas relacionadas a processos, que geram mudanças com resultados no longo prazo. Os projetos de longo prazo que comentou estariam relacionados às mudanças de modelos de gestão e de processos, além de alterações nas políticas assistenciais e comerciais que no longo prazo potencialmente impactariam no resultado do hospital, pois segundo relatos deste gestor afetariam positivamente a percepção dos clientes sobre o hospital.

Quanto às operadoras, percebe a diferença entre objetivos e as tensões típicas da relação entre operadora e hospital. Contudo considera factível alinhar esses objetivos e identifica esse relacionamento como uma parceria. Comentou sobre indicadores, metas e remuneração e a dificuldade de alinhar esses elementos com os processos, e como o sistema estratégico de mensuração de desempenho e a gestão por processos promoveriam esse alinhamento.

Acredita que a incerteza pode ser combatida e não deve ser regra no ambiente de trabalho. Quanto aos objetivos acha que no nível mais básico o ideal são indicadores e objetivos específicos ao invés do macro, mas que esses têm que estar alinhado com o macro, tarefa essa feita pelo supervisor.

Assistencialmente percebe o hospital como um conjunto de atividades assistenciais com objetivos distintos que poderiam ser entendidas como unidades de negócio independentes. Também destaca a importância do atendimento com qualidade ao paciente, não só no aspecto assistencial técnico, mas na condição de acolhimento do paciente e, também dos familiares.

Quanto ao sistema de remuneração gerencial por desempenho, argumenta que a existência de indicadores coletivos é benéfica, pois faz com que todos vejam a organização com um "ser único", e induz o sentimento de participação em algo maior. Logo defende o uso de indicadores coletivos e individuais. Para o gestor P14-G, os indicadores utilizados não deveriam ser apenas quantitativos e financeiros, mas também indicadores qualitativos, 
tanto para avaliação quanto para acompanhamento das atividades, potencialmente serviriam como metas, segundo seu relato.

\subsubsection{Participante P15-E}

Possui mais de 10 anos com experiência em gestão hospitalar com responsável pelas atividades operacionais de um hospital de grande porte. Segundo seu relato, esse gestor percebe sua OTG como de curto prazo, e o tempo despendido em resolução de problemas do dia a dia era $90 \%$ do trabalho, destes $20 \%$ do tempo despendido se dava para conduzir o relacionamento com as operadoras de saúde, em atividades variadas, tais como discussão de glosas, auditoria médica, autorizações e negociação de tabelas.

Percebe o hospital como uma atividade complexa, com desafios na gestão hospitalar para alinhar a gestão financeira e a gestão assistencial. Relatou ter constante envolvimento com programas de qualidade e certificação, focando em resultados no longo prazo, bem como no desenvolvimento e aprimoramento de indicadores de produção, processos, resultados e financeiros. Entre as tarefas sugeriu como relevantes às questões operacionais do dia a dia, planejamento e controle da enfermagem e hotelaria, gestão de pessoas, gestão da qualidade e resolução de conflitos.

Identificou segundo os relatos um processo de melhoria contínua na qualidade do processo assistencial e no controle e informação. Entretanto trouxe relatos da dificuldade constante de trabalho com o corpo clínico e a adoção, pelos mesmos, dos processos do hospital. Não possui remuneração variável, e sugeriu que a tarefa a ser desempenhada era o motivador para alcançar as metas, assim como a manutenção do emprego.

\subsubsection{Participantes P16-O, P17-O e P18-O}

Os participantes P16-O, P17-O e P18-O são gestores de operadoras de saúde, as entrevistas com os mesmos foram realizadas com o intuito de aprofundar o entendimento dos dilemas e tensões entre operadoras de saúde e hospitais.

Esses gestores comentaram os mesmos dilemas que o hospital apresentou acerca da operadora, mas com a percepção do outro agente nessa relação, com o foco no controle de 
sinistro e minimizar a imprevisibilidade do atendimento assistencial típico do ambiente hospitalar. Argumentaram a dificuldade de gestão do custo de sinistro.

Outro relato interessante foi o do descasamento temporal entre a receita e custos, visto que a receita da operadora seria a mensalidade paga pelos segurados e os custos seriam conforme a utilização da estrutura assistencial pelos usuários do plano. Apesar de sugerir um dilema contábil de regime de caixa e competência, esse elemento reforça a condição de tensão entre operadora e hospital.

Um dos gestores ainda comentou a necessidade da operadora focar em ações de longo prazo e não apenas no controle do sinistro atual ${ }^{15}$, sobretudo em ações de prevenção e programas de saúde que possam refletir uma menor utilização do uso da estrutura assistencial que a operadora oferece, e consequentemente o custo do sinistro.

Para alcançar os objetivos da pesquisa, realizou-se a caracterização do perfil dos gestores e dos eixos temáticos e assim identificar os fatores relacionados a cada objetivo. Dessa maneira, a seguir serão apresentados os dilemas no setor de saúde, a categorização das tarefas de curto e longo prazo e pressupostos preliminares para modelo causal de OTG.

\subsection{Dilemas no Setor de Saúde}

A partir da pesquisa de campo foram levantados os principais dilemas e tensões enfrentados pelos gestores entrevistados, exclusivas do setor de saúde, sobretudo aqueles pautados no relacionamento entre hospital e operadoras de saúde.

Essa análise foi feita com base nos pontos levantados pelos gestores hospitalares, confrontando com as opiniões dos gestores de operadoras de saúde. Os depoimentos acerca dos pontos de relacionamento entre os setores e as diferenças de foco na agregação de valor foram apresentados no "nó" relacionamento com operadoras de saúde. A tabela 10 apresenta os principais dilemas identificados.

\footnotetext{
${ }^{15} \mathrm{O}$ sinistro atual é referente a utilização da estrutura assistencial, que a operadora de saúde é credenciada e oferece a seus segurados, pelos usuários na competência atual, acarretando saídas de caixa presente para a operadora, tais qual a utilização dos hospitais, para cirurgias, internações, medicamentos, materiais, a realização de exames laboratoriais, consultas diversas e outras estruturas assistências que a operadora pode cobrir.
} 
Tabela 10: Dilemas entre Operadora de Saúde e Hospital

\begin{tabular}{lc}
\hline Dilemas & Gestores $^{16}$ \\
\hline Autorização de Procedimentos & 10 \\
Auditoria Médica & 10 \\
Autorização Materiais, Medicamentos e OPME & 9 \\
Discussão Glosa & 8 \\
Comercialização de Planos de Saúde versus Atendimento & 8 \\
Assistencial & 6 \\
Previsibilidade Atendimento Assistencial & 4 \\
Fonte Pagadora versus Paciente & 3 \\
Credenciamento do Plano versus Utilização do hospital &
\end{tabular}

Os temas foram segregados conforme o foco dado pelos gestores no discurso. Cumpre ser destacado que esses temas estão interligados, por exemplo, a autorização de procedimentos está relacionada a auditoria médica, dado que na prática a auditoria médica é realizada para verificar a consistência entre os procedimentos autorizados e executados. Outro exemplo dessa interligação é a glosa, que é quando a operadora define que não irá reembolsar o hospital por algum procedimento ou material que a auditoria médica entendeu que era indevido o uso.

Toda a discussão é suportada pelo pressuposto de que, conforme elementos colhidos nas entrevistas, as operadoras procuram controlar o sinistro para isso buscariam a previsibilidade no atendimento hospitalar, enquanto, com base na pesquisa de campo, sugere-se que o hospital foca no atendimento assistencial, denotando objetivos distintos entre essas organizações. A seguir serão detalhados cada um desses dilemas e a posição dos gestores.

O dilema "Autorização de Procedimentos" foi referenciado pelos gestores de áreas assistências e de apoio do hospital, tais como gerência de enfermagem, gerência médica, gerência de farmácia, assim como dos gestores relacionados ao faturamento de contas. Os gestores assistenciais definem que a atividade de autorizações de procedimentos são referentes a soluções de problemas de autorização de realização de procedimentos, que em muitos casos oneraria o atendimento, ao passo que o paciente ficaria mais tempo no

\footnotetext{
${ }^{16}$ A coluna gestores refere-se a quantidade de gestores que comentaram sobre o assunto.
} 
hospital que o necessário, decorrente, em diversos casos, de questões burocráticas com a operadora.

Segundo os gestores assistenciais, para casos de urgência o passo de negociação de autorização de procedimento não seria realizado, primeiro seria realizado o atendimento assistencial e só depois seriam tratados com a operadora os procedimentos burocráticos.

Por outro lado, os gestores de operadoras de saúde argumentam que o custo com a negociação de autorizações de procedimentos seria menor que o custo da auditoria médica para a operadora, e que o custo da glosa para o hospital.

Assim, a autorização de procedimentos seria condição necessária para que a operadora possa ter o controle do custo assistencial, ao passo que seus recursos são limitados ao fluxo de caixa do recebimento dos segurados e essa gestão do custo seria necessária para minimizar a imprevisibilidade do atendimento assistencial.

O dilema "Auditoria Médica" foi referenciado pelos gestores hospitais como o tempo alocado em atendimento a auditoria médica da operadora. Trata-se do serviço que verifica se tudo o que foi cobrado na conta hospitalar é devido, se não existem procedimentos, taxas, diárias, materiais ou medicamentos não autorizados, e quando não autorizados promove a verificação da responsabilização por essa utilização, se é responsabilidade do hospital ou da operadora o custo desses procedimentos e recursos.

Os gestores hospitalares entendem que essa tarefa produz resultados de curto prazo, e interfere na atividade assistencial, ao passo que seria necessário reservar tempo para explicar as ocorrências à operadora. Do lado da operadora, a auditoria médica se faz necessária para o controle do sinistro e entendimento das situações que ocorreram fora do padrão. Um dos gestores hospitalares ainda evidenciou a necessidade do hospital ser transparente com as operadoras, de maneira a criar uma relação de confiança e parceria. Esse gestor acredita que essa relação geraria resultados no longo prazo, sendo possível alinhar os interesses de operadora e hospital.

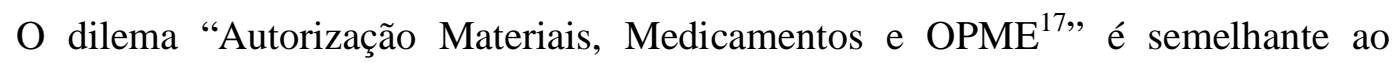
dilema "Autorização de procedimentos", a diferença identifica se dá em relação à tensão entre operadora e hospital que é o uso de matérias e medicamentos e OPME de alto custo. Os gestores hospitalares defendem que o uso desses itens de maior custo é necessário para a

\footnotetext{
${ }^{17}$ Órtese, Prótese e Materiais Especiais
} 
qualidade do atendimento assistencial, assim como para a consistência e continuidade do efeito na saúde do paciente. Foram exemplificadas situações em que o uso de determinados materiais e medicamentos mais caros no paciente reflete em um efeito mais duradouro e consistente no paciente, reduzindo a taxa de retorno ao hospital no longo prazo. Para os entrevistados em nesses casos os pacientes podem ter maior chance de deixar o hospital mais cedo e ter menor risco de imprevisibilidade no atendimento assistencial. Essa política, segundo os gestores hospitalares, seria benéfica para a operadora no longo prazo.

Por outro lado, os gestores da operadora argumentam que é necessário controlar o sinistro, e por isso materiais e medicamentos com alto custo possuem mais restrições e análises na utilização. Trata-se de um ponto relevante de divergência entre as partes, ao passo que a discussão é estritamente técnica quanto aos efeitos de usar um ou outro material ou medicamento, bem como qual seria efeito nos resultados de curto e longo prazo.

Nos discursos dos gestores de operadoras foram relatados casos que a utilização de recursos mais "baratos" produziu o mesmo efeito que o uso de recursos similares mais "caros". Porém, não foi apresentada, pelos gestores de planos de saúde, uma análise do efeito no longo prazo para o paciente em termos de utilização da estrutura assistencial da operadora de saúde, em especial o referido retorno ao hospital.

O dilema "Discussão de Glosa" é referente à discussão dos itens que o hospital utilizou e a operadora glosou ${ }^{18}$. Para o hospital a resolução de glosa toma tempo do gestor com a explicação e negociação de faturamento, sobretudo por representar um custo que potencialmente não será reembolsado, já para a Operadora trata-se um custo não autorizado e não previsto que ela economizará, adequando seu fluxo de caixa para futuras eventualidades.

Nota-se que os dilemas acima são referentes à diferença no objetivo institucional de cada organização, o hospital e a operadora, representada pelo dilema "Comercialização Planos de Saúde versus Atendimento assistencial".

O foco principal do hospital é o atendimento assistencial enquanto o objetivo geral da operadora de saúde é a comercialização de planos de saúde, são objetivos distintos. Na

\footnotetext{
${ }^{18} \mathrm{~A}$ glosa é o valor referente a procedimentos e recursos que o hospital utilizou e que a operadora não aceitou pagar, essa situação ocorre após a discussão das autorizações e da auditoria médica.
} 
perspectiva da operadora o hospital é o fornecedor do atendimento assistencial aos usuários dos planos de saúde, já na perspectiva do hospital a operadora seria a fonte pagadora das demandas dos pacientes. Portanto, operadora procura vender planos de saúde e reduzir o custo assistencial, o que, em tese, direcionaria seu trabalho para o controle dos custos assistenciais e para o gerenciamento do risco da carteira de clientes. O controle de custos assistenciais seria realizado por meio de autorizações, auditoria médica e glosas, enquanto o gerenciamento do risco da carteira de clientes pela análise do perfil dos usuários que estão contratando os planos de saúde, quando da adesão e seguindo as diretrizes da ANS.

Entre os gestores das operadoras, pode-se colher elementos de que as operadoras de saúde precisam focar em ações preventivas, para afetar os resultados no longo prazo, e percebem que atualmente o foco é no resultado de curto prazo, com o controle do custo assistencial. Outro ponto comentado foi em relação à regulação da ANS e o aumento do rol de procedimentos a serem segurados e a limitação dos prazos de atendimento, limitando a comercialização de planos a essas novas condições e riscos.

Já o hospital está focado na qualidade do atendimento assistencial, com o objetivo de oferecer ao paciente tratamento de qualidade e reduzir o risco operacional, adequando seus processos para o atendimento adequado do paciente para reestabelecer sua saúde.

Em tese, o hospital foca em um atendimento dentro do padrão, dentro do prazo esperado e com os custos necessários para tal assistência. Pode-se constatar pela pesquisa de campo que o hospital também possui a limitação de recursos vinculada com a tabela que foi negociada com a operadora e os riscos de glosas que podem ser realizadas. Com isso os gestores assistenciais enfrentam o dilema "Valor da vida" versus o custo assistencial, ou seja, como balancear para que seja oferecido um atendimento adequado ao paciente, nas condições e recursos que o hospital dispõe.

Tanto gestores hospitalares quanto assistenciais defenderam a transparência na negociação entre as partes, assim como o fato da previsibilidade do atendimento ser benéfica para ambos. Esses objetivos são complementares ao passo que o hospital busca um atendimento de qualidade para os pacientes e a operadora faz a gestão de risco e custos dos usuários. E o atendimento adequado ao paciente poderia fornecer maior probabilidade de previsibilidade no atendimento desse paciente no futuro. 
$\mathrm{Na}$ mesma linha de raciocínio, no dilema "Previsibilidade do Atendimento Assistencial" foi identificado que para a Operadora de Saúde o ideal seria a previsibilidade do atendimento assistencial, com procedimentos cujo atendimento ocorra conforme o previsto e autorizado, sem erro ou complicações. Contudo, segundo os relatos dos gestores hospitalares, quando se trata da saúde essa previsibilidade é um desafio para a gestão, tanto pelas ocorrências que podem acontecer enquanto o paciente está no hospital, como infecções e novas ocorrências, como outras complicações derivadas de situações préexistentes e não previstas.

Nos discursos dos gestores hospitalares foram identificados indícios de atendimentos que possuem maior ou menor previsibilidade, por exemplo, o atendimento cirúrgico eletivo é o mais previsível, com prazos e recursos bem definidos, mas ainda assim o paciente está exposto a complicações e infecções. Por outro lado, o atendimento clínico de emergência foi referido como aquele que possui a maior imprevisibilidade.

De maneira geral os atendimentos cirúrgicos são mais previsíveis que os atendimentos clínicos, assim como o atendimento eletivo é mais previsível que o atendimento de urgência, e este mais previsível que o atendimento de emergência.

Os hospitais estudados possuem protocolos e padrões de atendimento, nesse caso a imprevisibilidade estaria relacionada a evolução do quadro clínico do paciente. Logo, tanto para a operadora, quanto para o hospital a previsibilidade no atendimento seria uma condição benéfica, porém, o hospital repassa os impactos da imprevisibilidade para a operadora. Com isso modelos de negociação entre operadoras e hospitais com procedimento gerenciado ganham importância, nos casos observados o hospital precifica seus procedimentos em uma tabela padrão e assume o risco da imprevisibilidade.

O dilema "Fonte Pagadora versus Paciente" foi levantando pelos gestores hospitalares que diferenciam a operadora com a fonte pagadora do paciente que é o cliente do hospital e quem gera demanda.

O modelo de negócio do setor de saúde contempla o paciente que utiliza o serviço hospitalar, e esse serviço hospitalar é financiado pela operadora de saúde, que faz a gestão do risco da carteira, e é financiada pelos seus usuários que são potenciais paciente dos hospitais. Existem efeitos atuariais associados a carteira de clientes da operadora e riscos operacionais quando esses clientes se tornam pacientes. 
Por fim o dilema "Credenciamento do Plano versus Utilização do Hospital" foi levantado tanto por gestores hospitalares, quanto de operadoras de saúde. Pode-se constatar que o hospital e operadoras negociam a tabela e o credenciamento do hospital para ser utilizado pelos usuários da operadora, mas isso não significa que a operadora vai utilizar o hospital. Nesse caso, em tese, o hospital precisaria manter uma relação próxima com a operadora, com os médicos e com a comunidade, além disso, trabalhar em programas que fortaleçam a imagem do hospital com a comunidade, com tabelas diferenciadas e maior previsibilidade no atendimento, tudo isso para ser referenciado pelas operadoras, assim como fortalecer a imagem com os médicos, que são quem normalmente indicam os hospitais aos pacientes, que pareceu ser uma preocupação latente dos gestores hospitalares.

Com efeito, a relação hospital e operadora é complexa, sendo estas instituições representativas no modelo assistencial brasileiro, muitas vezes com objetivos dissonantes, pois enquanto o hospital trabalha no atendimento assistencial a operadora oferece planos de saúde e faz a gestão de risco da carteira.

Os dilemas no setor de saúde, sobretudo na relação hospital e operadora, afetam as decisões gerenciais, e por consequência a OTG dos gestores hospitalares. Com a apresentação desses dilemas será agora apresentado a categorização das tarefas nos processos hospitalares que possuem efeitos no curto e longo prazo, sendo um dos grupos identificados o próprio relacionamento entre hospital e operadora.

\subsection{Categorização Tarefas com Efeitos no Curto e Longo Prazo}

A categorização das tarefas com efeito nos resultados de curto e longo prazo foi realizada com base no levantamento dos próprios gestores hospitalares sobre as atividades que desempenham e os resultados temporais que foram descritos para cada ação. Foram identificadas, no total, 72 tarefas pontuadas por diferentes gestores, que foram agrupadas em sete grupos, que são Ambiente externo, Apoio ao atendimento assistencial, Estrutura física, Gestão, Pessoas e recursos, Processo assistencial e Relacionamento com operadoras.

Em termos de metodologia, sempre que a essência da tarefa era a mesma e o que mudava era a forma as tarefas foram agrupadas, por exemplo, buscar solução para falta de enxoval e buscar solução para falta de produtos de limpeza, ou falta de medicamentos e 
falta de materiais hospitalares. Note-se que a essência nos dois casos seria solucionar a falta de recursos, que pode variar de medicamentos, materiais hospitalares, enxoval, peças para reparo, etc. Em casos dessa natureza tarefas foram agrupadas e diferenciadas apenas pelo processo ao qual elas potencialmente atendem.

A relação de tarefas da tabela 12 (Apêndice B) se deu por temas e categorizada com o momento de ocorrência desse benefício, se está relacionada ao curto ou longo prazo. Essa categorização visa atender o objetivo de criar um instrumento de coleta da OTG de gestores em hospitais, através da definição das tarefas que impactam no resultado de curto prazo e no resultado de longo prazo, segregadas por perspectivas de atuação.

Importante ressaltar que para os sete temas identificados existem tarefas que resultam no curto prazo e tarefas que resultam no longo prazo. As tarefas com resultado no curto prazo mais referenciadas foram relacionadas a gestão com pessoas, como admissão, demissão e resolução de conflitos internos, e relacionamento com operadoras, referente a negociação de autorizações e glosas e atendimento a auditoria médica. Já as tarefas com resultado no longo prazo mais citadas foram o Controle de despesas e custo, a gestão da informação, a realização de treinamentos e cursos, o dimensionamento de pessoal e o planejamento terapêutico.

Com a caracterização das tarefas que na percepção dos gestores entrevistados impactam nos resultados curto e longo prazo, realizada com base na pesquisa de campo, foi identificada a percepção dos gestores entrevistados acerca da OTG e também os fatores associados com a OTG.

\subsection{Pressupostos Preliminares para modelo causal da OTG}

Com base na análise das categorias extrapoladas a partir da pesquisa de campo e com base na revisão da literatura foram levantados pressupostos preliminares ${ }^{19}$ de fatores que podem impactar na Orientação Temporal do Gestor. Essa análise foi feita com base nas perspectivas propostas por Laverty (1996) de avaliar a OTG, sob a perspectiva individual, organizacional e econômica.

\footnotetext{
${ }^{19}$ Sugere-se que para estudos futuros esses pressupostos sejam utilizados como hipóteses.
} 
$\mathrm{Na}$ condução da pesquisa foram levantadas 12 variáveis independentes que teoricamente poderiam impactar na OTG e na relação entre os elementos do sistema de remuneração gerencial e a OTG. No ambiente investigado os pressupostos consideram que essas variáveis poderiam impactar, tanto diretamente na OTG, interativamente com outras variáveis, como também moderando outras relações, além de impactar indiretamente na OTG, na medida em que impactariam diretamente as variáveis que impactam a OTG. A tabela 11 apresenta síntese das variáveis independentes identificadas com as análises de discurso.

Tabela 11: Variáveis independentes identificadas nos pressupostos preliminares para modelo causal de OTG $^{20}$

\begin{tabular}{|c|c|c|c|c|}
\hline Variável Independente & Perspectiva Teórica & $\begin{array}{l}\text { Perspectiva } \\
\text { OTG }\end{array}$ & Relação & Qtde \\
\hline $\begin{array}{l}\text { Comprometimento com a } \\
\text { meta não financeira }\end{array}$ & $\begin{array}{l}\text { Sistema de } \\
\text { Remuneração } \\
\text { Gerencial }\end{array}$ & Econômica & $\begin{array}{l}\text { Direta / Interativa / } \\
\text { Moderadora }\end{array}$ & 14 \\
\hline $\begin{array}{l}\text { Comprometimento com a } \\
\text { meta financeira }\end{array}$ & $\begin{array}{l}\text { Sistema de } \\
\text { Remuneração } \\
\text { Gerencial }\end{array}$ & Econômica & $\begin{array}{l}\text { Direta / Interativa / } \\
\text { Moderadora }\end{array}$ & 14 \\
\hline $\begin{array}{l}\text { Uso do Sistema estratégico } \\
\text { de mensuração de } \\
\text { desempenho }\end{array}$ & $\begin{array}{l}\text { Sistema de } \\
\text { Remuneração } \\
\text { Gerencial }\end{array}$ & Econômica & $\begin{array}{l}\text { Direta / Interativa / } \\
\text { Moderadora }\end{array}$ & 13 \\
\hline $\begin{array}{l}\text { Desenho do contrato do } \\
\text { Gestor }\end{array}$ & $\begin{array}{l}\text { Sistema de } \\
\text { Remuneração } \\
\text { Gerencial }\end{array}$ & Econômica & $\begin{array}{l}\text { Direta / Interativa / } \\
\text { Moderadora }\end{array}$ & 13 \\
\hline $\begin{array}{l}\text { Comunicação do } \\
\text { Planejamento Estratégico }\end{array}$ & $\begin{array}{l}\text { Sistema de } \\
\text { Remuneração } \\
\text { Gerencial }\end{array}$ & Econômica & $\begin{array}{l}\text { Direta / Interativa / } \\
\text { Moderadora }\end{array}$ & 12 \\
\hline $\begin{array}{l}\text { Tempo de trabalho como } \\
\text { gestor }\end{array}$ & Gestão em saúde & Individual & $\begin{array}{l}\text { Direta / Interativa / } \\
\text { Moderadora }\end{array}$ & 15 \\
\hline $\begin{array}{l}\text { Tempo de trabalho no setor } \\
\text { de saúde }\end{array}$ & Gestão em saúde & Individual & $\begin{array}{l}\text { Direta / Interativa / } \\
\text { Moderadora }\end{array}$ & 15 \\
\hline Motivação pró-social & $\begin{array}{l}\text { Public Service } \\
\text { Motivation }\end{array}$ & Individual & $\begin{array}{l}\text { Direta / Interativa / } \\
\text { Moderadora }\end{array}$ & 10 \\
\hline Uso de Gestão de Processos & Gestão de Processos & Organizacional & $\begin{array}{l}\text { Direta / Interativa / } \\
\text { Moderadora }\end{array}$ & 14 \\
\hline Incerteza da tarefa & Confiança em & Organizacional & Direta / Interativa / & 12 \\
\hline
\end{tabular}

\footnotetext{
${ }^{20} \mathrm{O}$ quadro possui na primeira coluna a variável independente, em seguida a perspectiva teórica relacionada a essa variável na literatura, a terceira coluna é a perspectiva proposta por Laverty (1996), depois o tipo de relacionamento com a OTG dessa variável e por fim a quantidade de gestores entrevistados (entre os 15 gestores hospitalares) que discutiram esses assuntos e relacionaram essas variáveis com sua tomada de decisão quanto a alocação de recursos em atividades com resultado no curto e longo prazo.
} 


\begin{tabular}{lllll}
\hline & $\begin{array}{l}\text { indicadores de } \\
\text { desempenho contábeis }\end{array}$ & Organizacional & $\begin{array}{l}\text { Direta / Interativa / } \\
\text { Moderadora }\end{array}$ & 11 \\
Incerteza do ambiente & $\begin{array}{l}\text { Confiança em } \\
\text { indicadores de } \\
\text { desempenho contábeis }\end{array}$ & Organizacional & $\begin{array}{l}\text { Direta / Interativa / } \\
\text { Moderadora }\end{array}$ & 10 \\
\hline $\begin{array}{l}\text { Desenho do contrato com } \\
\text { Operadoras de Saúde }\end{array}$ & Gestão em saúde & 10 & & \\
\hline
\end{tabular}

$\mathrm{Na}$ perspectiva econômica foram identificados fatores relacionados aos elementos do sistema de remuneração gerencial, como indicadores de desempenho e meta de desempenho, de maneira que o "comprometimento com a meta financeira" $\mathrm{e}$ "comprometimento com a meta não financeira" foram aspectos relacionados pelos gestores que potencialmente afetariam suas escolhas gerenciais. Nesse sentido o "uso de sistemas estratégicos de mensuração de desempenho" também impactaria ao passo que aproxima do gestor o alinhamento entre as metas financeiras e não financeiras e com os objetivos estratégicos.

Tais pressupostos levantados com base nos discursos analisados vão ao encontro dos achados pela literatura, como Webb (2004), que identificou que o uso de metas não financeiras, alinhadas com metas financeiras, devido o uso de sistemas estratégicos de mensuração de desempenho aumenta o comprometimento com as metas financeiras e com o planejamento estratégico, assim como Van Rinsum (2006), Aguiar (2011) e Aguiar, Pinheiro e Oyadomari (2014) que verificam que não há ainda consistência entre o uso de indicadores financeiros e não financeiros.

Portanto a partir da pesquisa de campo pode-se sugerir os seguintes pressupostos preliminares para investigações futuras:

$\mathrm{H}_{1}$ : O comprometimento com metas não financeiras modera a relação dos elementos do sistema de remuneração gerencial sobre a OTG.

$\mathrm{H}_{2}$ : $\mathrm{O}$ comprometimento com metas financeiras modera na relação dos elementos do sistema de remuneração gerencial sobre a OTG.

$\mathrm{H}_{3}$ : $\mathrm{O}$ uso de sistemas estratégicos de mensuração de desempenho modera a relação dos elementos do sistema de remuneração gerencial sobre a OTG. 
$\mathrm{H}_{4}$ : $\mathrm{O}$ uso de sistemas estratégicos de mensuração de desempenho modera o impacto do planejamento estratégico na a OTG de longo prazo.

$\mathrm{H}_{5}$ : $\mathrm{O}$ uso de sistemas estratégicos de mensuração de desempenho afeta diretamente a OTG de longo prazo.

$\mathrm{H}_{6}$ : A comunicação do planejamento estratégico modera o impacto do planejamento estratégico na OTG de longo prazo.

Cumpre ser ressaltado que não existe consenso, na literatura acadêmica, quanto ao impacto da importância de medidas de desempenho não-financeiros inclusas no sistema de remuneração gerencial na perspectiva temporal da escolha do gestor. Ainda assim, medidas financeiras, como informações contábeis, são percebidas como úteis para fornecer informações quanto ao esforço gerencial dedicado a tarefas que afetam o resultado de curto-prazo (NARAYANAN, 1985; SLIWKA, 2002; DIKOLLI, VAYSMAN, 2006), e ainda possuem uma defasagem temporal para capturar esforços para resultado de longo prazo (SLIWKA, 2002).

Dessa maneira, indicadores financeiros induziriam à OTG de curto prazo consistentemente, ao passo que a natureza da captação dos esforços que essa medida possui privilegia esforços para resultado de curto prazo e eventos passados, e são incapazes de fornecer informações quanto À criação de valor futuro (KAPLAN; NORTON, 1996; DIKOLLI, 2000; DIKOLLI. VAYSMAN, 2006). Em contrapartida, uma maior importância relativa a medidas de desempenho não financeiro induziria a OTG consistente de longo prazo (KAPLAN, NORTON; 1996 DIKOLLI. VAYSMAN, 2006; VAN RINSUM, 2006).

Apesar disso, estudos realizados quanto ao assunto apresentam resultados contraditórios, Aguiar (2009) e Abernethy et al. (2012) encontraram que uma maior importância de medidas não financeiras impactou em OTG de curto prazo, portanto tanto medidas de desempenho financeiras como não financeiras possuem algum nível de tendência de resultados futuros, e não há consenso quanto a tempestividade dos indicadores não financeiros em reconhecer resultados futuros (LUFT; SHIELDS, 2003; VAN RINSUM, 2006).

Os indícios e pressupostos observados no discurso dos gestores alinham-se ao encontro da literatura, inclusive no que se refere à falta de consenso quanto ao impacto de 
cada tipo de informação. O que foi observado nas entrevistas é a importância do sistema estratégico de mensuração de desempenho nas escolhas intertemporais dos gestores, fato esse que necessita de mais investigação, sobretudo pela a importância dada a esses sistemas na prática gerencial nos hospitais investigados.

Em paralelo, seria importante analisar separadamente cada um dos elementos do sistema estratégico de mensuração de desempenho, como as metas não financeiras, financeiras e a "comunicação do planejamento estratégico" por meio do desmembramento em objetivos e estratégias específicas.

Outro fator levantando na investigação foi o "desenho do contrato ex-ante do gestor", que parece influenciar significativamente na OTG do mesmo. Isso pois, nas entrevistas alguns gestores justificaram suas escolhas de alocação de recursos em atividades no curto ou longo prazo conforme o que foi acordado com o gestor em sua contratação ou negociação de cargo.

Portanto, parece que ex-ante a contratação o gestor superior já defini o perfil que busca para o gestor intermediário, de maneira que o profissional que assume o cargo já sabe o direcionamento temporal dele esperado.

Com isso parece relevante investigar qual o efeito do desenho do contrato ex-ante do gestor na OTG, considerando a relação que esse contrato possa ter efeito do sistema de remuneração gerencial na OTG. Ainda parece que existe uma segregação do próprio gestor superior em contratar gestores com diferentes OTG e já definir na própria contratação o perfil desse gestor e alinhar com o mesmo o que é esperado dele. Assim, sugere-se o seguinte pressuposto preliminar de investigação:

$\mathrm{H}_{7}$ : $\mathrm{O}$ desenho do contrato do gestor para tarefas de longo prazo afeta a OTG, de longo prazo.

Quanto aos fatores individuais foram identificados o "tempo de trabalho como gestor", o "tempo de trabalho no setor de saúde" e a "motivação pró-social" como aspectos cognitivos que interferem na OTG. O tempo de trabalho como gestor e no setor de saúde parece interferir no horizonte temporal do gestor, não apenas pela expectativa em continuar na empresa, mas também por sua experiência profissional. 
Então, parece que os gestores com mais experiência no setor e em cargos de liderança possuem maior discernimento do que são tarefas que produzem efeitos no curto e no longo prazo. Assim como, aparentemente demonstram maior propensão no envolvimento com projetos e atividades que resultam em efeitos no longo prazo. Dessa maneira, sugere-se os seguintes pressupostos preliminares:

$\mathrm{H}_{8}$ : Gestores com mais tempo de experiência em gestão possuem a OTG com maior importância relativa para o longo prazo e mais consistência em suas escolhas.

$\mathrm{H}_{9}$ : Gestores com mais tempo de experiência no segmento em que atuam possuem a OTG com maior importância relativa para o longo prazo e mais consistência em suas escolhas

A literatura contábil relata frequentemente o efeito do uso de elementos de incentivo como direcionador da OTG, tal qual bônus por ações, remuneração variável, entre outros (NARAYANAN, 1985; LEWELLEN et al., 1987; DECHOW e SLOAN, 1995; BHOJRAJ; LIBBY, 2005; AGUIAR, 2009), e neste estudo foi verificado que tais incentivos relacionados a ganhos pecuniários, financeiros, não são tão eficazes, visto a quantidade de gestores que desconheciam as regras pelas quais eram remunerados financeiramente, nesse sentido a teoria da motivação do serviço público (PERRY; WISE, 1990) pode explicar o fator motivacional dos gestores em atingir as metas.

Logo é esperado que gestores de hospitais, pela responsabilidade social do serviço, possuam fatores cognitivos e motivacionais diferenciados, voltados à satisfação e realização pessoal, realização da função social, e o patriotismo de benevolência, que é a necessidade do gestor hospitalar possuem de garantir os direitos básicos à saúde aos pacientes que atende (PERRY; WISE, 1990).

Conforme os autores as motivações provenientes de serviços à sociedade podem ser mais duradouras do que aquelas baseadas em lucros, o que pode impactar na OTG de longo prazo do gestor. Assim, pode-se sugerir o seguinte pressupost preliminar:

$\mathrm{H}_{10}$ : Uma maior importância relativa da motivação pró-social do gestor aumenta a OTG de longo prazo. 
Com efeito, em relação aos fatores organizacionais que potencialmente afetariam a OTG do gestor foram levantados o "uso de gestão de processos", "a incerteza da tarefa", "a incerteza do ambiente" e o "desenho do contrato com as operadoras de saúde".

O uso da gestão de processos foi relacionado com a OTG de longo prazo ao passo que está diretamente relacionado às atividades dos gestores, com foco na visão macro, no core business e na agregação de valor ao cliente. Com essa mudança de foco o gestor potencialmente passaria a ter uma percepção mais ampla sobre suas atividades e os efeitos delas, com maior poder preditivo dos possíveis resultados que suas atividades vão ter ao longo do tempo.

Outro fator bastante comentado foi o relacionamento com as operadoras de saúde, tratado como tarefas com resultado no curto prazo, entretanto algumas iniciativas denotam que o desenho do relacionamento com a operadora de saúde poderia impactar que as tarefas realizadas que promoveriam impactos no longo prazo.

A incerteza do ambiente, e da tarefa, parece induzir o gestor a OTG de curto prazo, ao passo que essa incerteza potencialmente dificulta o entendimento dos resultados de longo prazo. Diante dessas percepções constituídas a partir da pesquisa de campo, sugere-se os seguintes pressupostos preliminares:

$\mathrm{H}_{11}$ : $\mathrm{O}$ uso da gestão de processo afeta diretamente o aumento da OTG de longo prazo.

$\mathrm{H}_{12}$ : O desenho do contrato com as operadoras de saúde com foco no longo prazo afeta a OTG de longo prazo.

$\mathrm{H}_{13}$ : A incerteza do ambiente afeta diretamente positivamente a OTG de curto prazo.

$\mathrm{H}_{14}$ : A incerteza da tarefa afeta diretamente positivamente a OTG de curto prazo

$\mathrm{H}_{15}$ : A incerteza do ambiente e da tarefa, afeta diretamente positivamente a inconsistência da OTG.

$\mathrm{H}_{16}$ : $\mathrm{O}$ desenho do contrato com as operadoras de saúde afeta a incerteza de tarefa.

$\mathrm{H}_{17}$ : A motivação pró-social afeta o comprometimento com metas não financeiras.

Cumpre ser ressaltado que as hipóteses preliminares de pesquisa foram levantadas de acordo com o que já vem sendo pesquisado e com o que foi verificado na análise dos discursos dos gestores entrevistados. A utilização de gestores hospitalares para verificar novas hipóteses de fatores que podem impactar na OTG trouxe benefícios ao passo que o hospital representa um ambiente com significativas diferenças institucionais e com gestores 
com diferentes percepções de incertezas de tarefa e ambiente, experiência em gestão, níveis de utilização de artefatos econômicos diferentes e conhecimento de processos.

As hipóteses preliminares levantadas sintetizam os fatores referenciados mais enfaticamente pelos gestores entrevistados, ainda assim as 17 hipóteses preliminares não esgotam as possibilidades de hipóteses que a pesquisa de campo permite inferir, dado que existe relacionamentos interativos, diretos, indiretos e moderadores que não foram detalhados, sendo que para possíveis estudos seria interessante analisar cada fator e as possibilidades de relacionamento com outros fatores e com OTG.

A figura 3, a seguir, apresenta a síntese dos principais relacionamentos entre variáveis independentes e OTG conforme a categorização dos eixos temáticos, e com a quantidade de gestores que referenciaram esses fatores e relacionaram com as decisões gerencias e escolhas intertemporais.

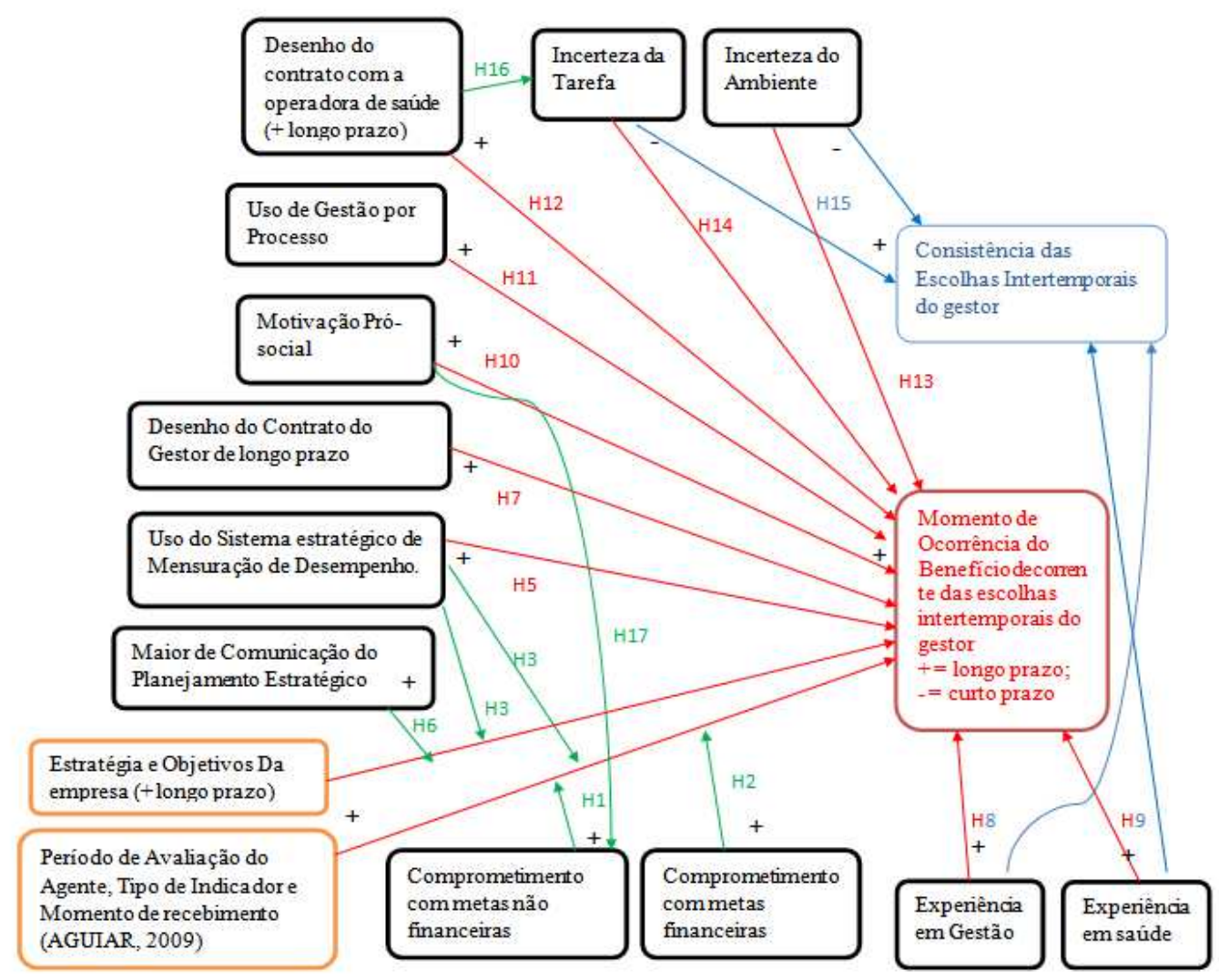

Figura 3: Síntese dos eixos temáticos associados com OTG. ${ }^{21}$

21 Na figura 3 os retângulos com cantos arredondados com borda preta representam as variáveis independentes identificadas nas hipóteses preliminares com base no estudo de campo, os retângulos com borda laranja são as variáveis independentes identificadas em outros estudos. O retângulo vermelho representa o critério da OTG momento de ocorrência do benefício, e o retângulo azul representa o critério da 
Fonte: elaborada pelo autor.

O presente capítulo analisou os fatores que potencialmente podem estar associados a OTG e que podem representar hipóteses para estudos futuros, cumpre ser ressaltado que os enfoques analisados não esgotam as possibilidades de aplicação desses conceitos. $\mathrm{O}$ capítulo a seguir apresenta as considerações finais desta pesquisa.

OTG consistência das escolhas intertemporais. As setas vermelhas representam as hipóteses com relação direta com o critério da OTG momento de ocorrência dos benefícios, enquanto as setas azuis a relação direta com o critério da OTG consistência das escolhas intertemporais. As setas verdes representam relações moderadoras e indiretas. 


\section{CONSIDERAÇÕES FINAIS}

O objetivo principal deste estudo foi investigar os fatores econômicos, organizacionais e cognitivos que podem interferir nas decisões gerenciais, tendo como objetivos específicos identificar os dilemas entre operadoras de saúde e hospitais, identificar quais eram as tarefas que resultam no curto e longo prazo em um hospital, e avaliar os resultados das entrevistas sobre possíveis causas para OTG sob as perspectivas propostas Laverty (1996).

O interesse em realizar esse estudo surgiu da crença que as particularidades da atividade e gestão hospitalar poderiam gerar conhecimento e informações úteis para o entendimento do modelo causal e dos fatores que afetam a OTG, e assim contribuir com o conhecimento em controladoria e contabilidade. A gestão hospitalar por si também foi motivo de interesse de estudo, dado sua complexidade e dificuldade na utilização de artefatos econômicos na gestão de seus processos.

Com isso o intuito da pesquisa foi contribuir tanto para o conhecimento em Controladoria e Contabilidade, quanto para o conhecimento em Gestão Hospitalar, bem como aproximar os conceitos da Gestão de Processo aos conceitos de Controladoria e Gestão Hospitalar.

A revisão de literatura demonstrou que existem diversos conceitos semelhantes abordados nessas diferentes áreas temáticas do conhecimento, que podem ser analisados juntos para aumentar a consistência no entendimento desses construtos. Os elementos da gestão de processos apresentaram bastante aderência aos conceitos estudados em controladoria e gestão, inclusive com estudos demonstrando a importância de unir esses conhecimentos.

A metodologia escolhida foi o estudo multicasos justamente pela possibilidade de aprofundar o conhecimento acerca do fenômeno, observando e avaliando detalhadamente os fatores que impactam nas atividades do gestor hospitalar, e como isso se relaciona com suas escolhas intertemporais, com o sistema de remuneração gerencial, assim como a importância dos processos hospitalares e modelos de gestão.

Para análise dos dados coletados nas entrevistas foi utilizado a técnica de análise de conteúdo, que foi analisado detalhadamente pelos eixos temáticos identificados e também pelo perfil dos participantes. 
A análise de discurso das entrevistas com os gestores resultou em hipóteses sobre a interferência de fatores cognitivos, organizacionais e econômicos sobre a OTG, um levantamento das tarefas que resultam no curto e longo prazo e a identificação e análise dos dilemas entre operadora e hospital apontados pelos gestores, corroborando com os objetivos específicos da pesquisa.

A análise dos dados resultou em oito dilemas recorrentes e significativos entre operadoras de saúde e hospitais, estando todos relacionados a diferença de interesses entre hospital e operadora e a questão da previsibilidade do atendimento assistencial e gestão de sinistro da operadora.

Já a identificação das tarefas que resultam no curto ou longo prazo em uma entidade hospitalar é subsídio para futuras pesquisas que podem investigar a OTG dos gestores dessas instituições, com uma base de dados maior e com relevância estatística.

E os pressupostos levantados são consistentes com a literatura relacionada ao tema, ao mesmo tempo em que se alicerça na percepção e na experiência prática dos gestores hospitalares. E trata-se de uma proposta inicial, a qual necessita de outros estudos para a validação das hipóteses, tanto para o modelo geral de OTG quanto para a OTG em gestores de instituições de saúde.

A limitação da pesquisa consiste em ser uma análise comparativa qualitativa com 18 entrevistados, não sendo possível a generalização dos resultados, ainda assim a seleção dos entrevistados foi criteriosa, apesar de ser por conveniência, para não gerar viés de seleção. Dessa maneira os gestores entrevistados possuem variabilidade no que tange à posição hierárquica, à função exercida, à formação acadêmica e escolaridade, à idade, à experiência profissional e à experiência no setor de saúde. Fato que foi verificado nas entrevistas com a variabilidade de respostas, casos e informações coletadas com esses gestores.

Para futuras pesquisas sugere-se utilizar os resultados dessa pesquisa para a preparação de um instrumento de coleta para uma survey, de maneira que os resultados e hipóteses, aqui identificados e sugeridos, possam ser testados e generalizados, assim como o estudo pode ser aprofundado em outros hospitais e com outros gestores. Da mesma forma um estudo focado nos gestores de operadoras de saúde podem apresentar resultados significativos para o conhecimento em controladoria. 
Assim, existe espaço para novas pesquisas sobre o tema em instituições de saúde, de maneira a conciliar a prática profissional e a reflexão acadêmica. E o presente estudo contribui para o conhecimento científico com a caracterização dos dilemas enfrentados pelos gestores hospitalares e gestores de operadoras de saúde, com a caracterização das tarefas que afetam o resultado no curto e no longo prazo e com o levantamento de hipóteses preliminares quanto aos fatores que poderiam impactar na OTG. 


\section{REFERÊNCIAS}

ABBAS, K. Gestão de Custos em Organizações Hospitalares. 2011. 171 f. Dissertação (Mestrado em Engenharia de Produção), Universidade Federal de Santa Catarina, Santa Catarina, 2011.

ABERNETHY, M. A.; STOELWINDER, J. Budget use, task uncertainty, system goal orientation and subunit performance: a test of the "fit" Hypothesis in not-for-profit hospitals. Accounting Organizations and Society, v.16, n.2, p.105-120, 1991.

ABERNETHY, M A.; BROWNELL, P. The role of accounting in organizations facing strategic change: an empirical analysis in hospitals. Accounting Organizations and Society, v. 24, n. 3, p. 189-204, 1999.

ABERNETHY, M A.; BOUWENS, J; LENT, L. V. The role of performance measures in the intertemporal decisions of business unit managers. Contemporary accounting research, v. 30, n.2, p. $925-961,2013$.

AGUIAR, A. B. Sistemas de remuneração gerencial e Orientação Temporal dos Gestores. 2009. 218 f. Tese (Doutorado em Ciências Contábeis) - Departamento de Contabilidade e Atuária da Faculdade de Economia, Administração e Contabilidade, Universidade de São Paulo, São Paulo, 2009.

AGUIAR, A. B. Orientação Temporal dos Gestores: Potenciais Dimensões e Significados. Revista Universo Contábil, v. 7, n. 4, p. 06-21, 2011.

AGUIAR, A. B.; FREZATTI, F. Efeito direto e interativo do período de avaliação sobre a orientação temporal dos gestores. Revista de Administração de Empresas, São Paulo, v. 48, n. 1, p. 67-79, 2013.

AGUiAR, A. B.; PINHEIRO, P. N.; OYADOMARI, J. C. T. How do different performance measures affect managerial time orientation? Empirical evidence from sales managers in the oil and gas industry. Advances in Accounting, 2014. Disponível em: < http://dx.doi.org/10.1016/j.adiac.2014.03.001>. Acesso em: 15 de Abr. de 2014.

AL-BALUSHI, S.; SOHAL, A.; SINCH, P.J. Readiness Factors for Lean Implementation in Healthcare Settings-A Literature Review. Journal of Health Organization and Management. v.28, n.2, p. 135-153, 2014.

ALCHIAN, A. A.; DEMSETZ, H. Production, Information Costs, and Economic Organization. American Economic Review, v. 62, n.5, p. 777-795, 1972. 
ALVES, A. Financiamento e eficiência em dois hospitais privados filantrópicos paulista. 1997. 129f. Tese (Doutorado em Saúde Pública) - Faculdade de Saúde Pública. Universidade de São Paulo, São Paulo, 1997.

ANANTHARAMAN, D.; LEE, Y. G. Managerial risk taking incentives and corporate pension policy. Journal of Financial Economics. v. 111, n. 2, p. 328-351, 2014.

AQUINO, A. C. B. Economia dos arranjos híbridos: o caso da coordenação de serviços em uma usina siderúrgica. 2005. 231 f. Tese (Doutorado em Ciências Contábeis) Departamento de Contabilidade e Atuária da Faculdade de Economia, Administração e Contabilidade da Universidade de São Paulo, São Paulo, 2005.

ARAÚJO, P. V. R; VIEIRA, M. J. A questão da morte e do morrer. Revista Brasileira de Enfermagem, v. 57, n.3, p. 361-363, 2004.

ASSAF NETO, A. Finanças corporativos e valor. São Paulo: Atlas, 2003.

BANKER, R. D.; DATAR, S. M.. Sensitivity, precision, and linear aggregation of signals for performance evaluation. Journal of Accounting Research, v.27, n. 1, p. 21-39, 1989.

BARDIN, L. Análise de Conteúdo. Lisboa, Portugal: Edições 70, LDA, 2009.

BARIGOZZI, F.; LEVAGGI, R. Emotions in physician agency. Health Policy, v. 88 n.1, p. 1-14, 2008.

BAZELEY, Pat. Qualitative Data Analysis with NVivo. London: Sage, 2007.

BERNARDES, A. et al. Os ruídos encontrados na construção de um modelo democrático e participativo de gestão hospitalar. Ciência e saúde coletiva, Rio de Janeiro, v. 12, n. 4, p. $861-870,2007$.

BERNARTZI, S.; THALER, R. H.. Myopic loss aversion and the equity premium puzzle. The Quarterly Journal of Economics, v. 110, n. 1, p. 73-92, 1995.

BHOJRAJ, S.; LIBBY, R.. Capital market pressure, disclosure frequency-induced earnings/cash flow conflict, and managerial myopia. The Accounting Review, v. 80, n. 1, p. 1- 20, 2005.

BITTAR, O. J. N. V. Hospital qualidade e produtividade. São Paulo: Sarvier, 1997.

Gestão de processos e certificação para qualidade em saúde. Revista da Associação Médica Brasileira, São Paulo , v. 46, n. 1, p. 70-76, 2000.

BONACIM, C. A. G. O Cálculo do Valor Econômico Agregado à Sociedade por Hospitais Universitários Públicos: um estudo de caso no Hospital das Clínicas da FMRP. 2006. 166 f. Dissertação (Mestrado em Ciências Contábeis) - Departamento de 
Contabilidade da Faculdade de Economia, Administração e Contabilidade de Ribeirão Preto, Universidade de São Paulo, Ribeirão Preto, 2006.

BONACIM, C. A. G.; ARAUJO, A. M. P. Valor econômico agregado por hospitais universitários públicos. Revista de Administração de Empresas, São Paulo, v. 49, n. 4, p. $419-433,2009$.

- Gestão de custos aplicada a hospitais universitários públicos: a experiência do Hospital das Clínicas da Faculdade de Medicina de Ribeirão Preto da USP. Revista de Administração Pública, Rio de Janeiro, v. 44, n. 4, p. 903 - 931, 2010a

Influência do capital intelectual na avaliação de desempenho aplicada ao setor hospitalar. Ciência saúde coletiva, Rio de Janeiro, v. 15, n. 1, p. 1249-1261, 2010b

Avaliação de desempenho econômico-financeiro dos serviços de saúde: os reflexos das políticas operacionais no setor hospitalar. Ciência saúde coletiva, Rio de Janeiro, v. 26, n. 1., p. 1055-1068, 2011.

BONNER, S. E.; SPRINKLE, G. B. The effects of monetary incentives on effort and task performance: theories, evidence, and a framework for research. Accounting, Organizations and Society, Elsevier, v. 27, n. 4-5, p. 303-345, 2002.

BORBA, G. S.; KLIEMANN NETO, F. J. Gestão Hospitalar: identificação das práticas de aprendizagem existentes em hospitais. Saude e sociedade, São Paulo, v. 17, n. 1, p. 4460, 2008.

BRASIL. Instituto Brasileiro de Geografia e Estatística. Indicadores Sóciodemográficos e de Saúde no Brasil. Estudos e Pesquisas número 25. 2009.

BRASIL. Instituto Brasileiro de Geografia e Estatística. Um panorama da saúde no Brasil: acesso e utilização dos serviços, condições de saúde e fatores de risco e proteção à saúde 2008. Pesquisa Nacional por amostra de domicílios. 2010.

BRASIL. Instituto Brasileiro de Geografia e Estatística. Conta Satélite de Saude 20072009. Contas nacionais n 37. 2012.

BRAUER, M.F. The effects of short-term and long-term oriented managerial behavior on medium-term financial performance: longitudinal evidence from Europe. Journal of Business Economics and Management, v. 14, n. 2, p. 386-402, 2013.

BRUCHEY, S. Success and Failure Factors: American Merchants in Foreign Trade in the Eighteenth and Early Nineteenth Centuries. Business History Review, v. 32, n. 3, p. 272292, 1958. 
BURGESS N. et al. Taxonomy of Lean in Healthcare: A framework for evaluating activity and impact, In: 16th International Annual EurOMA Conference, Göteborg, Sweden, 14-17, Jun 2009.

BURLTON, R.. Delivering business strategy through process management. In: VOM BROCKE, J.; ROSEMANN, M. (Eds.). Handbook on business process management: strategic alignment, governance, people and culture. Berlin: Springer, v. 2, n. 1, p. 5-37, 2010 .

BUSHEE, B. J. Do institutional investors prefer near-term earnings over long-run value? Contemporary Accounting Research, v. 18, n. 2, p. 207-246, 2001.

CALDANA, G.; GABRIEL, C. S.; BERNARDES, A.; ÉVORA, Y. D. M.. Indicadores de desempenho em serviço de enfermagem hospitalar: revisão integrativa da literatura. Revista da Rede de Enfermagem do Nordeste, v. 12, n. 5, p. 189-197, 2011.

CALLEN, J. L; FANG, X. Institutional investor stability and crash risk: Monitoring versus short-termism? Journal of Banking \& Finance, v. 37, n. 8, p. 3047-3063 , 2013.

CAMACHO, R. R.; ROCHA, W.; MORAES, R. O. Preços e níveis de complexidade dos serviços praticados por hospitais privados junto à operadoras de planos de saúde. Enfoque: Reflexão Contábil, v. 30, n. 2, p. 24-35, 2011.

CAMPOS, G.W. S. Educação médica, hospitais universitários e o Sistema Único de Saúde. Cadernos de Saúde Pública, Rio de Janeiro, v. 15, n.1, p 187-194, 1999.

CAMPOS, G. W. S.; AMARAL, M. A. A clínica ampliada e compartilhada, a gestão democrática e redes de atenção como referenciais teórico-operacionais para a reforma do hospital. Ciência saúde coletiva, Rio de Janeiro, v. 12, n. 4, p. 849-859, 2007.

CARAPINHEIRO, G.. Saberes e poderes no hospital. 4a. Ed. Porto: Edições Afrontamento, 2005.

CARR, C.; TOMKINS, C.. Context, culture and the role of the finance function in strategic decisions. A comparative analysis of Britain, Germany, the USA and Japan. Management accounting research, v. 9, n. 23, p. 213-230, 1998.

CATELLI, A. (coord.). Controladoria: uma abordagem da gestão econômica GECON. São Paulo: Atlas, 1999.

CECCIM, R. B.; FEUERWERKER, L. C. M... O quadrilátero da formação para a área da saúde: ensino, gestão, atenção e controle social. Physis,v. 14, n. 1, p. 41-65, 2004.

CHENG, S. J.. R\&D expenditures and CEO compensation. Journal of Accounting and Economics, v. 79, n. 2, p. 305-328, 2004. 
CHENNAL, R. H. Reliance on manufacturing performance measures, total quality management and organizational performance. Management Accounting research, v. 8, n. 2, p. 187-206, 1997.

Management control systems design within its organizational context: findings from contingency-based research and directions for the future. Accounting, Organizations and Society, v. 28, n. 2-3, p. 127-168, 2003.

CHOW, C. W.; KATO, Y.; MERCHANT, K. A. The use of organizational controls and their effects on data manipulation and management myopia: a Japan vs U.S. comparison. Accounting, Organizations and Society, v. 21, n. 2-3, p. 175-192, 1996.

CONNOLLY, T.; DEUTSCH, S. J. Performance Measurement: Some Conceptual Issues. Evaluation and Program Planning, v. 3, n. 1, p. 35-43, 1980.

COVALESKI, M.et al. Budgeting research: three theoretical perspectives and criteria for selective integration. In: CHAPMAN, Christopher S.; HOPWOOD, Anthony G.; SHIELDS, Michael D. Handbook of Management Accounting Research. v. 1. Oxford: Elsevier, p. 587- 624, 2007.

COATES, J.; DAVIS, T.; STACEY, R. Performance measures systems, incentive reward schemes and short-termism in multinational companies: a note. Management Accounting Research, v. 6, n.2, p. 125-135, 1995.

CRESWELL, J. W. Educational reasearch: planning, conducting, and evaluating quantitative and qualitative research. 4. ed. Boston: Pearson Education, 2012.

CUNHA, J. A. C. Avaliação de desempenho e eficiência em organizações de saúde: um estudo em hospitais filantrópicos. 2011. 242 f. Tese (Doutorado em Administração) Departamento de Administração da Faculdade de Economia, Administração e Contabilidade, Universidade de São Paulo, São Paulo, 2011.

DAHLGAARD, J. J.; PETTERSEN, J; Quality and lean health care: A system for assessing and improving the health of healthcare organizations. Total Quality Management \& Business Excellence, v. 22, n. 6, p. 673-689, 2011.

DAL POZ, M. R. et al. .Produtividade e desempenho dos recursos humanos nos serviços de saúde. Programa de desenvolvimento de recursos humanos. Organização Pan Americana de Saúde, 1997.

DALMÁCIO, F. Z.; AGUIAR, A. B.; REZENDE, A. J. Uma Aplicação do Time-Driven ABC Model no Setor de Serviço Hospitalar: a nova abordagem do ABC proposta por Kaplan e Anderson. Contabilidade Vista e Revista, v.18, n. 2, p.11-34, 2007.

DAVIES, R et al. Measuring the costs of short-termism. Journal of Financial Stability, v. 23, p. 16-25, 2014. 
DE MASI, D. O ócio criativo. Sextante: 2000.

DECHOW, P. M.; SLOAN, R. G. Executive incentives and horizon problems. Journal of Accounting and Economics, v. 14, n. 1, p. 51-89, 1991.

DEMIRAG, I. S. Short-term performance pressures: is there a consensus view? The European Journal of Finance, v. 1, n. 1, p. 41-56, 1995.

DEVLIN, R. A.; SARMA, S. Do physician remuneration schemes matter? The case of Canadian family physicians. Journal of Health Economics, v. 27, n. 5, p. 1168-1181, 2008.

DIAS, S. R. L. A interferência da cultura organizacional na atividade do auditor interno: um estudo com auditores internos de instituições financeiras. 2013. $69 \mathrm{f}$. Dissertação (Mestrado em Controladoria Empresarial) - Universidade Presbiteriana Mackenzie, São Paulo, 2013.

DIAS, C. M. M. Liderança em enfermagem : Estudo do líder, do liderado e da motivação. 2001. 199 f. Dissertação (Mestrado em Ciências da Enfermagem) - Instituto de Ciências Biomédicas de Abel Salazar, Universidade do Porto, 2001.

DIKOLLI, S. S. Agent employment horizons and contracting demand for forward-looking performance measures. Journal of accounting research, v. 39, n. 3, p. 481-493, 2001.

DIKOLLI, S. S.; VAYSMAN, I.. Contracting on the stock price and foward-looking performance. European Accounting review, v. 15, n. 4, p. 445-464, 2006.

DUTTA, S.; REICHELSTEIN, S. Leading indicator variables, performance measurement, and long-term versus short-term contracts. Journal of accounting research, v. 41, n 5, p. 837-866, 2003.

EISENHARDT, K. M. Building theories from case study research. The academy of management review, v. 14, n. 4, p. 532-550, 1989.

ESCRIVÃO JUNIOR, A. Uso da informação na gestão de hospitais públicos. Ciência \& Saúde Coletiva, v. 12, n.3, p. 655-666, 2007.

ESCRIVAO JUNIOR, A.; KOYAMA, M. F. O relacionamento entre hospitais e operadoras de planos de saúde no âmbito do Programa de Qualificação da Saúde Suplementar da ANS. Ciência e saúde coletiva, Rio de Janeiro, v. 12, n. 4, p. 903-914, 2007.

FARREL, A. M.; KADOUS, K.; TOWRY, K. L. Contracting on contemporaneous vs. forward-looking measures: an experimental investigation. Contemporary Accounting Research, v. 25, n. 3, p. 773-802, 2008. 
FELTHAM, G. A.; XIE, J. Performance measure congruity and diversity in multi-task principal/agent relations. The accounting review, v. 69, n. 3, p. 429-453, 1994.

FRANCO, L. M.; BENNETT, S.; KANFER, R. Health sector reform and public sector health worker motivation: a conceptual framework. E- Social science \& medicine, v. 54, n. 8, p. 1255-1266, 2002.

FREDERICK, S.; LOEWENSTEIN, G.; O'DONOGHUE, T. Time discounting and time preference: a critical review. Journal of Economic Literature, v. 40, n.2, p. 351-401, 2002.

FREY, B. S.; STUTZER, A. What can economists learn from happiness research? Journal of Economic Literature, v. 40, n. 2, p. 402-435, 2002.

GABRIEL, C. S. et al. Utilização de indicadores de desempenho em serviço de enfermagem de hospital público. Revista Latino-Americana de Enfermagem (Online), v. 19, n. 5, p. 1247-1254, 2011.

Usage of quality indicators in hospital nursing services in Brazil. Journal of Hospital Administration, v. 2, n. 4, p. 91-99, 2013.

GERSCH, M.; HEWING, M.; SCHÖLER, B. Business Process Blueprinting - an enhanced view on process performance. Business Process Management Journal, v. 17, n. 5, p. 732-747, 2011.

GIBBS, M.; MERCHANT, K. A.; VAN DER STEDE, W.; VARGUS, M. E.. Determinants and effects of subjectivity in incentives. The Accounting Review, v. 2, n. 79, p. 409-436, 2004.

GOVINDARAJAN, V.; GUPTA, A. K.. Linking control system to business unit strategy: impact on performance. Accounting, Organizations and Society, v. 10, n. 1, p. 51-66, 1985.

GRANLUND, M.; TAIPALEENMAKI, J. Management control and controllership in new economy firms - a life cycle perspective. Management Accounting research, v. 16, n.1, p. 21-57, 2005.

GROHMANN, M. Z.; BATTISTELLA, L. F.; BARATTO, J. S. Competencias del gestor hospitalario: estudio en un hospital público brasileño. Enfermería lobal, v. 11, n. 26, p. 209-226, 2012.

HARTMANN, F. G. H. The appropriateness of RAPM: toward the further development of theory. Accounting, Organizations and Society, v. 25, n. 4-5, p. 451-482, 2000. 
The effects of tolerance for ambiguity and uncertainty on the appropriateness of accounting performance measures. Abacus, v. 41, n. 3, p. 241-264, 2005.

HARTMANN, F.; SLAPNICAR, S. How formal performance evaluation affects trust between superior and subordinate managers. Accounting, Organizations and Society, v. 34, n. 6-7, p. 722-737, 2009.

HERNAUS, T. Influence of strategic approach to BPM on financial and non-financial performance. Baltic Journal of Management, v. 7, n. 4, p. 376-396, 2012.

HO, J. L. Y.; WU, A.; WU, S. Y. C. Performance measures, consensus on strategy implementation, and performance: Evidence from the operational-level of organizations. Accounting, Organizations and Society, v. 39, n. 1, p. 38-58, 2014.

HOLMSTROM, B. Moral hazard and observability. The Bell Journal of Economics, v. 10, n. 1, p. 74-91, 1979.

IJIRI, Y.; JAEDICKE, R. K. Reability and Objectivity of Accounting Measurements. The Accountig review, v. 41, n. 3, p. 474-483, 1966.

INDJEJIKIAN, R.J. Performance evaluation and compensation reseach: an agency perspective. Accounting Horizons, v. 13, n. 2, p. 147-157, 1999.

JACOBSON, R.; AAKER, D. Myopic management behavior with efficient, but imperfect, financial markets. Journal of Accounting and Economics, v. 16, n. 4, p. 383-405, 1993.

JAEGHER, K. de. The Value of Private Patient Information in the Physician-Patient Relationship: A Game-Theoretic Account. Computational and Mathematical Methods in Medicine, v. 2012, ID 847396, 16 pages, 2012.

JENSEN, M. C.; MECKLING, W. H. Theory of the Firm: Managerial Behavior, Agency Costs and Ownership Structure. Journal of Financial Economics, v. 3, n. 4, p. 305-360, 1976.

JOOSTEN, T.; BONGERS, I.; JANSSEN, R. Application of lean thinking to health care: issues and observations. Journal for Quality in Health Care, v. 21, n. 5, p. 341-347, 2009.

KAMEL, H. The Measurement of the Organizational Performance: Case Study of the Economic Public Companies (EPC). International Business Management, v. 1, n.4, p. 118-129, 2007.

KANG, S.; LEE, J.; LEE, D.; \& BAIK, J. A Framework for Measuring and Managing Value Achievement in Business Processes. The Institute of Electronics, Information and Communication Engineers, v. 10, p. 2456-2468, 2012. 
KAPLAN, R. S.; NORTON, D. The balanced scorecard. Boston: Harvard Business Press, 1996.

KAPLAN, R. S.; ATKINSON, A. A. Advanced Management Accounting. 3nd ed. New Jersey: Prentice hall, 1998.

KELLY, K. O. Feedback and incentives on nonfinancial value drivers: effects on managerial decision making. Contemporary accounting research. v. 24, n. 2 , p. 523-556, 2007.

LA FORGIA, G. M.; COUTTOLENC, B. F. Desempenho hospitalar no Brasil: em busca da excelência. São Paulo: Singular, 2009.

LAGE, M. C. Utilização do software NVivo em pesquisa qualitativa: uma experiência em EaD. ETD - Educação Temática Digital, v. 12, n. esp., p. 198-226, 2011.

LAMBERT, R. A.. Contracting theory and accounting. Journal of Accounting and Economics, v. 32, n. 1-3, p. 3-87, 2001.

LAPSLEY, I. New Public Management: The Cruellest Invention of the Human Spirit? Abacus, v.45, n.1, p.1-21, 2009.

LAVERTY, K. J. Economic "short-termism": The debate, the unresolved issues, and the implications for management practice and research. Academy of Management Review, v. 21, n. 3, p. 825-860, 1996. managerial systems in valuing the long-term. Management Decision, v. 42, n. 8, p. 949962, 2004.

LAWLER, E. E. Motivation in work organizations. San Francisco: Jossey-Bass Publishers, 1994.

LEWELLEN, W.; LODERER, C.; MARTIN, K. Executive compensation and executive incentive problems: an empirical analysis. Journal of Accounting and Economics, v. 9, n.3, p. 287-310, 1987.

LIMA, T. S. et al. Motivação_no trabalho do enfermeiro: estudo realizado em instituições_hospitalares_de João Pessoa. Revista de Enfermagem (UFPE On-line), v. 3, n. 2, p. 275-281, 2009.

LIMA-GONÇALVES, E. Administração hospitalar: condicionantes internos e externos da atividade do hospital-empresa. Revista de Administração de Empresas eletrônica, v.1, n. $2,2002$. 
LOEWENSTEIN, G. F. Anticipation and the valuation of delayed consumption. The Economic Journal,, v. 97, n. 387, p. 666-684, 1987.

LOEWENSTEIN, G. F. Out of control: visceral influences on behavior. Organizational Behavior and Human Decision Processes, v. 65, n. 3, p. 272-292, 1996.

LUFT, J.; SHIELDS, M. D. Mapping management accounting: graphics and guidelines for theory-consistent empirical research. Accounting, Organizations and Society, v. 28, n. 2 3, p. 169-249, 2003.

MAHONEY, J. Path dependence in historical sociology. Theory and Society, v. 29, p.507$548,2000$.

MALIK, A. M.; VELOSO, G. G. Análise do Desempenho Econômico-financeiro de Empresas de Saúde. RAE - eletrônica, v. 9, n. 1, art. 2, 2010.

MALINA, M. A.; SELTO, F. H. Communicating and controlling strategy: an empirical study of the effectiveness of the balanced scorecard. Journal of Management Accounting Research, v. 13, p. 441-469, 2011.

MARGINSON, D.; MCAULAY, L.. Exploring the debate on short-termism: a theoretical and empirical analysis. Strategic Management Journal, v. 29, n. 3, p. 273-292, 2008.

MARGINSON, D.; MCAULAY, L.; ROUSH, M.; ZIJL, T. V. Performance measures and short-termism: an exploratory study. Accounting and Business Research, v. 40, n. 4, p. $353,2010$.

MARCUSCHI, L. A. Análise da conversação. São Paulo: Atlas, 1986.

MARTINS, E. Contabilidade de custos. São Paulo: Atlas, 2003.

MARTINS, V. F. et al. Gestão de custos em organizações hospitalares: uma necessidade no processo de gestão. Revista de Administração, v. 11, n. 20, p. 97-118, 2013.

MARTINS, E. L.; ALVES, R.N., GODOY, S. A. F. Reações e sentimentos do profissional de enfermagem diante da morte. Revista Brasileira de Enfermagem, v. 52, p. 105-17, 1999.

MARTINS, G. A.; THEÓPHILO, C. R. Produção Científica em Contabilidade no Brasil: Dez Pecados. In: LOPES, J.; RIBEIRO FILHO, J. F.; PEDERNEIRAS, M. (Orgs). Educação contábil: tópicos de ensino e pesquisa. São Paulo: Atlas, p.1-14, 2008.

MATTSON, M.; TORBIÖN, I.; HELLGREN, J. Effects of staff bonus systems on safety behaviors. Human Resource Management Review, v. 24, n. 1, p. 17-30, 2014 
MCKINNON, J. Reliability and Validity in Field Research: Some Strategies and Tactics. Accounting, Auditing \& Accountability Journal, v. 1, n. 1, p. 34-54, 1988.

MCCLELLAND D. C.; LIBERMAN, A. M. The Effect of Need for Achievement of Recognition of Need-Related Words. Journal of Personality, v. 18, n. 2, p. 236-251, 1949.

MERCHANT, K. A.; BRUNS JR., W. J. Measurements to cure management myopia. Business Horizons, v. 29, n.3, p. 56-64, 1986.

MERCHANT, K. A.. The effects of financial controls on data manipulation and management myopia. Accounting, Organizations and Society, v. 15, n. 4, p. 297-313, 1990.

MERCHANT, K. A.; VAN DER STES, W. A. Management control systems: Performance, measurement, evaluation, and incentives. Harlow: Prentice Hall, 2003.

METCALFE, J.; MISCHEL, W.. A hot/cool analysis of delay of gratification: Dynamics of willpower. Psychological Review, v. 106, n. 1, p.3-19, 1999.

MILGROM, P.; ROBERTS, J.. Economics, Organization and Management, Harlow: Prentice Hall, 621 pp., 1992.

MIRANDA, G. J. et al . Custeio ABC no ambiente hospitalar: um estudo nos hospitais universitários e de ensino brasileiros. Revista contabilidade e finanças. São Paulo , v. 18, n. 44, p.33-43, 2007.

MOERS, F. Performance measure properties and delegation. The accounting review. v. 81, n. 4, p. 897-924, 2006.

MOONEY, G.; RYAN, M. Agency in health care: getting beyond first principles. Journal of Health Economics, v. 12, n. 2, p. 125-238. 1993.

Ministério da Saúde [Internet]. Secretaria Executiva. Datasus [acesso em jul. 2013]. Informações de Saúde. Disponível em: 〈http://www.datasus.gov.br〉

NARAYANAN, M. P. Managerial incentives for short-term results. The Journal of Finance, v. 40, n. 5, p. 1469-1484, 1985.

NEUMANN, E.; NEUMAN, S. Agency in health-care: are medical care-givers perfect agents? IZA Discussion Papers, n. 2727, 2007.

NIEHAVES, B., PLATTFAUT, R., \& BECKER, J. Business process governance: a comparative study of Germany and Japan. Business Process Management Journal, v. 18 n. 2, p. 347-371, 2012. 
O'DONOGHUE, T.; RABIN, M.. Incentives for procrastinators. The Quarterly Journal of Economics, v. 114, n. 3, p. 769-816, 1999.

OHIRA, Regina Hitomi Fukuda; CORDONI JUNIOR, Luiz; NUNES, Elisabete de Fátima Polo de Almeida. Perfil dos gerentes de Atenção Primária à Saúde de municípios de pequeno porte do norte do Paraná, Brasil. Ciência e saúde coletiva, Rio de Janeiro, v. 19, n. $2,2014$.

OYADOMARI, J. C. T. ; PEDRIQUE, A. L. ; BIDO, D. S. ; REZENDE, A. J.. Uso do controle gerencial e decisões em organizações de saúde brasileiras: um estudo exploratório. BBR. Brazilian Business Review (English Edition. Online), v.11, n.2, p. 1-34 2014.

PERRY, J.L.; HONDEGHEM, A.; WISE, L.R. Revisiting the Motivational Bases of Public Service: Twenty Years of Research and an Agenda for the Future. Public Administration Review, v.70, n.5, p.681-690, 2010.

PERRY, J.L.; WISE, L.R. The Motivational bases of public sector. Public Administration Review, v.50, n.3, p.367-373, 1990.

PINHEIRO, P. N.; GALDI, F. C.; OYADOMARI, J. C. T.. Efeitos da gestão baseada em EVA® nas decisões intertemporais: um estudo com gerentes de vendas. Revista Administração de empresas, São Paulo, v. 47, n. 2, p.231-248, 2012.

PITTA, A.. Hospital: dor e morte como ofício. 3a. Ed. São Paulo: Hucitec, 1994.

PIZZINI, M. J.. The relation between cost-system design, managers' evaluations of the relevance and usefulness of cost data, and financial performance: an empirical study of US hospitals. Accounting, Organizations and Society, v. 31, n. 2, p.179-210, 2006.

PORTELA, M. C. et al. Estrutura e qualidade assistencial dos prestadores de serviços hospitalares à saúde suplementar no Brasil. Cadernos de Saúde Pública, Rio de Janeiro, v. 26, n. 2, p. 399-408, 2010.

PRELEC, D.; LOEWENSTEIN, G.. Decision making over time and under uncertainty: a common approach. Management Science, v. 37, n. 7, p. 770-786, 1991.

RAE, J.. The Sociological Theory of Capital. London: Macmillan, 1834.

RICHARDSON, Roberto J. Pesquisa Social: Métodos e Técnicas. 3. ed. São Paulo: Atlas, 2008.

ROTTA, C. S. G. Utilização de indicadores de desempenho hospitalar como instrumento gerencial. 2004. 143 f. Tese (Doutorado em Saúde Pública) - Departamento de Prática de Saúde Pública da Faculdade de saúde Pública, Universidade de São Paulo, São Paulo, 2004. 
SAMUELSON, P. A.. A note on Measurement of Utility. The Review of Economics Studies, v. 4, n. 2, p. 155-161, 1937.

SANTOS, M.A.; HORMANEZ, M. Atitude frente à morte em profissionais e estudantes de enfermagem: revisão da produção científica da última década. Ciência \& Saúde Coletiva, v. 18 , n. 9, p. 2757-2768, 2013.

SATO, F. R. L.. A teoria da agência no setor da saúde: o caso do relacionamento da Agência Nacional de Sáude Suplementar com as operadoras de planos de assistência supletiva no Brasil. Revista de Administração Pública, v. 41, n. 1, p. 49-62, 2007.

SCHIOZER, R. F.; SAITO, C. C.; SAITO, R. Financial health and customer satisfaction in private health care providers in Brazil. Cadernos de Saúde Pública, Rio de Janeiro, v. 27, n. 11, p. 2175-2187, 2011.

SCHRAIBER, L. B. et al.Planejamento, gestão e avaliação em saúde: identificando problemas. Ciência \& Saúde Coletiva, v. 4, n. 2, p.221-61, 1999.

SCORSOLINI-COMIN, F.; SANTOS, M. A. dos. O estudo científico da felicidade e a promoção da saúde: revisão integrativa da literatura. Revista Latino-Americana de Enfermagem, Ribeirão Preto, v. 18, n. 3, p. 472-479, 2010.

SCOTT, A.; VICK, S.. Patients, Doctors and Contracts: Na Application of Principal-Agent Theory to the doctor-patient relationship. Scottish Journal of Political Economy, v.46, n. 2, p. 111-134, 1999.

SEIXAS, M. S.; MELO, H. T. Desafios do administrador hospitalar. Gestão \& Planejamento, v. 1, n. 10, 2008.

SENIOR, N.W.. An Outline of the Science of Political Economy. London: Clowes \& Sons. 1836.

SHI, W.S.; YANG, H.; PRESCOTT, J. E. The impact of long-term orientation on decision making process. Academy of Management Prooceding, January 2013.

SILBERSTEIN, A. C. L.. Um estudo de casos sobre a aplicação de princípios enxutos em serviços de saúde no Brasil .Rio de Janeiro: UFRJ/COPPEAD, 2006.

SILVA, A. R.; ROSEMANN, M. Processpedia: an ecological environment for BPM stakeholders' collaboration. Business Process Management Journal, v. 18, n. 1, p. 20-42, 2012.

ŠKRINJAR, R.; TRKMAN, P. Increasing process orientation with business process management: Critical practices'. International Journal of Information Management, v. 33, n. 1, p. 48-60, 2013. 
SLIWKA, D. On the use of nonfinancial performance measures in management compensation. Journal of Economics and Management Strategy. v. 11, n. 3, p. 487-511, 2002.

SMART, P.A.; MADDERN, H.; MAULL, R.S. Understanding Business Process Management: Implications for Theory and Practice. British Journal of Management, v. 20, n. 4, p. 491-507, 2009.

SOUSA, K.; MENDONÇA, H.; LIEVYNS, A.; VANDERDONCKT, J. Getting users involved in aligning their needs with business processes models and systems. Business Process Management Journal, v. 17, n. 5, p. 748-786, 2011.

SOUZA, L. B.; PIDD, M. Exploring the barriers to learn health care implementation. Public Money \& Management, v. 31, n. 1, p. 59-66, 2011.

STEVENS, S. S. On the Theory of Scales of Measurement. Science, v. 103, n. 2684, p. 677-680, 1946.

STROBL, G. Stock-based managerial compensation, price informativeness, and the incentive to overinvest. Journal of Corporate Finance. 2014. Disponível em: < http://dx.doi.org/10.1016/j.jcorpfin.2013.12.003>. Acesso em: 13 de Mar de 2014.

TANAKA, O. Y., TAMAKI, E. M. O papel da avaliação para a tomada de decisão na gestão de serviços de saúde. Ciência e Saúde Coletiva, v.17, n.4, p.821-828, 2012.

TARABOUlSI, F. A. Serviços Hospitalares. Teoria e Prática. Compreender para Atender e Surpreender. São Paulo: Reichmann e Autores Editores, 2005.

VALLEJO, C.; ROMERO, D.; MOLINA, A. Enterprise integration engineering reference framework and toolbox, v. 50, n. 6, p. 1489-1511, 2012.

TEXEIRA, S. F.; MENDONÇA, M. H.. Reformas Sanitárias na Itália e no Brasil: comparações. In: Teixeira SF, organizadora, reforma Sanitária em busca de uma teoria. São Paulo: Cortez; Rio de Janeiro, Associação Brasileira de Pós-Graduação em Saúde Coletiva, 1989.

THALER, R. H.; SHEFRIN, H. M. An economic theory of self-control. The Journal of Political Economy, v. 89, n. 2, p. 392-406, 1981.

THALER, R. H.. Mental Accounting Matters. Jornaul of Behaviour and Decision Making, v. 12, n.3, p. 183-206, 1999.

TOFAN, G., BODOLICA, V.; SPRAGGON, M.. Governance mechanisms in the physician-patient relationship: a literature review and conceptual framework. Health Expectations, v. 16, n. 1, p. 14-31, 2013. 
TROPE, Y.; LIBERMAN, N. Temporal construal and time-dependent changes in preference. Journal of Personality and social Psychology, v. 79, n. 6, p. 876-889, 2000.

TSOUNIS, A.; SARAFIS, P.; BAMIDIS, P. Motivation among Physicians in Greek Public Health-Care Sector. British Journal of Medicine, v. 4, n. 5, p. 1094-1105, 2014.

TVERSKY, A.; KAHNEMAN, D. Loss Aversion in Riskless Choice: A ReferenceDependent Model. The Quarterly Journal of Economics, v. 106, n. 4, p. 1039-1061, 1991.

UGA, M. A. D. et al. Mecanismos de microrregulação aplicados por operadoras de planos de saúde sobre hospitais privados. Revista de Saúde Pública, São Paulo, v. 43, n. 5, p. 832-838, 2009.

UGA, M. A. D. Sistemas de alocação de recursos a prestadores de serviços de saúde - a experiência internacional. Ciência e saúde coletiva, Rio de Janeiro, v. 17, n. 12, p. 34373445, 2012.

VAN DER STEDE, W. A. The relationship between two consequences of budgetary controls: budgetary slack creation and managerial short-term orientation. Accounting, Organizations and Society, v. 25, n. 6, p. 609-622, 2000.

VAN RINSUM, M.. Performance measurement and managerial time orientation. ERIM Ph.D. Series Research in Management, Rotterdam, 2006

VIEGAS, S. M. F.; PENNA, C. M. M.. O SUS é universal, mas vivemos de cotas. Ciência e saúde coletiva, Rio de Janeiro, v. 18, n. 1, p. 181-190, 2013.

VON NEUMANN, J.; MORGENSTERN, O. Theory of Games and Economic Behavior. Princeton: University Press, 1944.

YIN, R. K. Estudo de caso: planejamento e métodos. 3. ed. Porto Alegre: Bookman, 2005.

WEBB, A. Managers' commitment to the goals contained in a strategic performance measurement system. Contemporary Accounting research, v. 21, n. 4, p. 925-958, 2004.

WEBER, B. J.; CHAPMAN, G. B.. The combined effects of risk and time on choice: does uncertainty eliminate the immediacy effect? Does delay eliminate the certainty effect? Organizational behavior and human decision process, v. 96, p. 104-118, 2005.

WEBER, L.; GRISCI, C. L. I. Trabalho, gestão e subjetividade: dilemas de chefias Intermediárias em contexto hospitalar. Cadernos EBAPE.BR, Rio de Janeiro, v. 8, n. 1, p. 53-70, 2010. 


\section{APÊNDICES}

\section{APÊNDICE A}

O apêndice A apresenta as aprovações e dos comitês de ética e autorizações coletadas nos hospitais, assim como o modelo do termo de consentimento livre e esclarecido que será preenchido por cada gestor que participar da pesquisa.

\section{APROVAÇÃO DO PROJETO NO COMITÊ DE ÉTICA EM PESQUISA DA \\ FACULDADE DE FILOSOFIA, CIÊNCIAS E LETRAS DE RIBERÃO PRETO.}

Ribeirão Preto, 21 de maio de 2013

Prezado Pesquisador,

Comunicamos a V. Sa. que o projeto de pesquisa intitulado "A RELAÇÃO ENTRE A UTILIZAÇÃO DE INDICADORES DE DESEMPENHO, ESTRUTURA ORÇAMENTÁRIA E O PLANEJAMENTO ESTRATÉGICO COM A ORIENTAÇÃO TEMMPORAL DO GESTOR E O REAL DESEMPENHO FINANCEIRO E OPERACIONAL" foi reanalisado pelo Comitê de Ética em Pesquisa da FFCLRP-USP, em sua $120^{\text {a }}$ Reunião Ordinária, realizada em 16.05.2013, e enquadrado na categoria: APROVADO (CAAE n. ${ }^{\circ}$ 13520813.3.0000.5407).

Solicitamos que eventuais modificações ou emendas ao projeto de pesquisa sejam apresentadas ao CEP, de forma sucinta, identificando a parte do projeto a ser modificada e suas justificativas, e que, ao término do estudo, um relatório final seja entregue, via Plataforma Brasil (item IX.2 da Res. CNS 196/96).

Atenciosamente,

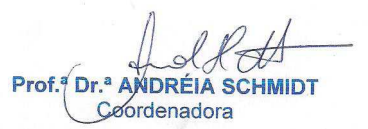

Ao Senhor

Diego Queirantes

Programa de Pós-graduação em Contabilidade e Controladoria da FEARP USP

$c / C:$

Prof, Dr. Carlos Alberto Grespan Bonacim

Departamento de Contabilidade da FEARP USP

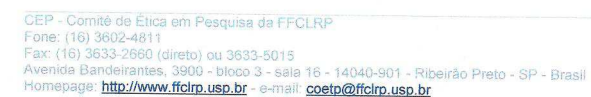




\section{APROVAÇÃO dO PROJETO NO COMITÊ DE ÉTICA EM PESQUISA DO HOSPITAL DAS CLÍNICAS DA FACULDADE DE MEDICINA DE RIBEIRÃO PRETO DA UNIVERSIDADE DE SÃO PAULO}

Projeto de pesquisa: "A relação entre a Utilização de Indicadores de Desempenho, estrutura orçamentária e o planejamento estratégico com a Orientação Temporal do Gestor e o real desempenho Financeiro e Operacional."

Pesquisador responsável: Diego Queirantes e Carlos Alberto Grespan Bonacim

Instituição Proponente: Faculdade de Filosofia, Ciências e Letras de Ribeirão Preto- USP

"O CEP do HC e da FMRP-USP concorda com o parecer ético emitido pelo CEP da Instituição Proponente, que cumpre as Resoluções Éticas Brasileiras, em especial a Resolução CNS 196/96. Diante disso, o HCFMRP-USP, como instituição co-participante do referido projeto de pesquisa, está ciente de suas co-responsabilidades e de seu compromisso no resguardo da segurança e bemestar dos sujeitos desta pesquisa, dispondo de infra-estrutura necessária para a garantia de tal segurança e bem-estar.

Ciente e de acordo:

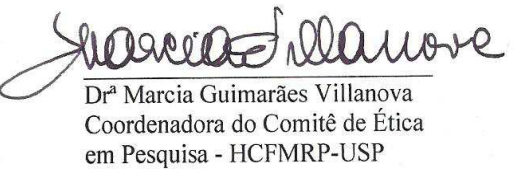

Prof. Dr. José Alexandre de Souza Crippa Coordenador Téenico Científico da Unidade de Pesquisa Clínica - HCFMRP-USP 


\section{FOLHA DE ROSTO PARA O COMITÊ DE ÉTICA EM PESQUISA COM APROVAÇÃO DA FACULDADE DE ECONOMIA, ADMINISTRAÇÃO E CONTABILIDADE DE RIBEIRÃO PRETO DA UNVIERSIDADE DE SÃO PAULO}

Plobaforma MINISTÉRIO DA SAÚDE - Conselho Nacional de Saúde - Comissão Nacional de Ética em Pesquisa - CONEP Grasil

FOLHA DE ROSTO PARA PESQUISA ENVOLVENDO SERES HUMANOS

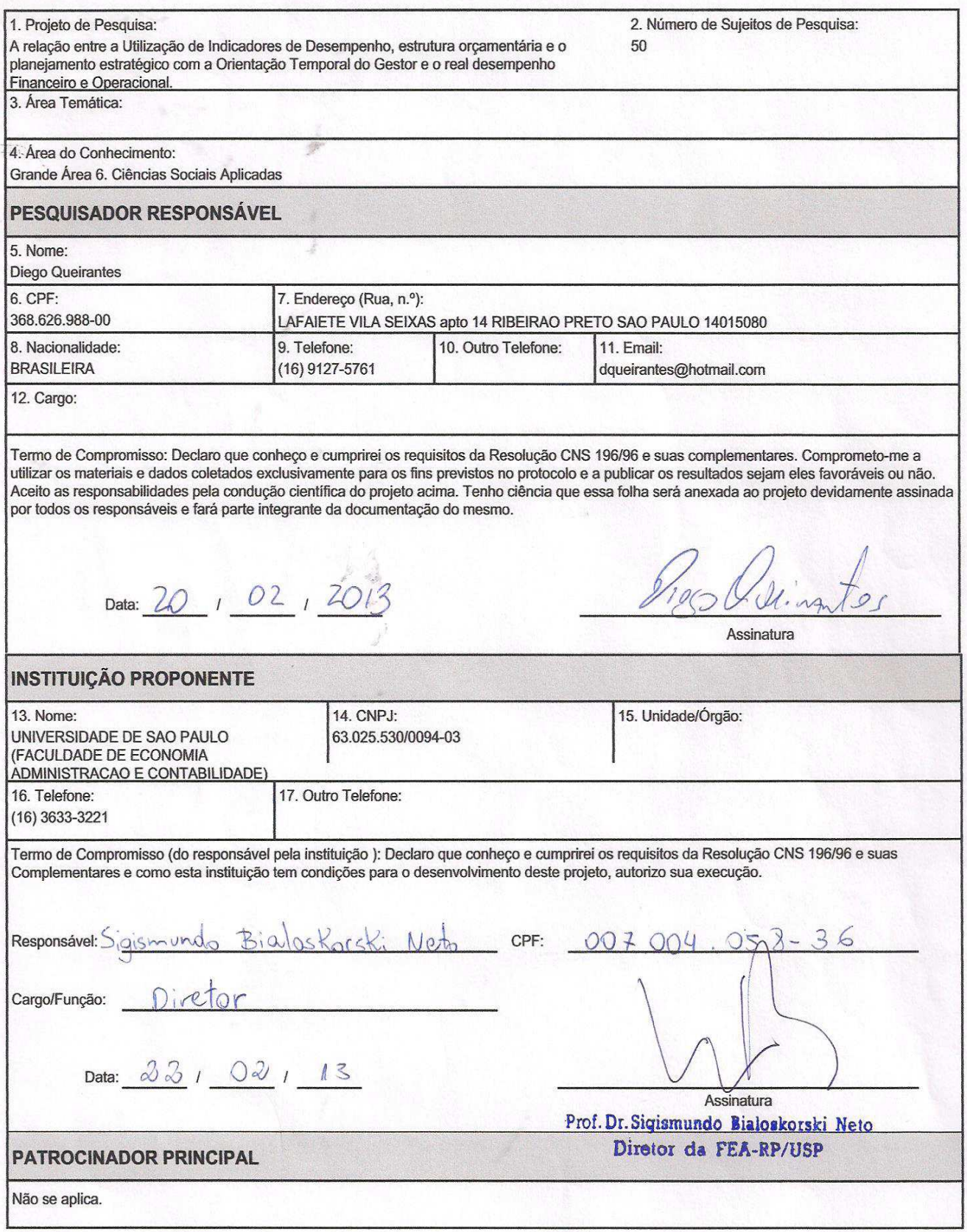




\section{TERMO DE CONSENTIMENTO}

\section{Dados de identificação}

Título do Projeto A interferência de aspectos econômicos, organizacionais e cognitivos na relação entre o sistema de remuneração gerencial e a Orientação Temporal do Gestor em instituições de saúde.

Pesquisador Responsável: Diego Queirantes

Instituição a que pertence o Pesquisador Responsável: Faculdade de Economia, Administração e Contabilidade de Ribeirão Preto - USP

Telefones para contato: (16) 9127-5761 - (16) 3602-0501

Nome do voluntário:

Idade: anos

\section{R.G.}

O Sr. $\left({ }^{a}\right)$ está sendo convidado(a) a participar do projeto de pesquisa "A relação entre a Utilização de Indicadores de Desempenho, estrutura orçamentária e o planejamento estratégico com a Orientação Temporal do Gestor e o real desempenho Financeiro e Operacional" de responsabilidade do pesquisador Diego Queirantes, a qual pretende entender. os mecanismos econômicos, organizacionais e cognitivos que impactam no processo decisório dos gestores e funcionários em instituições hospitalares, ou seja, quais os fatores pessoais (como formação acadêmica, ambiente social, idade, etc), as características da organização de saúde (privada, publica, escola, filantrópica, complexidade, etc) e modelos de mensuração de desempenho e remuneração que influenciam os funcionários de saúde na tomada de decisão na alocação de recursos

Sua participação é voluntária e se dará por meio de entrevista gravada referente à utilização de indicadores de desempenho e processo de tomada de decisão, além da forma de alocação dos recursos disponíveis. O local de entrevista será no local de trabalho do entrevistado, com duração média de 30 minutos, as entrevistas serão gravadas para melhor aproveitamento da entrevista e para manter a fielmente as palavras do entrevistado, em seguida serão transcritas e utilizadas para análise de discurso. A análise discurso irá analisar a utilização das palavras e contextos com o propósito de encontrar relações entre os conceitos pesquisados, de maneira a entender os fatores que afetam o processo decisório do gestor. Após a tabulação e análise discursiva das entrevistas as gravações serão deletadas, e as transcrições ficarão em poder do pesquisador em meio eletrônico.

Não existem riscos previsíveis decorrentes de sua participação na pesquisa, visto as informações geradas serão confidencias e sua privacidade garantida. Se você aceitar participar, estará contribuindo para o entendimento dos efeitos de aspectos econômicos, medidas de desempenho e aspectos cognitivos no processo decisório de agentes em instituições de saúde no momento de alocação de recursos.

Se depois de consentir em sua participação o $\mathrm{Sr}$ (a) desistir de continuar participando, tem o direito e a liberdade de retirar seu consentimento em qualquer fase da pesquisa, seja antes ou depois da coleta dos dados, independente do motivo e sem nenhum prejuízo a sua pessoa. $\mathrm{O}$ (a) $\mathrm{Sr}$ (a) não terá nenhuma despesa e também não receberá nenhuma 
remuneração. Os resultados da pesquisa serão analisados e publicados, mas sua identidade não será divulgada, sendo guardada em sigilo.

Para qualquer outra informação, o (a) $\mathrm{Sr}$ (a) poderá entrar em contato com o pesquisador no endereço Avenida dos Bandeirantes $n^{\circ} 3900$ / Sala 5 / Bloco A, Universidade de São Paulo, Faculdade de Economia, Administração e Contabilidade de Ribeirão Preto, Monte Alegre - Ribeirao Preto, CEP: 14040-900, SP - Brasil. Acerca de esclarecimentos referente aos aspectos éticos da pesquisa se informar com o Comitê de Ética em Pesquisa da Faculdade de Filosofia, Ciências e Letras de Ribeirão Preto (contato em nota de rodapé).

$\mathrm{Eu}$, RG:

fui informado sobre o que o pesquisador quer fazer e porque precisa da minha colaboração, e entendi a explicação. Por isso, eu concordo em participar do projeto, sabendo que não vou ganhar nada e que posso sair quando quiser. Este documento é emitido em duas vias que serão ambas assinadas por mim e pelo pesquisador, ficando uma via com cada um de nós.

de de

Nome e assinatura do participante

Nome e assinatura do pesquisador responsável 


\section{APÊNDICE B}

Tabela 12: Tarefas com efeitos no curto e longo prazo

\begin{tabular}{|c|c|c|c|}
\hline Tarefas & Tema & OTG & $\mathrm{Qtde}^{22}$ \\
\hline Adequação às alterações regulatórias & Ambiente externo & Curto Prazo & 6 \\
\hline $\begin{array}{l}\text { Adequação para atendimento de } \\
\text { volume extraordinário }\end{array}$ & Ambiente externo & Curto Prazo & 5 \\
\hline $\begin{array}{l}\text { Mapeamento do perfil } \\
\text { epidemiológico e sazonalidade }\end{array}$ & Ambiente externo & Longo Prazo & 6 \\
\hline Acompanhamento contrato terceiros & $\begin{array}{l}\text { Apoio ao atendimento } \\
\text { assistencial }\end{array}$ & Curto Prazo & 5 \\
\hline $\begin{array}{l}\text { Atualização dos contratos de } \\
\text { serviços }\end{array}$ & $\begin{array}{l}\text { Apoio ao atendimento } \\
\text { assistencial }\end{array}$ & Curto Prazo & 5 \\
\hline Controle material consignado & $\begin{array}{l}\text { Apoio ao atendimento } \\
\text { assistencial }\end{array}$ & Curto Prazo & 4 \\
\hline Correções em equipamentos & $\begin{array}{l}\text { Apoio ao atendimento } \\
\text { assistencial }\end{array}$ & Curto Prazo & 3 \\
\hline Dispensação medicamentos & $\begin{array}{l}\text { Apoio ao atendimento } \\
\text { assistencial }\end{array}$ & Curto Prazo & 3 \\
\hline Estocagem medicamentos & $\begin{array}{l}\text { Apoio ao atendimento } \\
\text { assistencial }\end{array}$ & Curto Prazo & 3 \\
\hline Análise prescrição médica & $\begin{array}{l}\text { Apoio ao atendimento } \\
\text { assistencial }\end{array}$ & Curto Prazo & 2 \\
\hline Controle de materiais & $\begin{array}{l}\text { Apoio ao atendimento } \\
\text { assistencial }\end{array}$ & Curto Prazo & 2 \\
\hline Projeto de acolhimento ao paciente & $\begin{array}{l}\text { Apoio ao atendimento } \\
\text { assistencial }\end{array}$ & Longo Prazo & 5 \\
\hline $\begin{array}{l}\text { Conscientização no descarte de } \\
\text { resíduos }\end{array}$ & $\begin{array}{l}\text { Apoio ao atendimento } \\
\text { assistencial }\end{array}$ & Longo Prazo & 4 \\
\hline Conscientização no uso do enxoval & $\begin{array}{l}\text { Apoio ao atendimento } \\
\text { assistencial }\end{array}$ & Longo Prazo & 3 \\
\hline Manutenção do estoque mínimo & $\begin{array}{l}\text { Apoio ao atendimento } \\
\text { assistencial }\end{array}$ & Longo Prazo & 3 \\
\hline $\begin{array}{l}\text { Mudanças no uso materiais e } \\
\text { medicamentos }\end{array}$ & $\begin{array}{l}\text { Apoio ao atendimento } \\
\text { assistencial }\end{array}$ & Longo Prazo & 3 \\
\hline $\begin{array}{l}\text { Serviços de prevenção na } \\
\text { manutenção }\end{array}$ & $\begin{array}{l}\text { Apoio ao atendimento } \\
\text { assistencial }\end{array}$ & Longo Prazo & 3 \\
\hline Estruturação farmácia clínica & $\begin{array}{l}\text { Apoio ao atendimento } \\
\text { assistencial }\end{array}$ & Longo Prazo & 2 \\
\hline $\begin{array}{l}\text { Conserto de equipamentos } \\
\text { quebrados }\end{array}$ & $\begin{array}{l}\text { Estrutura Física e } \\
\text { equipamentos }\end{array}$ & Curto Prazo & 4 \\
\hline $\begin{array}{l}\text { Resolução de problemas estruturais } \\
\text { que restringem uso do setor }\end{array}$ & $\begin{array}{l}\text { Estrutura Física e } \\
\text { equipamentos }\end{array}$ & Curto Prazo & 3 \\
\hline
\end{tabular}

\footnotetext{
${ }^{22}$ A coluna "Qtde" refere-se a quantidade de gestores que referenciaram essa tarefa.
} 


\begin{tabular}{|c|c|c|c|}
\hline Resolução problemas com energia & $\begin{array}{l}\text { Estrutura Física e } \\
\text { equipamentos }\end{array}$ & Curto Prazo & 2 \\
\hline Ampliação de setor & $\begin{array}{l}\text { Estrutura Física e } \\
\text { equipamentos }\end{array}$ & Longo Prazo & 6 \\
\hline $\begin{array}{l}\text { Implementação e reformas de } \\
\text { unidades }\end{array}$ & $\begin{array}{l}\text { Estrutura Física e } \\
\text { equipamentos }\end{array}$ & Longo Prazo & 6 \\
\hline Compra novos equipamentos & $\begin{array}{l}\text { Estrutura Física e } \\
\text { equipamentos }\end{array}$ & Longo Prazo & 5 \\
\hline Apresentação de indicadores & Gestão & Curto Prazo & 7 \\
\hline Gestão micro processos específicos & Gestão & Curto Prazo & 6 \\
\hline $\begin{array}{l}\text { Resolução de relacionamento com } \\
\text { fornecedores }\end{array}$ & Gestão & Curto Prazo & 5 \\
\hline Faturamento de contas & Gestão & Curto Prazo & 4 \\
\hline Controle notas de sala & Gestão & Curto Prazo & 3 \\
\hline Controle despesas e custos & Gestão & Longo Prazo & 8 \\
\hline Gestão da informação & Gestão & Longo Prazo & 8 \\
\hline $\begin{array}{l}\text { Implementação Unidades de } \\
\text { Negócio }\end{array}$ & Gestão & Longo Prazo & 7 \\
\hline Mudança nos processos de negócio & Gestão & Longo Prazo & 7 \\
\hline $\begin{array}{l}\text { Realização planejamento estratégico } \\
\text { e acompanhamento }\end{array}$ & Gestão & Longo Prazo & 7 \\
\hline Análise da DRE e metas & Gestão & Longo Prazo & 6 \\
\hline Gestão macro processos & Gestão & Longo Prazo & 6 \\
\hline Abertura novos mercados & Gestão & Longo Prazo & 4 \\
\hline Admissão, demissão & Pessoas e Recursos & Curto Prazo & 8 \\
\hline Relacionamento com corpo médico & Pessoas e recursos & Curto Prazo & 5 \\
\hline Treinamentos e cursos & Pessoas e Recursos & Longo Prazo & 10 \\
\hline $\begin{array}{l}\text { Enquadramento programa cargos e } \\
\text { salários }\end{array}$ & Pessoas e Recursos & Longo Prazo & 5 \\
\hline Projetos de Informática & Pessoas e Recursos & Longo Prazo & 5 \\
\hline Alterações sistemas de informática & Pessoas e Recursos & Longo Prazo & 4 \\
\hline Resolução problemas dos pacientes & Processo Assistencial & Curto Prazo & 6 \\
\hline Planejamento cirúrgico & Processo Assistencial & Curto Prazo & 5 \\
\hline $\begin{array}{l}\text { Uso de recursos mais baratos com } \\
\text { efeitos menos longo }\end{array}$ & Processo Assistencial & Curto Prazo & 5 \\
\hline Problemas materiais cme & Processo Assistencial & Curto Prazo & 4 \\
\hline $\begin{array}{l}\text { Acompanhamento consumo } \\
\text { materiais }\end{array}$ & Processo Assistencial & Curto Prazo & 4 \\
\hline $\begin{array}{l}\text { Acompanhamento da utilização de } \\
\text { protocolos }\end{array}$ & Processo Assistencial & Curto Prazo & 4 \\
\hline $\begin{array}{l}\text { Diminuir tempo de atendimento PA } \\
\text { em períodos de lotação }\end{array}$ & Processo Assistencial & Curto Prazo & 4 \\
\hline Problema na escala médica & Processo Assistencial & Curto Prazo & 3 \\
\hline Problema sobreaviso & Processo Assistencial & Curto Prazo & 3 \\
\hline Dimensionamento de pessoal & Processo Assistencial & Longo Prazo & 8 \\
\hline
\end{tabular}




\begin{tabular}{|c|c|c|c|}
\hline Preparação Planejamento terapêutico & Processo Assistencial & Longo Prazo & 7 \\
\hline Mapeamento recursos necessários & Processo Assistencial & Longo Prazo & 6 \\
\hline Programa qualidade & Processo Assistencial & Longo Prazo & 6 \\
\hline Obtenção certificação & Processo Assistencial & Longo Prazo & 5 \\
\hline $\begin{array}{l}\text { Planejamento de consumo de } \\
\text { materiais }\end{array}$ & Processo Assistencial & Longo Prazo & 5 \\
\hline Preparação Mapa Assistencial & Processo Assistencial & Longo Prazo & 5 \\
\hline $\begin{array}{l}\text { Uso de recursos mais caros com } \\
\text { efeitos mais longo }\end{array}$ & Processo Assistencial & Longo Prazo & 5 \\
\hline $\begin{array}{l}\text { Reunião para trazer novas } \\
\text { tecnologias }\end{array}$ & Processo Assistencial & Longo Prazo & 4 \\
\hline Campanha higienização das mãos & Processo Assistencial & Longo Prazo & 3 \\
\hline Criação protocolos & Processo Assistencial & Longo Prazo & 3 \\
\hline $\begin{array}{l}\text { Negociação autorizações com plano } \\
\text { de saúde }\end{array}$ & $\begin{array}{l}\text { Relacionamento com } \\
\text { operadoras de saúde }\end{array}$ & Curto Prazo & 10 \\
\hline Auditoria médica & $\begin{array}{l}\text { Relacionamento com } \\
\text { operadoras de saúde }\end{array}$ & Curto Prazo & 8 \\
\hline Negociação glosas & $\begin{array}{l}\text { Relacionamento com } \\
\text { operadoras de saúde }\end{array}$ & Curto Prazo & 8 \\
\hline Adequação das guias e autorizações & $\begin{array}{l}\text { Relacionamento com } \\
\text { operadoras de saúde }\end{array}$ & Curto Prazo & 6 \\
\hline Reajuste tabelas & $\begin{array}{l}\text { Relacionamento com } \\
\text { operadoras de saúde }\end{array}$ & Curto Prazo & 3 \\
\hline Visitas às operadoras & $\begin{array}{l}\text { Relacionamento com } \\
\text { operadoras de saúde }\end{array}$ & Curto Prazo & 2 \\
\hline Credenciamento de operadoras & $\begin{array}{l}\text { Relacionamento com } \\
\text { operadoras de saúde }\end{array}$ & Longo Prazo & 3 \\
\hline $\begin{array}{l}\text { Preparação novos modelos } \\
\text { comerciais (tabelas e planos de } \\
\text { venda) }\end{array}$ & $\begin{array}{l}\text { Relacionamento com } \\
\text { operadoras de saúde }\end{array}$ & Longo Prazo & 3 \\
\hline
\end{tabular}

